\title{
DEVELOPMENT OF NOVEL POLYSTYRENE COMPOSITE BEADS FOR DEFECT-FREE LOST FOAM CASTING
}

by

Satiendra (Uttam) Jagoo, B. Eng. (Aerospace Engineering), Ryerson University (Canada), 2005

\author{
A thesis \\ presented to Ryerson University \\ in partial fulfillment of the \\ requirements for the degree of \\ Master of Applied Science \\ in the Program of \\ Mechanical Engineering
}

Toronto, Ontario, Canada, 2007

(C) (Satiendra Jagoo) 2007 


\section{AUTHOR'S DeClaration}

I hereby declare that I am the sole author of this thesis.

I authorize Ryerson University to lend this thesis to other institutions or individuals for the purpose of scholarly research.

Satiendră Jagoo

I further authorize Ryerson University to reproduce this thesis by photocopying or by other means, in total or in part, at the request of other institutions or individuals for the purpose of scholarly research.

Satiendra Jagòo 


\section{BORROWER'S PAGe}

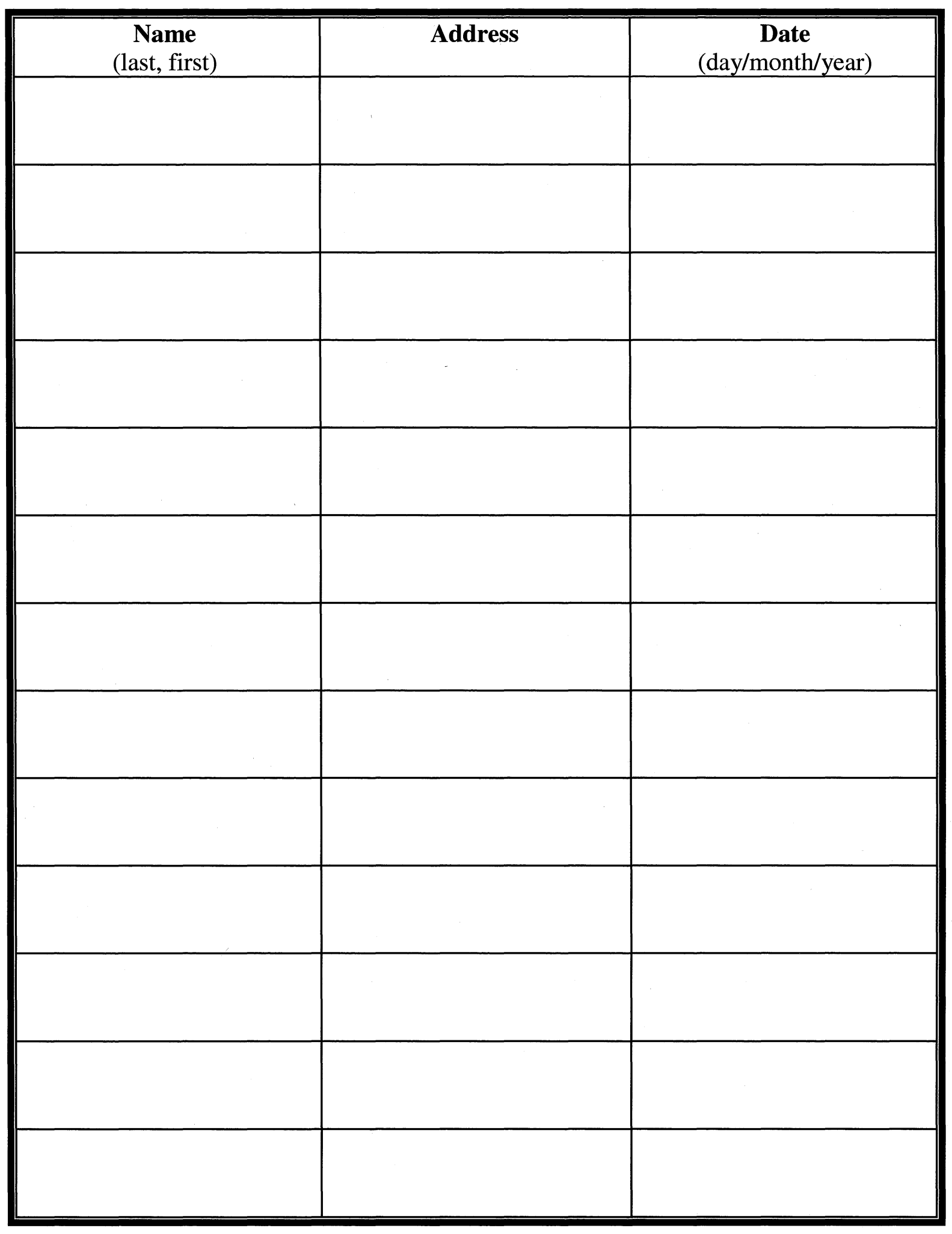




\title{
AbSTRACT \\ Development of Novel Polystyrene Composite Beads for Defect-Free Lost Foam Casting
}

(C) Satiendra Jagoo, 2007

Master of Applied Science

\author{
In the Program of \\ Mechanical Engineering
}

Toronto, Ontario, Canada, 2007

The wider adoption of the Lost Foam Casting (LFC) process by the foundry industry has been impeded by the occurrence of fold defects. It is well known that a new foamed polymer, which degrades with less thermal energy (or less endothermic) and produces fewer gaseous pyrolysis products, may be a solution to fold defects. Hence, this pioneering research was an attempt to develop novel polystyrene composite beads for the LFC process through suspension polymerization. Low molecular weight polystyrene composite beads were initially produced, and the presence of the additives inside these beads was confirmed by Energy Dispersive X-ray (EDX) analysis. High molecular weight polystyrene composite beads were then produced. The thermal properties of these low and high molecular weight beads were studied using advanced characterization techniques such as thermo-gravimetric analysis (TGA) and differential scanning calorimetry (DSC). It was found that these polystyrene composite beads degrade faster and at lower onset temperatures of degradation than the unmodified polystyrene beads. Finally, such novel polymers have the potential to replace the currently used polystyrene beads in the LFC industry to reduce casting defects. 


\section{RÉSUMÉ}

Développement de nouvelles billes à base de polystyrène pour minimiser les défauts de fonderie dans le procédé de moulage à modèle gazéifiable (LFC)

\section{(C) Satiendra Jagoo, 2007}

\section{Maîtrise en sciences appliquées}

\section{Dans le cadre du programme de génie mécanique \\ Toronto, Ontario, Canada, 2007}

Le procédé de moulage à modèle gazéifiable tend à produire un certain nombre de défauts associés à la décomposition du modèle en polymère lors de la coulée du métal. L'adoption plus large de ce procédé par l'industrie de la fonderie en a donc été freinée. La formulation d'un polymère dont la température de composition serait plus basse et qui produirait moins de produits de décomposition pourrait constituer une solution à ce problème. Dans ce contexte, cette recherche pilote visait à développer de nouvelles billes à base de polystyrène par le processus de polymérisation par suspension. Initialement, des billes à base de polystyrène de poids moléculaire relativement bas ont été produites et la présence des additifs à l'intérieur de ces billes a été confirmée par l'analyse $\mathrm{X}$ par dispersion d'énergie. Par la suite, des billes de poids moléculaire plus élevé ont été produites. Les propriétés thermiques et physiques de ces deux types de billes ont été étudiées en utilisant des techniques de caractérisation avancées. Il a été constaté que les billes se dégradent plus rapidement et à des températures plus basses que les billes non modifiées. Finalement, de tels polymères ont le potentiel de remplacer les billes de polystyrène actuellement utilisées dans l'industrie du procédé de moulage à modèle gazéifiable (LFC) pour réduire les défauts de fonderie. 


\section{ACKNOWLEDGEMENTS}

The author would like to take this opportunity to express his sincerest gratitude and appreciation to Prof. C. (Ravi) Ravindran for his time, wisdom, guidance, encouragement, motivation and advice.

The author would also like to acknowledge Prof. P. Chan for his invaluable discussions, advice and support. The author would like to express his gratitude and appreciation to Mr. Alan Machin for his continued support, advice, motivation and many discussions.

The author is grateful to Materials Manufacturing Ontario (MMO) and in particular Mr. Harvey Pellegrini for financial support. The author would like to thank Foseco-Morval, in particular Mr. Dennis Nolan. His collaboration and advice inspired this study and will hopefully lead to future research projects.

Special consideration and appreciation is given to Mr. Tom Pang and Prof. R. Dhib for their invaluable discussions. The author would also like to thank Mr. Joseph Amankrah for his technical assistance, Mr. Q. Li for SEM assistance, Ms. Connie Barry for particle milling assistance, Ms. Georgeta Masson and Mr. Frank Gibbs for TGA/DSC analysis, Dr. Neil Coombs for microtome assistance, Dr. H. Stover, Dr. Nicholas Burke and Dr. Xudong Lou for GPC analysis.

The author wishes to thank Miss S. Lun Sin, Mr. L. Bichler, Mr. K. Lee, Mr. A. Elsayed, Mr. F. D'Elia, Mr. N. Dahata and Mr. A. Haldar for their support in the laboratory and discussions.

Finally, the author would like to express heartfelt gratitude to his family, in particular to his parents and wife, Mrs. Varsha Jagoo. Their patience, spontaneous support and prayers led to the successful completion of this thesis. 
Dedicated to my Family, my Grandmother, Mrs. Socil Jagoo and to the memory of my Cate Grandfather Mr. Deoputh Jagoo 


\section{TABLE of CONTENTS}

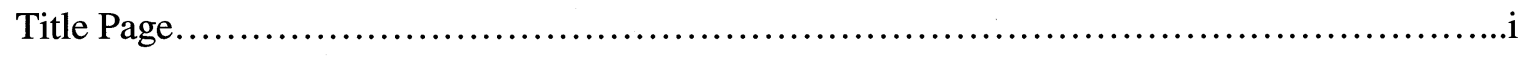

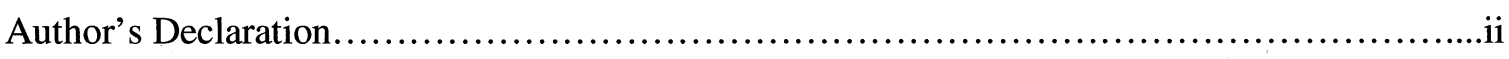

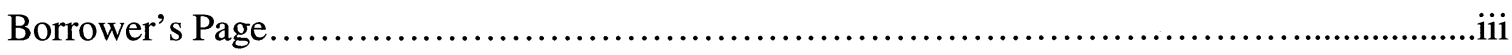

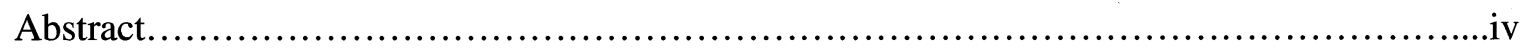

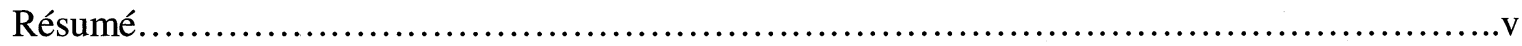

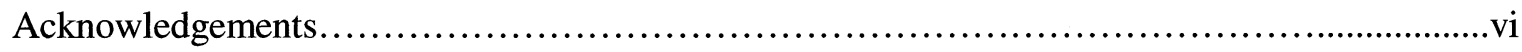

Dedication.......................................................................

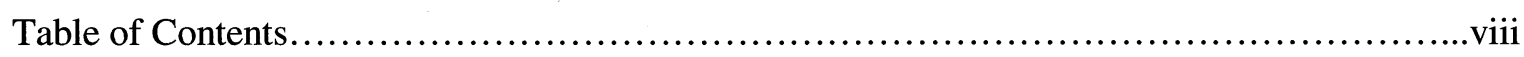

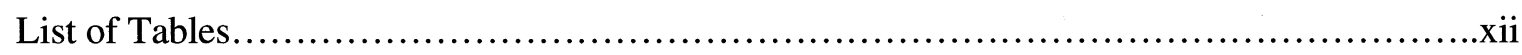

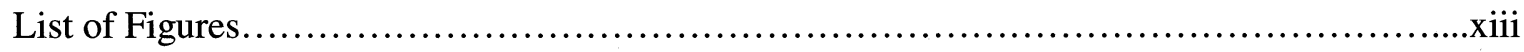

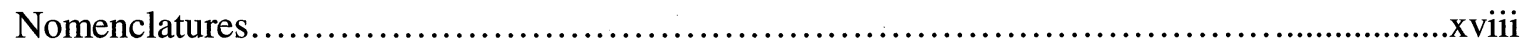

Chapter 1 - Introduction 1

1.1 Problem Statement.................................................................

1.2 Thesis Structure....................................................................

Chapter 2 - Literature Review 4

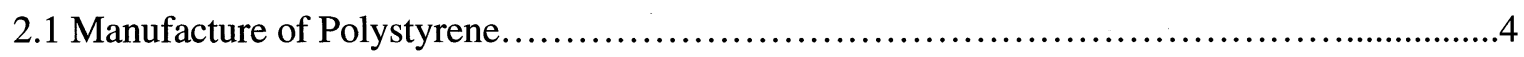

2.1.1 Stirred Reactor...............................................................

2.1.2 Suspending Stabilizers.....................................................

2.1.3 Initiators and Temperature Control.........................................

2.1.4 Blowing Agent Impregnation............................................

2.2 Parameters Affecting the Molecular Weight of Polystyrene.............................8

2.3 Manufacture of Polystyrene Composite Beads...........................................10

2.4 Manufacture of Expandable Polystyrene..............................................

2.5 Manufacture of Expandable Polystyrene Pattern..................................... 12

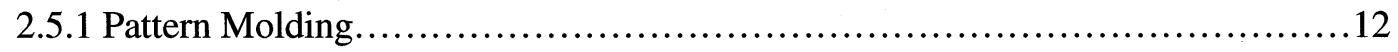

2.5.2 Pattern Assembly.......................................................

2.6 Thermal Properties of Polystyrene and Expandable Polystyrene..........................17

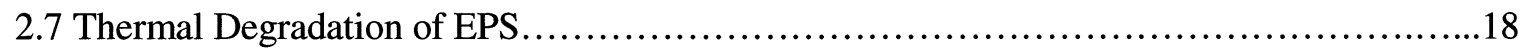

2.7.1 Initiation Reactions........................................................ 18 
2.7.2 Propagation Reactions...................................................... 19

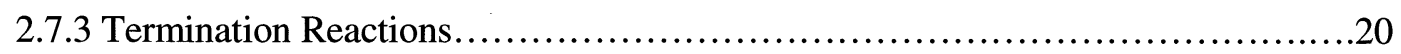

2.8 Thermal Degradation of EPS in Presence of Additives.......................................21

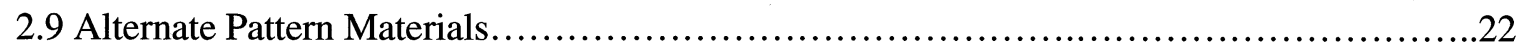

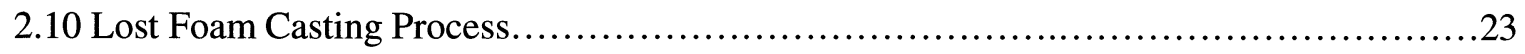

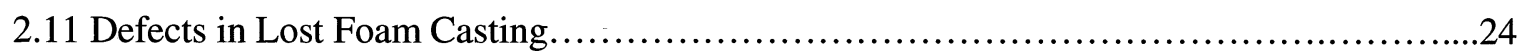

Chapter 3 - Experimental Procedures 29

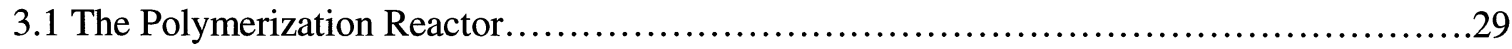

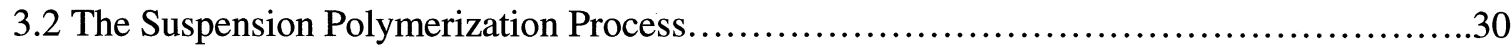

3.3 Production of Low Molecular Weight Polystyrene with Additives.............................31

3.3.1 Identification of Additives to be Incorporated into Polystyrene Beads.......................31

3.3.2 Milling of Additives to be Incorporated into Polystyrene Beads......................32

3.3.3 Polymerization Formulations for Low Molecular Weight Polystyrene with

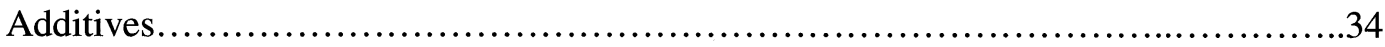

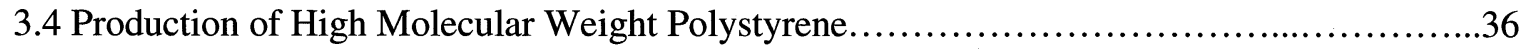

3.5 Production of High Molecular Weight Polystyrene with Silica-Alumina.........................39

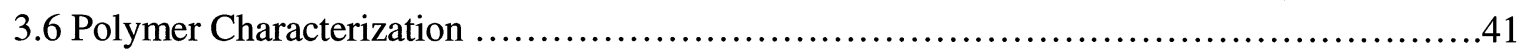

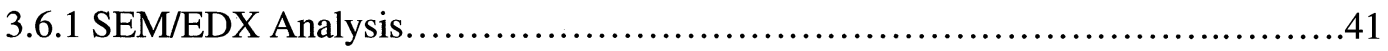

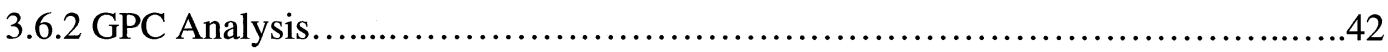

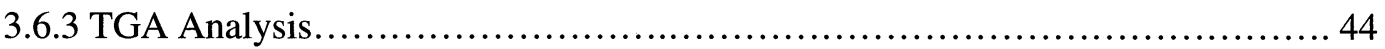

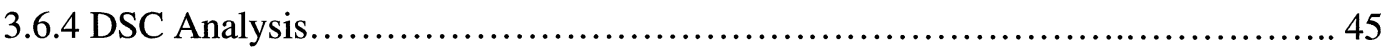

Chapter 4 - Results $\quad 46$

4.1 Results in the Production of Low Molecular Weight Polystyrene with Additives..............46

4.1.1 SEM/EDX Analysis of Low Molecular Weight Polystyrene with Additives.........47

4.1.2 GPC Analysis of Low Molecular Weight Polystyrene with Additives..............51

4.1.3 DSC Analysis of Low Molecular Weight Polystyrene with Additives................54

4.1.4 TGA Analysis of Low Molecular Weight Polystyrene with Additives..............56

4.2 Results in the Production of High Molecular Weight Polystyrene.............................59

4.2.1 Effect of Reaction Time on Molecular Weight.....................................59

4.2.2 Effect of Mass of Initiators on Molecular Weight..............................67

4.3 Results in the Production of High Molecular Weight Polystyrene with Silica-Alumina.....72 
4.3.1 SEM/EDX Analysis of High Molecular Weight Polystyrene with Silica-Alumina.73

4.3.2 GPC Analysis of High Molecular Weight Polystyrene with Silica-Alumina.........77

4.3.3 DSC Analysis of High Molecular Weight Polystyrene with Silica-Alumina.........81

4.3.4 TGA Analysis of High Molecular Weight Polystyrene with Silica-Alumina.......84

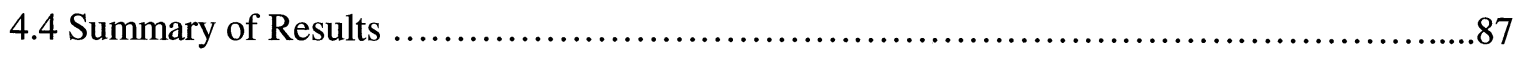

Chapter 5 - Discussion $\quad 91$

5.1 Discussion on the Production of Low Molecular Weight Polystyrene with Additives.........91

5.1.1 Effect of Additives on Molecular Weight....................................91

5.1.2 Effect of Additives on Onset Temperature of Degradation, $\mathrm{T}_{0} \ldots \ldots \ldots \ldots \ldots \ldots . . . .2$

5.1.3 Effect of Additives on Glass Transition Temperature, $\mathrm{T}_{\mathrm{g}} \ldots \ldots \ldots \ldots \ldots \ldots \ldots \ldots . . . .65$

5.1.4 Effect of Molecular Weight on Thermal Degradation.............................96

5.2 Discussion on the Production of High Molecular Weight Polystyrene.......................104

5.2.1 Effect of Reaction Time on Monomer Conversion.................................104

5.2.2 Effect of Reaction Time on Bead Size Distribution.............................. 105

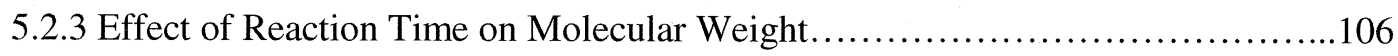

5.2.4 Effect of Mass of Initiators on Size Distribution................................. 108

5.2.5 Effect of Mass of Initiators on Monomer Conversion.............................. 108

5.2.6 Effect of Mass of Initiators on Molecular Weight................................109

5.3 Discussion on the Production of High Molecular Weight Polymer with Silicaalumina.

5.3.1 Entrapment Mechanism of Silica-Alumina in the Production of Polystyrene Composite Beads. 110

5.3.2 Effect of Weight Percent of Silica-Alumina on Molecular Weight. 112

5.3.3 Effect of Weight Percent of Silica-Alumina on Onset Temperature of Degradation, $\mathrm{T}_{\mathrm{o}}$

5.3.4 Effect of Weight Percent of Silica-Alumina on Rate of Degradation. 115

5.3.5 Effect of Weight Percent of Silica-Alumina on Glass Transition Temperature, $\mathrm{T}_{\mathrm{g}}$

\section{Appendix A - Molecular Weight Calculations}


Appendix B - Pictures of Sieves and SEM of Polystyrene Beads

References

125

Curriculum Vitae 


\section{LIST of TABLES}

Table 1: Thermal Properties of Polystyrene and EPS [42-45] ............................. 18

Table 2: Formulations and Reaction Conditions for Low Molecular Weight Polymer............35

Table 3: Formulations and Reaction Conditions for Higher Molecular Weight Polystyrene by

Varying Reaction Time.

Table 4: Formulations and Reaction Conditions for Higher Molecular Weight Polystyrene by Varying Mass of Initiators .38

Table 5: Formulations and Reaction Conditions for Higher Molecular Weight Polystyrene

Composite Beads by Varying Mass of Silica-Alumina.....................................40

Table 6: Bead Size and Percent Yield of Polymer Beads...................................46

Table 7: Molecular Weight for Grades A, B, C and D....................................53

Table 8: Glass Transition Temperature for Grades A, B, C and D...........................56

Table 9: Onset Temperature of Degradation for Grades A, B, C and D......................58

Table 10: Mass Distribution of Bead Sizes for Different Reaction Time.......................60

Table 11: GPC Results for Grades A1, A2, A3 and A4 ................................67

Table 12: Mass Distribution of Bead Sizes for Different Mass of Initiators.....................67

Table 13: GPC Results for Grades A5, A6, A7 and A8 ............................... 72

Table 14: Bead Size and Percent Yield of Polymer Beads................................ 72

Table 15: Molecular Weight for Grades B1, B2, B3, B4 and B5...........................80

Table 16: Glass Transition Temperature for Grades B1, B2, B3, B4 and B5..................84

Table 17: Onset Temperature of Degradation for Grades B1, B2, B3, B4 and B5..............87

Table 18: Summary of Analysis of Low Molecular Polystyrene with Additives .................88

Table 19: Summary of GPC Results of High Molecular Weight Polystyrene ....................89

Table 20: Summary of Analysis of High Molecular Polystyrene with Silica-Alumina ...........90

Table 21: Molecular Weight for Grade BM......................................... 102

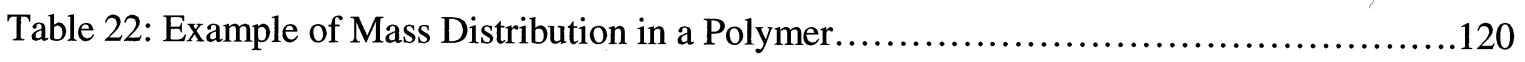




\section{LIST of FIGURES}

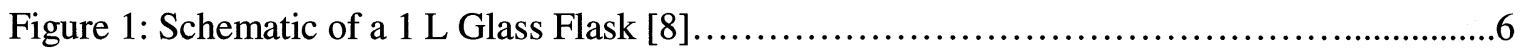

Figure 2: Polystyrene Beads (left) and Expandable Polystyrene Beads (right) [33].............11

Figure 3: Fata-Big Vertically Acting Mold Machine [33] ................................ 12

Figure 4: Wright-Big Horizontally Acting Mold Machine [33] ...........................13

Figure 5: Schematic of an EPS Molding Machine [33] .................................14

Figure 6: Over-Fused Pattern (Wrinkled Surface Finish) [33] ........................... 15

Figure 7: Under-Fused Pattern (Rough Surface Finish) [33] ........................... 15

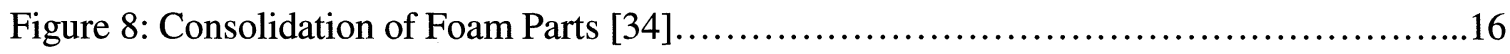

Figure 9: EPS Engine Block (right) and Metal Engine Block (left) after Pouring [34]..........16

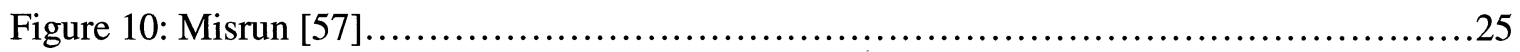

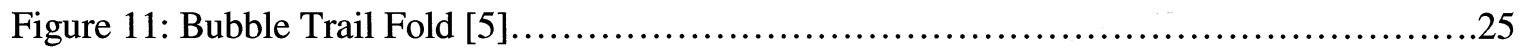

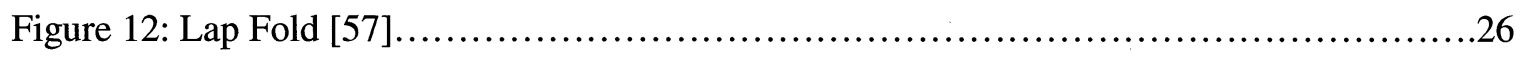

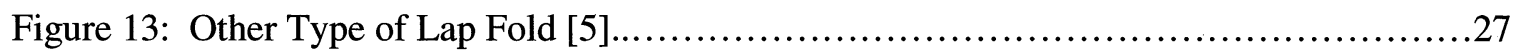

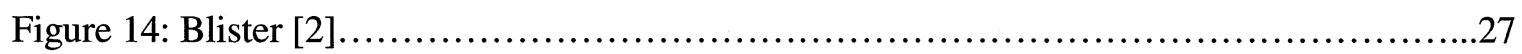

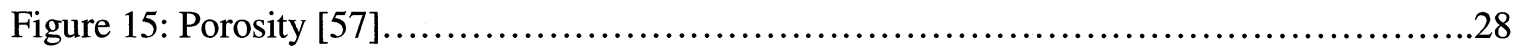

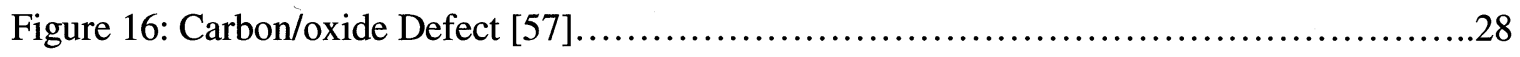

Figure 17: Pressure Reactor for the Suspension Polymerization Process [8]..................30

Figure 18: Changes in the Level of Fusion Level due to Additives [3].......................

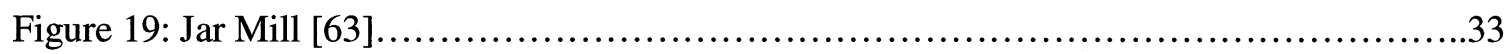

Figure 20: SEM of Microtomed Polystyrene Composite Beads............................42

Figure 21: The Molecular Weight Distribution of a Polymer [70]...........................43

Figure 22: Method to Determine the Onset Temperature [39]...........................44

Figure 23: Method to Determine the Glass Transition Temperature [72] ....................45

Figure 24: SEM Micrograph of Grade A (no additive)..................................47 
Figure 25: SEM Micrograph of a Typical Commercial Bead [73] ..........................47

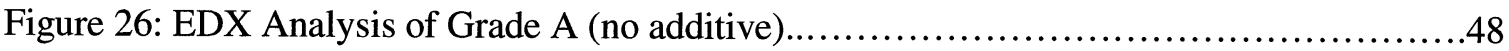

Figure 27: SEM Micrograph of Grade B (2 wt \% silica-alumina)............................48

Figure 28: SEM Micrograph of Grade C (2 wt \% iron-based catalyst).......................48

Figure 29: SEM Micrograph of Grade D (1 wt \% silica-alumina and $1 \mathrm{wt} \%$ iron-based catalyst)

Figure 30: EDX Analysis of Grade B (2 wt \% silica-alumina).

Figure 31: EDX Analysis of Grade D (1 wt \% silica-alumina and 1 wt \% iron-based catalyst)....50

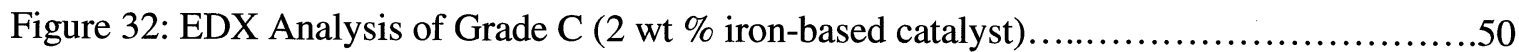

Figure 33: GPC Graph of Grade A (no additive).......................................51

Figure 34: GPC Graph of Grade B (2 wt \% silica-alumina)................................52

Figure 35: GPC Graph of Grade C (2 wt \% iron-based catalyst).............................52

Figure 36: GPC Graph of Grade D (1 wt \% silica-alumina and 1 wt \% iron-based catalyst)..... 53

Figure 37: DSC Graph of Grade A (no additive)........................................54

Figure 38: DSC Graph of Grade B (2 wt \% silica-alumina).................................54

Figure 39: DSC Graph of Grade C (2 wt \% iron-based catalyst) ...........................55

Figure 40: DSC Graph of Grade D (1 wt \% silica-alumina and $1 \mathrm{wt} \%$ iron-based catalyst)......55

Figure 41: TGA Graph of Grade A (no additive) ...................................... 56

Figure 42: TGA Graph of Grade B (2 wt \% silica-alumina) ............................. 57

Figure 43: TGA Graph of Grade C (2 wt \% iron-based catalyst) ........................... 57

Figure 44: TGA Graph of Grade D (1 wt \% silica-alumina and 1 wt \% iron-based catalyst).......58

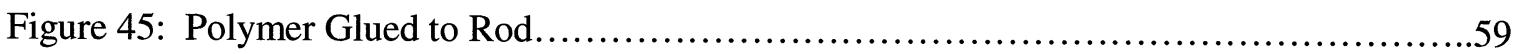

Figure 46: Polymer Glued to Blade...............................................59

Figure 47: Polymer Trapped in Flask.............................................60

Figure 48: Polymer Glued to Thermowell...........................................60

Figure 49: SEM Image of LFC Type Beads (bead diameter: 150 - 595 microns)...............61 
Figure 50: SEM Image of CUP Type Beads (bead diameter: 595 - 1680 microns)...........61

Figure 51: SEM Images of (a) Agglomerate and (b) Larger Beads.........................62

Figure 52: GPC Graph of Grade A1 (3 hrs)..........................................63

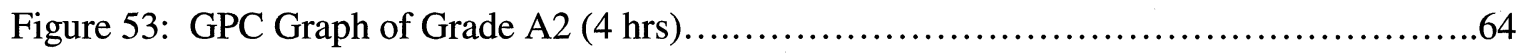

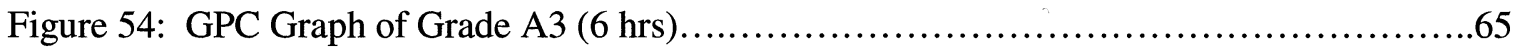

Figure 55: GPC Graph of Grade A4 (6 hrs).........................................66

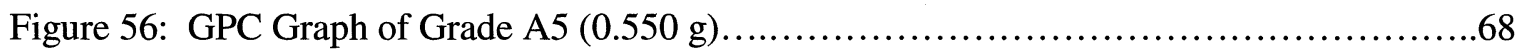

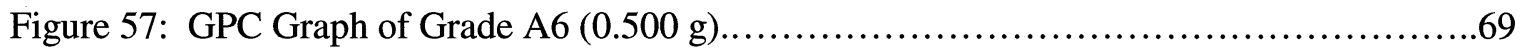

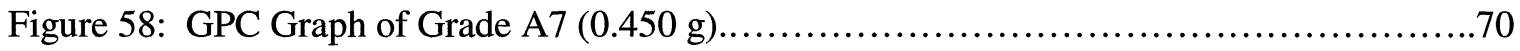

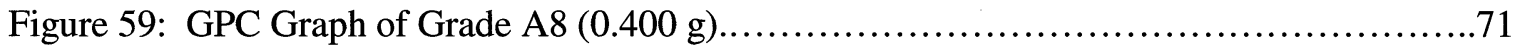

Figure 60: SEM Micrograph of Grade B1 (no additive).....................................73

Figure 61: EDX Analysis of Grade B1 (no additive)....................................... 73

Figure 62: SEM Micrograph of Grade B2 (1 wt \% silica-alumina) ..........................74

Figure 63: SEM Micrograph of Grade B3 (2 wt \% silica-alumina) .........................74

Figure 64: SEM Micrograph of Grade B4 (3 wt \% silica-alumina)............................75

Figure 65: SEM Micrograph of Grade B5 (5 wt \% silica-alumina)............................75

Figure 66: EDX Analysis of Grade B2 (1 wt \% silica-alumina) $\ldots \ldots \ldots \ldots \ldots \ldots \ldots \ldots \ldots \ldots \ldots \ldots$

Figure 67: EDX Analysis of Grade B3 (2 wt \% silica-alumina)...........................76

Figure 68: EDX Analysis of Grade B4 (3 wt \% silica-alumina)............................77

Figure 69: EDX Analysis of Grade B5 (5 wt \% silica-alumina).............................77

Figure 70: GPC Graph of Grade B1 (no additive) ....................................... 78

Figure 71: GPC Graph of Grade B2 (1 wt \% silica-alumina).............................

Figure 72: GPC Graph of Grade B3 (2 wt \% silica-alumina)...............................79

Figure 73: GPC Graph of Grade B4 (3 wt \% silica-alumina)................................79

Figure 74: GPC Graph of Grade B5 (5 wt \% silica-alumina) .............................80

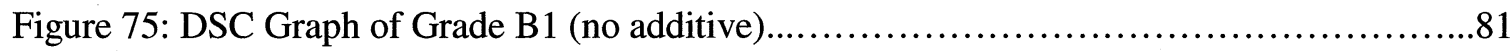


Figure 76: DSC Graph of Grade B2 (1 wt \% silica-alumina).

Figure 77: DSC Graph of Grade B3 (2 wt \% silica-alumina)............................... 82

Figure 78: DSC Graph of Grade B4 (3 wt \% silica-alumina) ...............................83

Figure 79: DSC Graph of Grade B5 (5 wt \% silica-alumina) $\ldots \ldots \ldots \ldots \ldots \ldots \ldots \ldots \ldots \ldots \ldots \ldots . \ldots \ldots$

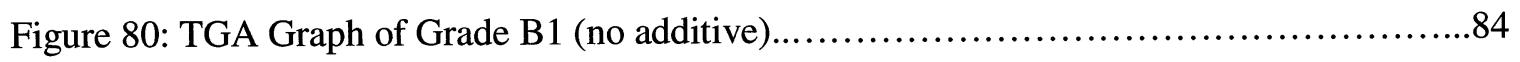

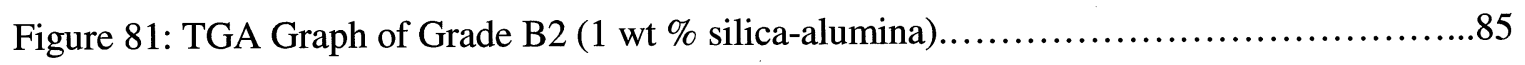

Figure 82: TGA Graph of Grade B3 (2 wt \% silica-alumina)..............................85

Figure 83: TGA Graph of Grade B4 (3 wt \% silica-alumina) ..............................86

Figure 84: TGA Graph of Grade B5 (5 wt \% silica-alumina).............................86

Figure 85: Degradation of Grades A, B, C and D (based on Figures $41-44) \ldots \ldots \ldots \ldots \ldots \ldots . . . . .92$

Figure 86: Degradation of Grades A, B, C and D with Respect to Time......................94

Figure 87: Rate of Degradation of Grades A, B, C and D with Respect to Temperature..........95

Figure 88: Effect of Additives on $\mathrm{T}_{\mathrm{g}}$ for Grades A, B, C and D (based on Figures $\left.37-40\right) \ldots . .96$

Figure 89: Dependence of Molecular Weight on the Decomposition Temperature [41].........97

Figure 90: Effect of Molecular Weight on $\mathrm{T}_{\mathrm{d}}$ for Grades A, B, C and D...................98

Figure 91: Molecular Weight of Polystyrene versus Temperature [87]....................99

Figure 92: Effect of Molecular Weight on $\mathrm{T}_{\mathrm{o}}$ for Grades A, B, C and D.................... 100

Figure 93: Dependence of Rate of Random Chain Scission (k) on Weight Average Molecular

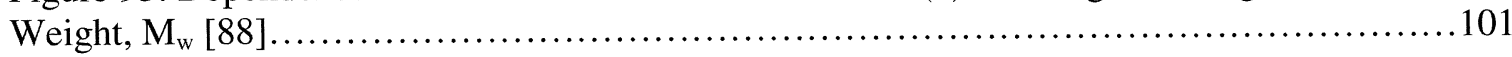

Figure 94: GPC Graph of Grade BM............................................. 102

Figure 95: TGA Graph of Grade BM.............................................. 103

Figure 96: Rate of Degradation of Grade A, B and BM with Respect to Temperature...........103

Figure 97: Effect of Reaction Time on Monomer Conversion...........................105

Figure 98: Effect of Reaction Time on Bead Size Distribution..........................106

Figure 99: Effect of Reaction Time on Molecular Weight...............................107

Figure 100: Effect of Bead Size on Molecular Weight [92]............................. 107 
Figure 101: Effect of Mass of Initiators on Bead Size Distribution........................108

Figure 102: Effect of Mass of Initiators on Monomer Conversion........................109

Figure 103: Effect of Mass of Initiators on Molecular Weight...........................110

Figure 104: SEM Micrograph of High Molecular Weight Polystyrene Composite Beads.......111

Figure 105: Effect of Amount of Silica-Alumina on Molecular Weight.....................112

Figure 106: Degradation of Grades B1, B2, B3, B4 and B5 (based on Figures $80-84) \ldots . . . .113$

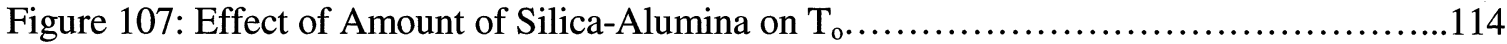

Figure 108: Degradation of Grades B1, B2, B3, B4 and B5 with Respect to Time..............115

Figure 109: Rate of Degradation of Grades B1, B2, B3, B4 and B5 with Respect to

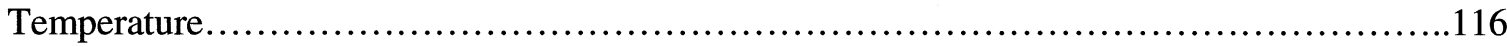

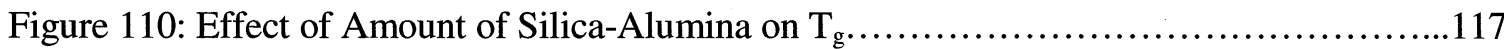

Figure 111: Top-Side View of the Sieves (showing the agglomerates)......................121

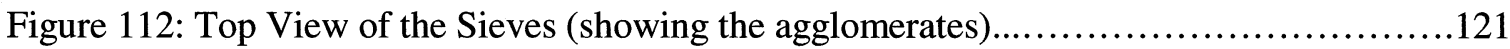

Figure 113: Top View of the Agglomerates and Big Beads (bead diameter: > 1680 microns)..122

Figure 114: Top View of the CUP Beads (bead diameter: 595 - 1680 microns).............122

Figure 115: Top View of the LFC Beads (bead diameter: 150 - 595 microns)...............123

Figure 116: SEM of Big Beads (Referred to as agglomerates in this study) (bead diameter: >

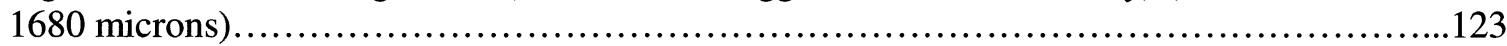

Figure 117: SEM of CUP Beads (bead diameter: 595 - 1680 microns) $\ldots \ldots \ldots \ldots \ldots \ldots \ldots \ldots \ldots 124$

Figure 118: SEM of LFC Beads (bead diameter: 150 - 595 microns).........................124 


\section{NOMENCLATURE}

Symbol

\section{English}

A

B

$\mathrm{C}_{\mathrm{p}}$

d

f

g

[I]

$\mathrm{K}_{\mathrm{d}}$

$\mathrm{K}_{\mathrm{p}}$

$\mathrm{K}_{\mathrm{t}}$

L

[M]

$\mathrm{M}_{\mathrm{i}}$

$\mathrm{M}_{\mathrm{n}}$

$\mathrm{M}_{\mathrm{w}}$

$\mathrm{N}_{\mathrm{i}}$

No.

$\mathrm{P}$

pcf

$\mathrm{t}$

$\mathrm{T}$

$\mathrm{T}_{\mathrm{d}}$

$\mathrm{T}_{\mathrm{g}}$

$\mathrm{T}_{\mathrm{m}}$

$\mathrm{T}_{\mathrm{o}}$

$V_{t}$

\section{Greek}

$\alpha$

$\Sigma$

$\rho$

$\mu$

$v$

Description

Units

$\mathrm{MPa}$

$\mathrm{MPa}$

$\mathrm{J} /{ }^{\circ} \mathrm{C}$

$\mathrm{m}$

Initiator efficiency

Acceleration of free fall

Concentration of initiator

Rate constant of decomposition

Rate constant of propagation

Rate constant of termination

Liter

Concentration of monomer

Molecular weight of a polymer

Number average molecular weight

Weight average molecular weight

Number of molecules of a polymer

Number

Tensile strength

Pounds per cubic foot

Time

Temperature

Degradation temperature

Glass transition temperature

Melting temperature

Onset temperature of degradation

Settling velocity $\mathrm{m} / \mathrm{s}^{2}$

$\mathrm{mol} / \mathrm{dm}^{3}$

$\mathrm{s}^{-1}$

$\mathrm{s}^{-1}$

$\mathrm{s}^{-1}$

$\mathrm{cm}^{3}$

$\mathrm{mol} / \mathrm{dm}^{3}$

$\mathrm{Da}$

$\mathrm{Da}$

Da

$\mathrm{MPa}$

$\mathrm{lb} / \mathrm{ft}^{3}$

$\mathrm{s}$

${ }^{\circ} \mathrm{C}$

${ }^{\circ} \mathrm{C}$

${ }^{\circ} \mathrm{C}$

${ }^{\circ} \mathrm{C}$

${ }^{\circ} \mathrm{C}$

$\mathrm{m} / \mathrm{s}$ $\mathrm{kg} / \mathrm{m}^{3}$

$\mathrm{kg} / \mathrm{m}$.s 


\section{Acronyms}

AFS

AMS

BCP

CFC

CTA

CUP

DBPO

DC

DCP

DSC

EDX

EPS

EPAC

EPMMA

GPC

HM

LFC

$\min$

hrs

PDI

PHM

PVA

RPM

RV

SEM

TCP

TGA

wt \%
American Foundry Society

Alpha Methyl Styrene

tert-Butyl-Cumyl Peroxide

ChloroFluoroCarbon

Chain Transfer Agent

Polystyrene beads used for making cups

Di-Benzoyl Peroxide

Direct Current

Dicumyl Peroxide

Differential Scanning Calorimetry

Energy Dispersive X-ray

Expandable Polystyrene

Expandable PolyAlkylene Carbonate

Expanded PolyMethylMethAcrylate

Gel Permeation Chromatography

Proton Mordenite

Lost Foam Casting

Minute

Hours

PolyDispersity Index

Phosphoric Proton Mordenite

PolyVinyl Alcohol

Revolution per Minute

Retention Volume

Scanning Electron Microscopy

Tri-Calcium Phosphate

Thermo-Gravimetric Analysis

Weight percentage

\section{Elements}

$\begin{array}{ll}\mathrm{Al} & \text { Aluminum } \\ \mathrm{Ba} & \text { Barium } \\ \mathrm{Br} & \text { Bromine } \\ \mathrm{C} & \text { Carbon } \\ \mathrm{Ca} & \text { Calcium } \\ \mathrm{Cl} & \text { Chlorine } \\ \mathrm{F} & \text { Fluorine } \\ \mathrm{Fe} & \text { Iron } \\ \mathrm{H} & \text { Hydrogen } \\ \mathrm{Na} & \text { Sodium } \\ \mathrm{O} & \text { Oxygen } \\ \mathrm{P} & \text { Phosphorus } \\ \mathrm{Si} & \text { Silicon } \\ \mathrm{Zn} & \text { Zinc }\end{array}$





\section{Chapter 1 - Introduction}

The beginning of this chapter describes the trend of aluminum castings produced via the Lost Foam Casting (LFC) process in recent years, followed by the importance of this casting process. Some technical problems and solutions associated with the LFC process are also briefly described. In the next portion of this chapter, the objectives of this study are stated followed by a brief description of the importance of this work. The routes used to tackle these problems and the techniques used to verify whether the objectives of this research were met, are also discussed. The rest of chapter describes the global structure of this thesis.

\subsection{Problem Statement}

A recent survey [1] showed that 2.735 million tons of aluminum castings were produced in North America during 2006, and the dominant end-use market was the motor-vehicle industry. The survey also showed that $56 \%$ of all the aluminum castings were produced via Die-casting and less than $6 \%$ of these castings were made via LFC. However, the American Foundry Society (AFS) estimated that as much as $30 \%$ of aluminum castings may be produced through LFC in the near future, if casting defects associated with this process are reduced.

With the trend toward lighter castings in the automotive sector to enhance fuel efficiency and to reduce greenhouse gases, there is a growing interest in lighter materials and near-net shape processes such as LFC. Folds associated with LFC are caused by the entrapment of polymer pattern pyrolysis products in the metal matrix. These defects result in lower casting yields (higher scrap) and impair the mechanical properties of the castings. Minimization of folds may result in an increase in light weight alloy castings produced by LFC process.

Research has shown that quick removal of Expandable Polystyrene (EPS) foam pyrolysis products, a low amount of gaseous pyrolysis products and a low metal superheat loss during 
mold fill may reduce fold defects [2]. Thus, increasing the rate of polymer decomposition, lowering the polymer decomposition temperature $[3,4]$ and decreasing the viscosity $[3,5]$ of the polymer residue may be a solution to fold defects.

Accordingly, the overall aim of this novel and interdisciplinary research involving polymer processing and metalcasting was to develop new polymers (foams) with the ideal thermal properties to produce completely fold-free castings. Thus, the objectives of this study were:

1. To identify novel additives to be impregnated into the polystyrene beads during the suspension polymerization process.

2. To produce polystyrene composites beads using the identified additives.

3. To determine the thermal properties of the polystyrene composite beads.

4. To produce commercial standard polystyrene composite beads for possible IP and patent.

5. To recommend novel polystyrene composite beads to make foam patterns for the LFC process.

In this research, several chemicals were added during the polymerization process to produce novel polystyrene composite beads for the LFC process. Several types of novel polystyrene composite beads were manufactured through the suspension polymerization process in the newly developed Polymerization Facility at the Centre for Near-Net-Shape Processing of Materials at Ryerson University.

In addition to the manufacture of several types of novel polystyrene composite beads, polymer characterization techniques such as Scanning Electron Microscope/Energy Dispersive X-rays (SEM/EDX), Thermo-gravimetric Analysis (TGA), Differential Scanning Calorimetry (DSC) and Gel Permeation Chromatography (GPC) were used to analyze these beads. Moreover, polystyrene beads with high molecular weight, currently used in the LFC process, were also produced. 


\subsection{Thesis Structure}

This thesis has been structured as follows:

Chapter two presents a literature review that contains the theory involved in manufacturing polystyrene beads through suspension polymerization followed by its thermal properties and the mechanisms involved in its degradation. The expansion process, which involves the conversion of polystyrene beads into pre-puffs, and the manufacture of foam patterns, are also discussed. At the end of this chapter, the LFC process, the foam removal mechanism, and the casting defects are described.

In chapter three, the experimental procedure involving the manufacture of polystyrene and polystyrene composite beads is presented. The identification of novel additives, the suspension polymerization reactor and the recipes are detailed. The end section of chapter three describes the polymer characterization techniques that were used to analyze the properties of these polymer beads.

Chapter four shows the results of all the analysis performed in this study along with some brief discussion. Chapter five presents a detailed discussion of the results. It also shows that the objectives of this thesis were successfully met. Moreover, methods to increase the molecular weight of the polystyrene beads for commercial purposes are also discussed. Finally, chapter six gives the principal conclusions of this study and the recommendations for future work. 


\section{Chapter 2 - Literature Review}

In section 2.1, the manufacture of polystyrene beads is described and in section 2.2 , the parameters affecting the molecular weight of polystyrene are discussed. Section 2.3 describes the process involved in expanding the solid spherical beads into pre-puff ("popcorn"). Section 2.4 describes the manufacture of foam patterns. Section 2.5 gives an account of the alternate polymeric foams used in the LFC process followed by the thermal properties and the thermal degradation mechanisms of the polystyrene in sections 2.6, 2.7 and 2.8, respectively. Section 2.9 describes the LFC process and the foam removal mechanisms. Finally, section 2.10 deals with the formation of casting defects in LFC.

\subsection{Manufacture of Polystyrene}

In the manufacture of beads for EPS patterns, it is essential to understand the basics of polystyrene technology. Styrene is a hydrocarbon, $\mathrm{C}_{8} \mathrm{H}_{8}$, with a molecular weight of 104 Daltons (Da), containing $92 \%$ carbon and $8 \%$ hydrogen by weight. It is produced by the reaction of benzene and ethene in the presence of catalysts, aluminum chloride and hydrogen chloride at $95{ }^{\circ} \mathrm{C}$ to obtain ethyl benzene (Equation 1), which is subsequently dehydrogenated in the presence of a zinc catalyst at $600{ }^{\circ} \mathrm{C}$ (Equation 2). Finally, polystyrene is formed by joining molecules of styrene (Equation 3) [6].
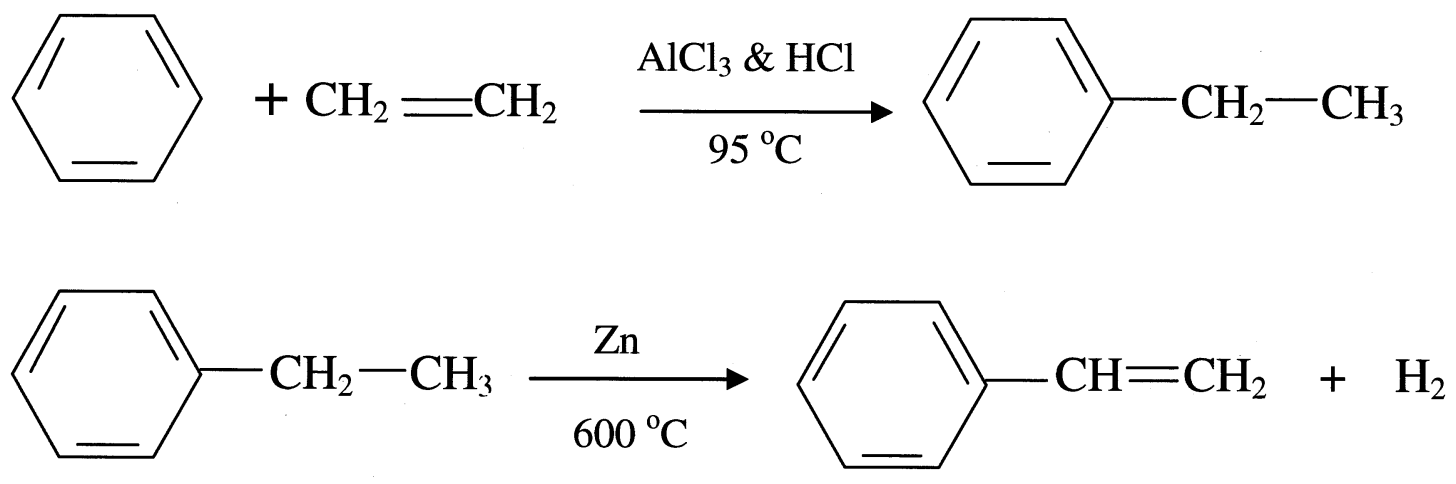
$\mathbf{n}$

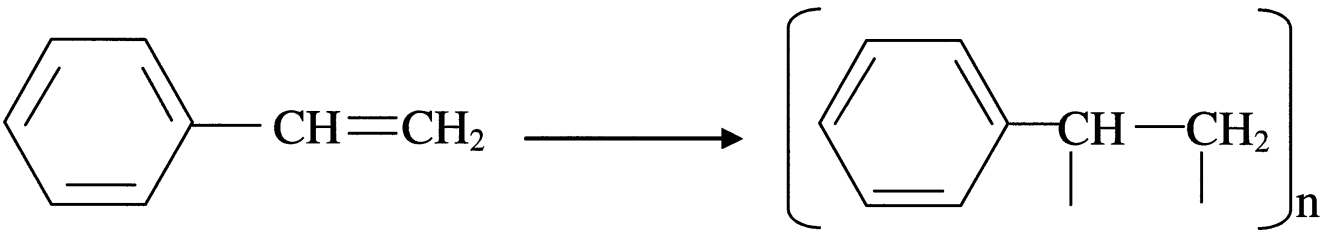

In the industry, the polystyrene beads used for making foam patterns for the LFC process are manufactured via the suspension polymerization process. The term "suspension polymerization" is applied to a system in which a monomer which is insoluble in water is dispersed, by means of agitation, into liquid droplets, and, upon polymerization, the resultant polymer is obtained as a dispersed solid phase [7]. The requirements of suspension polymerization are:
(a) Stirred Reactor
(b) De-ionized Water
(c) Suspending Stabilizer
(d) Initiators and Temperature Control
(e) Blowing Agent Impregnation

\subsubsection{Stirred Reactor}

Round bottom cylindrical-glass flasks (1 to 2 L capacity) are most widely used for laboratory scale suspension runs. Figure 1 shows a schematic representation of a glass flask used in this research. This flask has a maximum capacity of $1 \mathrm{~L}$ and it has a big neck in the middle for the stirrer and four small necks on the periphery. The required amount of de-ionized water is fed into a reactor at room temperature and then agitation is started. 


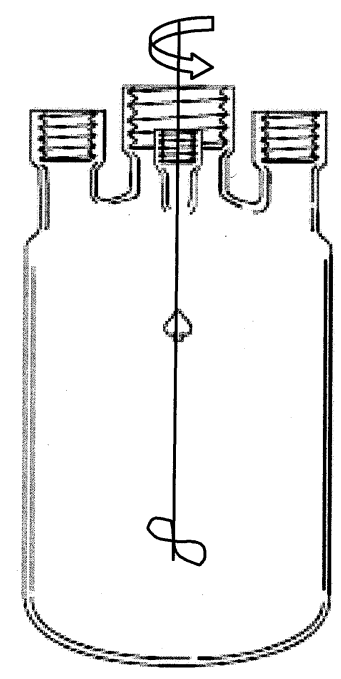

Figure 1: Schematic of a 1 L Glass Flask [8]

\subsubsection{Suspending Stabilizers}

Suspending stabilizers hinder the coalescence of the small drops of monomer during the polymerization process. Suspending stabilizer, either an inorganic-insoluble finely divided powder such as tri-calcium phosphate (TCP) or a water-soluble polymer such as polyvinyl alcohol (PVA), is added into the stirred reactor. During the polymerization process, droplets of styrene are formed and polymerization reactions occur within these beads. The stability of these droplets is maintained mainly by surface forces. Stabilizers enable the proper size of the drops. Stabilizers help to decrease the surface tension and break the large drops into small droplets. The increase in viscosity of the dispersed phase (during the polymerization process) and the effect of surface tension of the drops increase their ability to retain the spherical shape [7].

The older suspension systems based on finely-divided insoluble inorganic powder (TCP) have been substituted for, to a great extent, by water-soluble polymer (PVA). This polymer has several advantages over the inorganic powder [9]:

(a) Stable morphology and performance. TCP changes in morphology with changes in time, moisture and temperature that affect its coverage and distribution characteristics. 
(b) Concentrations of $0.1-0.5$ weight percent (monomer) of PVA is needed, whereas 0.5 to 1.0 weight percent (monomer) of TCP is required to obtain the same drop-size of polystyrene.

(c) PVA may remain attached to the bead surface without adverse processability effects, whereas TCP must be eliminated from the bead surface.

\subsubsection{Initiators and Temperature Control}

An initiator is an agent which causes a chemical reaction to commence and which enters into the reaction to become part of the resultant compound. Initiator (e.g., dibenzoyl peroxide or DBPO) and finishing initiator (e.g., dicumyl peroxide or DCP) are added into the stirred reactor. The reactor is closed and the heating cycle starts. The temperature controls the polymerization rate, which affects the polymerization cycles (5 - 7 hours) and the molecular weight. Droplet sizing occurs during the heating cycle and when the polymerization temperature is reached (between 75 and $95{ }^{\circ} \mathrm{C}$ ), the initiators decompose to produce free radicals. These free radicals react with the droplets of styrene to form solid, spherical beads of polystyrene [9].

\subsubsection{Blowing Agent Impregnation}

A blowing agent (e.g., pentane) produces a cellular structure in polystyrene beads when it expands. The suspension polymerization process is categorized as a one-step or two-step process, depending on the addition of the blowing agent (a volatile organic compound) to the polystyrene beads. In the one-step process, after $70 \%$ of styrene monomers have been polymerized, pentane is added in the stirred reactor followed by a coating such as zinc stearate to prevent clumping of the beads. Finally, when the polymerization process is complete (i.e., 100 $\%$ styrene has been polymerized), the reactor is stopped and the polystyrene beads are washed, dried and screened [10]. 
In the two-step process, styrene monomers are completely polymerized to produce the polystyrene beads. The beads are washed, dried, screened and they are transferred back into the reactor. Then, pentane is added in the reactor. After completion of pentane impregnation, the beads are dried again and coated to prevent clumping [10].

\subsection{Parameters Affecting the Molecular Weight of Polystyrene}

High molecular weight polystyrene is an essential prerequisite for the production of foam patterns with the appropriate processability and acceptable mechanical properties. In general, the tensile strength of polystyrene increases with its molecular weight [11]. This increase is often attributed to additional entanglements in the molecular structure of polystyrene produced at higher molecular weights [12]. Flory [13] developed an empirical relation between the tensile strength and molecular weight of polymers given in Equation 4.

$\mathrm{P}=\mathrm{A}+\mathrm{B} / \mathrm{M}$

Where $\mathrm{P}$ represents the tensile strength $(\mathrm{Pa}), \mathrm{M}$ represents molecular weight $(\mathrm{Da}), \mathrm{A}$ and $\mathrm{B}$ are constants. The constant B is a negative value. For polystyrene, $\mathrm{B}$ has a value in the range of -4.7 x $10^{4} \sim-1.08 \times 10^{5} \mathrm{MPa}[14]$.

It is well known that in a free radical polymerization process [15], the kinetic chain length $(v)$ is expressed using Equation 5 given below:

$v=K_{p}[M] / 2\left(f K_{d} K_{t}[I]\right)^{1 / 2}$

Where $K_{p}$ represents the rate constant of propagation $\left(\mathrm{s}^{-1}\right),[\mathrm{M}]$ represents the concentration of monomer $\left(\mathrm{mol} / \mathrm{dm}^{3}\right)$, f represents the initiator efficiency, $K_{d}$ represents the rate constant of initiator decomposition $\left(\mathrm{s}^{-1}\right), \mathrm{K}_{\mathrm{t}}$ represents the rate constant of termination $\left(\mathrm{s}^{-1}\right)$ and $[\mathrm{I}]$ represents 
the concentration of initiator $\left(\mathrm{mol} / \mathrm{dm}^{3}\right)$. According to Equation 5, an increase in the molecular weight can be achieved by decreasing the concentration of the initiator or by increasing the concentration of the monomer.

Jahanzad et al. [16] found that higher initiator concentration increases the radical concentration and hence decreases the molecular weight. They found that a high rate of free radical initiation produces a shorter critical chain length in the growing oligomers (Equation 3: $\mathrm{n}<20$ ) due to higher termination reactions. Consequently, larger particles composed of low molecular-weight polymer are produced. Further, Horak et al. [17] found that smaller particles present a greater surface area and they increase the molecular weight by absorbing more oligomer radicals from the continuous phase.

There are other parameters that also affect the molecular weight of a polymer. Ahmad et al. [18] found that CTA terminates the growing polymer chain and initiates a new chain. Further, Tefera et al. [19] found that CTA reduces the magnitude and delays the onset of gel effect. The gel effect is a state when the polymer grows indefinitely, and this stage is also referred to as a living polymer [15]. They also found that increasing the CTA content increases the mobility of the polymer chains, which leads to higher termination rates.

Lyoo et al. [20] and Nunes et al. [21] found that bead size decreases with increasing agitation speed. Further, this decrease in bead size was found to increase the molecular weight. Horak et al. [17], Lazrak et al. [22], Kalfas et al. [23] and Singh et al. [24] found that polymerization performed in the absence of a stabilizer, results in a highly viscous resin, and polymerization conducted in the presence of a stabilizer results in the formation of spherical beads. They also found that increasing the stabilizer concentration decreases the size of the beads. Further, Ye $e t$ al. [25] suggested that the increase in molecular weight with increasing stabilizer concentration was due to the capture of oligomeric radicals from the continuous phase. These radicals subsequently undergo solid phase polymerization and grow into higher molecular weights due to the gel effect. 
Lyoo et al. [20] found that decreasing the monomer to water ratio results in higher molecular weight. They suggested that the ability of water to effectively spread the heat generated during polymerization and to cool the medium increases the molecular weight by lowering the termination rate of the process.

It is well known that molecular weight was a function of time [26] and a longer reaction time, resulted in higher molecular weight. Sonnenberg et al. [10] found that the reaction time was in the range of 7 - 9 hours to produce commercial polystyrene beads. Further, the presence of oxygen in a reactor lowers the monomer to polymer conversion rate. Hence, nitrogen gas [20 23, 27 - 29] is used to remove all traces of oxygen in the reactor. A condenser is also used to condense the monomer vapours and reduce monomer loss evaporation during the polymerization process.

\subsection{Manufacture of Polystyrene Composite Beads}

Polystyrene beads are often modified in situ during polymerization to achieve enhanced mechanical and thermal properties. Polystyrene composite beads of varying compositions have been produced in the industry for different applications. Ding et al. [30] produced polystyrene beads coated with an inorganic compound through a two-stage copolymerization process. In the first stage, styrene monomers were polymerized to produce polystyrene beads and in the second stage, the polystyrene beads were copolymerized with an inorganic compound to produce inorganic coated polystyrene beads.

More recently, $\mathrm{Gu}$ et al. [31] produced a composite of polystyrene containing emulsion particles. These particles were dispersed in water in the presence of styrene monomers. These particles were broken with an aqueous solution of calcium chloride (electrolyte) and they diffused into the styrene monomers. Then, the suspension polymerization reaction was performed to produce polystyrene composite beads containing the emulsion particles. 


\subsection{Manufacture of Expandable Polystyrene}

A direct steam expander or a vacuum dry expander is used to expand the polystyrene beads. The direct steam expander causes expansion of the polystyrene by contacting the beads directly with steam in a chamber. The vacuum dry expander uses steam to heat the wall of the expansion chamber, which consequently causes the beads within the chamber to expand. The goal of the expansion process is to achieve the desired bulk density, reasonable levels of residual blowing agent, and a narrow bead size distribution required for different applications [32].

Prior to expansion, the polystyrene beads contain about $5-8 \%$ of pentane and they have a density of about $38-42 \mathrm{lb} / \mathrm{ft}^{3}$. When the temperature of the chamber/wall reaches $90{ }^{\circ} \mathrm{C}$, the beads soften and pentane increases the internal pressure of the beads. This softening and increasing internal pressure expands the beads to the required density of $1.3-1.8 \mathrm{lb} / \mathrm{ft}^{3}$. The volume of the expanded beads can increase 40 times compared to pre-expanded beads [32].

After achieving the proper density, the beads are stored in silos for several hours to reach equilibrium with the ambient atmosphere. This stabilization promotes the purging of excess water and blowing agent [32]. The EPS beads shown in the right side of Figure 2 are now ready to be molded into foam patterns for the LFC process.

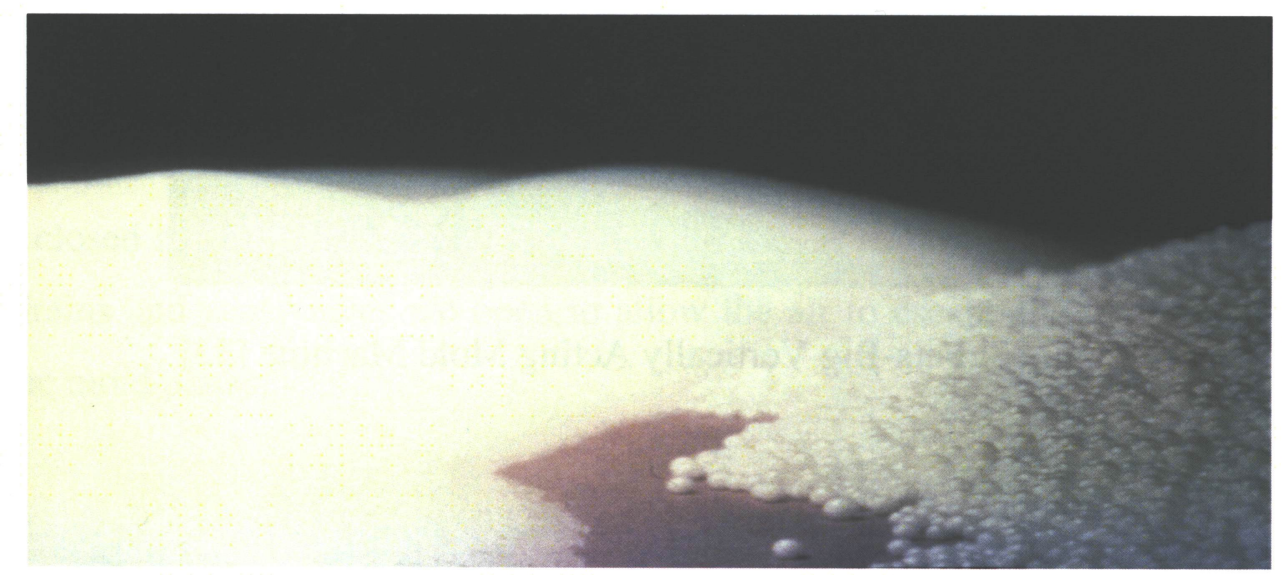

Figure 2: Polystyrene Beads (left) and Expandable Polystyrene Beads (right) [33] 


\subsection{Manufacture of Expandable Polystyrene Pattern}

The stabilized expanded beads are injected into a molding machine. Then the beads are heated with steam and expanded to the desired shape. This operation determines the quality of the patterns, dimensional stability and surface finish. Proper tool design is essential for producing premium quality foam patterns [32].

\subsubsection{Pattern Molding}

In the foam pattern molding industry, the foam molding machines can be either horizontallyacting (Figure 3 ) or vertically-acting (Figure 4). The use of a horizontally or vertically acting mold machine depends on the complexity and the geometry needs of the part to be molded. However, the steps involved in making the molded patterns are fairly similar in both horizontally and vertically acting machines.

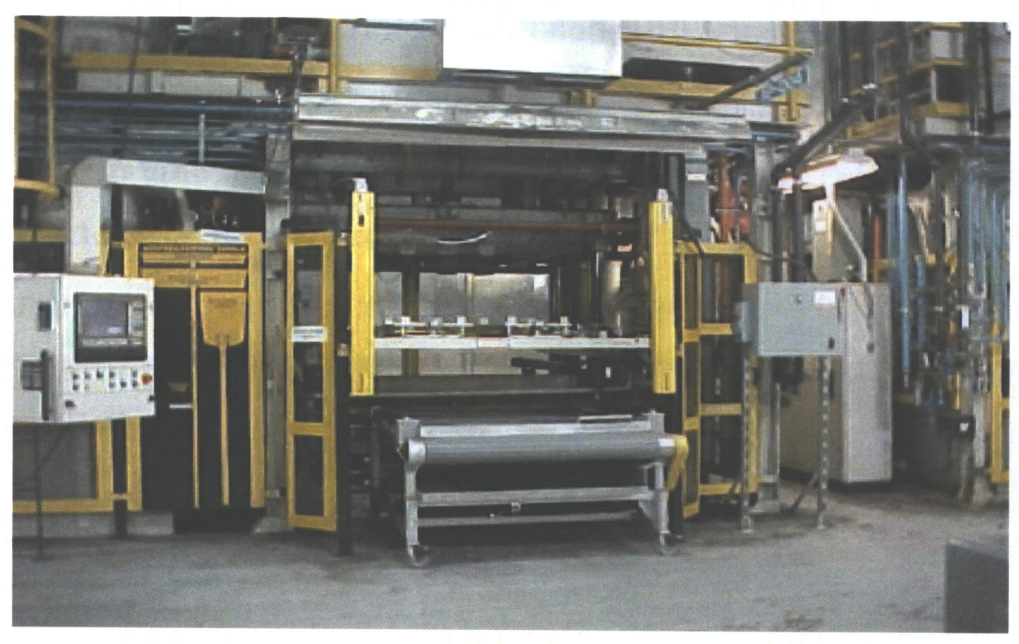

Figure 3: Fata-Big Vertically Acting Mold Machine [33] 


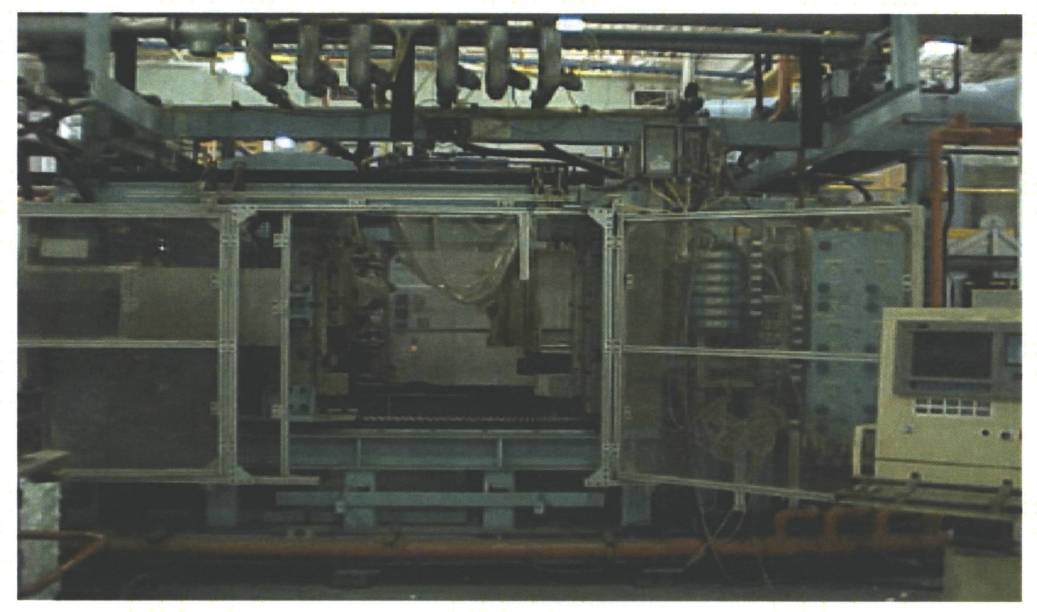

Figure 4: Wright-Big Horizontally Acting Mold Machine [33]

The pattern molding cycle consists of many steps such as:

- mold preheat

- bead fill

- bead fusion

- pattern cooling

- pattern removal

- pattern inspection

The first important step in the molding cycle is to preheat the mold with steam to remove any traces of water from the mold plates, which may inhibit the bead flow and cause a molding pattern defect. Figure 5 shows a schematic of a vertically acting, horizontally parted mold machine with its associated utility piping and EPS bead handling hoses. After preheating, the tooling is closed and the mold cavity is filled with EPS beads using fill guns. During the filling step, all drains and vent valves are open to allow the air to escape the mold cavity through the vents in the mold plates. 


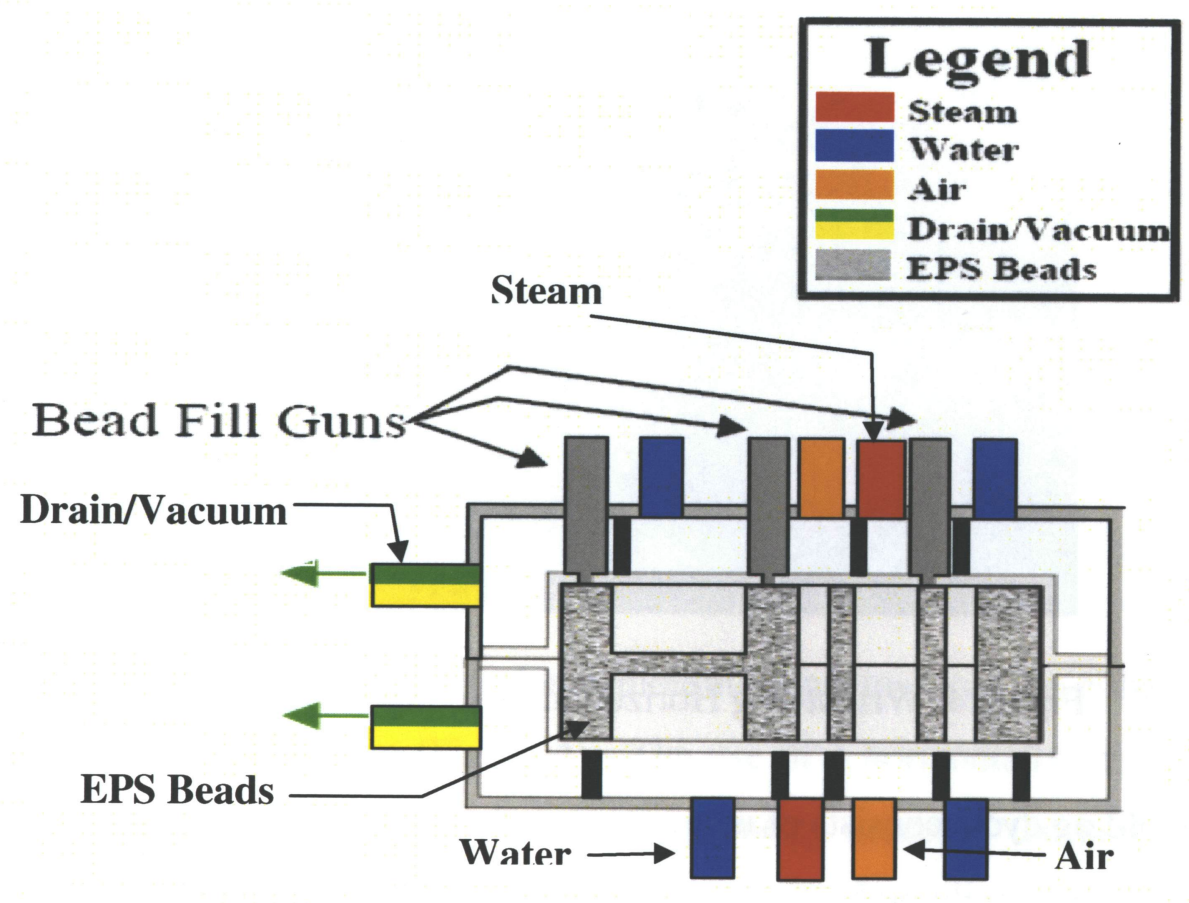

Figure 5: Schematic of an EPS Molding Machine [33]

The drain/vacuum valves are opened and the steam valves are modulated to achieve a pressure set point. This process is referred to as purging and it yields the initial fusion of the pattern at low pressures. The bead fusion level determines the strength with which the individual beads are held together. It also gives the pattern the strength to withstand the cluster coating and sand compaction steps during LFC.

After purging, all the drains are closed and the steam valves are modulated to achieve a set pressure. This process is called autoclaving and it reaches higher pressure and temperature than the purging and it yields the smooth surface finish desired for the casting. Then, the mold is cooled to allow easy removal from the tooling by opening the drain/vacuum valves to relieve the internal pressure. Simultaneously, chilled water is sprayed onto the back of the mold plates. As a result, this process cools the foam pattern and the pattern is removed from the tooling. 
During pattern making, over-fusion and under-fusion are common defects which result from the patterns that are experiencing too much or too little heat in a specific area. These defects can be reduced by controlling the pressure during the autoclaving. In addition, insufficient preheat can result in under-fusion, and inadequate cooling can result in over-fusion. Over-fused pattern (Figure 6) can be extremely flexible and has an irregular or wrinkled surface. This wrinkled surface is undesirable since it will be directly transferred to the casting surface.

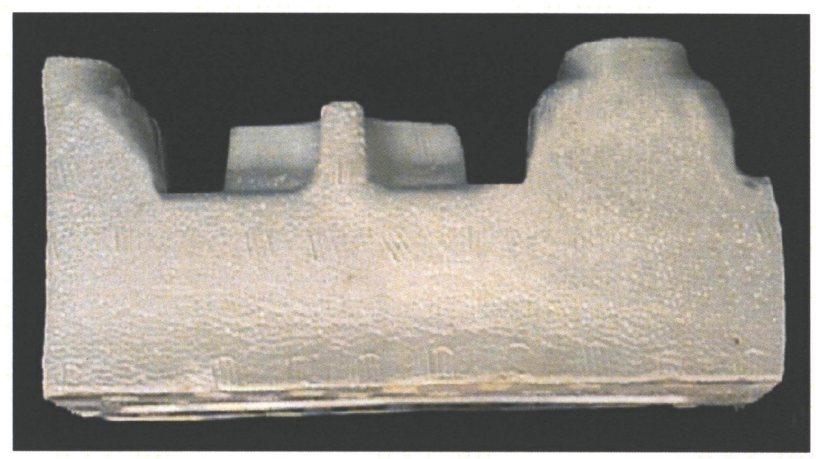

Figure 6: Over-Fused Pattern (Wrinkled Surface Finish) [33]

Under-fused patterns become very weak and the beads can easily flake off on a broken surface (Figure 7). When patterns are under-fused, they are more susceptible to damage during sand compaction. Under-fused patterns may also have a rough surface, which can lead to coatings being retained in the gaps between the beads after the casting is cleaned.

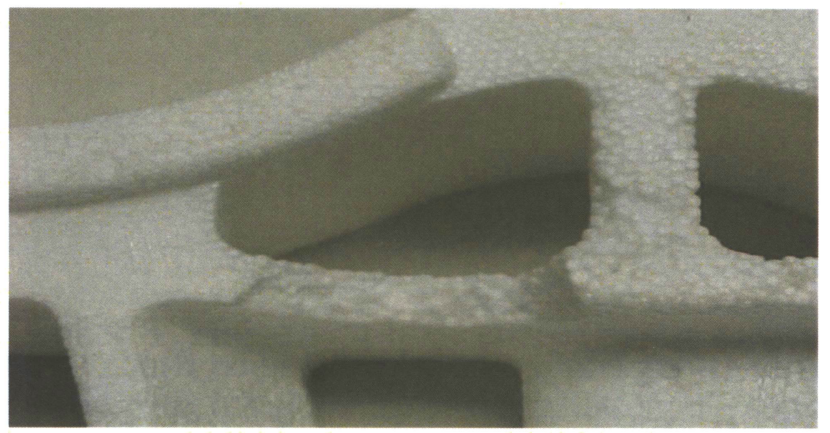

Figure 7: Under-Fused Pattern (Rough Surface Finish) [33] 


\subsubsection{Pattern Assembly}

In the LFC process, many complex components can be combined into one single part (Figure 8). Complex internal features are produced by assembling and gluing multiple foam sections together to form a single complex foam pattern. Thus, the weight of the combined components is reduced and since it is a near-net-shape process, the cost for post-cast machining is drastically minimized. Figure 9 shows a comparison of an EPS engine block and its metal counterpart.

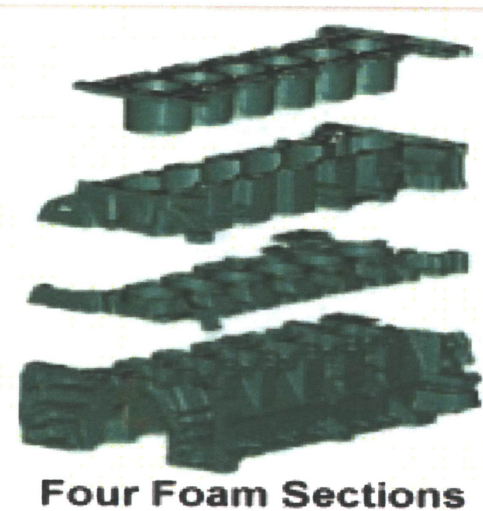

Figure 8: Consolidation of Foam Parts [34]

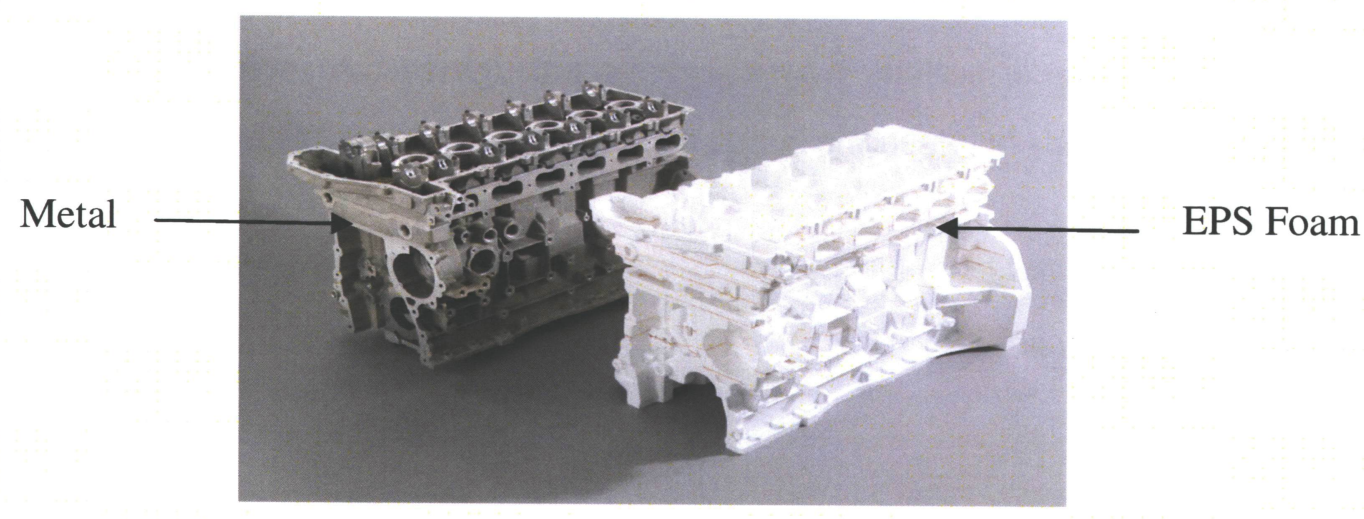

Figure 9: EPS Engine Block (right) and Metal Engine Block (left) after Pouring [34] 


\subsection{Thermal Properties of Polystyrene and Expandable Polystyrene}

Polystyrene beads are spherical in shape with diameter about $200-500 \mu \mathrm{m}$ for the LFC process. These beads have a bulk density of $608.70-640.74 \mathrm{~kg} / \mathrm{m}^{3}$. However, EPS beads are soft, spherical and roughly 30 - 40 times larger than the polystyrene beads in volume with bulk density of $16.02-27.23 \mathrm{~kg} / \mathrm{m}^{3}$. Table 1 shows some of the main thermal properties of polystyrene beads and EPS beads.

The glass transition temperature, $\mathrm{T}_{\mathrm{g}}\left({ }^{\circ} \mathrm{C}\right)$, is defined as the temperature when a polymer undergoes a rather sudden transition from a hard, glassy, or brittle condition to a flexible or rubbery condition [35]. A change in heat capacity $\left(\mathrm{C}_{\mathrm{p}}\right)$ occurs at the $\mathrm{T}_{\mathrm{g}}$. The heat capacity increases at $T_{g}$ due to a reduction in crystallinity and density of the polymer. $T_{g}$ is a good measure to analyze the viscosity of a polymer. Higher $T_{g}$ is equivalent to a higher thermal energy input to decrease the viscosity [36]. $\mathrm{T}_{\mathrm{g}}$ can be significantly decreased by addition of plasticizers into the polymer matrix. The plasticizers (or additives) embed themselves between the polymer chains and increase the intermolecular spacing. This allows the molecules to move past one another at lower temperatures. The molecular weight of a polymer also affects $T_{g}$. A decrease in molecular weight decreases $\mathrm{T}_{\mathrm{g}}$ of the polymer [37].

The melting point, $\mathrm{T}_{\mathrm{m}}\left({ }^{\circ} \mathrm{C}\right)$, is referred to as the temperature when the polymer changes from a solid state into a liquid state [38]. The melting point $\left(\mathrm{T}_{\mathrm{m}}\right)$ of a polymer also decreases with decrease in molecular weight. Hence, there exists a linear proportionality between $T_{g}$ and $T_{m}$ [15]. The heat energy required to degrade polystyrene is represented as the heat of degradation, $\mathrm{Q}_{\mathrm{d}}(\mathrm{J} / \mathrm{g})$, and is measured with a DSC. The onset temperature of degradation, $\mathrm{T}_{\mathrm{o}}\left({ }^{\circ} \mathrm{C}\right)$, describes the temperature when a polymer starts to degrade [39]. $T_{0}$ indicates the endothermic nature of polymer degradation. Higher $T_{0}$ suggests a high energy input and consequently endothermic degradation process [40]. The peak temperature of degradation, $T_{d}$, represents the temperature at the maximum rate of degradation of a polymer. $T_{d}$ decreases with increasing polymer's molecular weight [41]. 
Table 1: Thermal Properties of Polystyrene and EPS [42 - 45]

\begin{tabular}{|l|c|c||}
\hline & Polystyrene & EPS \\
\hline Glass Transition Temperature, $\mathrm{T}_{\mathrm{g}}\left({ }^{\circ} \mathrm{C}\right)$ & $\sim 100$ & $\sim 70$ \\
\hline Melting Point, $\mathrm{T}_{\mathrm{m}}\left({ }^{\circ} \mathrm{C}\right)$ & $190-260$ & $140-200$ \\
\hline Heat of Degradation, $\mathrm{Q}_{\mathrm{d}}(\mathrm{J} / \mathrm{g})$ & 1923 & 912 \\
\hline \hline Onset Temperature of Degradation, $\mathrm{T}_{\mathrm{o}}\left({ }^{\circ} \mathrm{C}\right)$ & 377 & 360 \\
\hline Peak Temperature of Degradation, $\mathrm{T}_{\mathrm{d}}\left({ }^{\circ} \mathrm{C}\right)$ & 460 & 420 \\
\hline
\end{tabular}

\subsection{Thermal Degradation of EPS}

The degradation of EPS is endothermic in nature. EPS absorbs energy as it degrades and this degradation occurs mainly by chain scission reactions, which involve the breakage of the backbone (C-C) bonds to yield free-radical segments. Chain scission reactions involve three degradation mechanisms: (1) random degradation, where the chain is broken at random sites, (2) depolymerization, where the monomer units are released at an active chain end and (3) weak-link degradation, where the chain breaks at the lowest-energy bonds [38].

The thermal degradation of polymers follows a typical radical chain mechanism, where initiation, propagation and termination reactions are the relevant types of reaction. A kinetic model [46] on the degradation of polystyrene was recently developed, which involves random chain scission and depolymerization mechanisms.

\subsubsection{Initiation Reactions}

The initiation reaction is the most important step in the degradation process of polystyrene. The purpose of this reaction is to break off the backbone (C-C) bond of polymer chains to form 
unstable free radicals. Random scission and depolymerization are the initiation reactions that occur. The schematic representations of these two reactions are given (Equations 6 and 7). Random scission:

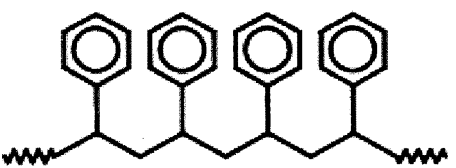

Chain-end scission:<smiles></smiles>
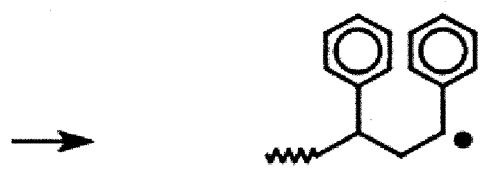

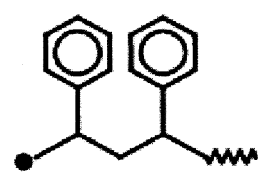

\subsubsection{Propagation Reactions}

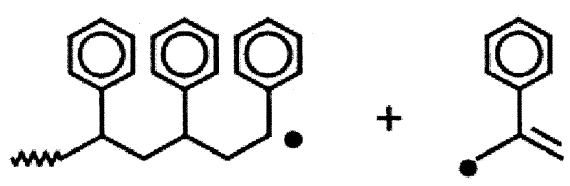

After the initiation reactions, the polystyrene continues to break via propagation reactions. The propagation reactions consist of the sequence of hydrogen-abstraction and unzipping reactions. There are two types of $\mathrm{H}$-abstraction reactions namely intermolecular and intramolecular. The schematic representations of these three reactions are given (Equations 8, 9 and 10):

Intermolecular abstraction — the radicals abstract the hydrogen from a different molecule

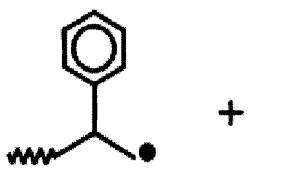<smiles></smiles><smiles>CCC(C)c1ccccc1</smiles>

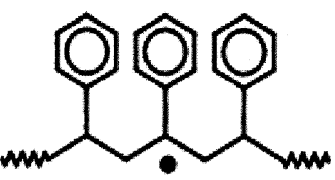


Intramolecular abstraction — the radicals abstract the hydrogen within the same molecule
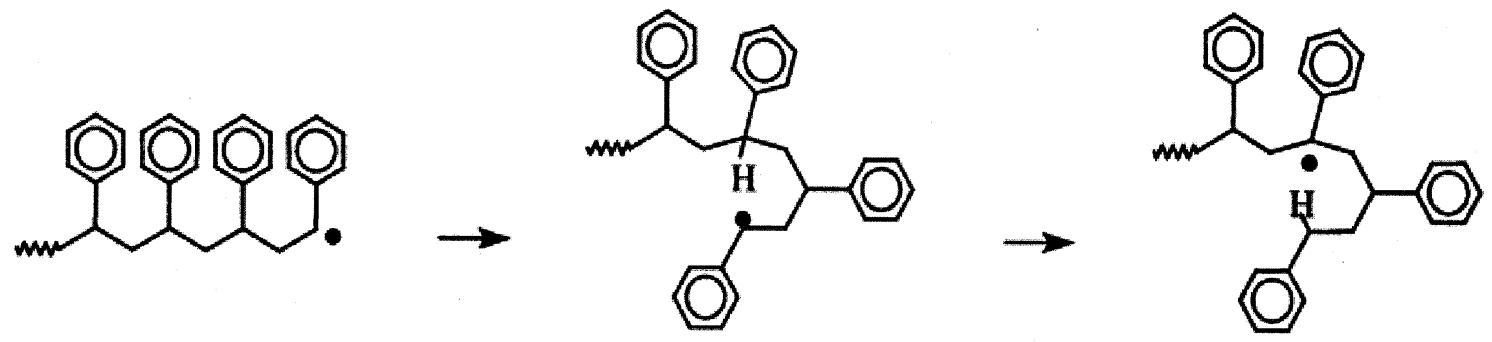

Unzipping - the end chain of the radicals breaks within the same molecule
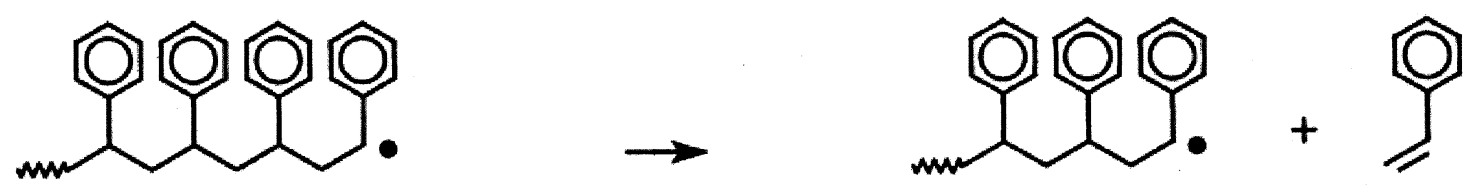

\subsubsection{Termination Reactions}

At the end of the degradation process of polystyrene, termination reactions take place. The free radicals react to form stable compounds (e.g., oligomers). The two common termination reactions are given (Equations 11 and 12).

Combination reaction:<smiles>CC[C@H]1C[C@H](C)c2cccc3cccc1c23</smiles><smiles>CCC1C[C@H](C)c2cccc3cccc1c23</smiles>

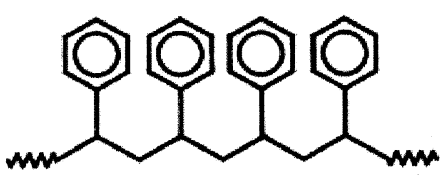


Disproportionation reaction of radicals:

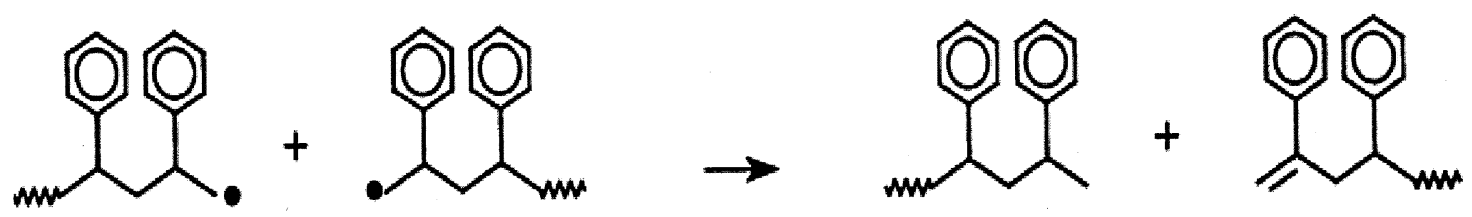

\subsection{Thermal Degradation of EPS in Presence of Additives}

EPS is often thermally degraded in presence of additives for economic reasons. For instance, in the recycling industry, EPS is recycled to produce styrene monomers. The catalysts are used to increase the rate of the EPS degradation and to increase the monomer yield.

New organic brominated compounds were recently introduced as coatings to prevent clumping of polystyrene beads. These organic brominated compounds act both as a fire retardant and as a lubricant during pattern molding. These compounds promote rapid degradation of EPS at lower temperatures, reduce the viscosity of the EPS residuals and also eliminate the use of commercial lubricants such as zinc stearate and silene [47].

Xue et al. [48] performed degradation experiments on EPS with Alpha-Methyl Styrene (AMS) in the presence of organic peroxides such as DCP and tert-Butyl Cumyl Peroxide (BCP). They found that DCP was more efficient than BCP in degrading EPS quicker and at a lower temperature.

Barium oxide [49], iron based catalyst [50], zeolites [51] and silica-alumina [52] are some of the common catalysts used in the waste and recycling industries to degrade polystyrene quicker. It has been found that these compounds increase the rate of degradation of polystyrene and also increase the yield of styrene monomers. 


\subsection{Alternate Pattern Materials}

The limitations imposed by the pyrolysis products of EPS have led to studies of alternate polymers for pattern production including Expanded Polymethylmethacrylate (EPMMA), Expanded Polyalkylene Carbonate (EPAC) and brominated EPS. The use of EPMMA in LFC of aluminum alloys requires some adjustments in the pouring operations such as the pouring temperature. The formation of carbon/oxide layer is minimized using EPMMA as foam pattern since the pyrolysis products are primarily gaseous products. However, the production of more gases acts as barrier between the molten metal front and the degrading foam. Thus, the filling rate decreases, solidification rate increases and the entrapment of pyrolysis products increases. It has been found that the use of EPMMA results in more porosity and more misruns in aluminum castings [32].

EPAC has been developed primarily for LFC of aluminum alloys and it is reported that this polymer has a lower decomposition temperature and a lower heat of decomposition than EPS. It has been found that the EPAC foam pattern prevented the formation of fold defects since it absorbed less heat from the molten metal front to degrade. It was also found that the fluidity of the molten metal was improved and the entrapment of liquid decomposition products in prematurely solidified metal was prevented. However, EPAC is not commercially available and it is very difficult to make foam patterns with the pre-puff beads of this polymer [32].

Organic brominated compounds are normally dissolved in pentane and then transferred to the polystyrene beads during the impregnation of pentane. However, these brominated compounds can also be added in-situ during the polymerization process. During the LFC process using the brominated EPS, the brominated compounds decompose and liberate bromine free radicals. These free radicals readily attack the EPS matrix and quickly reduce the molecular weight and the viscosity of the polymer. Thus, the fluidity of the molten metal increases and the pyrolysis products are easily removed from the mold. It has been reported that brominated EPS do not completely eliminate fold defects since it mainly reduces the viscosity of the foam $[5,6,53]$. 
It has also been reported that rate of degradation of brominated EPS increases through a change in the preexponential factor as shown in Equation 13. Brominated EPS has higher preexponential factor (A) than regular EPS [3]. The rate of degradation of a polymer is given by the Arrhenius equation:

$\mathrm{k}=\mathrm{A} \exp _{\mathrm{A}}^{-(\mathrm{ET})}$

Where $\mathrm{A}$ is preexponential factor, $\mathrm{k}$ is rate coefficient, $\mathrm{E}_{\mathrm{A}}$ is activation energy, $\mathrm{R}$ is universal gas constant and $\mathrm{T}$ is absolute temperature.

\subsection{Lost Foam Casting Process}

Lost Foam Casting (LFC) is a relatively new and cost effective near-net-shape process gaining impetus and significantly replacing die-casting process with the aim of reducing the vehicular weight and enhancing fuel efficiency. However, polymer pattern pyrolysis may result in laps, folds, porosity and bead fusion defects that impair integrity, fatigue and other strength properties, along with pressure tightness and aesthetics.

In the LFC process, the foam pattern is an exact replica of the casting to be produced. The foam pattern can either be molded to shape or it can be assembled by cutting foam slabs into pieces and then gluing the individual pieces together. The assembled pattern is coated with a refractory coating, which prevents the molten metal from penetrating the sand. It allows the foam pyrolysis products to escape into the sand. Coatings also provide dimensional stability during compaction.

The coating may be applied by dipping or spraying. It is normally supplied as slurry of a refractory in a water-based carrier. After applying the coating to the pattern, it is dried. This is usually done by leaving the pattern in a circulating-air oven for 24 hours at 40 to $60{ }^{\circ} \mathrm{C}$. After drying, the coating is placed in a flask and surrounded by unbonded sand. The mold is subsequently compacted on a vibrating table. This compaction enables sand to fill all internal 
cavities and provides support during pouring. Molten metal is then poured into the pattern. The molten metal degrades the foam pattern and replaces it, thus forming a near-net-shape casting.

The amount and types of pyrolysis products generated from the degradation of an EPS pattern during a casting depend on many variables such as pouring temperature, pouring rate, pattern geometry, gating design, refractory coating, sand, degree of bead fusion, size of the beads and foam density. The main degradation products are hydrogen, carbon dioxide, carbon monoxide, styrene, ethyl benzene, benzene, dimmers, trimmers and carbon [54 - 56].

\subsection{Defects in Lost Foam Casting}

The LFC process tends to produce defects associated with the removal of pyrolysis products. Folds, blisters, porosity and surface carbon defects are the common defects related to the entrapment of pyrolysis products in the metal matrix. Folds are discontinuities in the metal matrix of the casting which are composed of pyrolysis products. Folds are found when two metal fronts meet after traveling a considerable distance without properly fusing together due to entrapped products of pyrolysis. Folds can generally be divided into three main types: misrun, bubble trail fold, and lap fold [5].

Misrun (Figure 10) is formed when two converging metal fronts solidify without filling the cavity. The temperature loss due to the endothermic nature of the degrading EPS and the velocity difference due to different pattern geometries along with a long fill time required due to slow removal of the pyrolysis products cause the formation of Misruns [57]. 


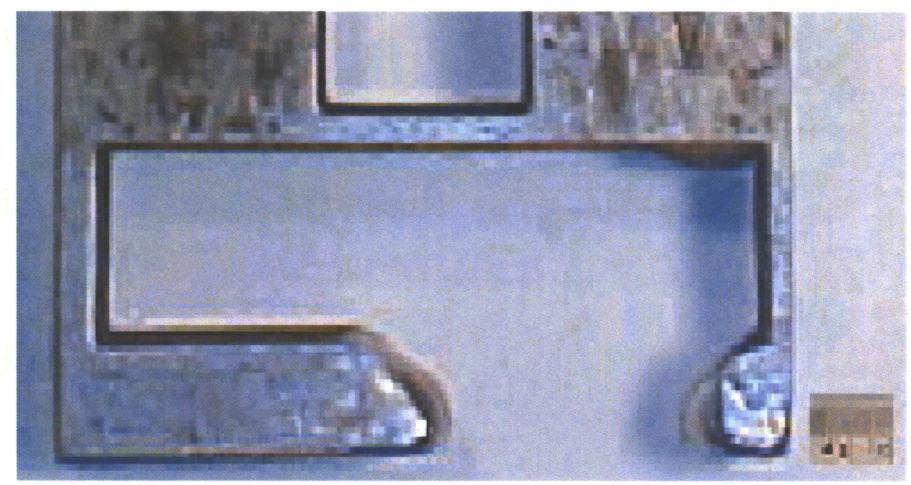

Figure 10: Misrun [57]

A bubble trail fold is formed when bubbles of pyrolysis products which rise through the molten metal get trapped into the metal matrix. These bubbles are formed when a chunk of foam and liquid polymer gets engulfed by the molten metal. As the temperature increases, the products of liquid pyrolysis changes to gas, and try to escape from the molten metal. Hence, the shape of these bubble trail folds is often triangular (Figure 11) [5].

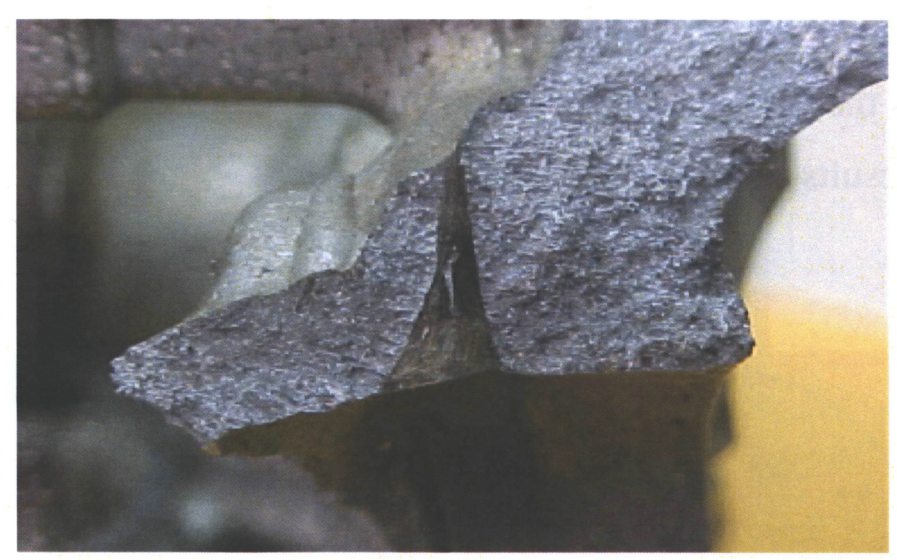

Figure 11: Bubble Trail Fold [5]

Lap fold is formed when two converging metal fronts do not fuse properly as a result of the entrapped products of pyrolysis. The microstructures of a lap fold (Figure 12) are the same on both sides of the discontinuity due to similar temperature and velocity gradients [57]. 


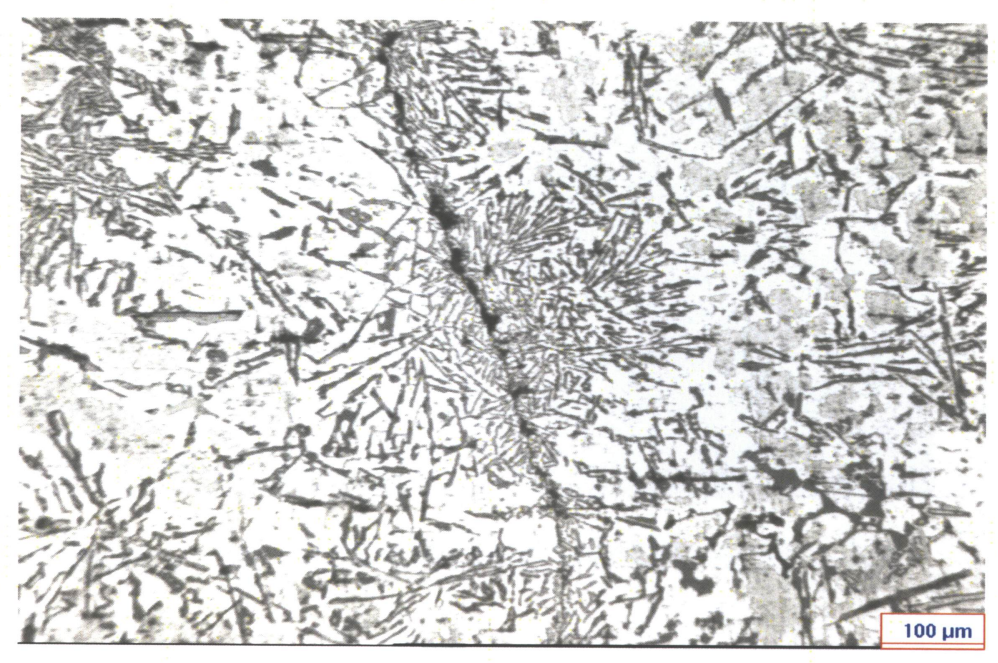

Figure 12: Lap Fold [57]

Other types of lap fold defects are caused due to entrapped pyrolysis products such as last area to fill fold (Figure 13(a)) and trapped polystyrene glob folds (Figure 13(b)). Last area to fill fold occurs at the end of the casting mainly due to inefficient metallostatic pressure to push the pyrolysis products outside the coating, whereas the trapped polystyrene glob fold occurs due to inefficient amount of thermal energy from the molten metal to degrade the polymer. The use of excessive glue also results in lap fold, which is referred to as glue line fold defect (Figure 13(c)) $[5,6]$.

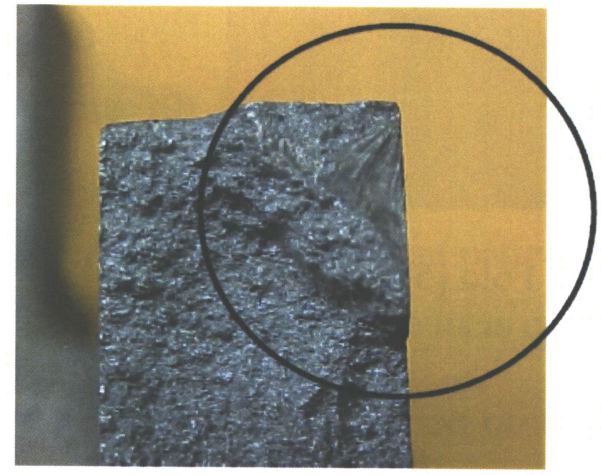

(a) Last Area-to-Fill Fold [5]

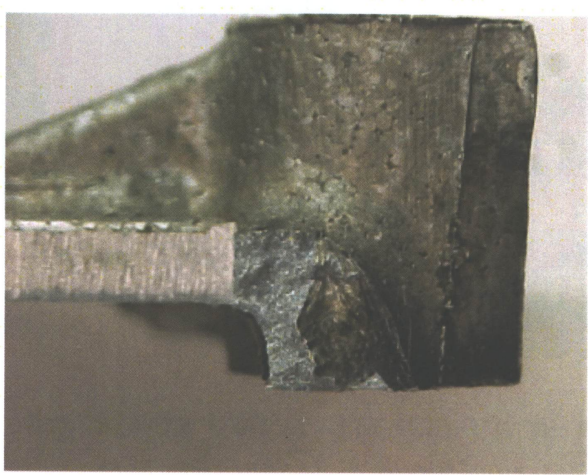

(b) Trapped Polystyrene Glob Fold [5] 


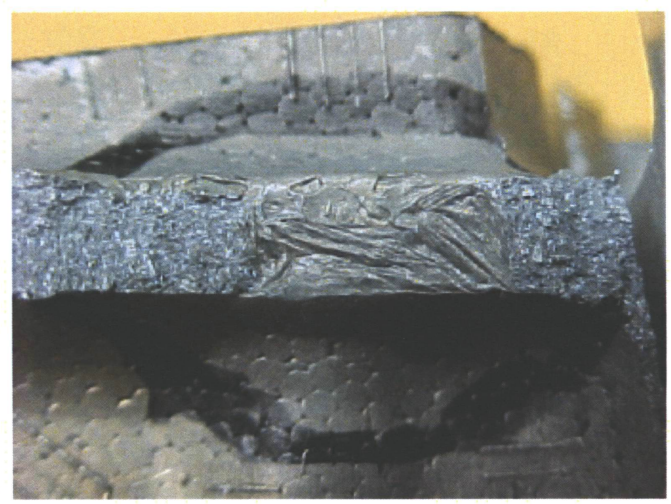

(c) Glue Line Fold [5]

Figure 13: Other Type of Lap Fold

A blister is composed of a thin layer of carbon/oxide as a result of pyrolysis entrapment and it is normally situated just below the surface of a casting (Figure 14). Blisters are also usually located in casting parts, close to the gating system (downsprues and ingates). A blister is classified as a subsurface defect and it is often referred to as a liquid styrene defect since most of the pyrolysis products are comprised of styrene $[2,3,58,59]$.

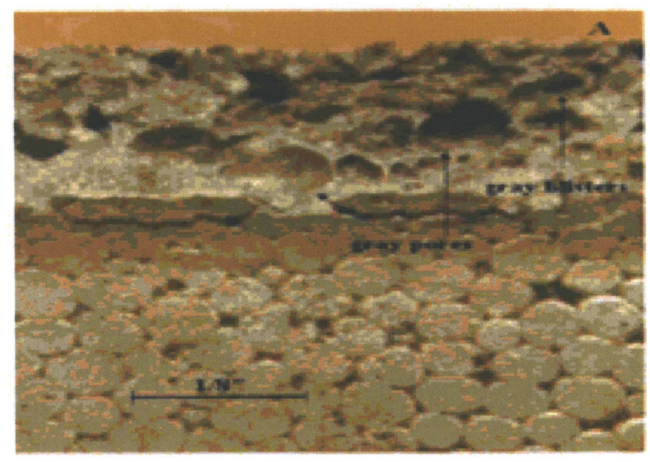

Figure 14: Blister [2]

Porosity is formed due to the shrinkage of the molten metal during solidification and it is referred to as shrinkage porosity. Porosity also occurs and due to the entrapment of hydrogen gas from the molten metal and from the products of pyrolysis, and this type of porosity is referred to as gas porosity. The entrapped pyrolysis products gasify and diffuse into molten metal leaving pores (Figure 15) [57 - 59]. 


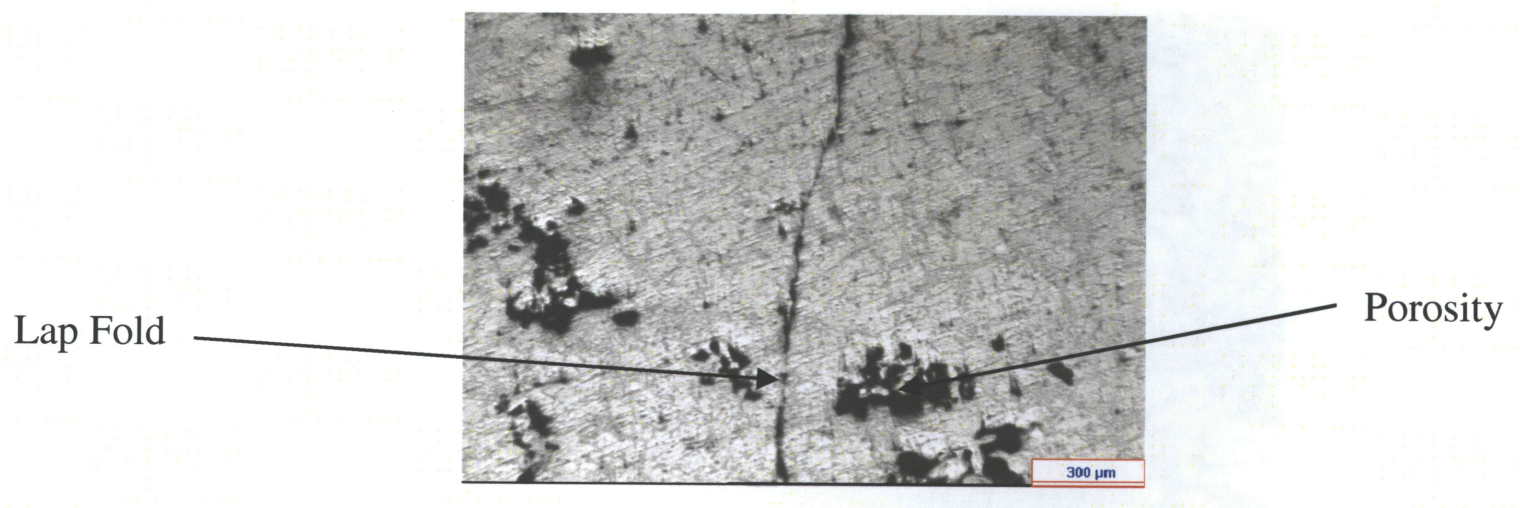

Figure 15: Porosity [57]

Carbon/oxide defects which resemble orange peel are often found on the surface of the castings. This kind of surface defect (Figure 16) is caused when liquid polymer that reaches the metalcoating interface are not quickly absorbed by the coating (wetting \& wicking). Thus, the liquid polymer pyrolyzes and produces a rough, wrinkled casting surface [3, 57].

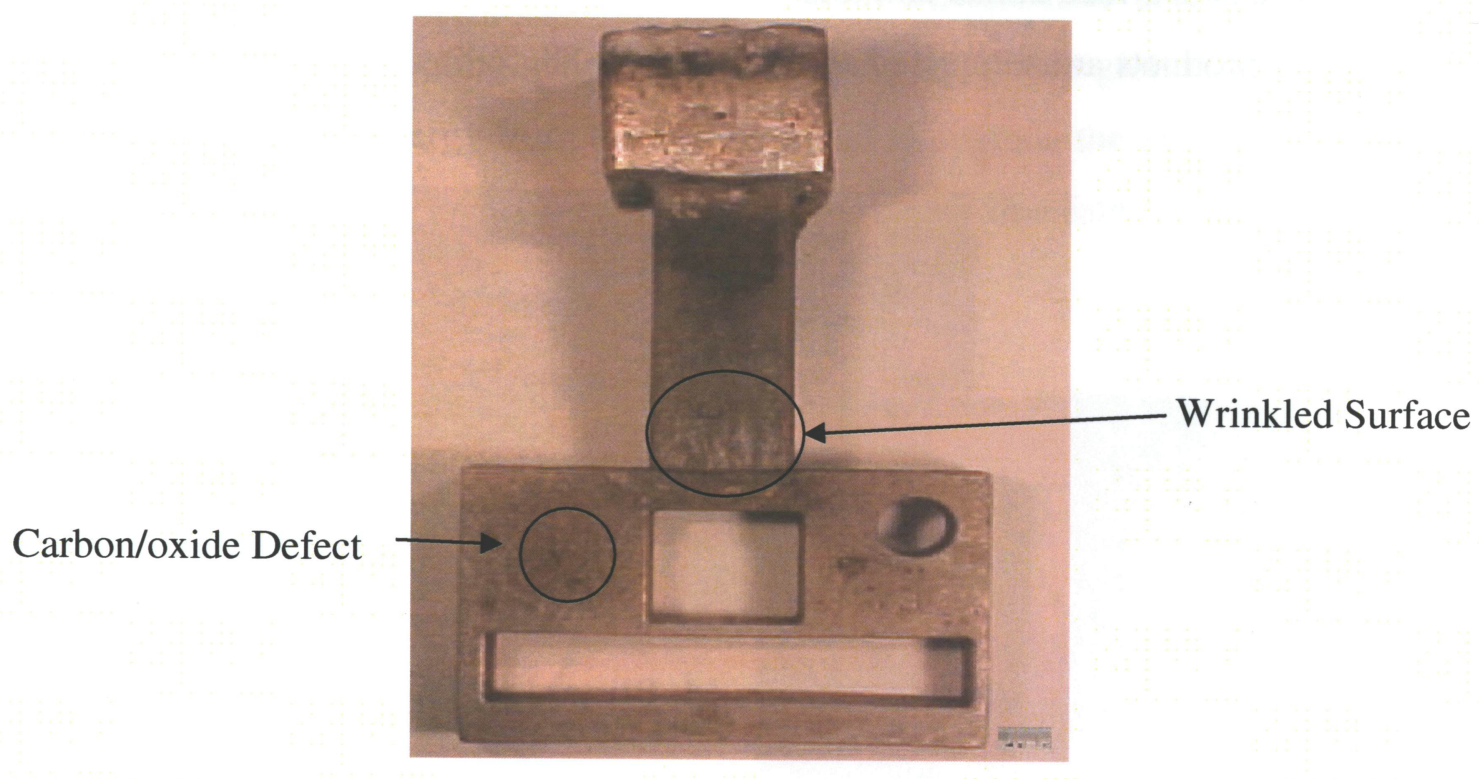

Figure 16: Carbon/oxide Defect [57] 


\section{Chapter 3 - Experimental Procedures}

This chapter describes the experimental plan to achieve the objectives of this study. Section 3.1 and 3.2 deal with the reactor and chemicals used to perform the experiments. Section 3.3 describes the production of low molecular weight polymer. Section 3.4 shows the methods to increase the molecular weight of polystyrene and section 3.5 shows the production of high molecular weight polymer. The final section of this chapter describes the polymer characterization techniques that were used to analyze the properties of these novel polymer beads.

\subsection{The Polymerization Reactor}

An integrated lab-scale pressure reactor system (Ace-Glass, New Jersey, USA) was used to perform the suspension polymerization process (Figure 17). The main parts of the pressure reactor consisted of a $1 \mathrm{~L}$ reactor flask, a motor/stirrer, a thermo-well and a heating mantle. A temperature controller connected to a thermocouple enabled control of the flask temperature to \pm $0.5{ }^{\circ} \mathrm{C}$. The stirrer in the flask was connected with the DC motor via a motor cable, and a variable speed controller was used to control the speed of the stirrer. An electric weight balance was used to measure the mass of the chemicals to $\pm 0.001 \mathrm{~g}$. 


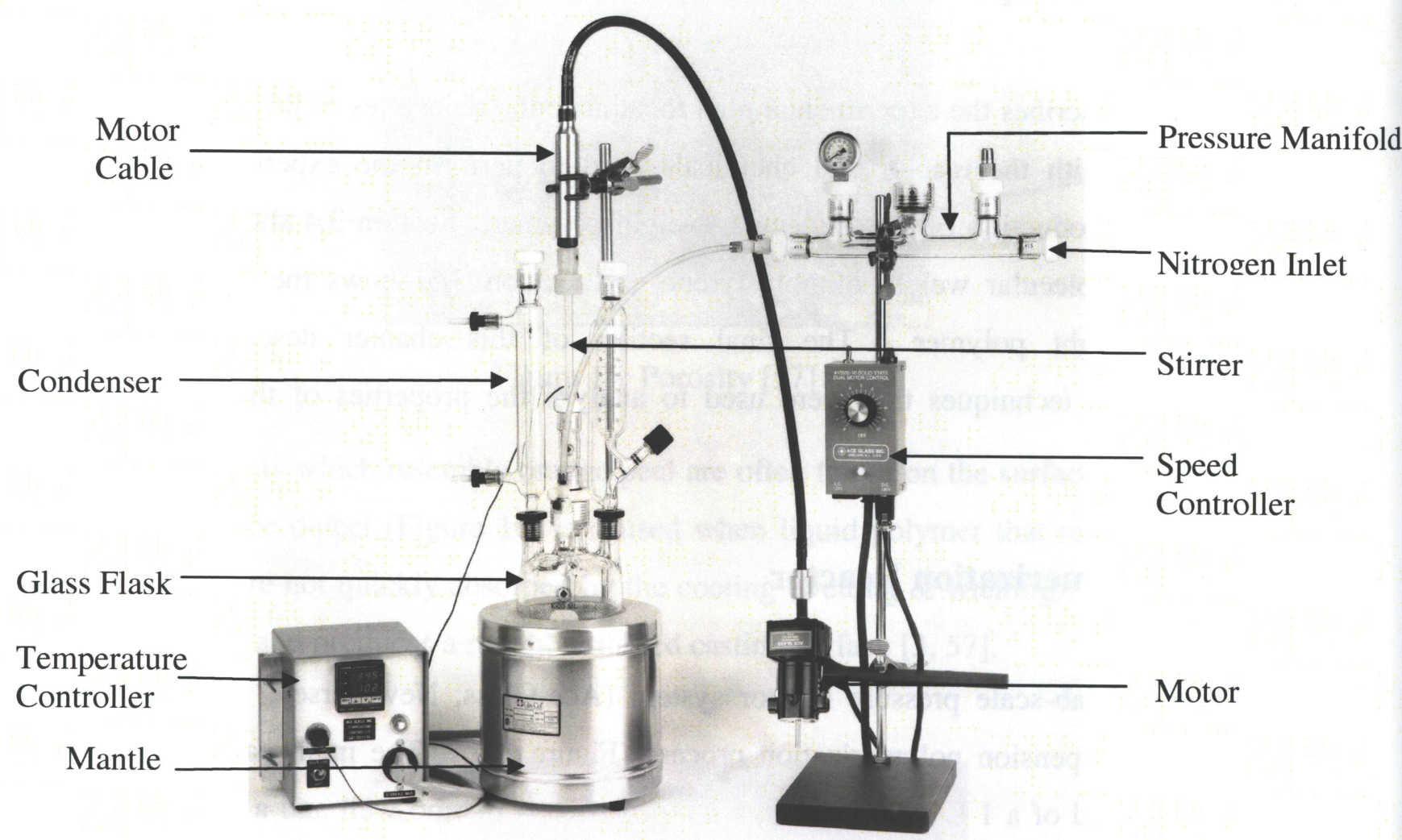

Figure 17: Pressure Reactor for the Suspension Polymerization Process [8]

\subsection{The Suspension Polymerization Process}

The standard method for manufacturing EPS beads is a batch-wise suspension polymerization process (please refer to section 2.1). A textbook recipe of a free-radical polymerization in a suspension process starts by dispersing the liquid monomer styrene in water, stabilized by a suspension stabilizer [60]. In this research, the mixture was stirred, heated to a suitable polymerization temperature and maintained at this temperature for a specified period of time. The spherical polystyrene beads were filtered, washed and dried. 
Styrene monomer with 0.005 wt \% tert-butylcatechol inhibitor and free radical initiators, DCP and DBPO were purchased from Sigma-Aldrich Canada Ltd. (Oakville, Ontario). The chain transfer agent (CTA), AMS monomer and suspending stabilizer, PVA were also purchased from Sigma-Aldrich Canada Ltd. The suspending stabilizer, TCP was purchased from Fisher Scientific Canada Ltd. (Ottawa, Ontario). All these chemicals were used as-received. The Department of Chemistry and Biology at Ryerson University supplied de-ionized water, which was used as the continuous phase.

\subsection{Production of Low Molecular Weight Polystyrene with Additives}

\subsubsection{Identification of Additives to be Incorporated into Polystyrene Beads}

EPS beads were recently blended with novel chemicals after the pre-expansion process prior to production of foam patterns [3]. These modified foam patterns reduced fold defects but did not result in defect-free castings. Defects such as porosity and carbon/oxide surface defects could not be eliminated. It was found that the presence of the chemicals on the bead surface resulted in poorly fused foam patterns (Figure 18(b)). The poorly fused foam appeared to prevent production of completely defect-free castings [3]. Further, it was suggested that incorporating the chemicals inside the beads may prevent changes in beads fusion (Figure 18(a)) and produce completely sound castings.

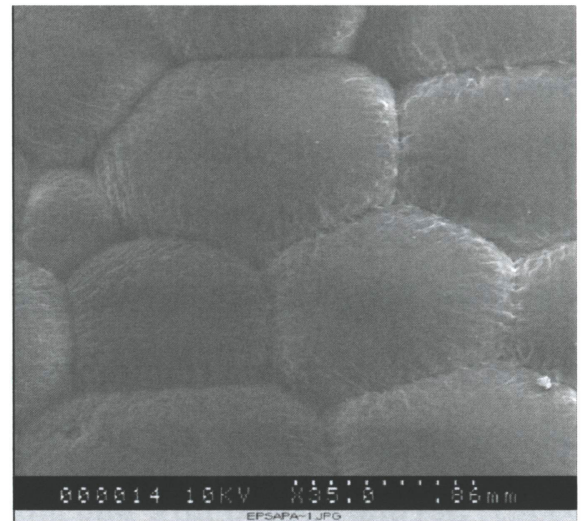

(a) Good degree of bead fusion

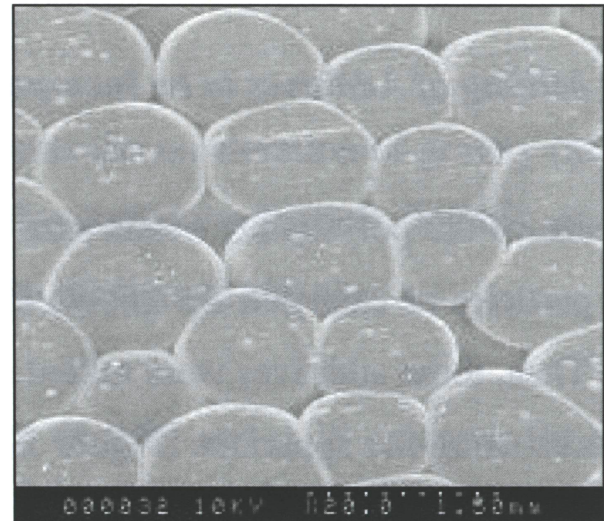

(b) Poor degree of bead fusion

Figure 18: Changes in the Level of Fusion Level due to Additives [3] 
Two chemicals, (a) silica-alumina (87 wt \% silica and $13 \mathrm{wt} \%$ alumina) and (b) iron based catalyst (76 wt \% alumina, $16 \mathrm{wt} \%$ iron (III) nitrate nano-hydrate and $8 \mathrm{wt} \%$ potassium carbonate), were chosen to be incorporated into the polystyrene beads during the suspension polymerization process to produce polystyrene composite beads (for selection criteria, please refer to section 2.8). These two chemicals are inorganic compounds and they do not react with water (continuous phase). Hence, the effectiveness of the continuous phase to hold the monomers was not affected. Silica-alumina ( 60 microns diameter-size) is commercially available and it was purchased from Sigma-Aldrich Canada Ltd. (Oakville, Ontario).

The iron-based catalyst was prepared by reacting $20.0 \mathrm{~g}$ of aqueous iron (III) nitrate nanohydrate and $10.0 \mathrm{~g}$ of aqueous potassium carbonate. Further, the resulting product was mixed with 100.0 $\mathrm{g}$ of alumina ( 60 microns diameter-size). The compound was dried in a furnace at $110{ }^{\circ} \mathrm{C}$ for 24 hours and was calcined at $500{ }^{\circ} \mathrm{C}$ for 12 hours [50].

The solubility of water in polystyrene matrix is very low and it will be difficult to incorporate the additives in the polystyrene matrix. Hence, starch (a water soluble polymer) was dispersed in water to absorb the additives into the polystyrene matrix [61] during the polymerization process. Furthermore, a recent research has shown that incorporating starch into polymer may make the polymer biodegradable. When the polymer is discarded, bacteria digest the starch, which in turn degrades the polymer [62].

\subsubsection{Milling of Additives to be Incorporated into Polystyrene Beads}

The size of the polystyrene beads used for the LFC process is in the 200 to 500 microns range. Fine particles of catalysts are known to be efficient, due to their large surface to volume ratio [38]. Thus, these additives were milled in dry porcelain mill jars with alundum milling media for 36 hours using the apparatus (Figure 19) to produce particles with diameter in the $1-2$ micron range. 


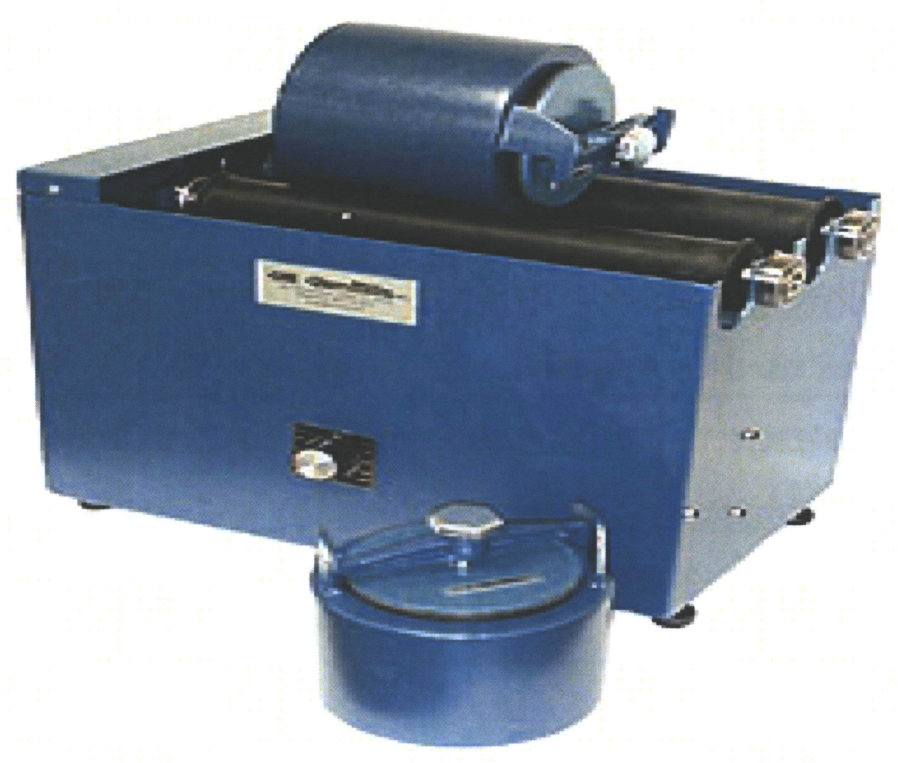

Figure 19: Jar Mill [63]

The particle size distribution was measured in a Horiba CAPA700 particle-size analyzer (McMaster University). The samples were dispersed in distilled water and a deflocculant (Darvan) was added. The mixture was agitated for five minutes in an ultrasonic bath prior to particle-size measurement. The Horiba particle-size analyzer measures the absorption of a light beam passing through the suspension as a function of time. This is related to a size distribution through calculations based on Stoke's Law of Settling (Equation 14).

$V_{t=} g d^{2}\left(\rho_{p}-\rho_{m}\right) / 18 \mu$

Where $V_{t}$ represents the settling velocity $(\mathrm{m} / \mathrm{s})$, g represents the acceleration of gravity $\left(\mathrm{m} / \mathrm{s}^{2}\right), d$ represents the particle diameter $(\mathrm{m}), \rho_{p}$ represents the density of the particle $\left(\mathrm{kg} / \mathrm{m}^{3}\right), \rho_{m}$ is the density of the medium $\left(\mathrm{kg} / \mathrm{m}^{3}\right)$ and $\mu$ is the viscosity of the medium $(\mathrm{kg} / \mathrm{m} . \mathrm{s})$.

The milling process produced particles of median size of 0.99 and 1.19 microns for silicaalumina and iron based catalyst, respectively. 


\subsubsection{Polymerization Formulations for Low Molecular Weight Polystyrene with Additives}

The main formulation was developed for the preparation of polystyrene and novel polystyrene composite beads (Table 2). Available literature, including patents $[10,64,65]$ and published journals $[6,7,9,60,61]$ were used to develop this formulation. DBPO $\left(\mathrm{T}_{\mathrm{d}}=85^{\circ} \mathrm{C}\right)$ was used as an initiator and DCP was used as a finishing initiator $\left(\mathrm{T}_{\mathrm{d}}=90^{\circ} \mathrm{C}\right)$. The use of both initiators enables production of polystyrene beads with a low residual monomer content [65]. Grade A was used as the "control formulation". It was produced by adding de-ionized water in the reactor followed by DBPO, DCP, PVA, TCP and starch. Grades B, C and D were composite beads, and included one or two catalysts.

The resulting mixture was stirred for 0.5 hours at 400 RPM at room temperature. The stirrer was stopped. Styrene and then AMS were added to the mixture. The temperature of the reactor was increased to $90{ }^{\circ} \mathrm{C}$ to decompose the initiators to produce free radicals and the agitation was increased to 800 RPM to produce small droplets. The polymerization reaction was carried out for 2.5 hours at this temperature. Finally, the process was stopped, and cooled to room temperature. The resulting beads were screened out, washed with distilled water and then dried at room temperature for 24 hours. 
Table 2: Formulations and Reaction Conditions for Low Molecular Weight Polymer

\begin{tabular}{|c|c|c|c|c|c|c|c|c|}
\hline Ingredients & \multicolumn{2}{|c|}{ Grade A } & \multicolumn{2}{|c|}{ Grade B } & \multicolumn{2}{|c|}{ Grade C } & \multicolumn{2}{|c|}{ Grade D } \\
\hline $\begin{array}{l}\text { Water (g) } \\
\text { (Continuous phase) }\end{array}$ & \multicolumn{2}{|c|}{420.0} & \multicolumn{2}{|c|}{420.0} & \multicolumn{2}{|c|}{420.0} & \multicolumn{2}{|c|}{420.0} \\
\hline $\begin{array}{l}\text { Styrene (g) } \\
\text { (Monomer) }\end{array}$ & \multicolumn{2}{|c|}{50.0} & \multicolumn{2}{|c|}{50.0} & \multicolumn{2}{|c|}{50.0} & \multicolumn{2}{|c|}{50.0} \\
\hline $\begin{array}{l}\text { Alpha Methyl } \\
\text { Styrene (g) (CTA) }\end{array}$ & \multicolumn{2}{|c|}{5.00} & \multicolumn{2}{|c|}{5.00} & \multicolumn{2}{|c|}{5.00} & \multicolumn{2}{|c|}{5.00} \\
\hline $\begin{array}{l}\text { Dibenzoyl Peroxide } \\
\text { (g) (Initiator) }\end{array}$ & \multicolumn{2}{|c|}{0.30} & \multicolumn{2}{|c|}{0.30} & \multicolumn{2}{|c|}{0.30} & \multicolumn{2}{|c|}{0.30} \\
\hline $\begin{array}{l}\text { Dicumyl Peroxide } \\
\text { (g) (Initiator) }\end{array}$ & \multicolumn{2}{|c|}{0.30} & \multicolumn{2}{|c|}{0.30} & \multicolumn{2}{|c|}{0.30} & \multicolumn{2}{|c|}{0.30} \\
\hline $\begin{array}{l}\text { Tri-Calcium } \\
\text { Phosphate (g) } \\
\text { (Stabilizer) }\end{array}$ & \multicolumn{2}{|c|}{0.20} & \multicolumn{2}{|c|}{0.20} & \multicolumn{2}{|c|}{0.20} & \multicolumn{2}{|c|}{0.20} \\
\hline $\begin{array}{l}\text { Polyvinyl Alcohol } \\
\text { (g) (Stabilizer) }\end{array}$ & \multicolumn{2}{|c|}{0.20} & \multicolumn{2}{|c|}{0.20} & \multicolumn{2}{|c|}{0.20} & \multicolumn{2}{|c|}{0.20} \\
\hline $\begin{array}{l}\text { Starch }(g) \\
\text { (Absorbent) }\end{array}$ & \multicolumn{2}{|c|}{0.15} & \multicolumn{2}{|c|}{0.15} & \multicolumn{2}{|c|}{0.15} & \multicolumn{2}{|c|}{0.15} \\
\hline $\begin{array}{l}\text { Silica-Alumina (g) } \\
\text { (Catalyst) }\end{array}$ & \multicolumn{2}{|c|}{-} & & & & & & \\
\hline $\begin{array}{l}\text { Iron Based Catalyst } \\
\text { (g) (Catalyst) }\end{array}$ & & & & & & & & \\
\hline $\begin{array}{l}\text { Reaction } \\
\text { Conditions }\end{array}$ & $\begin{array}{c}\text { Step } \\
1\end{array}$ & $\begin{array}{c}\text { Step } \\
2\end{array}$ & $\begin{array}{c}\text { Step } \\
1\end{array}$ & $\begin{array}{c}\text { Step } \\
2\end{array}$ & $\begin{array}{c}\text { Step } \\
1\end{array}$ & $\begin{array}{c}\text { Step } \\
2\end{array}$ & $\begin{array}{c}\text { Step } \\
1\end{array}$ & $\begin{array}{l}\text { Step } \\
2\end{array}$ \\
\hline Temperature $\left({ }^{\circ} \mathbf{C}\right)$ & 25 & 90 & 25 & 90 & 25 & 90 & 25 & 90 \\
\hline Agitation (RPM) & 400 & 800 & 400 & 800 & 400 & 800 & 400 & 800 \\
\hline Time (hrs) & 0.5 & 2.5 & 0.5 & 2.5 & 0.5 & 2.5 & 0.5 & 2.5 \\
\hline
\end{tabular}




\subsection{Production of High Molecular Weight Polystyrene}

The LFC process requires polystyrene beads with weight average molecular weight, $\mathbf{M}_{\mathrm{w}}$, between 180,000 - 280,000 Daltons (Da). Hence, new formulations to produce high molecular weight polystyrene beads were tested. This was achieved by varying reaction time and mass of initiators as shown in Tables 3 and 4, respectively. The source-references for these changes are given in square brackets.

1. The styrene monomer was stored in the fridge at $4{ }^{\circ} \mathrm{C}$ and was prevented from direct contact with sunlight

2. Alpha methyl styrene (AMS) acts as a chain transfer agent (CTA) and it was not used $[18,19]$.

3. The mass of starch was increased from 0.15 to $0.25 \mathrm{~g}$ [61].

4. The agitation speed was increased from 800 to 1000 RPM [20, 21].

5. The mass of the stabilizers was increased from 0.40 to $1.00 \mathrm{~g}[17,22-25]$.

6. The monomer to water ratio was decreased from 0.13 to 0.10 [20].

7. Nitrogen gas and a condenser were used [20 - 23, $27-29]$.

8. The reaction time was increased from 3 to $8 \mathrm{hrs}[10,26]$.

9. The mass of the initiators was decreased from 0.60 to $0.40 \mathrm{~g}[16,17]$.

The polystyrene composite beads produced were sieved using three (3) screens: U.S. Sieve No. 12 (1680 microns), U.S. Sieve No. 30 (595 microns) and U.S. Sieve No. 100 (150 microns). These beads were washed with distilled water and dried for 24 hours at room temperature. The polystyrene beads with bead diameter size in the range of 595-1680 microns were referred to as CUP and with diameter size in the range of $150-595$ microns were referred to as LFC. Both the molecular weight for the LFC and CUP beads were analyzed using GPC.

In order to produce quality beads, careful control of AMS concentration, use of nitrogen gas, use of condenser and proper styrene monomer storage were essential. 
Table 3: Formulations and Reaction Conditions for Higher Molecular Weight Polystyrene by Varying Reaction Time

\begin{tabular}{|c|c|c|c|c|c|c|c|c|}
\hline Ingredients & \multicolumn{2}{|c|}{ Grade A1 } & \multicolumn{2}{|c|}{ Grade A2 } & \multicolumn{2}{|c|}{ Grade A3 } & \multicolumn{2}{|c|}{ Grade A4 } \\
\hline $\begin{array}{l}\text { Water (g) (Continuous } \\
\text { phase) }\end{array}$ & \multicolumn{2}{|c|}{500.0} & \multicolumn{2}{|c|}{500.0} & \multicolumn{2}{|c|}{500.0} & \multicolumn{2}{|c|}{500.0} \\
\hline Styrene (g) (Monomer) & \multicolumn{2}{|c|}{50.0} & \multicolumn{2}{|c|}{50.0} & \multicolumn{2}{|c|}{50.0} & \multicolumn{2}{|c|}{50.0} \\
\hline $\begin{array}{l}\text { Dibenzoyl peroxide (g) } \\
\text { (Initiator) }\end{array}$ & \multicolumn{2}{|c|}{0.30} & \multicolumn{2}{|c|}{0.30} & \multicolumn{2}{|c|}{0.30} & \multicolumn{2}{|c|}{0.30} \\
\hline $\begin{array}{l}\text { Dicumyl peroxide (g) } \\
\text { (Initiator) }\end{array}$ & \multicolumn{2}{|c|}{0.30} & \multicolumn{2}{|c|}{0.30} & \multicolumn{2}{|c|}{0.30} & \multicolumn{2}{|c|}{0.30} \\
\hline $\begin{array}{l}\text { Tri-calcium phosphate }(\mathrm{g}) \\
\text { (Stabilizer) }\end{array}$ & \multicolumn{2}{|c|}{0.50} & \multicolumn{2}{|c|}{0.50} & \multicolumn{2}{|c|}{0.50} & \multicolumn{2}{|c|}{0.50} \\
\hline $\begin{array}{l}\text { Polyvinyl alcohol (g) } \\
\text { (Stabilizer) }\end{array}$ & \multicolumn{2}{|c|}{0.50} & \multicolumn{2}{|c|}{0.50} & \multicolumn{2}{|c|}{0.50} & \multicolumn{2}{|c|}{0.50} \\
\hline Starch $(g)$ & \multicolumn{2}{|c|}{0.25} & \multicolumn{2}{|c|}{0.25} & \multicolumn{2}{|c|}{0.25} & \multicolumn{2}{|c|}{0.25} \\
\hline Reaction conditions & $\begin{array}{c}\text { Step } \\
1\end{array}$ & $\begin{array}{c}\text { Step } \\
2\end{array}$ & $\begin{array}{c}\text { Step } \\
1\end{array}$ & $\begin{array}{l}\text { Step } \\
2\end{array}$ & $\begin{array}{c}\text { Step } \\
1\end{array}$ & $\begin{array}{c}\text { Step } \\
2\end{array}$ & $\begin{array}{c}\text { Step } \\
1\end{array}$ & $\begin{array}{l}\text { Step } \\
2\end{array}$ \\
\hline Temperature $\left({ }^{\circ} \mathrm{C}\right)$ & 25 & 90 & 25 & 90 & 25 & 90 & 25 & 90 \\
\hline Agitation (RPM) & 400 & 1000 & 400 & 1000 & 400 & 1000 & 400 & 1000 \\
\hline Time (hrs) & 0.5 & 2.5 & 0.5 & 3.5 & 0.5 & 5.5 & 0.5 & 7.5 \\
\hline
\end{tabular}


Table 4: Formulations and Reaction Conditions for Higher Molecular Weight Polystyrene by Varying Mass of Initiators

\begin{tabular}{|c|c|c|c|c|c|c|c|c|}
\hline Ingredients & \multicolumn{2}{|c|}{ Grade A5 } & \multicolumn{2}{|c|}{ Grade A6 } & \multicolumn{2}{|c|}{ Grade A7 } & \multicolumn{2}{|c|}{ Grade A8 } \\
\hline $\begin{array}{l}\text { Water (g) (Continuous } \\
\text { phase) }\end{array}$ & \multicolumn{2}{|c|}{500.0} & \multicolumn{2}{|c|}{500.0} & \multicolumn{2}{|c|}{500.0} & \multicolumn{2}{|c|}{500.0} \\
\hline Styrene (g) (Monomer) & \multicolumn{2}{|c|}{50.0} & \multicolumn{2}{|c|}{50.0} & \multicolumn{2}{|c|}{50.0} & \multicolumn{2}{|c|}{50.0} \\
\hline $\begin{array}{l}\text { Dibenzoyl peroxide (g) } \\
\text { (Initiator) }\end{array}$ & \multicolumn{2}{|c|}{0.275} & \multicolumn{2}{|c|}{0.250} & \multicolumn{2}{|c|}{0.225} & \multicolumn{2}{|c|}{0.200} \\
\hline $\begin{array}{l}\text { Dicumyl peroxide (g) } \\
\text { (Initiator) }\end{array}$ & \multicolumn{2}{|c|}{0.275} & \multicolumn{2}{|c|}{0.250} & \multicolumn{2}{|c|}{0.225} & \multicolumn{2}{|c|}{0.200} \\
\hline $\begin{array}{l}\text { Tri-calcium phosphate (g) } \\
\text { (Stabilizer) }\end{array}$ & \multicolumn{2}{|c|}{0.50} & \multicolumn{2}{|c|}{0.50} & \multicolumn{2}{|c|}{0.50} & \multicolumn{2}{|c|}{0.50} \\
\hline $\begin{array}{l}\text { Polyvinyl alcohol (g) } \\
\text { (Stabilizer) }\end{array}$ & \multicolumn{2}{|c|}{0.50} & \multicolumn{2}{|c|}{0.50} & \multicolumn{2}{|c|}{0.50} & \multicolumn{2}{|c|}{0.50} \\
\hline $\begin{array}{l}\text { Starch }(g) \\
\text { (Absorbent) }\end{array}$ & \multicolumn{2}{|c|}{0.25} & \multicolumn{2}{|c|}{0.25} & \multicolumn{2}{|c|}{0.25} & \multicolumn{2}{|c|}{0.25} \\
\hline Reaction conditions & $\begin{array}{c}\text { Step } \\
1\end{array}$ & $\begin{array}{c}\text { Step } \\
2\end{array}$ & $\begin{array}{c}\text { Step } \\
1\end{array}$ & $\begin{array}{c}\text { Step } \\
2\end{array}$ & $\begin{array}{c}\text { Step } \\
1\end{array}$ & $\begin{array}{c}\text { Step } \\
2\end{array}$ & $\begin{array}{c}\text { Step } \\
1\end{array}$ & $\begin{array}{l}\text { Step } \\
2\end{array}$ \\
\hline Temperature $\left({ }^{\circ} \mathrm{C}\right)$ & 25 & 90 & 25 & 90 & 25 & 90 & 25 & 90 \\
\hline Agitation (RPM) & 400 & 1000 & 400 & 1000 & 400 & 1000 & 400 & 1000 \\
\hline Time (hrs) & 0.5 & 3.5 & 0.5 & 3.5 & 0.5 & 3.5 & 0.5 & 3.5 \\
\hline
\end{tabular}




\subsection{Production of High Molecular Weight Polystyrene with Silica-Alumina}

The formulations to produce high molecular weight polystyrene composite beads by varying the weight percent (wt \%) of silica-alumina are summarized in Table 5. This experiment was carried out to analyze the effect of wt \% of silica-alumina on (1) the molecular weight and (2) thermal properties of the polymer. Many researchers investigating polymer composites used additives in the range of 0.5 to $25 \mathrm{wt} \%$ to the polymer matrix [10,66-68]. However, it is well known that additives in a polymer matrix will decrease the molecular weight. Hence, in this experiment, the additive was limited to $1-5$ wt $\%$. Two parameters were also modified in these new formulations relative to the formulations given earlier in Table 3.

1. The reaction time was kept constant at $6 \mathrm{hrs}[10,26]$.

2. The mass of the initiators was decreased from 0.60 to $0.20 \mathrm{~g}[16,17]$.

3. A new overhead stirrer (no wobbling) with digital RPM display was used to prevent turbulence in the reactor and to better control the agitation.

Again, the polystyrene composite beads produced were sieved using three (3) screens: U.S. Sieve No. 12 (1680 microns), U.S. Sieve No. 30 (595 microns) and U.S. Sieve No. 100 (150 microns). These beads were washed with distilled water and dried for 24 hours at room temperature. Only the polystyrene composite beads with bead diameter size in the range of $150-595$ microns (LFC) were analyzed using SEM/EDX, TGA, DSC and GPC. 
Table 5: Formulations and Reaction Conditions for Higher Molecular Weight Polystyrene Composite Beads by Varying Mass of Silica-Alumina

\begin{tabular}{|c|c|c|c|c|c|c|c|c|c|c|}
\hline Ingredients & \multicolumn{2}{|c|}{ Grade B1 } & \multicolumn{2}{|c|}{ Grade B2 } & \multicolumn{2}{|c|}{ Grade B3 } & \multicolumn{2}{|c|}{ Grade B4 } & \multicolumn{2}{|c|}{ Grade B5 } \\
\hline $\begin{array}{l}\text { Water (g) } \\
\text { (Continuous } \\
\text { phase) } \\
\end{array}$ & \multicolumn{2}{|c|}{500.0} & \multicolumn{2}{|c|}{500.0} & \multicolumn{2}{|c|}{500.0} & \multicolumn{2}{|c|}{500.0} & \multicolumn{2}{|c|}{500.0} \\
\hline $\begin{array}{l}\text { Styrene (g) } \\
\text { (Monomer) }\end{array}$ & \multicolumn{2}{|c|}{50.0} & \multicolumn{2}{|c|}{50.0} & \multicolumn{2}{|c|}{50.0} & \multicolumn{2}{|c|}{50.0} & \multicolumn{2}{|c|}{50.0} \\
\hline $\begin{array}{l}\text { Dibenzoyl } \\
\text { peroxide (g) } \\
\text { (Initiator) }\end{array}$ & \multicolumn{2}{|c|}{0.10} & \multicolumn{2}{|c|}{0.10} & \multicolumn{2}{|c|}{0.10} & \multicolumn{2}{|c|}{0.10} & \multicolumn{2}{|c|}{0.10} \\
\hline $\begin{array}{l}\text { Dicumyl peroxide } \\
\text { (g) (Initiator) }\end{array}$ & \multicolumn{2}{|c|}{0.10} & \multicolumn{2}{|c|}{0.10} & \multicolumn{2}{|c|}{0.10} & \multicolumn{2}{|c|}{0.10} & \multicolumn{2}{|c|}{0.10} \\
\hline $\begin{array}{l}\text { Tri-calcium } \\
\text { phosphate (g) } \\
\text { (Stabilizer) }\end{array}$ & \multicolumn{2}{|c|}{0.50} & \multicolumn{2}{|c|}{0.50} & \multicolumn{2}{|c|}{0.50} & \multicolumn{2}{|c|}{0.50} & \multicolumn{2}{|c|}{0.50} \\
\hline $\begin{array}{l}\text { Polyvinyl alcohol } \\
\text { (g) (Stabilizer) }\end{array}$ & \multicolumn{2}{|c|}{0.50} & \multicolumn{2}{|c|}{0.50} & \multicolumn{2}{|c|}{0.50} & \multicolumn{2}{|c|}{0.50} & \multicolumn{2}{|c|}{0.50} \\
\hline $\begin{array}{l}\text { Starch }(\mathrm{g}) \\
\text { (Absorbent) }\end{array}$ & \multicolumn{2}{|c|}{0.25} & \multicolumn{2}{|c|}{0.25} & & & & 25 & 0 . & \\
\hline $\begin{array}{l}\text { Silica-Alumina (g) } \\
\text { (Catalyst) }\end{array}$ & c & & & & & & & 50 & 2. & \\
\hline $\begin{array}{l}\text { Reaction } \\
\text { conditions }\end{array}$ & $\begin{array}{c}\text { Step } \\
1\end{array}$ & $\begin{array}{c}\text { Step } \\
2\end{array}$ & $\begin{array}{c}\text { Step } \\
1\end{array}$ & $\begin{array}{c}\text { Step } \\
2\end{array}$ & $\begin{array}{c}\text { Step } \\
1\end{array}$ & $\begin{array}{c}\text { Step } \\
2\end{array}$ & $\begin{array}{c}\text { Step } \\
1\end{array}$ & $\begin{array}{c}\text { Step } \\
2\end{array}$ & $\begin{array}{c}\text { Step } \\
1\end{array}$ & $\begin{array}{c}\text { Step } \\
2\end{array}$ \\
\hline Temperature $\left({ }^{\circ} \mathbf{C}\right)$ & 25 & 90 & 25 & 90 & 25 & 90 & 25 & 90 & 25 & 90 \\
\hline Agitation (RPM) & 400 & 1000 & 400 & 1000 & 400 & 1000 & 400 & 1000 & 400 & 1000 \\
\hline Time (hours) & 0.5 & 5.5 & 0.5 & 5.5 & 0.5 & 5.5 & 0.5 & 5.5 & 0.5 & 5.5 \\
\hline
\end{tabular}




\subsection{Polymer Characterization}

Specific laboratory techniques were used to determine the properties of polymers. GPC was used to determine $M_{w}$, the number average molecular weight $\left(M_{n}\right)$ and polydispersity $\left(M_{w} / M_{n}\right)$. Thermal properties $\left(\mathrm{T}_{\mathrm{g}}\right.$ and $\mathrm{T}_{\mathrm{o}}$ ) were determined by DSC and TGA, respectively. SEM/EDX was used to determine the morphology of the internal structure of the polymeric beads and the presence of the additives.

Characterizations of these beads were carried out using GPC, TGA and DSC analyses mainly at the University of Toronto (some of the analyses were also carried at McMaster University). SEM analysis was carried at Ryerson University.

\subsubsection{SEM/EDX Analysis}

The polystyrene composite beads were cut and the cross-sections were examined under the SEM. These beads were cut using a cryogenic microtome (Leica RM 2165). A thin layer of thermoplastic adhesive (Tempfix, Agar Scientific) was melted onto a plastic holder and the beads were sprinkled on the top [69]. The adhesive was cooled to room temperature and the beads became immobilized. The plastic holder was then mounted on a cryogenic microtome and thin slices of the exposed beads were cut to reveal the cross sections. Throughout this process, the temperature of the knife was kept at $-20^{\circ} \mathrm{C}$ and the temperature of the chamber was maintained at $-90{ }^{\circ} \mathrm{C}$.

The plastic holder was then mounted in the SEM chamber (JEOL JSM-6380LV) for SEM/EDX analysis. Figure 20 shows a SEM micrograph of five microtomed polystyrene composite beads. Larger diameter-sized beads were more exposed to the surface and they were more sliced than the smaller diameter-sized beads. 


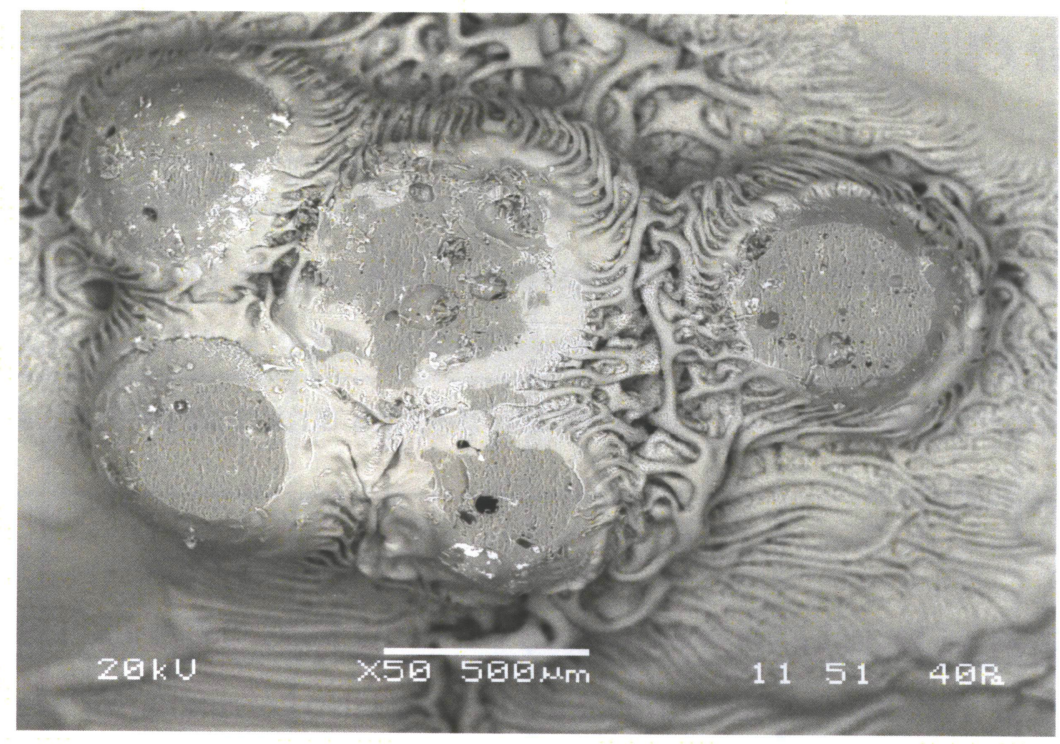

Figure 20: SEM of Microtomed Polystyrene Composite Beads (Magnification: 50X)

\subsubsection{GPC Analysis}

The molecular weight of the polystyrene composite beads was determined using GPC. Two GPC systems at University of Toronto were used: (1) Waters 2690 modular GPC with Viscotek T90A dual light scattering viscometry detector (performed in February 2007) and (2) Viscotek GPCmax with Viscotek TDA 302 triple detector array (performed in July 2007). The GPC system at McMaster University consisted of a Waters 515 HPLC and a Waters 2414 viscometry detector was also used (performed in October 2007).

The beads were dissolved in a solvent (tetrahydrofuran or THF) and this solution was introduced in column filled with cross-linked polystyrene beads that contained pores of different sizes at a flow rate of $0.6 \mathrm{~mL} / \mathrm{min}$. The smaller molecules of the polymer solution get trapped in the pores while the larger molecules escape the pores and pass or elute through the column more quickly. Hence, the larger molecules have a smaller Retention Volume (RV). The time required (or RV) for the polymer solution to elute through the column was used to determine the molecular weight of the polymer. Detectors were used to count the number of polymer molecules (Figure 21). 


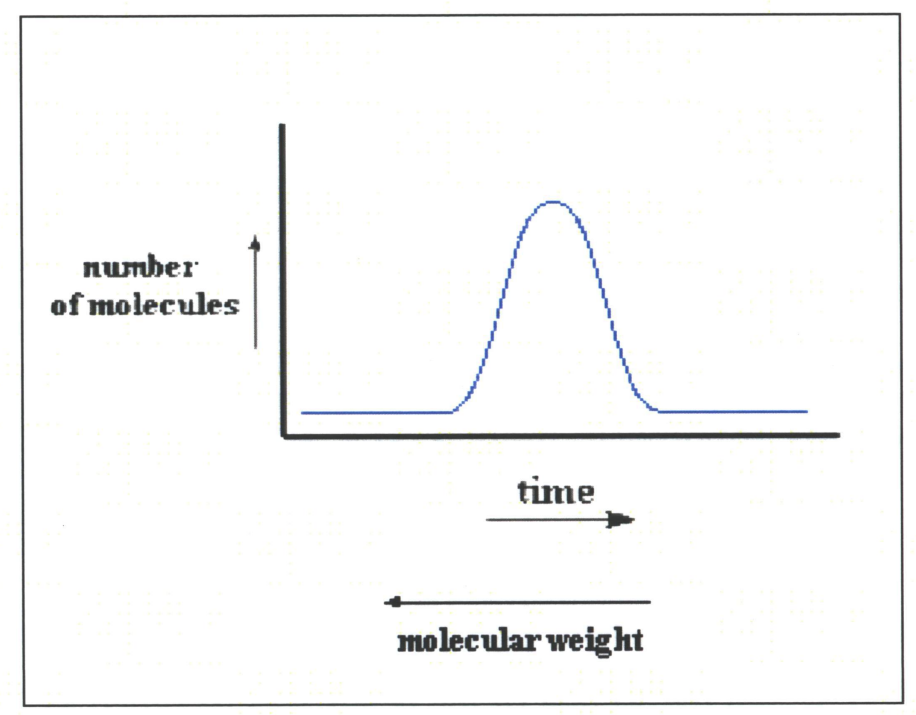

Figure 21: The Molecular Weight Distribution of a Polymer [70]

Polymer molecules can have different sizes (chain lengths), so the average molecular weight depends on the method of averaging. $\mathrm{M}_{\mathrm{n}}$ and $\mathrm{M}_{\mathrm{w}}$ are the more common parameters used to describe the molecular weight of the polymer. $M_{n}$ is determined using the relation given below (Equation 15) [71].

$\mathrm{M}_{\mathrm{n}}=\Sigma_{\mathrm{i}} \mathrm{N}_{\mathrm{i}} \mathrm{M}_{\mathrm{i}}^{\alpha} / \Sigma_{\mathrm{i}} \mathrm{N}_{\mathrm{i}} \mathrm{M}_{\mathrm{i}}^{\alpha-1}$

$\mathbf{M}_{\mathrm{w}}$ is determined by Equation 16 given below.

$\mathrm{M}_{\mathrm{w}}=\sum_{\mathrm{i}} \mathrm{N}_{\mathrm{i}} \mathrm{M}_{\mathrm{i}}^{\alpha} / \sum_{\mathrm{i}} \mathrm{N}_{\mathrm{i}} \mathrm{M}_{\mathrm{i}}^{\alpha-1}$

Where, $N_{i}$ is the number of molecules with molecular weight $M_{i}$.

$M_{w}$ has a weighting factor ( $\alpha$ ) of 2 and $M_{n}$ has a weighting factor of 1 . Hence, $M_{w}$ is always bigger than $\mathrm{M}_{\mathrm{n}}$. The distribution of molecular weights in a polymer sample is often described by the ratio of $M_{w}$ and $M_{n}$. This ratio is referred to as the PolyDispersity Index (PDI) and it is in the range of $2-5$ for suspension polymerization [15]. An example to calculate the $M_{n}, M_{w}$ and PDI $\left(\mathrm{M}_{\mathrm{w}} / \mathrm{M}_{\mathrm{n}}\right)$ of a polymer is given in Appendix A. 


\subsubsection{TGA Analysis}

TGA was used to determine the thermal stability and the fraction of volatile components of the beads by monitoring the weight change that occurs as the beads are heated. The TGA experiments were carried out in a nitrogen gas atmosphere using a Q500 (TA-instruments) at University of Toronto (performed in January - February 2007). The TGA experiments were also carried out in an argon gas atmosphere using a STA 409 PC/PG (NETZSCH-instruments) at McMaster University (performed in October 2007).

In TGA, the polystyrene composite beads were continuously heated at a rate of $10{ }^{\circ} \mathrm{C} / \mathrm{min}$ from room temperature to $600{ }^{\circ} \mathrm{C}$ and the weight of the beads was recorded as a function of increasing temperature. $\mathrm{T}_{\mathrm{o}}$ was determined with computer software. The software effectively determines this temperature by drawing tangents at two points $(90 \mathrm{wt} \%$ and $10 \mathrm{wt} \%$ ) to the curve as illustrated in Figure 22.

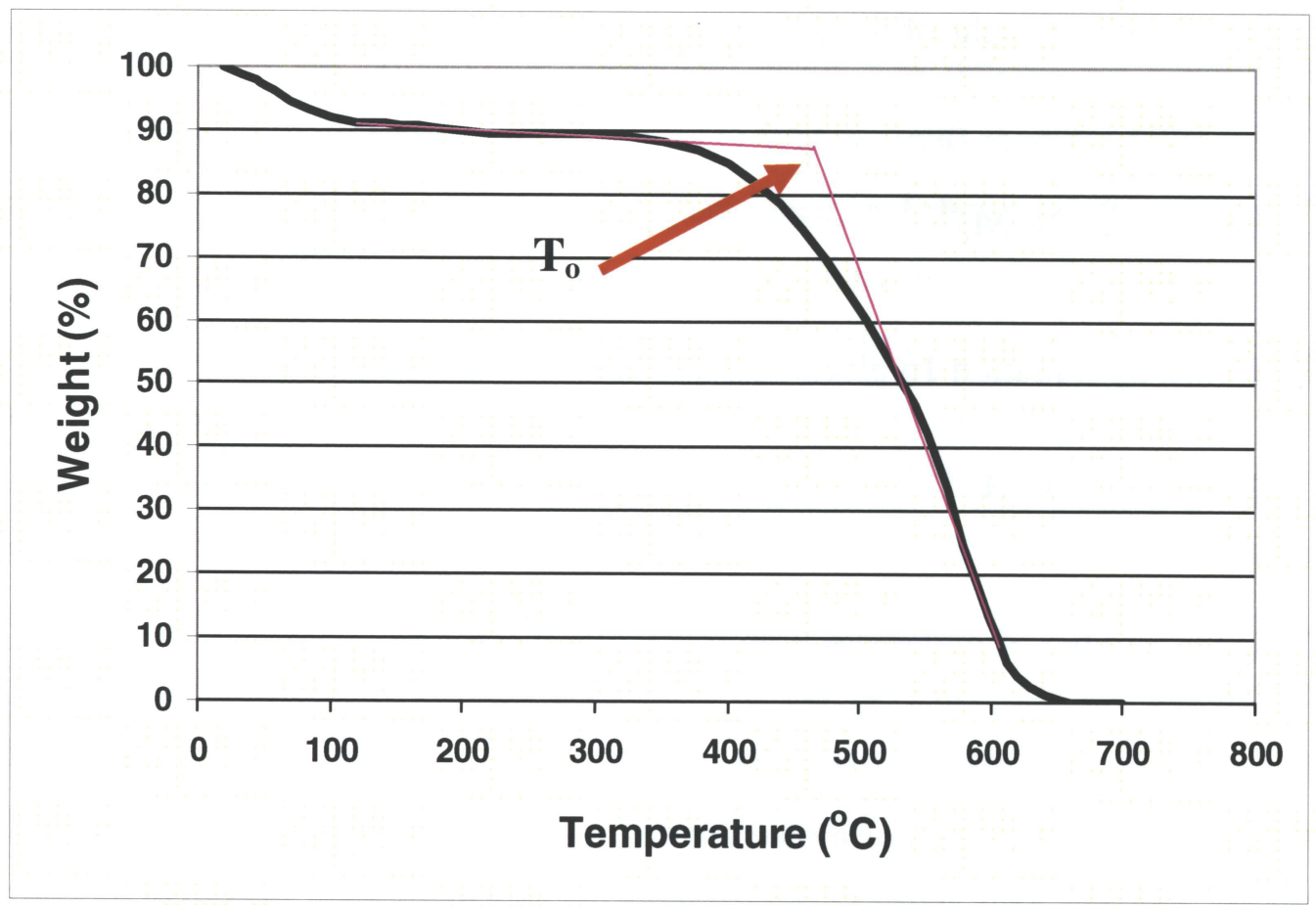

Figure 22: Method to Determine the Onset Temperature [39] 


\subsubsection{DSC Analysis}

The $\mathrm{T}_{\mathrm{g}}$ values of polystyrene composite beads were determined using DSC. The DSC experiments were carried out in the presence of nitrogen gas using the DSC 2920 (TAInstruments) at University of Toronto (performed in February 2007). The experiments were also carried out in a nitrogen gas atmosphere using the DCS 2910 (TA- Instruments) at McMaster University (performed in October 2007).

The polystyrene composite beads were continuously heated at a rate of $10{ }^{\circ} \mathrm{C} / \mathrm{min}$ from room temperature to $150{ }^{\circ} \mathrm{C}$ and then cooled down at the same rate to room temperature (cyclic method). The difference in the heat flow was recorded as a function of increasing and decreasing temperature. $T_{g}$ was determined with computer software. The software effectively chooses the mean temperature of the changing slope as illustrated in Figure 23.

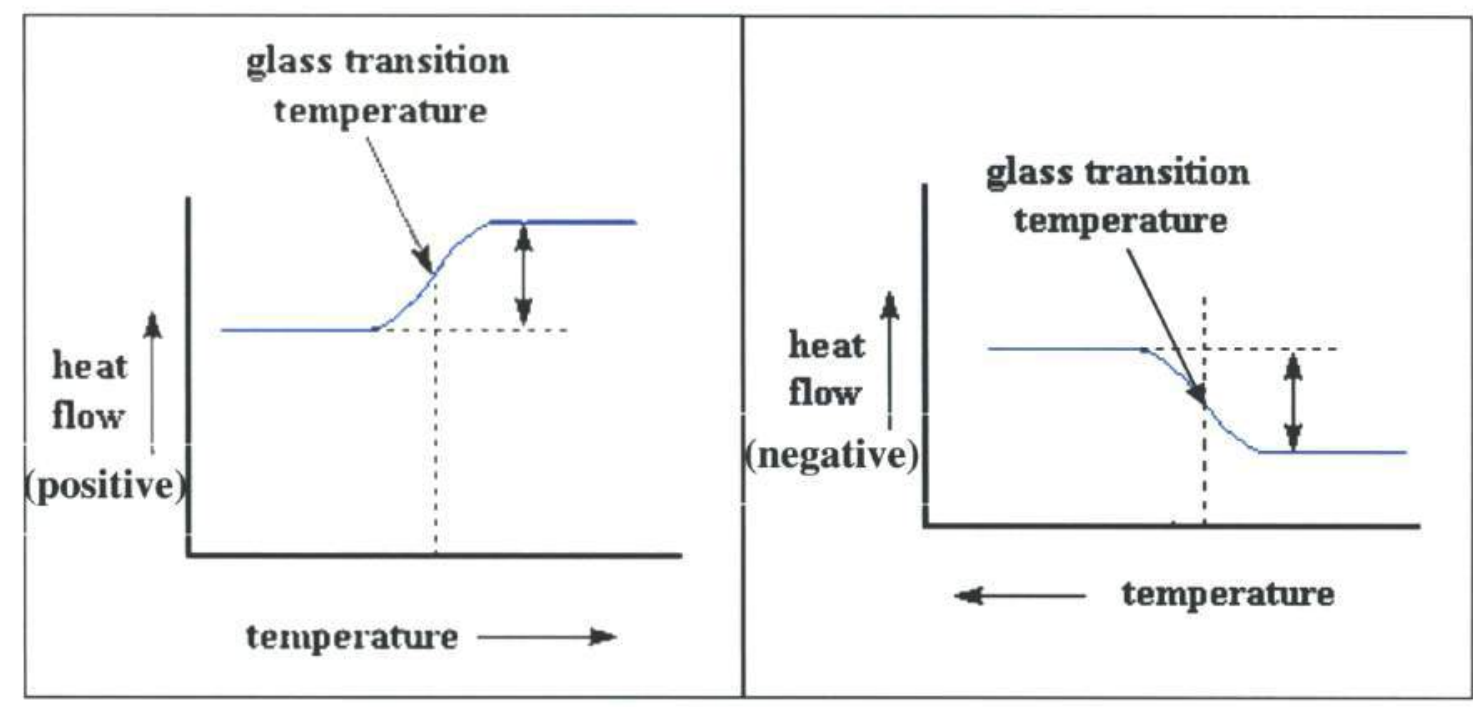

(a) Heating

(b) Cooling

Figure 23: Method to Determine the Glass Transition Temperature [72] 


\section{Chapter 4 - Results}

In this chapter, Section 4.1 describes the initial experiments that resulted in low molecular weight polystyrene composite beads. Section 4.2 shows the results in the production of high molecular weight polystyrene beads. Section 4.3 shows the results in the production of high molecular weight polystyrene composite beads. Finally, section 4.4 gives a summary of all the results in this study.

\subsection{Results in the Production of Low Molecular Weight Polystyrene with Additives}

Polystyrene beads with no additive (Grade A) and polystyrene composite beads (Grades B, C and D) were synthesized in the laboratory (Table 2). As seen in Table 6, the formulations for these grades resulted in low yield $(3.1-4.2 \mathrm{wt} \%)$. Possible reasons for such low yield are: (1) the escape of the monomer from the reactor, (2) a short reaction time, (3) poor quality of the monomer and (4) presence of oxygen (i.e. absence of non-oxidising atmosphere) in the reactor.

Table 6: Bead Size and Percent Yield of Polymer Beads

\begin{tabular}{|l||c||c||}
\hline & Bead Size (mm) & wt \% Solid Yield \\
\hline \hline Grade A (no additive) & $0.5-0.7$ & 3.1 \\
\hline \hline Grade B (2 wt \% silica-alumina) & $0.5-0.7$ & 3.8 \\
\hline $\begin{array}{l}\text { Grade C (2 wt \% iron-based } \\
\text { catalyst) }\end{array}$ & $0.5-0.7$ & 3.3 \\
\hline $\begin{array}{l}\text { Grade D (1 wt \% silica-alumina } \\
\text { and 1 wt \% iron-based catalyst) }\end{array}$ & $0.5-0.7$ & 4.2 \\
\hline
\end{tabular}




\subsubsection{SEM/EDX Analysis of Low Molecular Weight Polystyrene with Additives}

The SEM micrograph (Figure 24) shows a fibrous and porous internal structure of Grade A. This structure resembles to typical polystyrene bead structure (Figure 25) reported in the literature [73]. The presence of spherical pores inside the bead suggests the entrapment of water vapour during the polymerization process. EDX analysis (Figure 26) shows the presence of oxygen, which may confirm the entrapment of water vapour. The EDX analysis also shows the presence of phosphorous, calcium and chlorine, which suggests the entrapment of the suspending agents inside the bead.

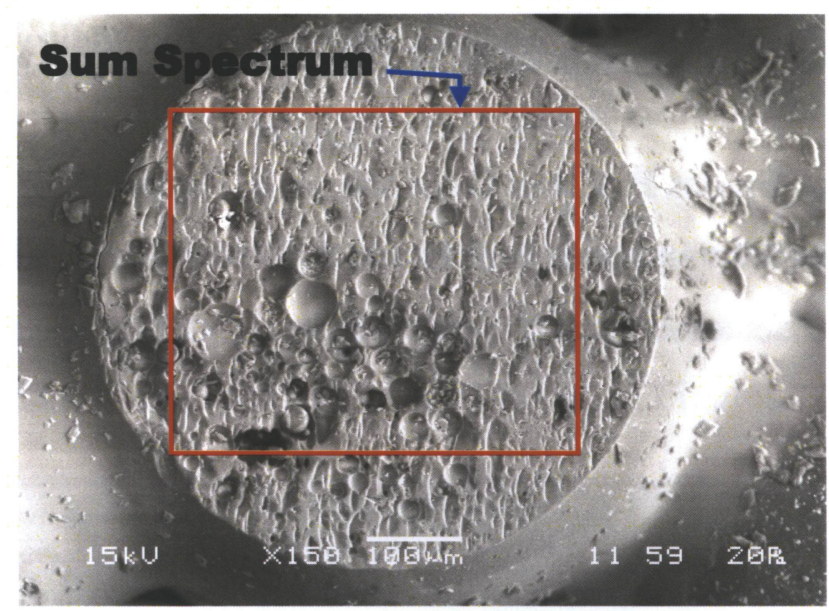

Figure 24: SEM Micrograph of Grade A (no additive)

(Magnification: 150X)

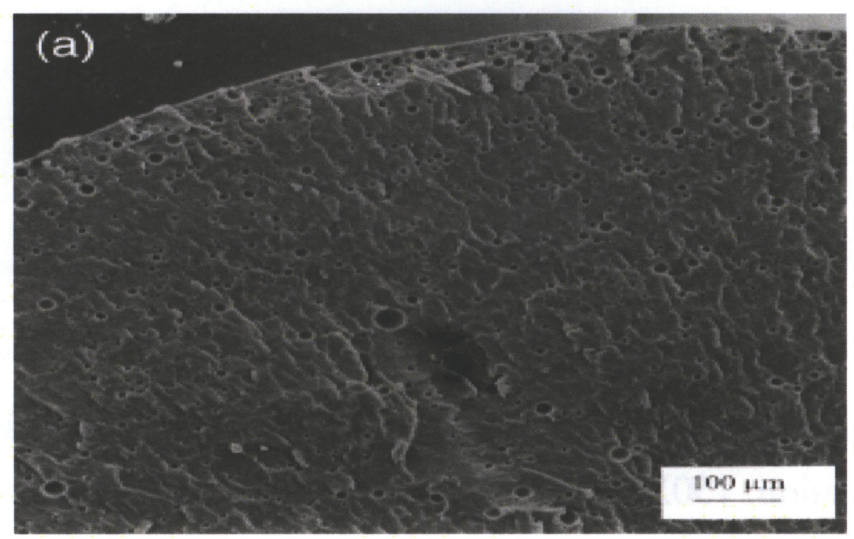

Figure 25: SEM Micrograph of a Typical Commercial Bead [73] 


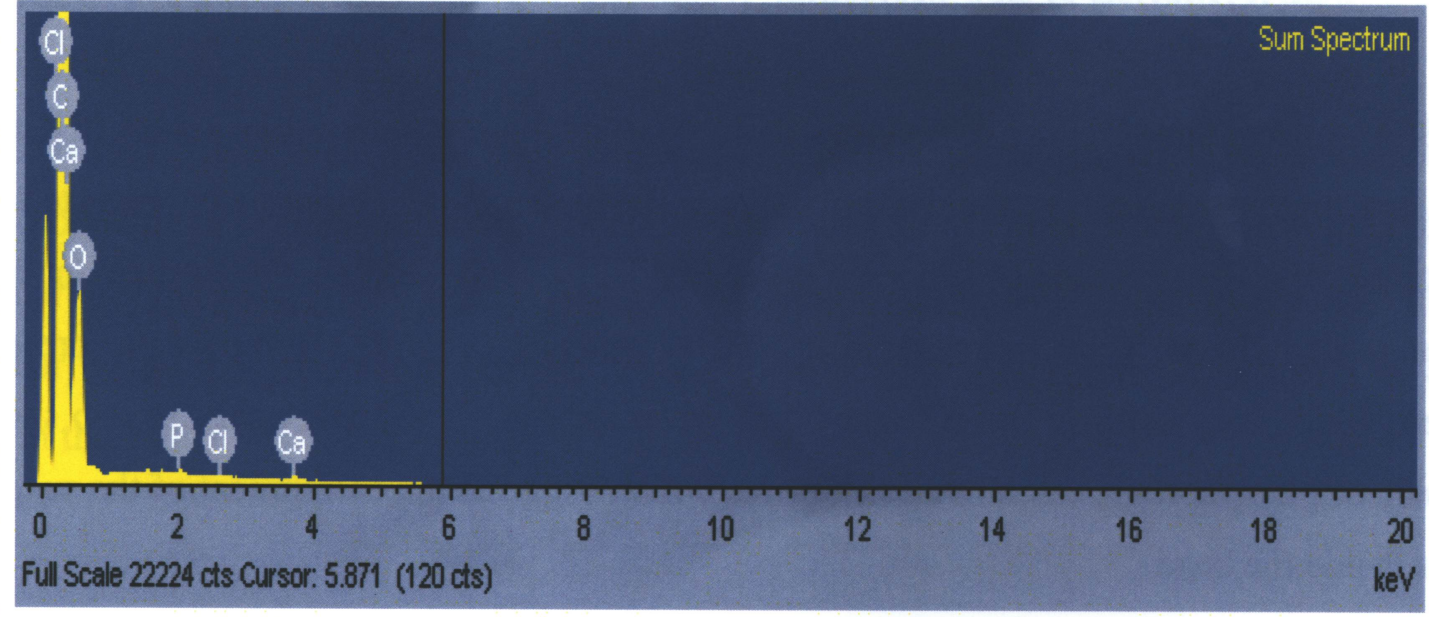

Figure 26: EDX Analysis of Grade A (no additive)

The SEM micrographs of Grades B, C and D are shown in Figures $27-29$, respectively. It was found that these grades had larger pores than Grade A. Some of the relatively dense particles of the additives might have detached from the polymer beads during sectioning, thus leaving large pores.

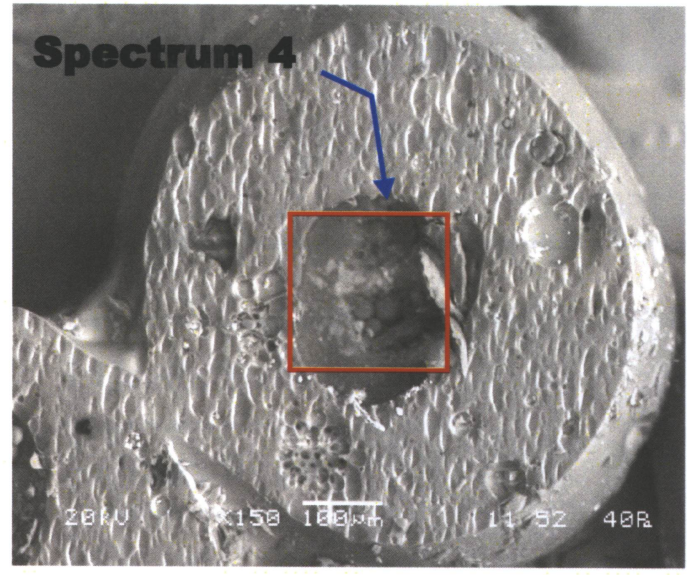

Figure 27: SEM Micrograph of Grade B

( 2 wt \% silica-alumina)

(Magnification: 150X)

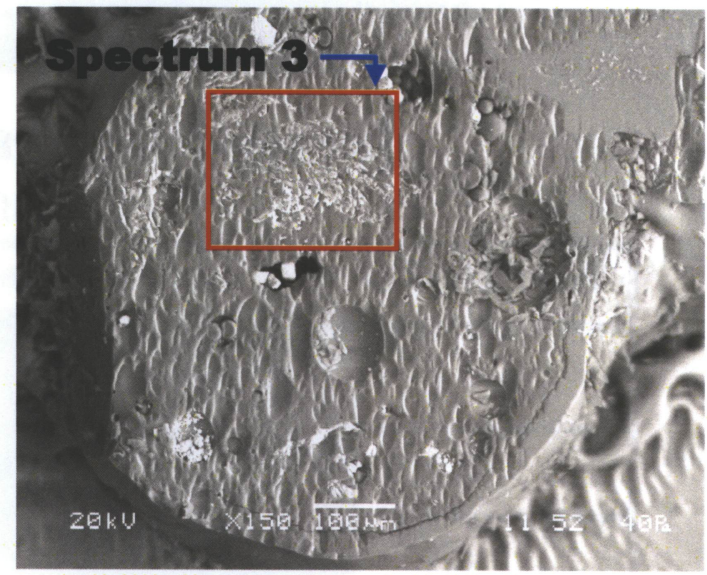

Figure 28: SEM Micrograph of Grade C

( 2 wt $\%$ iron based catalyst)

(Magnification: 150X) 


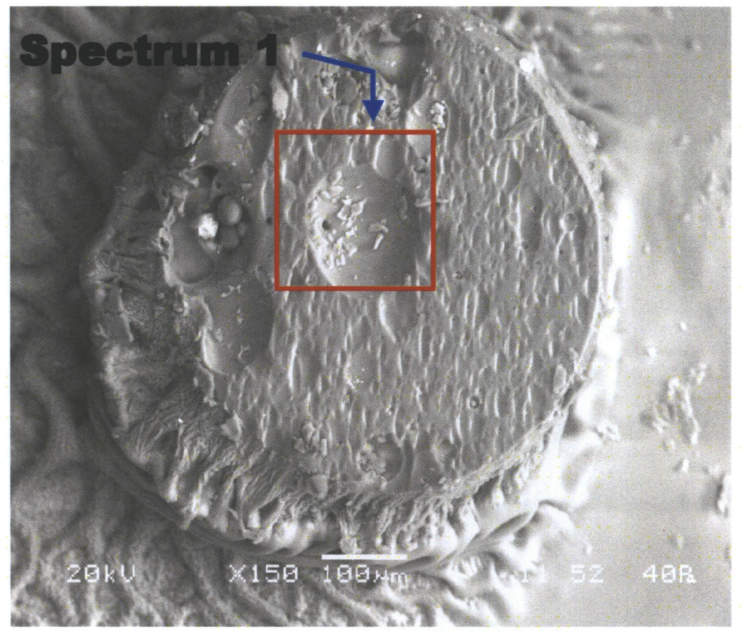

Figure 29: SEM Micrograph of Grade D (1 wt \% silica-alumina and 1 wt $\%$ iron-based catalyst) (Magnification: 150X)

EDX analysis confirmed that silica-alumina catalyst was incorporated inside the beads of Grades $\mathrm{B}$ and D as shown in Figures 30 and 31, respectively. The presence of iron based catalyst inside the beads of Grades C and D was also confirmed, as shown in Figures 31 and 32, respectively.

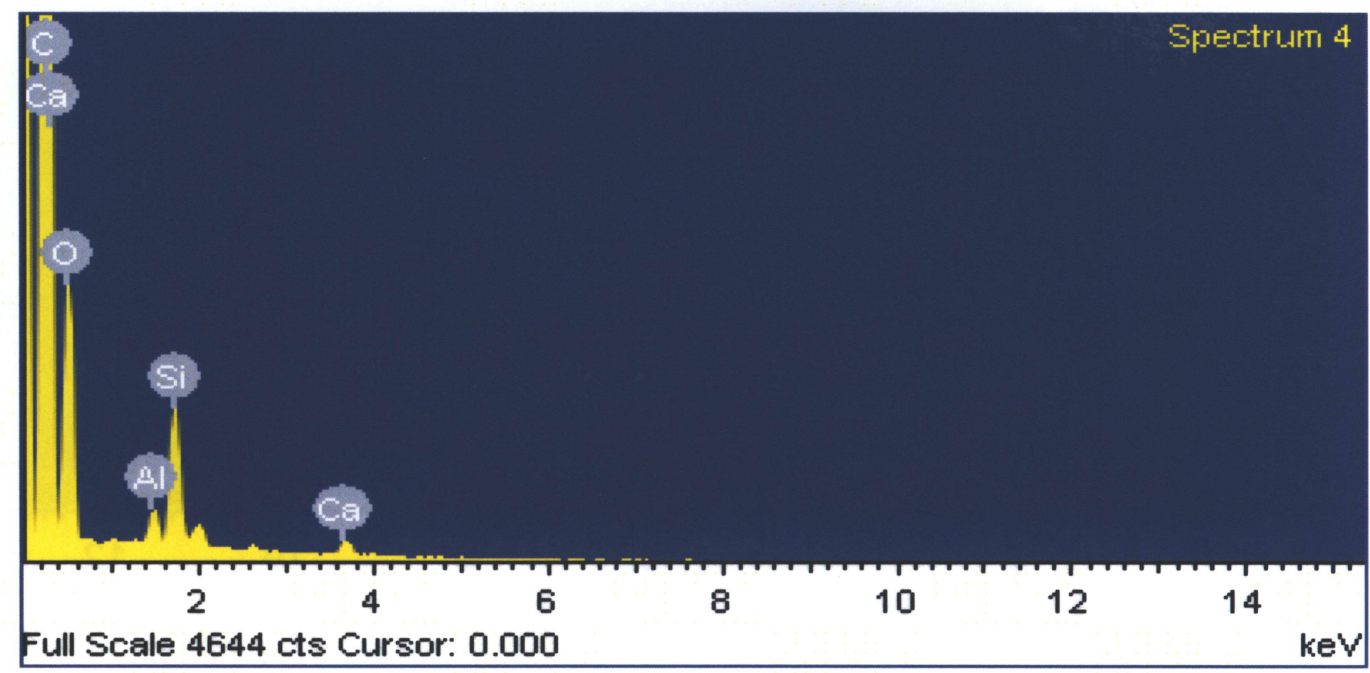

Figure 30: EDX Analysis of Grade B ( 2 wt \% silica-alumina) 


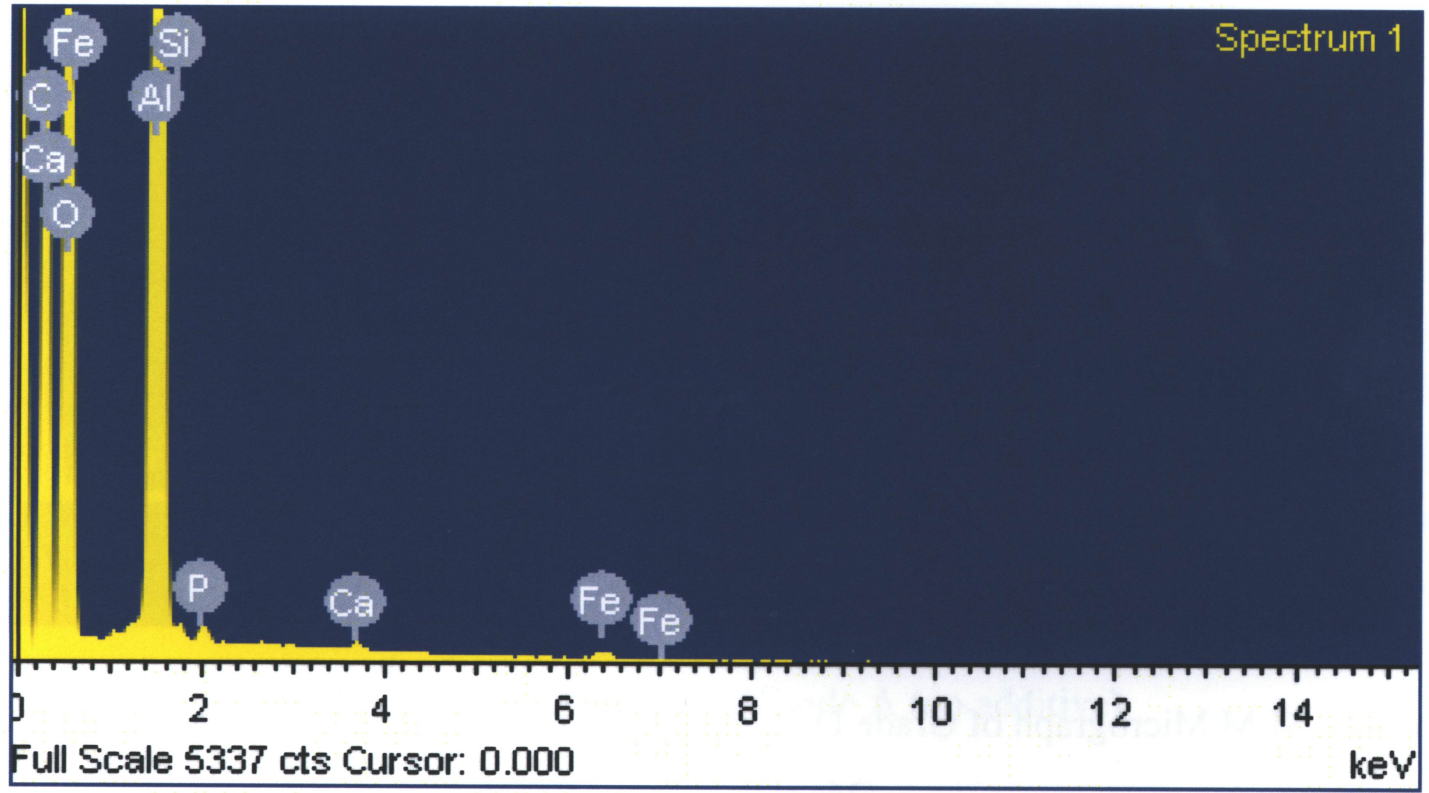

Figure 31: EDX Analysis of Grade D (1 wt \% silica-alumina and $1 \mathrm{wt} \%$ iron-based catalyst)

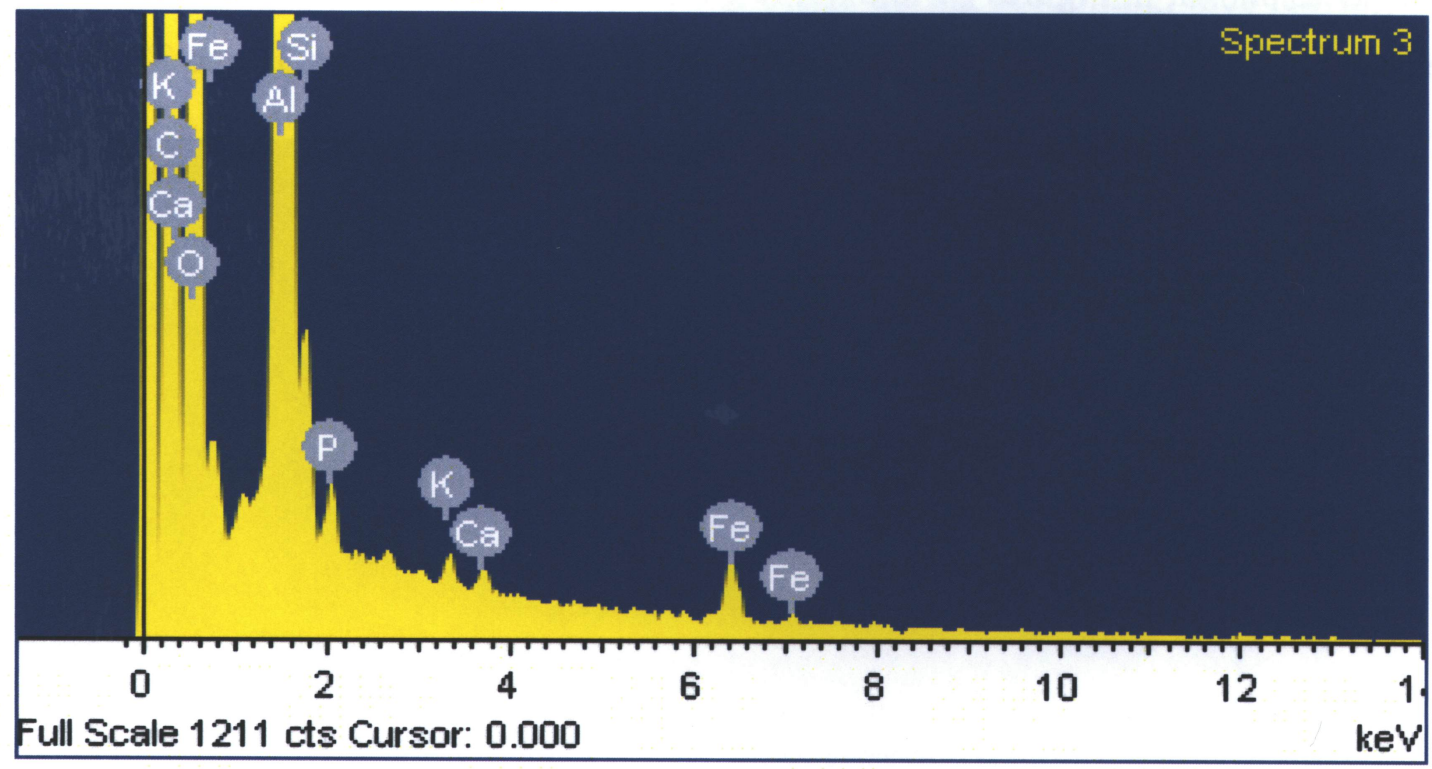

Figure 32: EDX Analysis of Grade C (2 wt \% iron-based catalyst) 


\subsubsection{GPC Analysis of Low Molecular Weight Polystyrene with Additives}

In a GPC analyzer, the larger molecules (i.e., higher molecular weight) elute faster through columns and they have shorter retention volume (RV) than smaller molecules. The GPC graphs of Grades A, B, C and D are shown in Figures $33-36$, respectively. A retention volume of 32 $\mathrm{mL}$ (Figure 33) represents the $\mathrm{M}_{\mathrm{w}}$ of the styrene monomer (104 Da) and $\mathrm{RV}$ above $32 \mathrm{~mL}$ represents impurities that are present in the sample. The area under the curve represents the weight distribution of the polymer molecules. The right tail area represents a low molecular weight polymer. The results of these GPC curves are summarized in Table 7. It was found that the $M_{w}$ values for Grades B, C and D were low and their PDI $\left(M_{w} / M_{n}\right)$ values were high relative to Grade A.

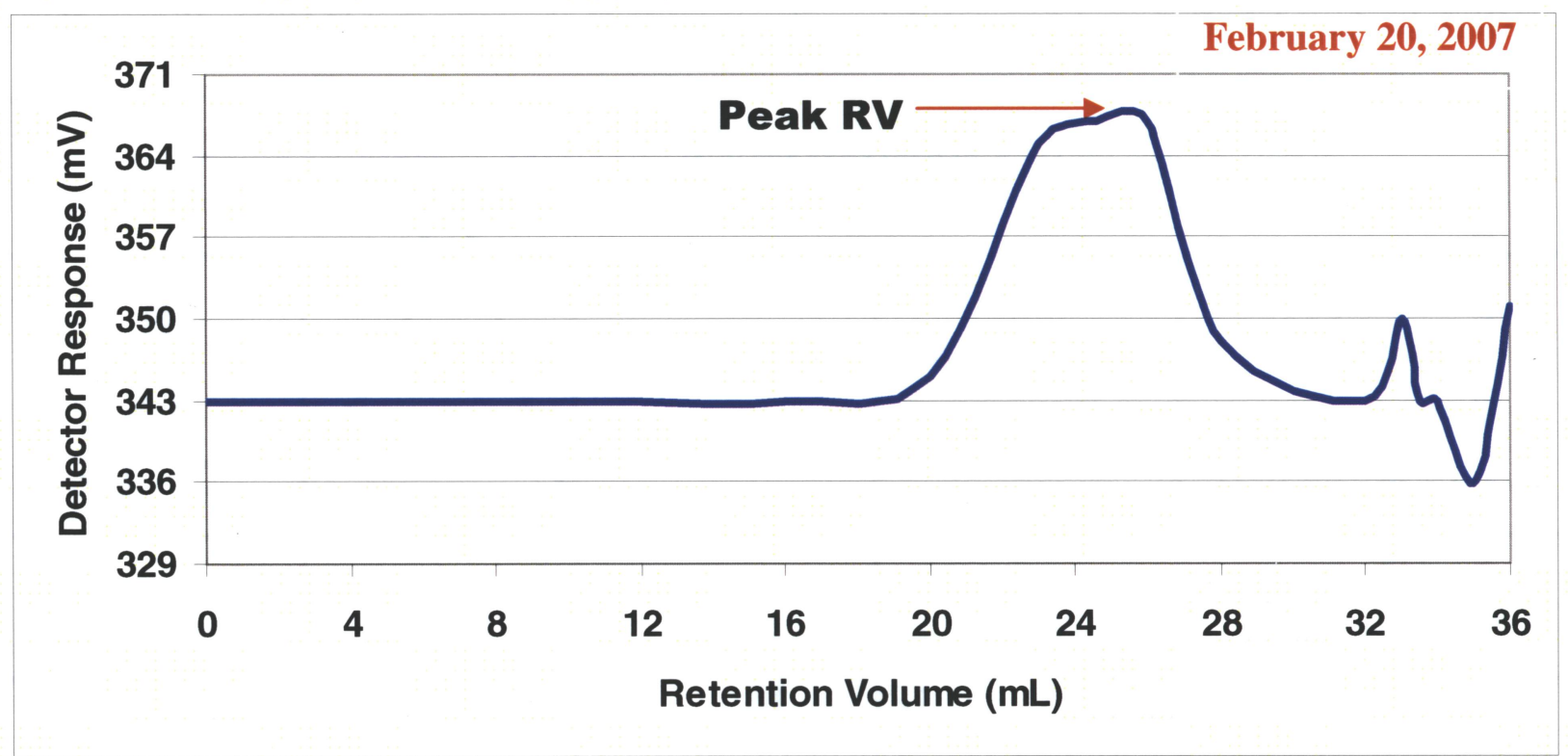

Figure 33: GPC Graph of Grade A (no additive) 


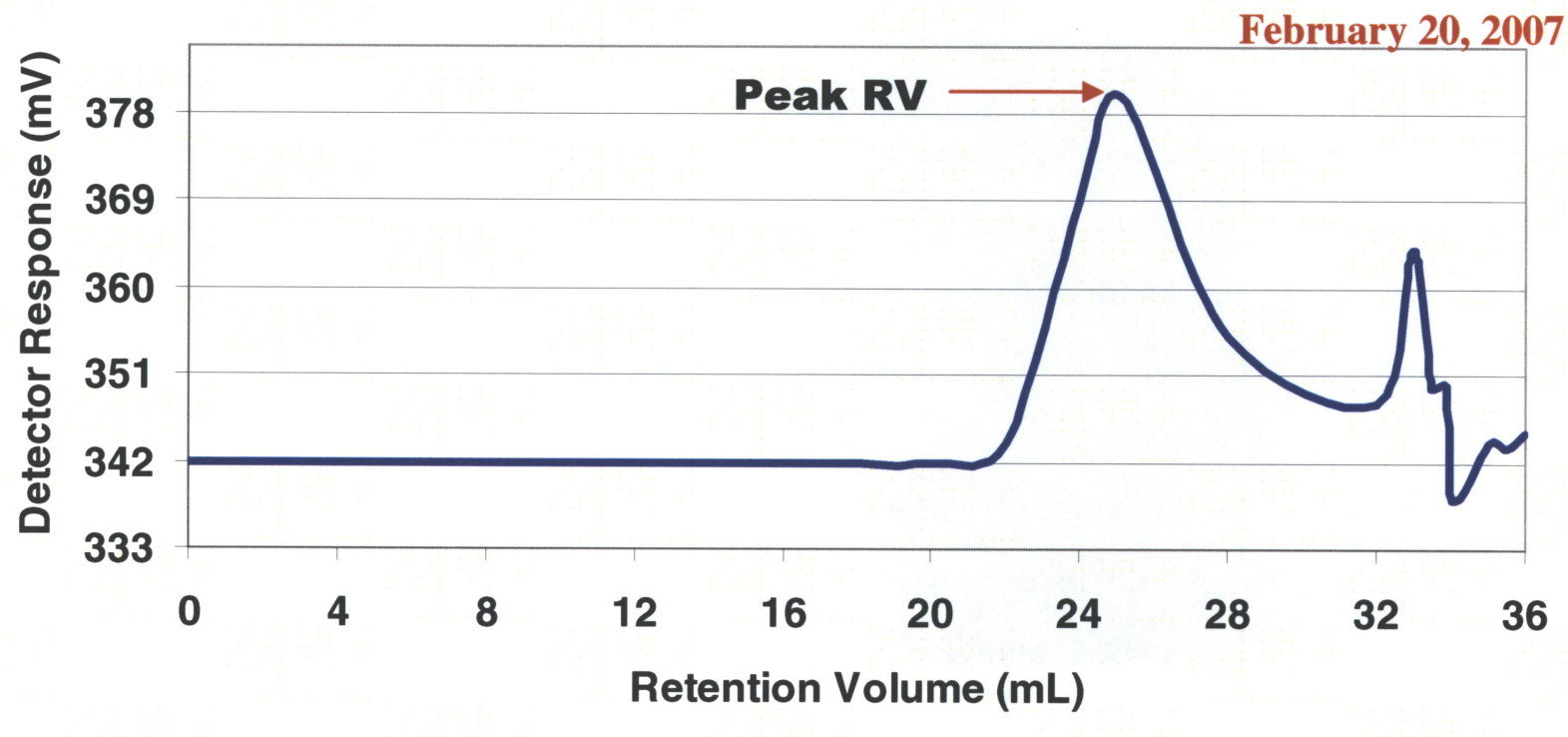

Figure 34: GPC Graph of Grade B ( 2 wt \% silica-alumina)

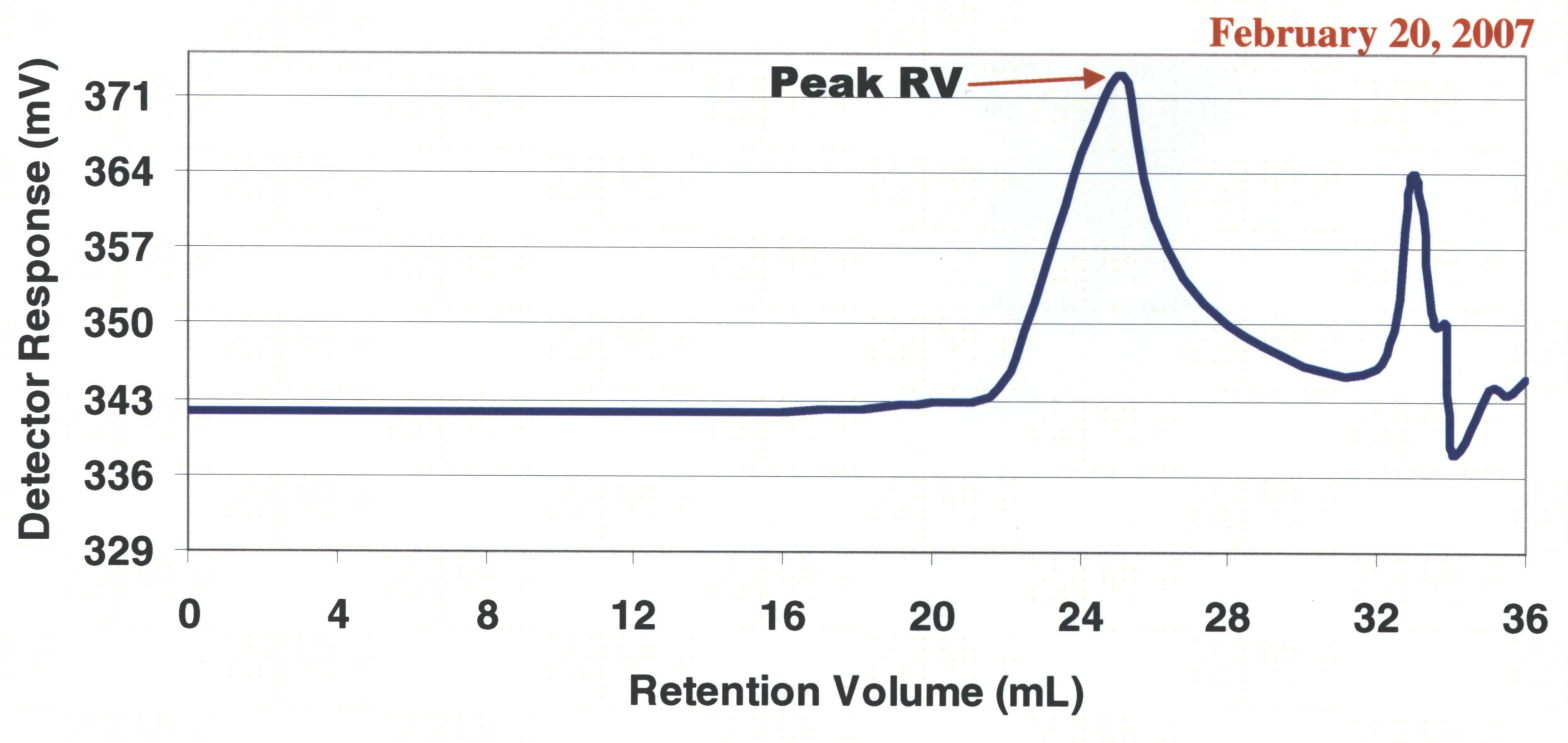

Figure 35: GPC Graph of Grade C (2 wt \% iron-based catalyst) 


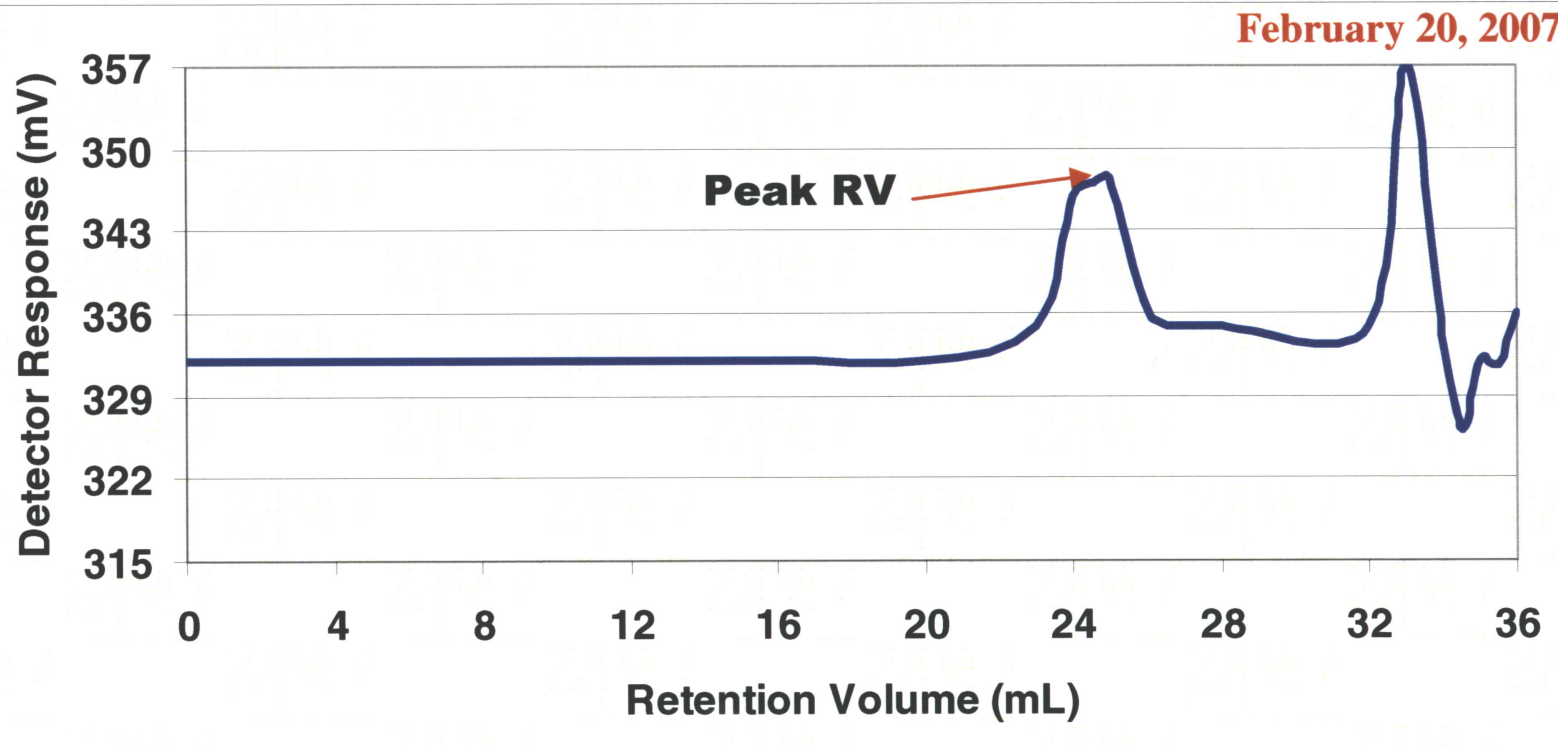

Figure 36: GPC Graph of Grade D (1 wt \% silica-alumina and 1 wt \% iron-based catalyst)

Table 7: Molecular Weight for Grades A, B, C and D

\begin{tabular}{|c|c|c|c|c|}
\hline & $\begin{array}{c}\text { Grade A } \\
\text { (no additive) }\end{array}$ & $\begin{array}{c}\text { Grade B } \\
\text { (2 wt \% silica- } \\
\text { alumina) }\end{array}$ & $\begin{array}{c}\text { Grade C } \\
\text { ( 2 wt \% iron- } \\
\text { based catalyst) }\end{array}$ & $\begin{array}{c}\text { Grade D } \\
\text { (1 wt \% silica- } \\
\text { alumina and 1 wt \% } \\
\text { iron-based catalyst) }\end{array}$ \\
\hline Peak RV ( $\mathbf{m L})$ & 24.592 & 25.124 & 25.132 & 24.570 \\
\hline $\mathbf{M}_{\mathbf{n}}(\mathbf{D a})$ & 10,564 & 3,546 & 4,679 & 3,067 \\
\hline $\mathbf{M}_{\mathbf{w}}(\mathbf{D a})$ & 30,213 & 20,155 & 21,948 & 25,873 \\
\hline & & & & \\
\hline
\end{tabular}




\subsubsection{DSC Analysis of Low Molecular Weight Polystyrene with Additives}

The molecules of a polymer have little mobility below $\mathrm{T}_{\mathrm{g}}$ due to the secondary and non-covalent bonds between the polymer chains. Above $T_{g}$, these bonds become weak and this causes the polymer to become rubbery [74]. The DSC graphs for Grades A, B, C and D are shown in Figures $37-40$, respectively and their $T_{g}$ values (please refer to section 3.6.4) are summarized in Table 8. It was found that the $\mathrm{T}_{\mathrm{g}}$ values for Grades $\mathrm{B}, \mathrm{C}$ and $\mathrm{D}$ were low relative to Grade $\mathrm{A}$.

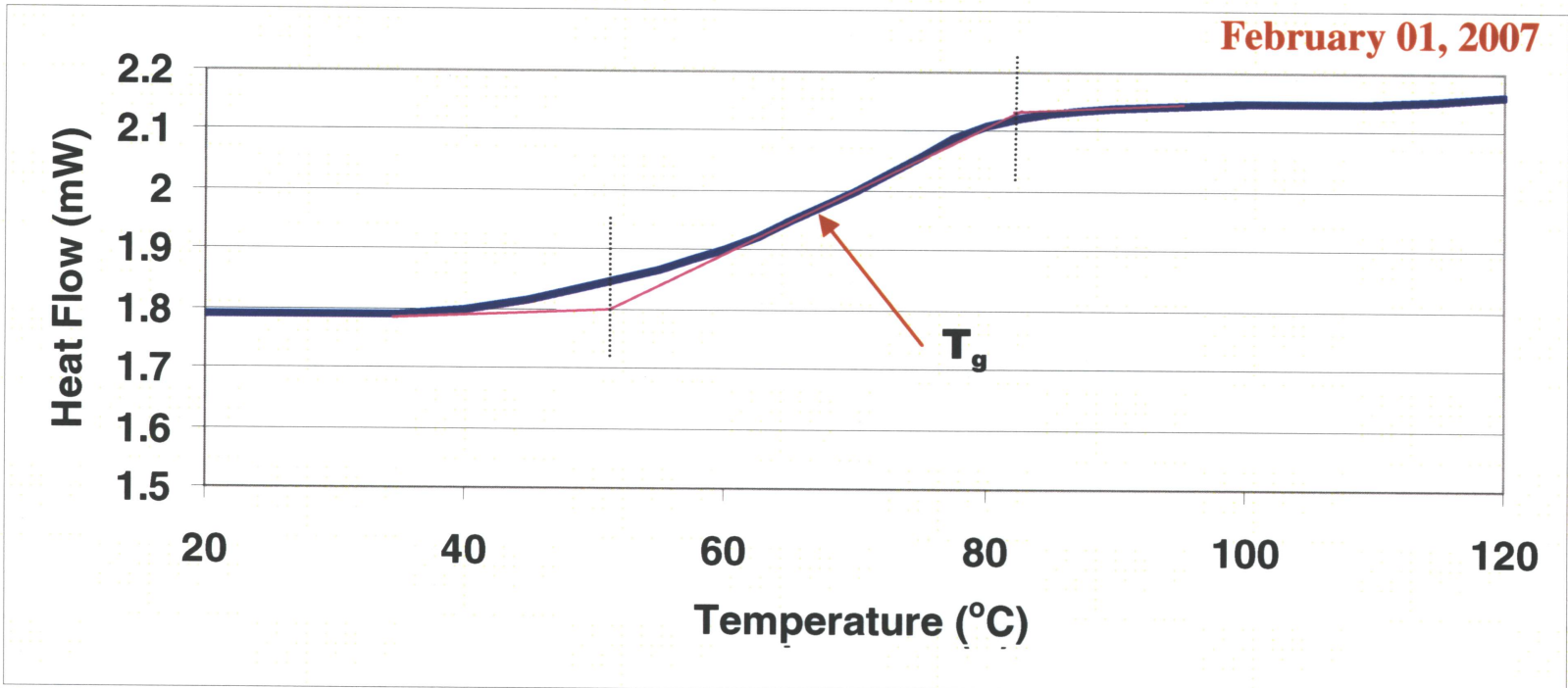

Figure 37: DSC Graph of Grade A (no additive)

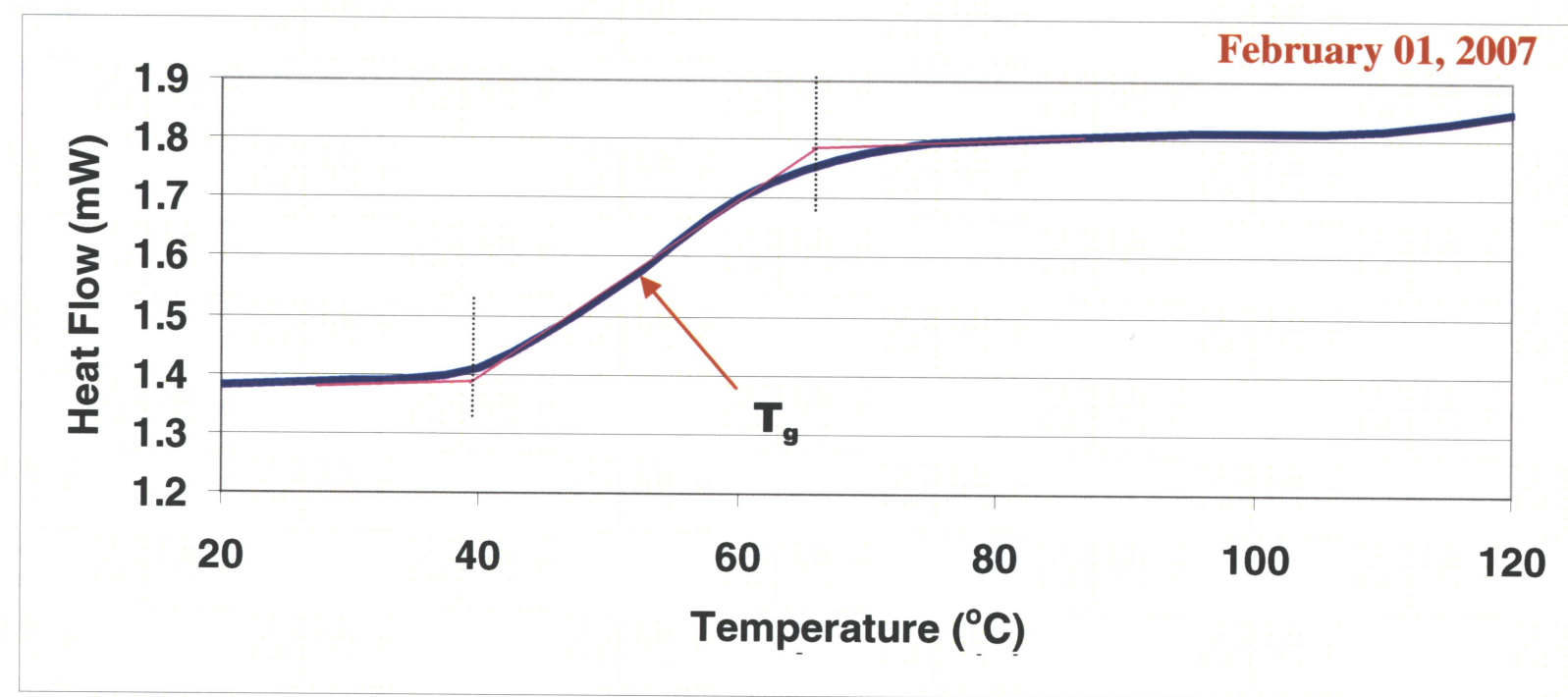

Figure 38: DSC Graph of Grade B (2 wt \% silica-alumina) 


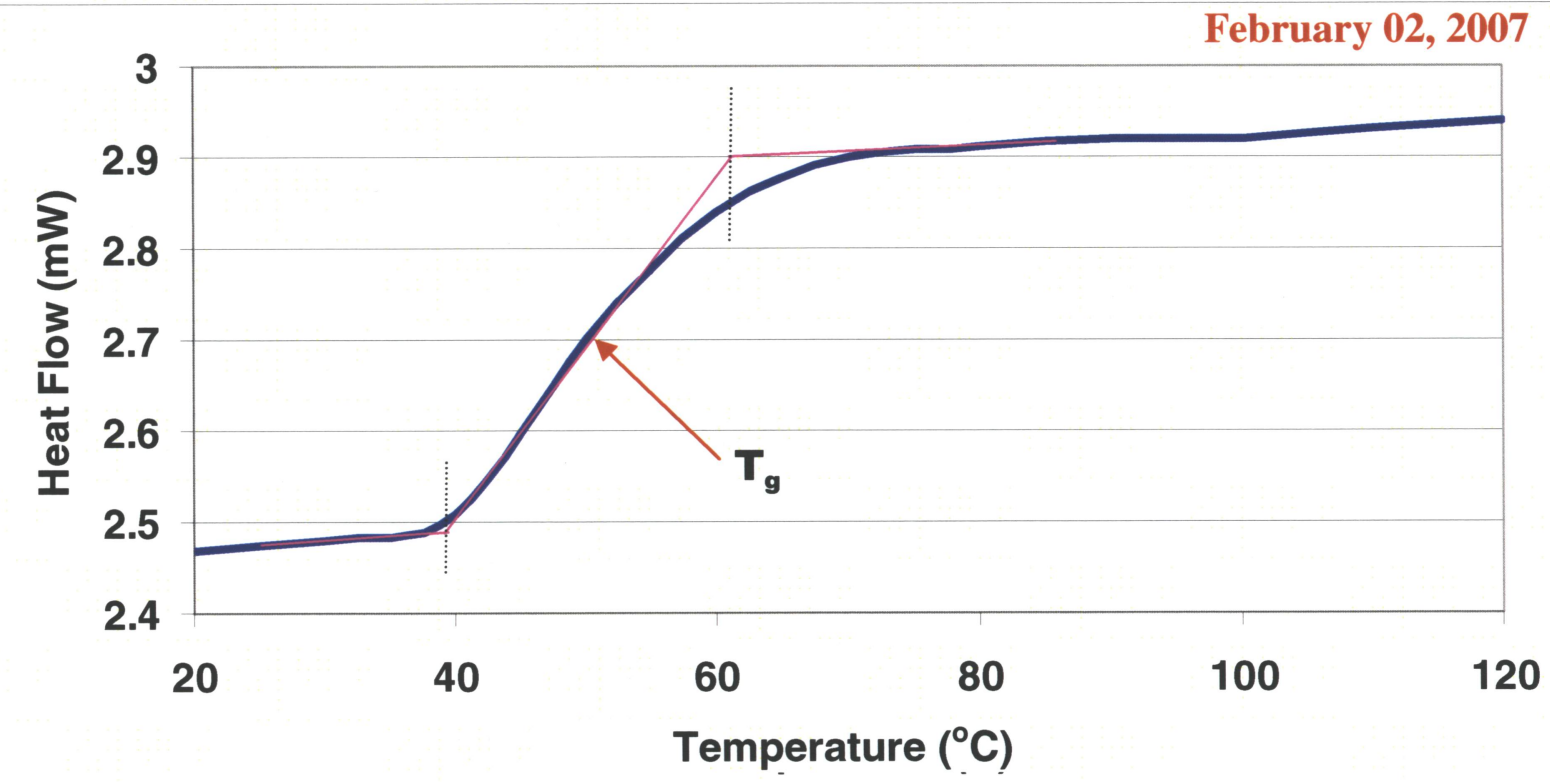

Figure 39: DSC Graph of Grade C (2 wt \% iron-based catalyst)

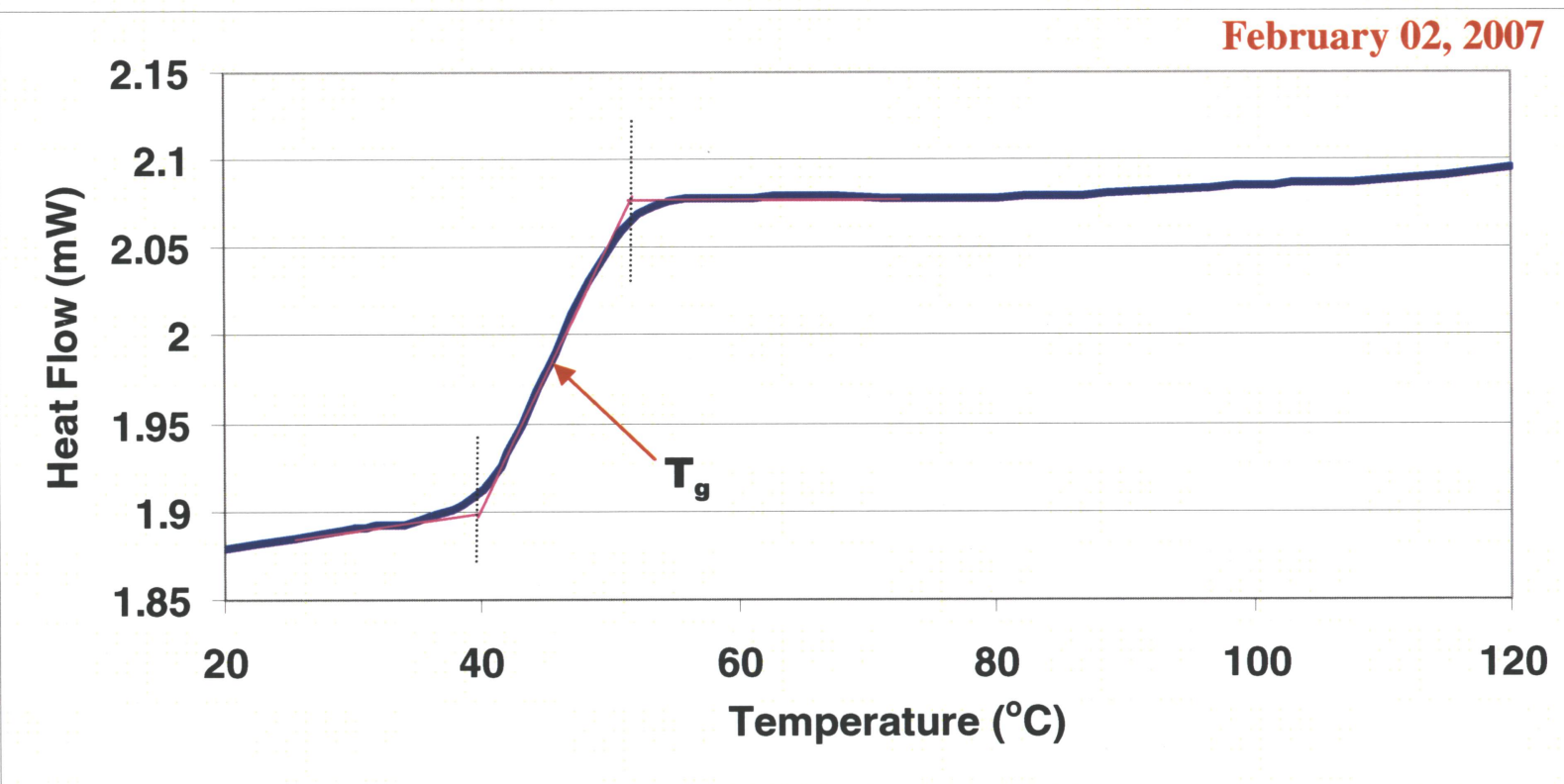

Figure 40: DSC Graph of Grade D (1 wt \% silica-alumina and $1 \mathrm{wt} \%$ iron-based catalyst) 
Table 8: Glass Transition Temperature for Grades A, B, C and D

\begin{tabular}{||l||c||}
\hline \multicolumn{1}{|c||}{ Samples } & Glass Transition Temperature, $\mathbf{T}_{\mathbf{g}}{ }^{\mathbf{0}} \mathbf{C}$ ) \\
\hline \hline Grade A (no additive) & $69 \pm 1$ \\
\hline \hline Grade B (2 wt \% silica-alumina) & $54 \pm 1$ \\
\hline \hline Grade C (2 wt \% iron-based catalyst) & $55 \pm 1$ \\
\hline $\begin{array}{l}\text { Grade D (1 wt \% silica-alumina and 1 } \\
\text { wt \% iron-based catalyst) }\end{array}$ & $44 \pm 1$ \\
\hline
\end{tabular}

\subsubsection{TGA Analysis of Low Molecular Weight Polystyrene with Additives}

TGA determines the changes in weight of a polymer with respect to temperature. TGA relies on a high degree of precision in measuring the weight and temperature [75]. The TGA graphs for Grades A, B, C and D are shown in Figures $41-44$, respectively and their $\mathrm{T}_{0}$ values (please refer to section 3.6.3) are summarized in Table 9. These TGA graphs show an initial weight loss below $200{ }^{\circ} \mathrm{C}$ and it was found that the $\mathrm{T}_{\mathrm{o}}$ values for Grades $\mathrm{B}, \mathrm{C}$ and $\mathrm{D}$ were low relative to Grade A.

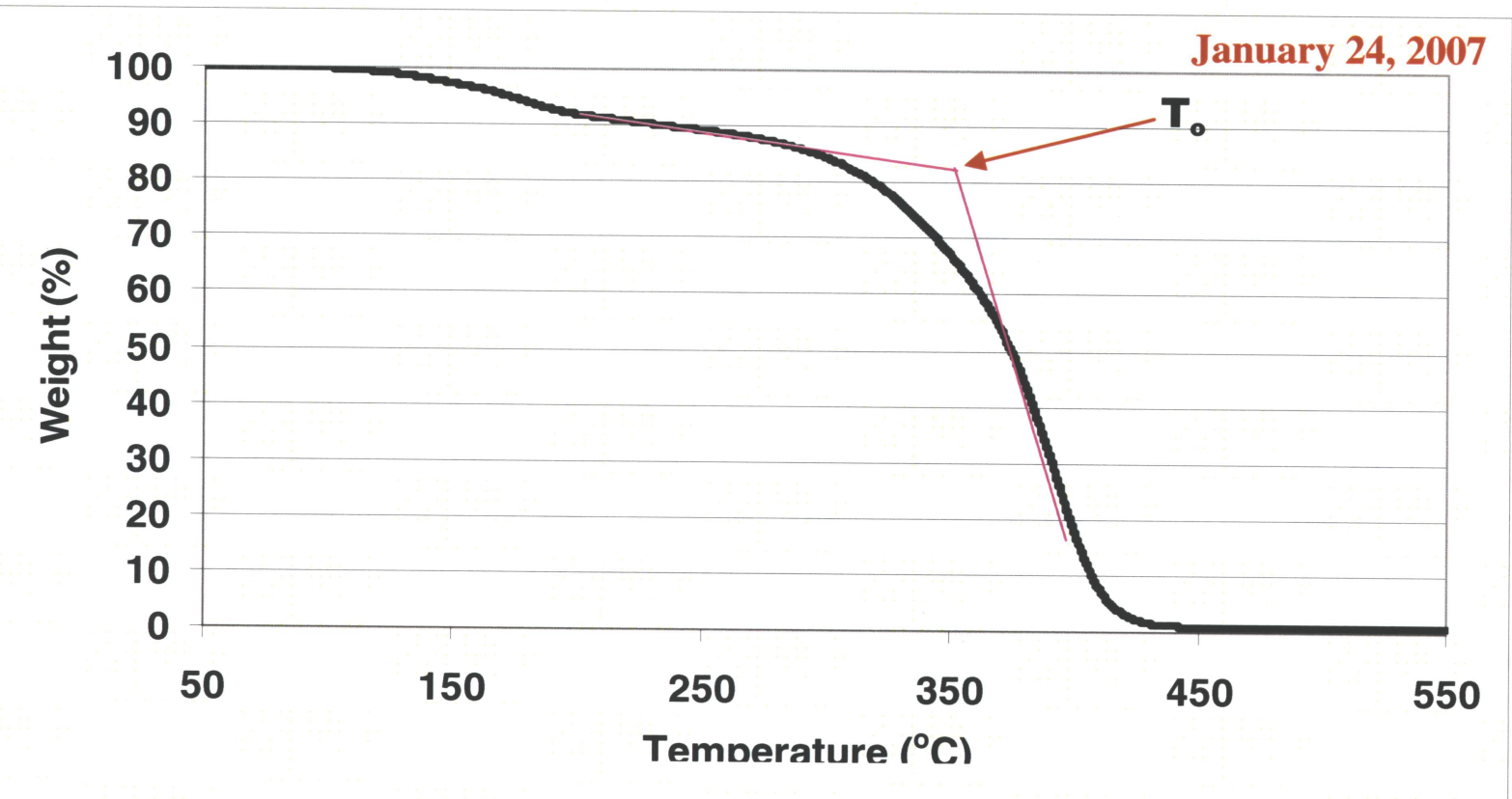

Figure 41: TGA Graph of Grade A (no additive) 


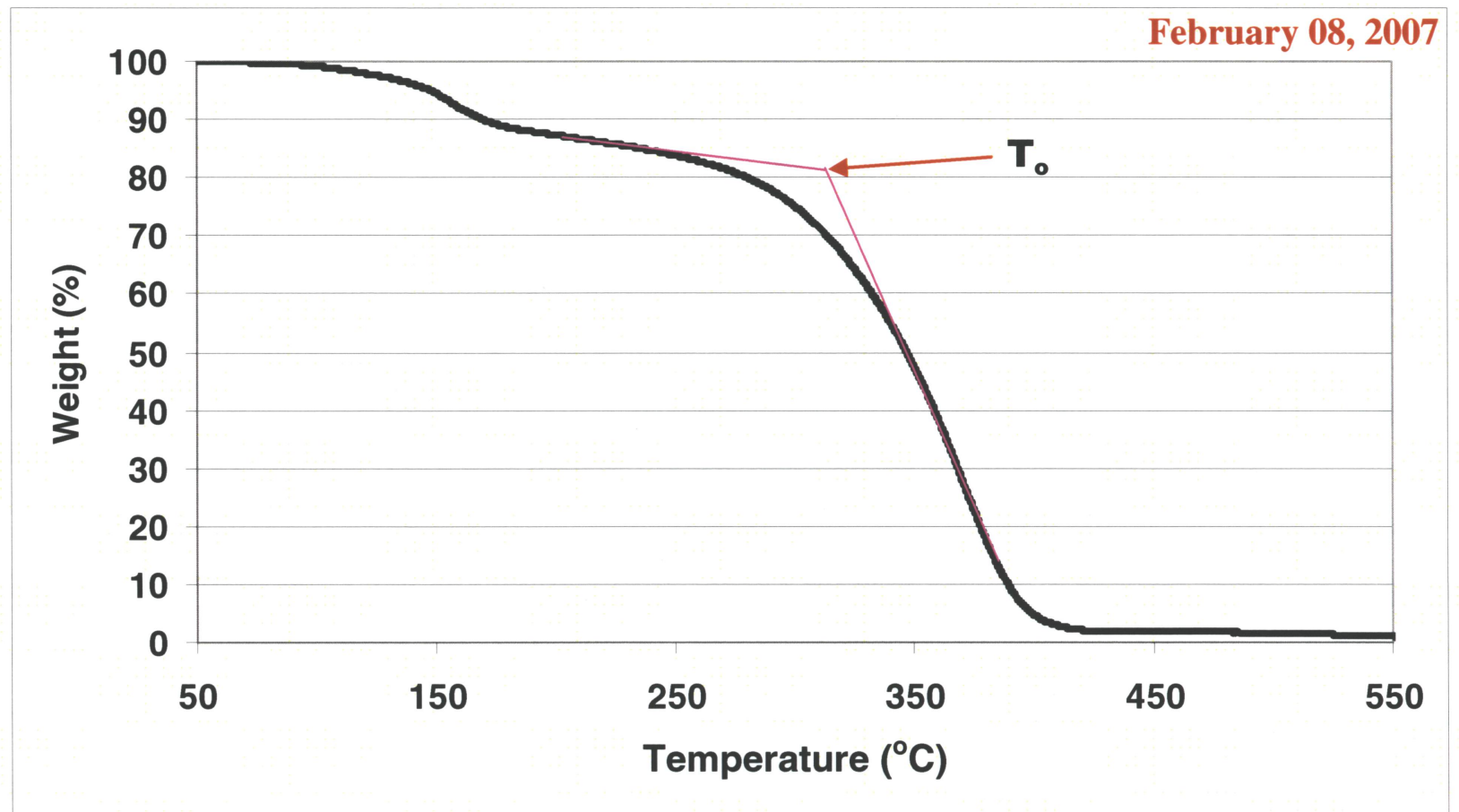

Figure 42: TGA Graph of Grade B ( 2 wt $\%$ silica-alumina)

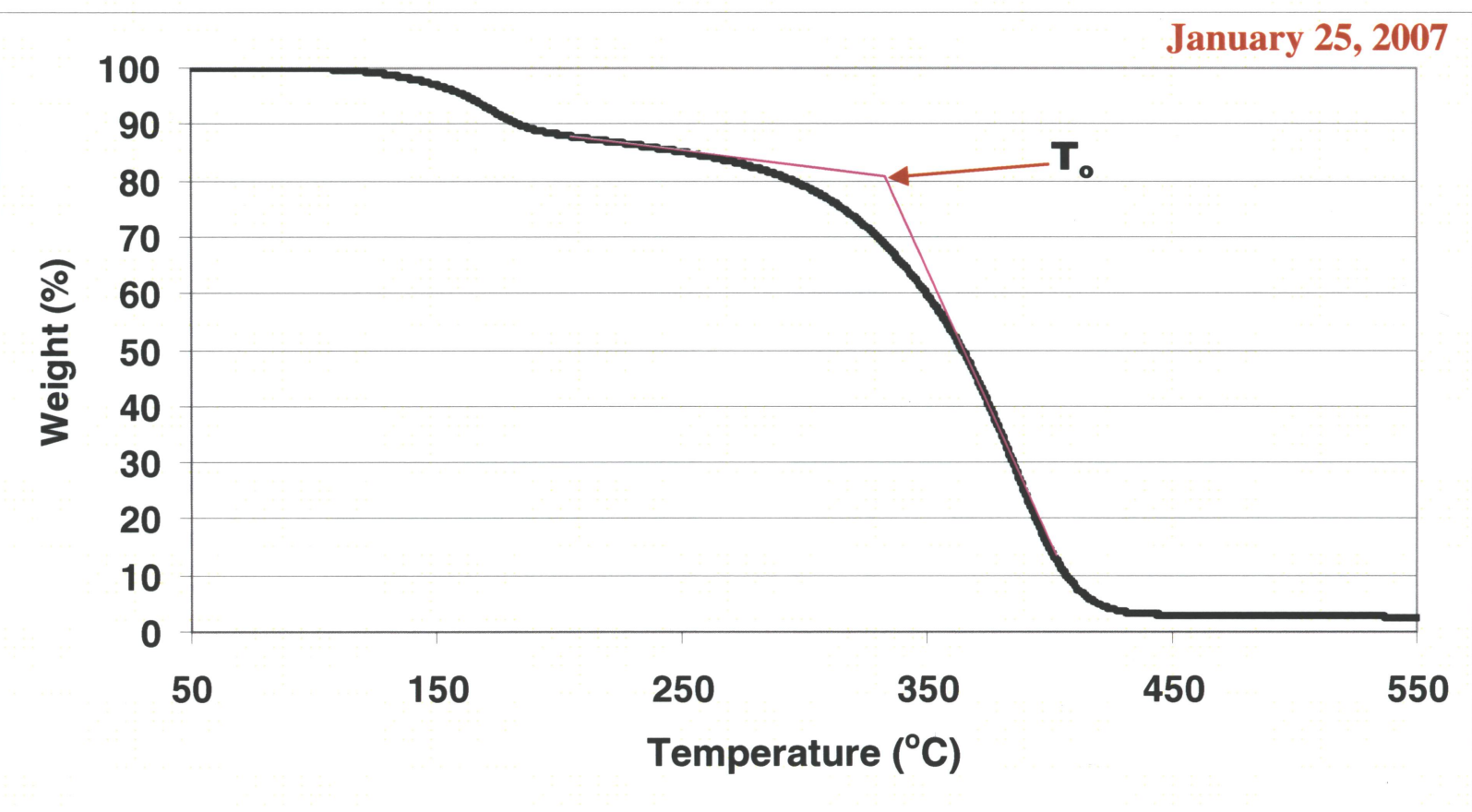

Figure 43: TGA Graph of Grade C ( 2 wt \% iron-based catalyst) 


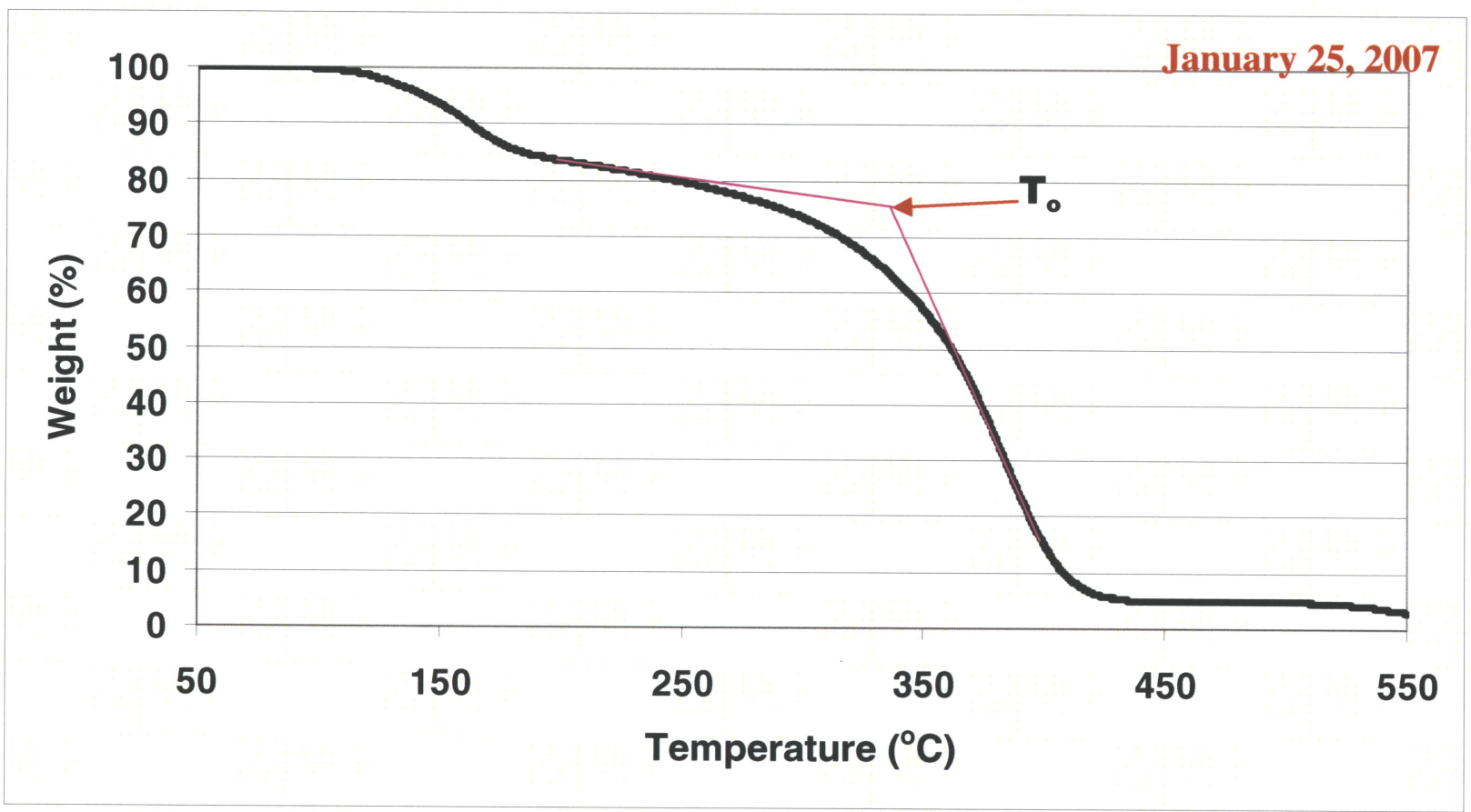

Figure 44: TGA Graph of Grade D (1 wt \% silica-alumina and $1 \mathrm{wt} \%$ iron-based catalyst)

Table 9: Onset Temperature of Degradation for Grades A, B, C and D

\begin{tabular}{||l||c||}
\hline \multicolumn{1}{|c||}{ Samples } & Onset Temperature of Degradation, $\mathbf{T}_{\mathbf{o}}\left({ }^{\mathbf{0}} \mathbf{C}\right)$ \\
\hline \hline Grade A (no additive) & $352 \pm 2$ \\
\hline \hline $\begin{array}{l}\text { Grade B (2 wt \% silica- } \\
\text { alumina) }\end{array}$ & $332 \pm 2$ \\
\hline $\begin{array}{l}\text { Grade C (2 wt \% iron-based } \\
\text { catalyst) }\end{array}$ & $338 \pm 2$ \\
\hline $\begin{array}{l}\text { Grade D (1 wt \% silica- } \\
\text { alumina and } 1 \text { wt \% iron- } \\
\text { based catalyst) }\end{array}$ & $341 \pm 2$ \\
\hline
\end{tabular}




\subsection{Results in the Production of High Molecular Weight Polystyrene}

\subsubsection{Effect of Reaction Time on Molecular Weight}

The mass of the agglomerate consisted of the very large beads (>1680 microns) and large particles in the screen (U.S. Sieve No. 12). Some polystyrene beads, which were glued to the stirring rod (Figure 45), blade (Figure 46), reactor flask (Figure 47) and the thermowell (Figure 48), were not accounted for, while measuring the mass of the agglomerate.

The mass of the LFC, CUP and agglomerate (please refer to section 3.4) were recorded as given in Table 10. It was found that the total mass (or amount) of Grades A2, A3 and A4 were relatively higher than Grade A1. It was also found that the mass of agglomerates for these grades were low relative to Grade A. SEM images of LFC, CUP and agglomerate are shown in Figures $49-51$, respectively.

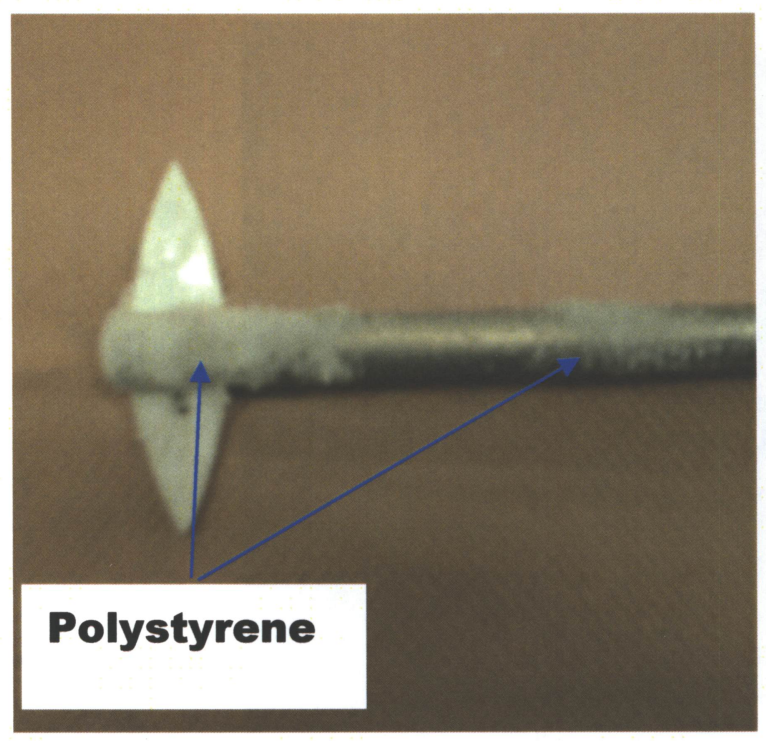

Figure 45: Polystyrene Glued to Rod

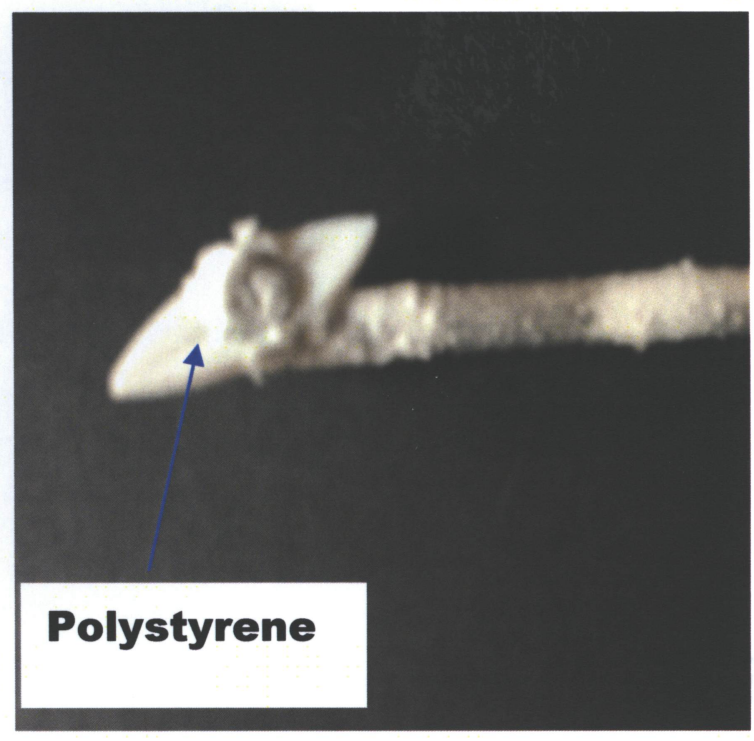

Figure 46: Polystyrene Glued to Blade 


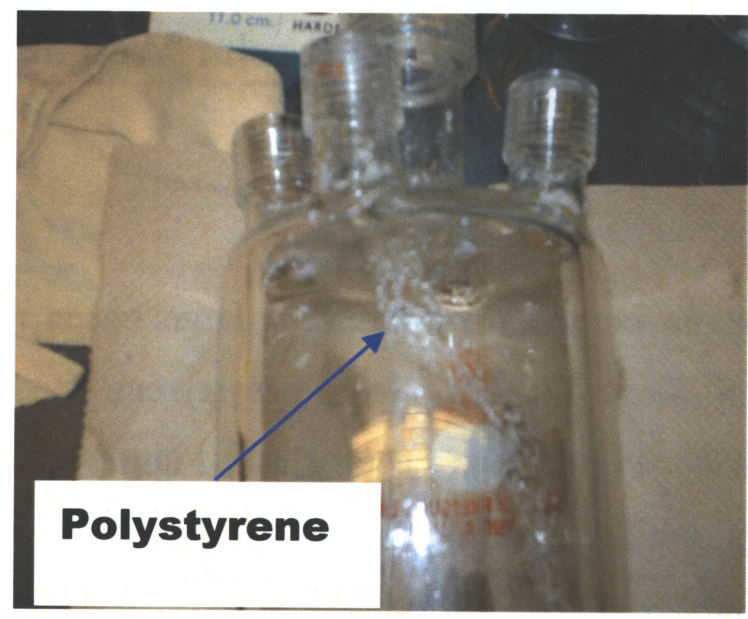

Figure 47: Polymer Trapped in Flask

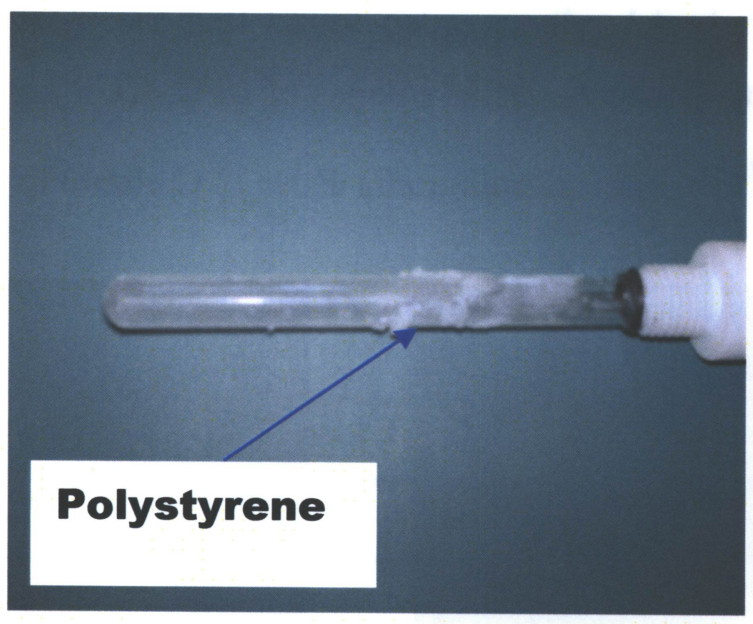

Figure 48: Polymer Glued to Thermowell

Table 10: Mass Distribution of Bead Sizes for Different Reaction Time

\begin{tabular}{|l|c|c|c|c|}
\hline \multirow{2}{*}{ Type } & \multicolumn{4}{|c|}{ GRADE } \\
\cline { 2 - 5 } & A1 (3 hrs) & A2 (4 hrs) & A3 (6 hrs) & A4 (8 hrs) \\
\hline LFC (g) & 5.87 & 6.72 & 3.77 & 4.98 \\
\hline CUP (g) & 8.75 & 19.79 & 27.39 & 30.84 \\
\hline Agglomerate (g) & 13.86 & 4.92 & 4.71 & 4.53 \\
\hline
\end{tabular}




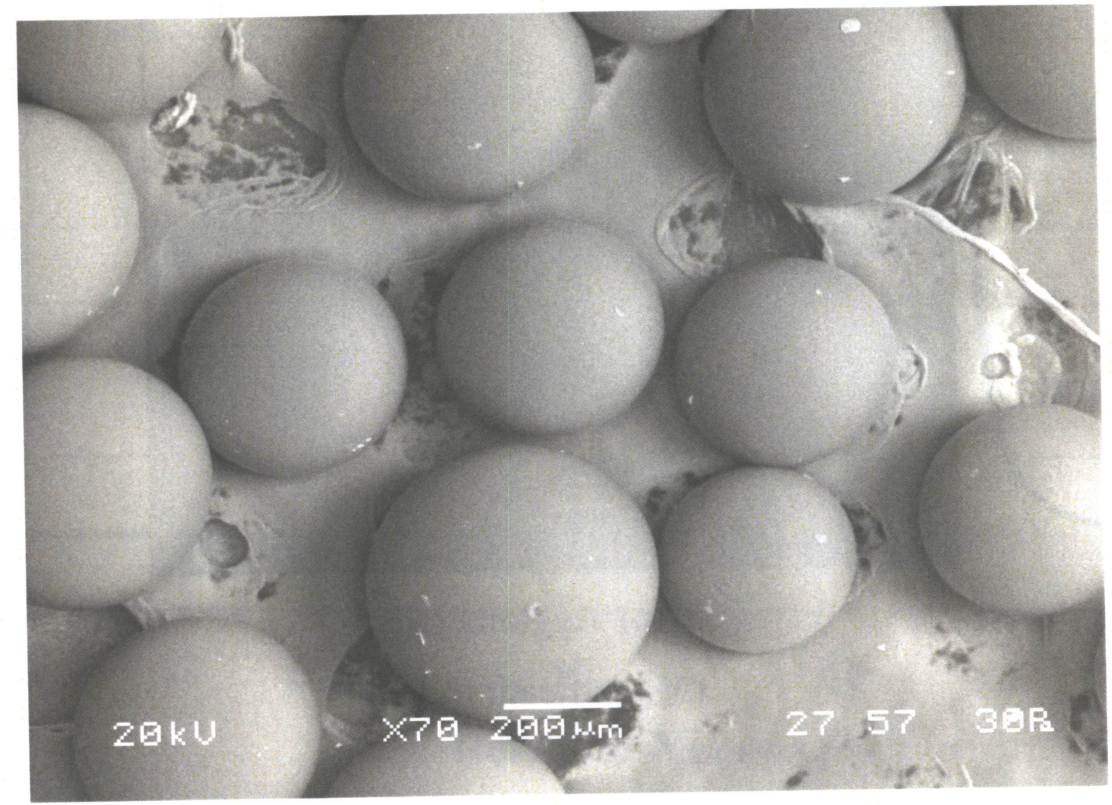

Figure 49: SEM Image of LFC Beads (bead diameter: 150 - 595 microns) (Magnification: 70X)

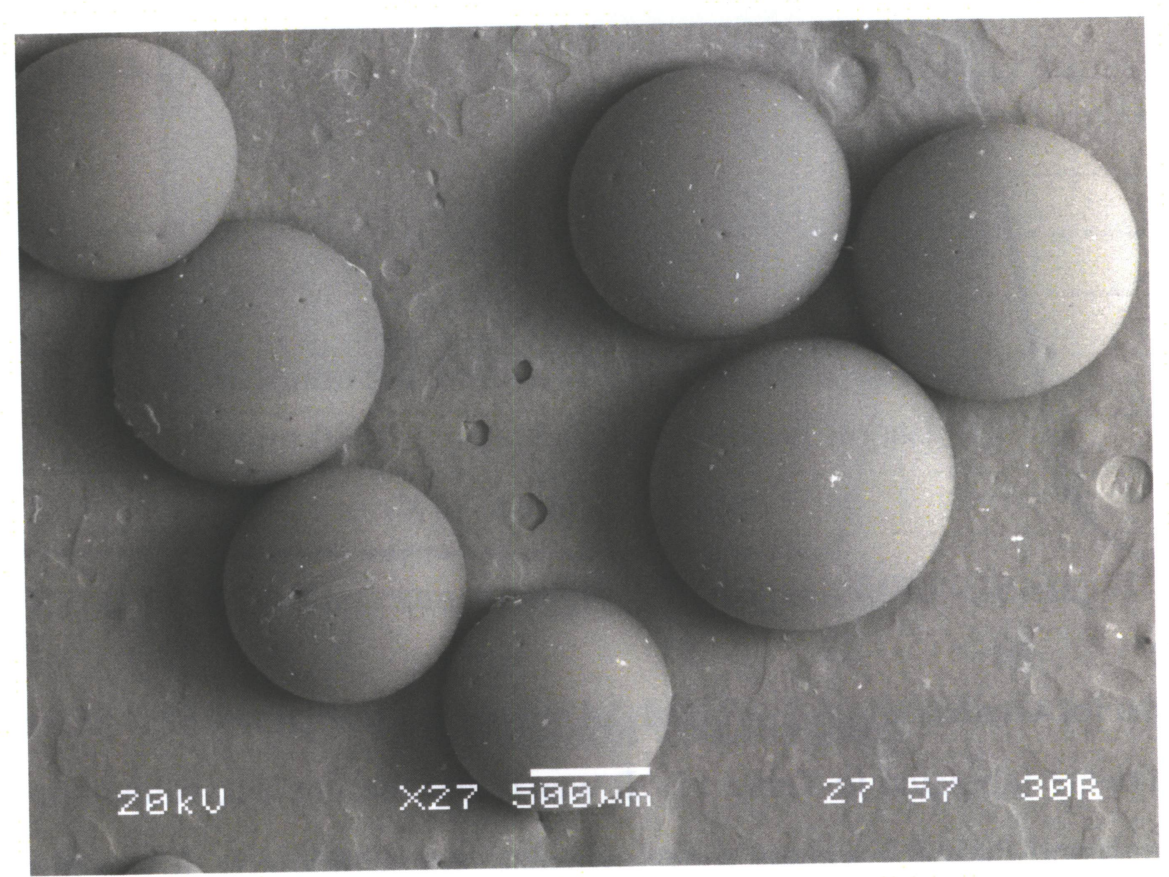

Figure 50: SEM Image of CUP Beads (bead diameter: 595 - 1680 microns) (Magnification: 27X) 


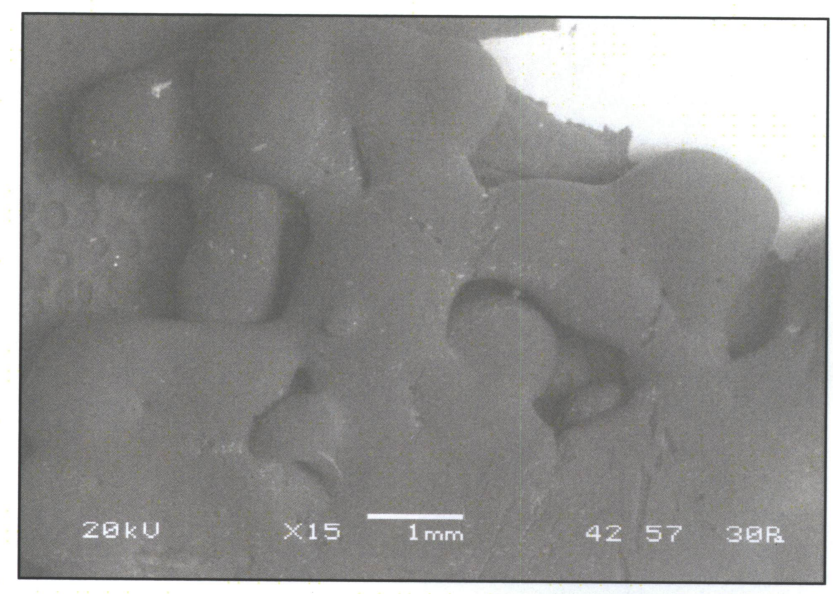

(a) Agglomerate

(Magnification: 15X)

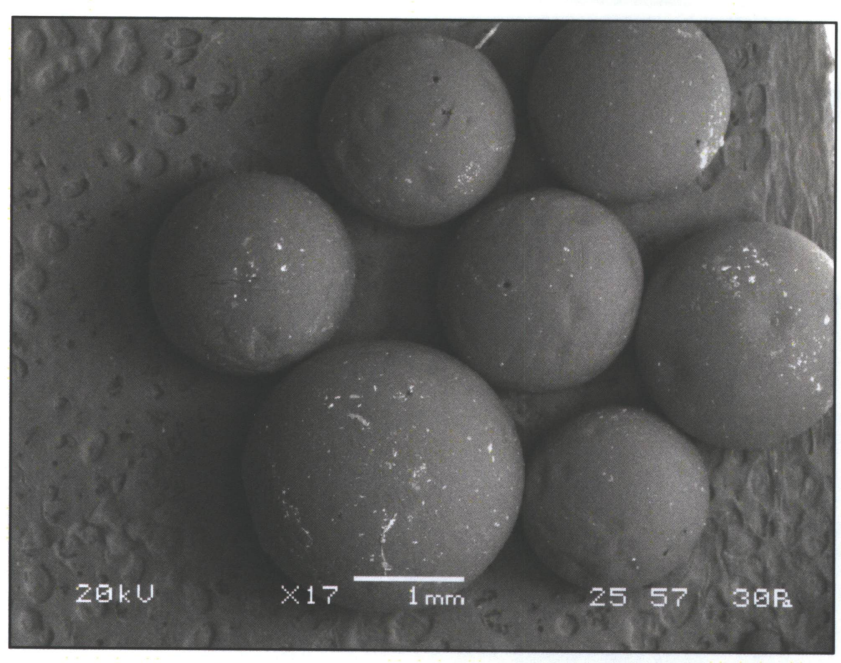

(b) Larger Beads (bead diameter: > 1680 microns)

(Magnification: 17X)

Figure 51: SEM Images of (a) Agglomerate and (b) Larger Beads

The GPC graphs for Grades A1, A2, A3 and A4 are shown in Figures 52 - 55, respectively, and their GPC results are tabulated in Table 11. It was found that the $\mathrm{M}_{\mathrm{w}}$ values for Grades A2, A3 and A4 were high and their RV values were low relative to Grade A1. It was also found that the PDI for all the grades was in the range of $2.209-2.801$, as expected for suspension polymerization [15]. 


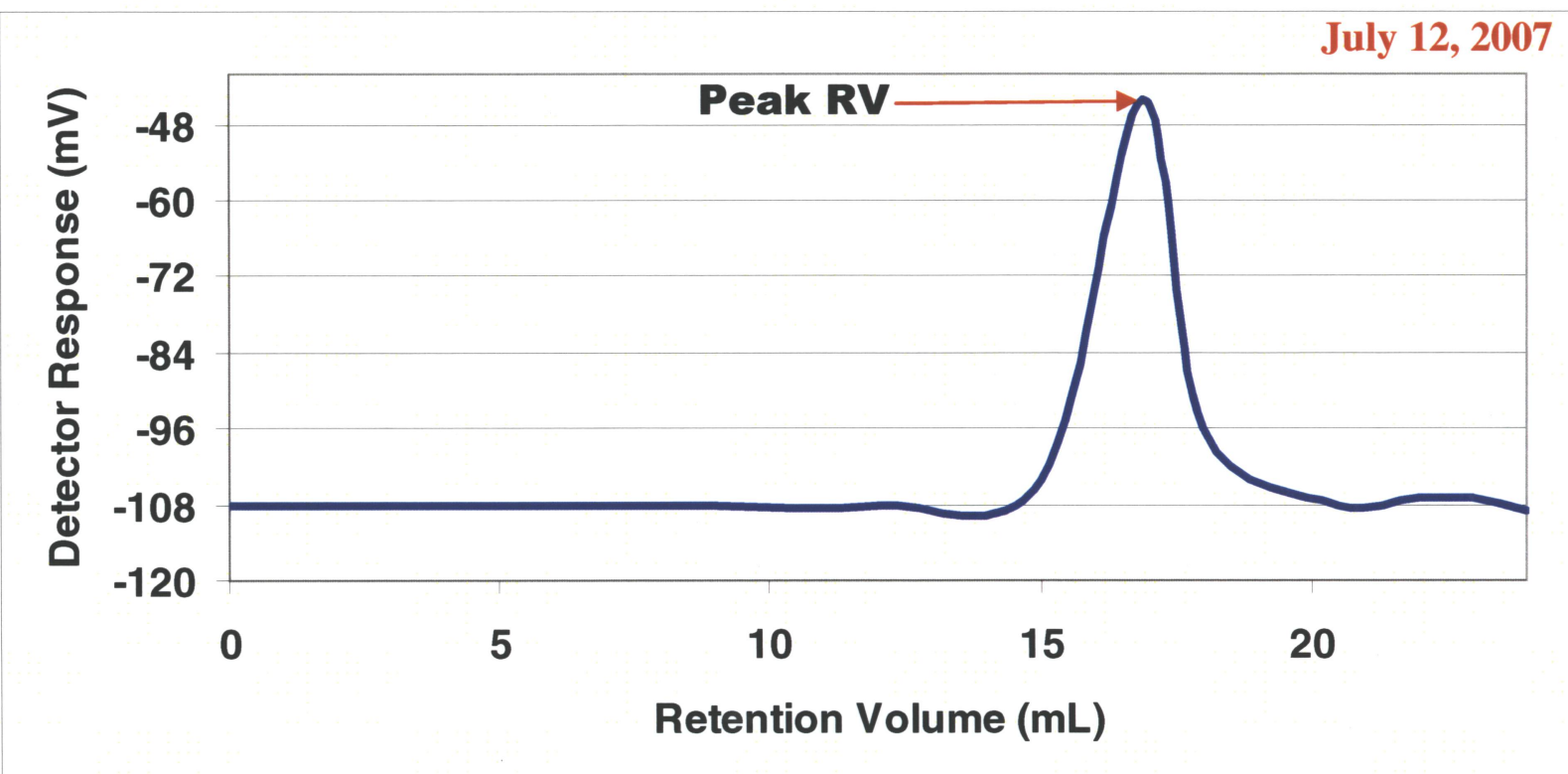

(a) LFC (bead diameter: 150 - 595 microns)

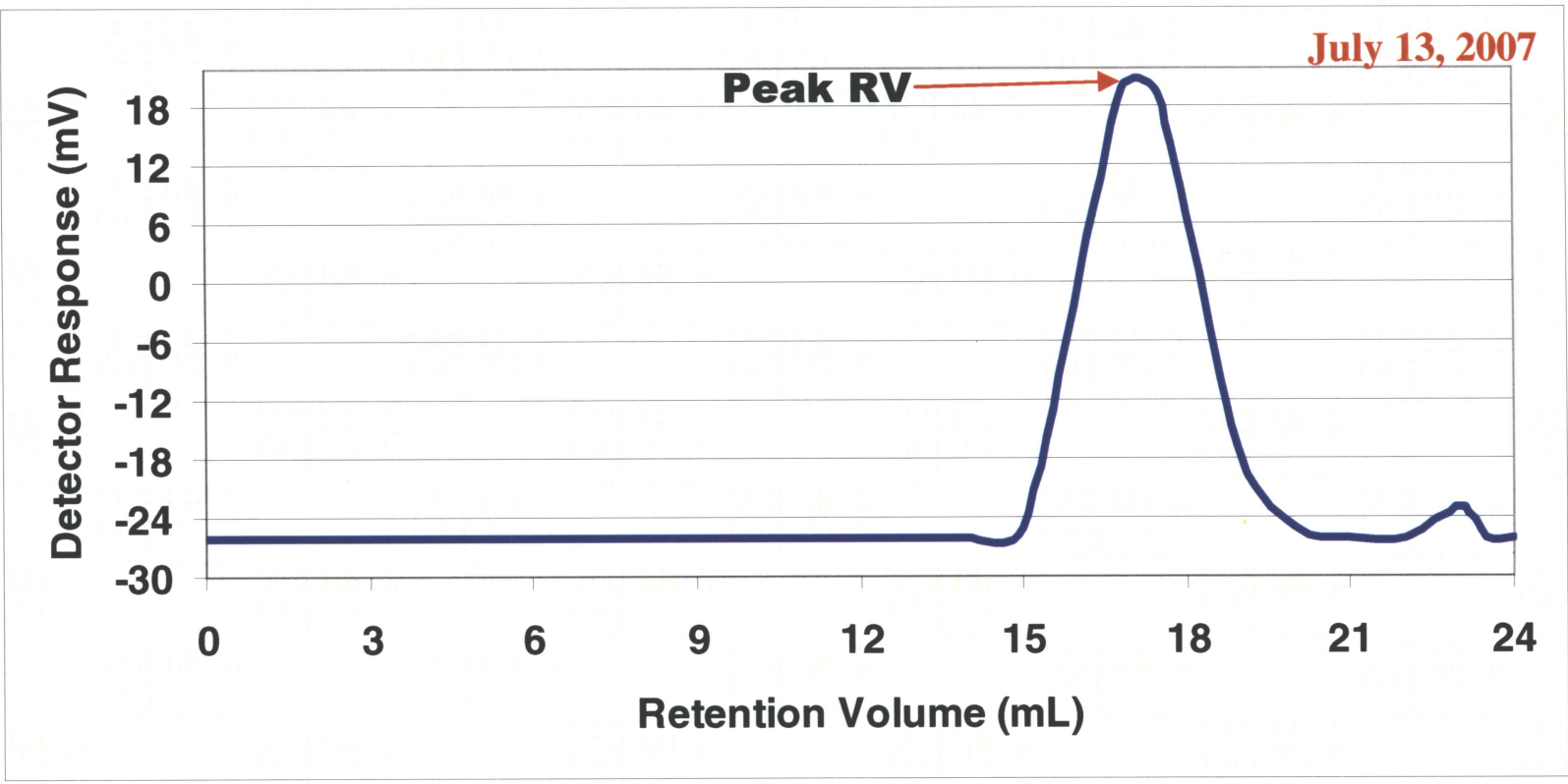

(b) CUP (bead diameter: 595 - 1680 microns)

Figure 52: GPC Graph of Grade A1 (3 hrs) 


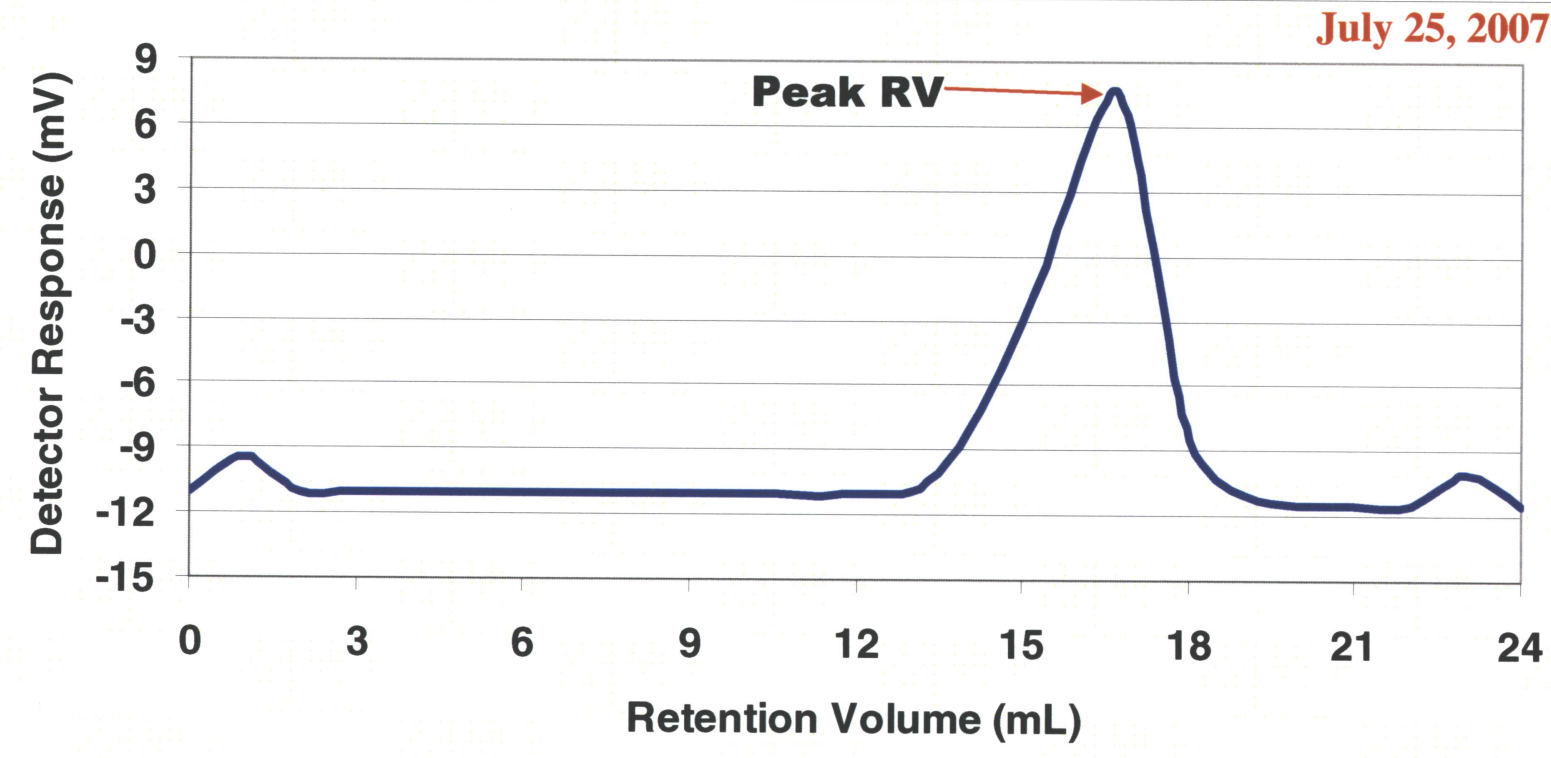

(a) LFC (bead diameter: $150-595$ microns)

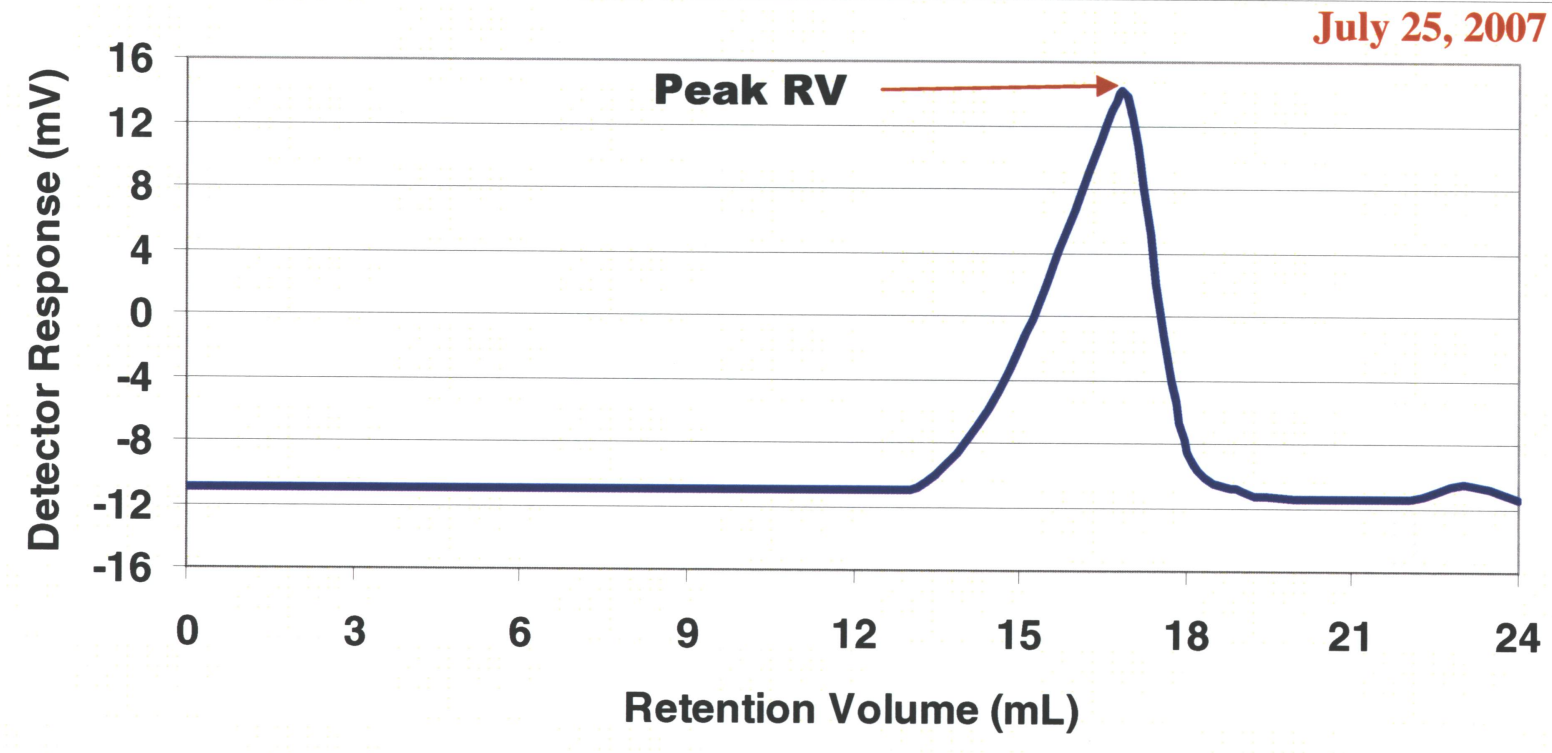

(b) CUP (bead diameter: 595 - 1680 microns)

Figure 53: GPC Graph of Grade A2 (4 hrs) 


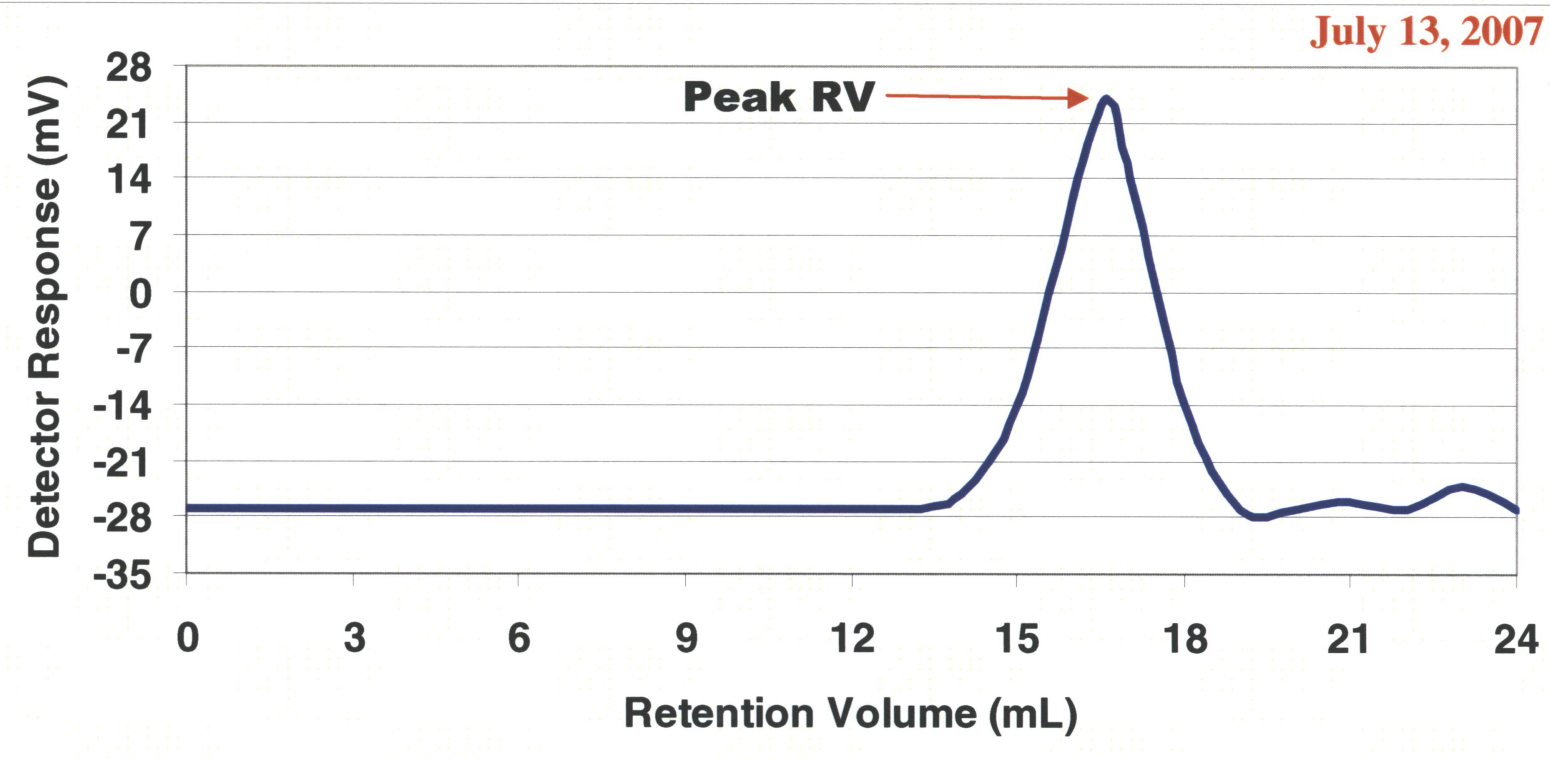

(a) LFC (bead diameter: $150-595$ microns)

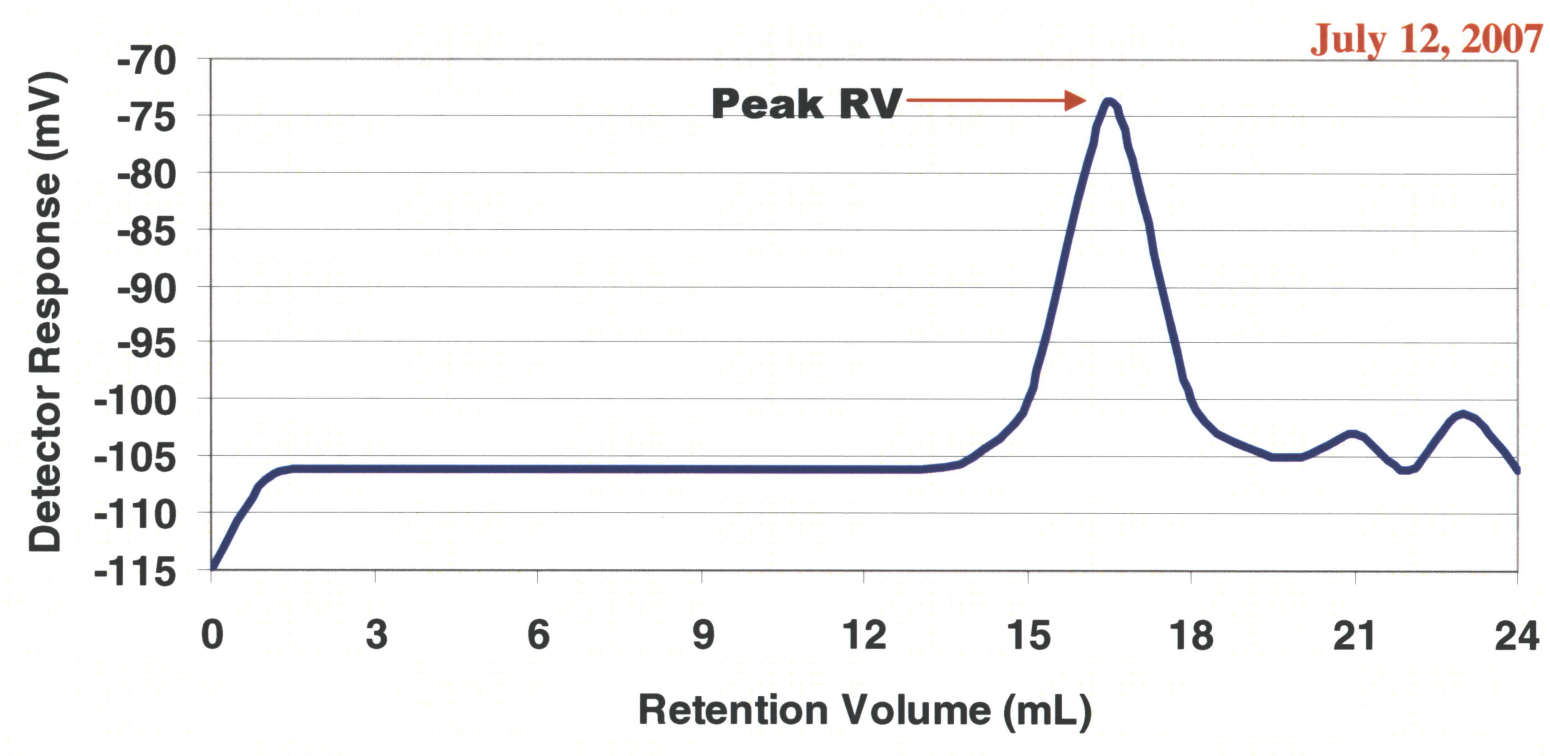

(b) CUP (bead diameter: 595 - 1680 microns)

Figure 54: GPC Graph of Grade A3 (6 hrs) 


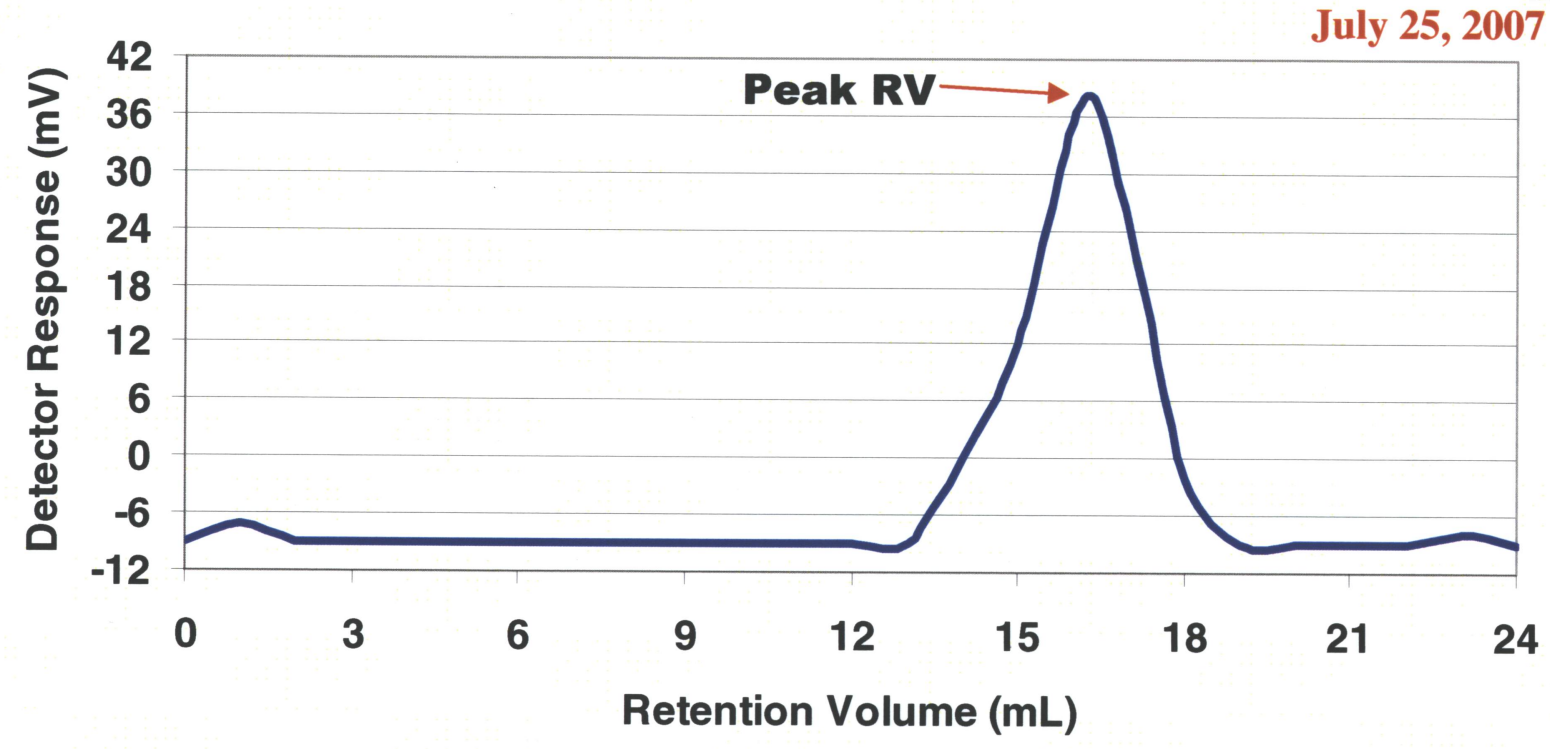

(a) LFC (bead diameter: 150 - 595 microns)

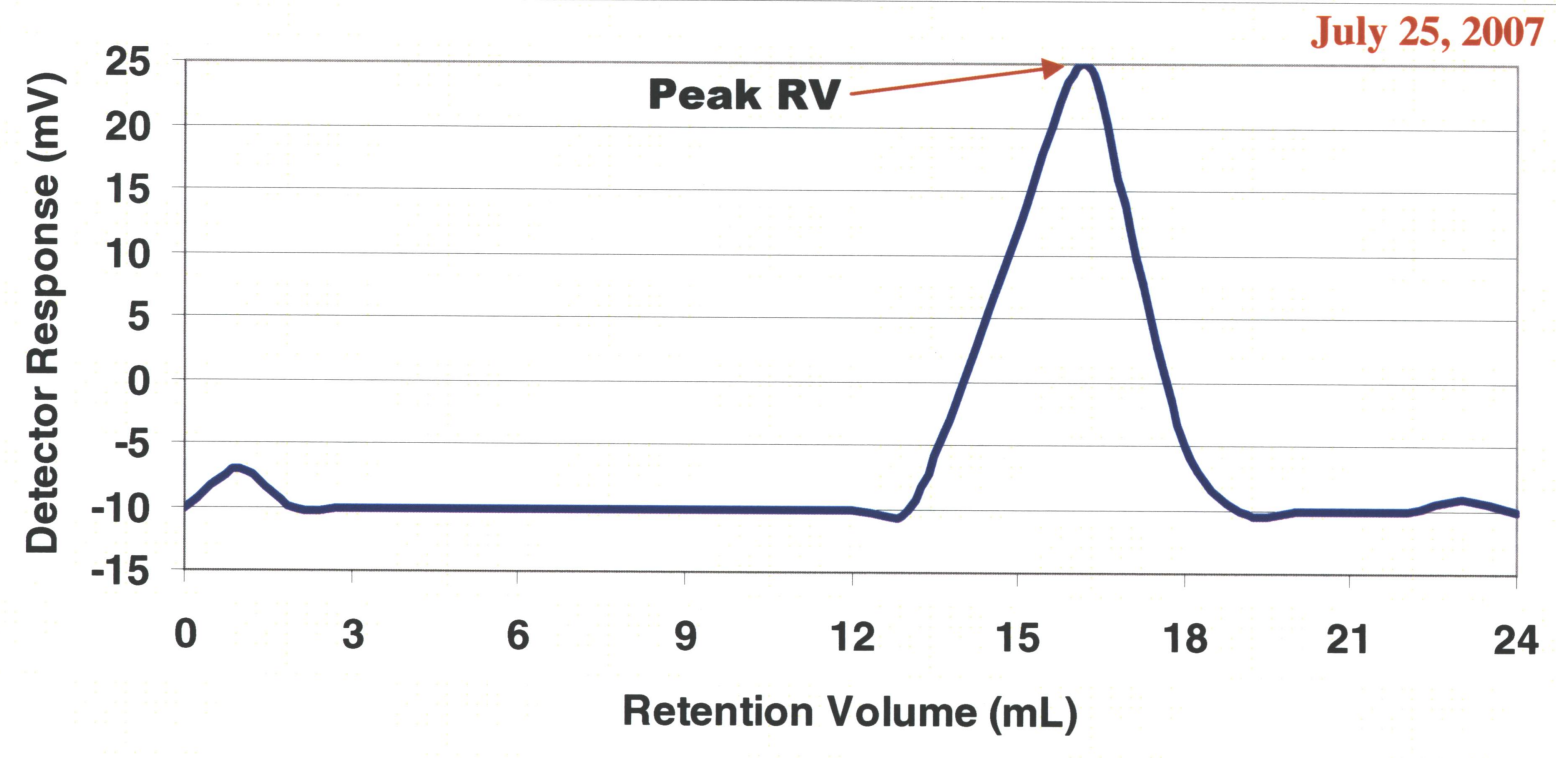

(b) CUP (bead diameter: 595 - 1680 microns)

Figure 55: GPC Graph of Grade A4 (8 hrs) 
Table 11: GPC Results for Grades A1, A2, A3 and A4

\begin{tabular}{|c||c||c||c||c||}
\hline Grade & RV & $\mathbf{M}_{\mathbf{n}}(\mathbf{D a})$ & $\mathbf{M}_{\mathbf{w}}(\mathbf{D a})$ & PDI $^{\left(\mathbf{M}_{\mathbf{w}} / \mathbf{M}_{\mathbf{n}}\right)}$ \\
\hline \hline A1 (3 hrs) - LFC & 16.894 & 28,470 & 68,253 & 2.397 \\
\hline \hline A1 (3 hrs) - CUP & 16.832 & 29,460 & 75,592 & 2.566 \\
\hline \hline A2 (4 hrs) - LFC & 16.595 & 40,313 & 104,996 & 2.605 \\
\hline \hline A2 (4 hrs) - CUP & 16.534 & 44,262 & 123,963 & 2.801 \\
\hline \hline A3 (6 hrs) - LFC & 16.512 & 43,830 & 101,363 & 2.313 \\
\hline \hline A3 (6 hrs) - CUP & 16.427 & 50,199 & 110,905 & 2.209 \\
\hline \hline A4 (8 hrs) - LFC & 16.174 & 60,539 & 155,183 & 2.563 \\
\hline \hline A4 (8 hrs) - CUP & 16.176 & 61,212 & 157,220 & 2.568 \\
\hline
\end{tabular}

\subsubsection{Effect of Mass of Initiators on Molecular Weight}

The mass for LFC, CUP and agglomerate were recorded as shown in Table 12. It was found that the mass of agglomerate for Grades A6, A7 and A8 were high relative to Grade A5. The GPC graphs for Grades A5, A6, A7 and A8 are shown in Figures 56 - 59, respectively, and their GPC results are listed in Table 13. It was found that the $M_{w}$ values for Grades $A 6, A 7$ and $A 8$ were high and their RV values were low relative to Grade A5. It was also found that the PDI for all the grades was in the range of $2.229-3.930$.

Table 12: Mass Distribution of Bead Sizes by Varying Mass of Initiators

\begin{tabular}{|l||c|c|c|c|}
\hline \multirow{2}{*}{ Type } & \multicolumn{4}{|c|}{ GRADE } \\
\cline { 2 - 5 } & A5 (0.550 g) & A6 (0.500 g) & A7 (0.450 g) & A8 (0.400 g) \\
\hline LFC (g) & 5.53 & 4.86 & 1.49 & 0.51 \\
\hline CUP $(\mathbf{g})$ & 18.51 & 15.55 & 17.17 & 14.12 \\
\hline Agglomerate (g) & 5.16 & 10.37 & 15.01 & 19.83 \\
\hline
\end{tabular}




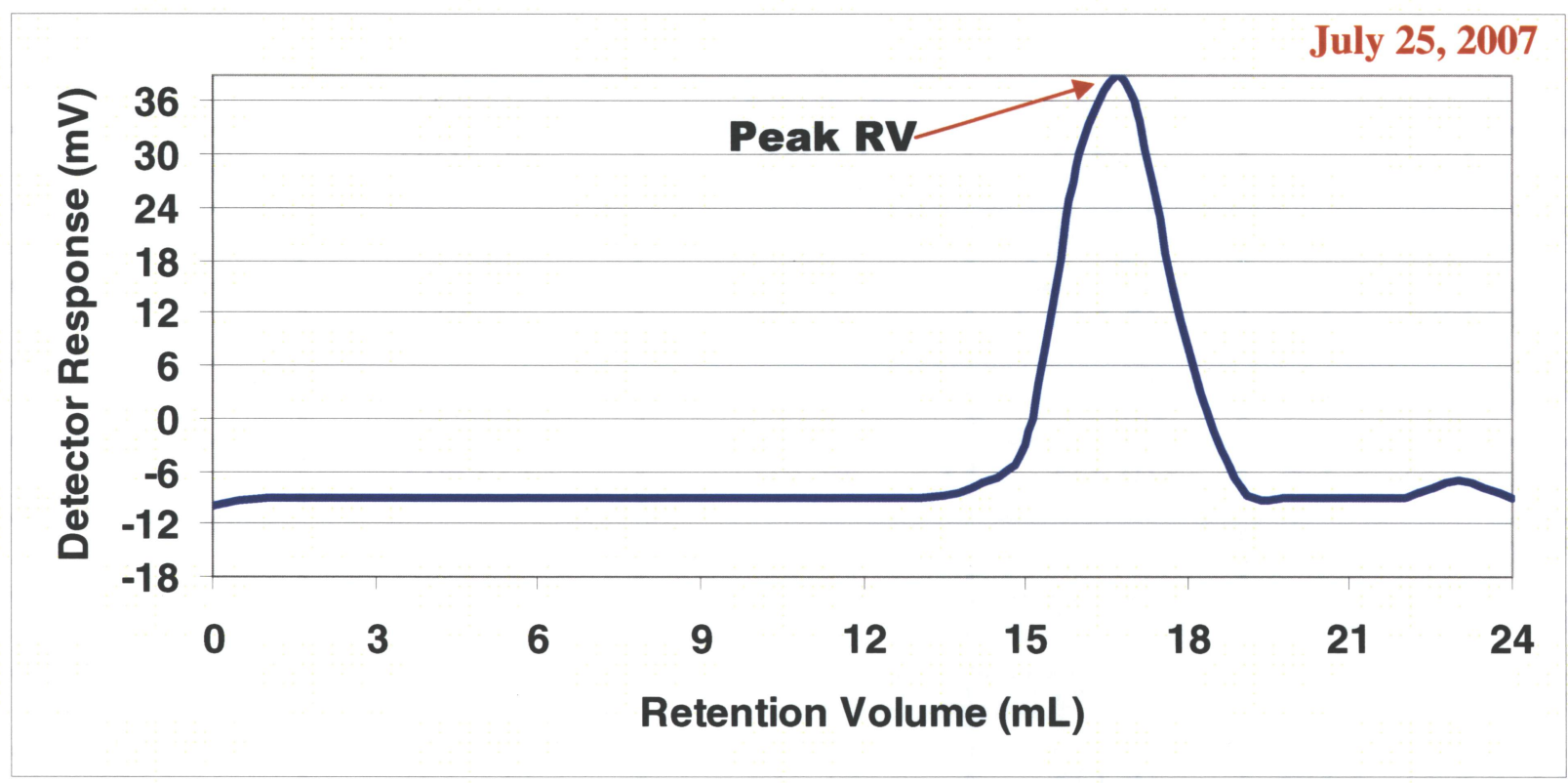

(a) LFC (bead diameter: 150 - 595 microns)

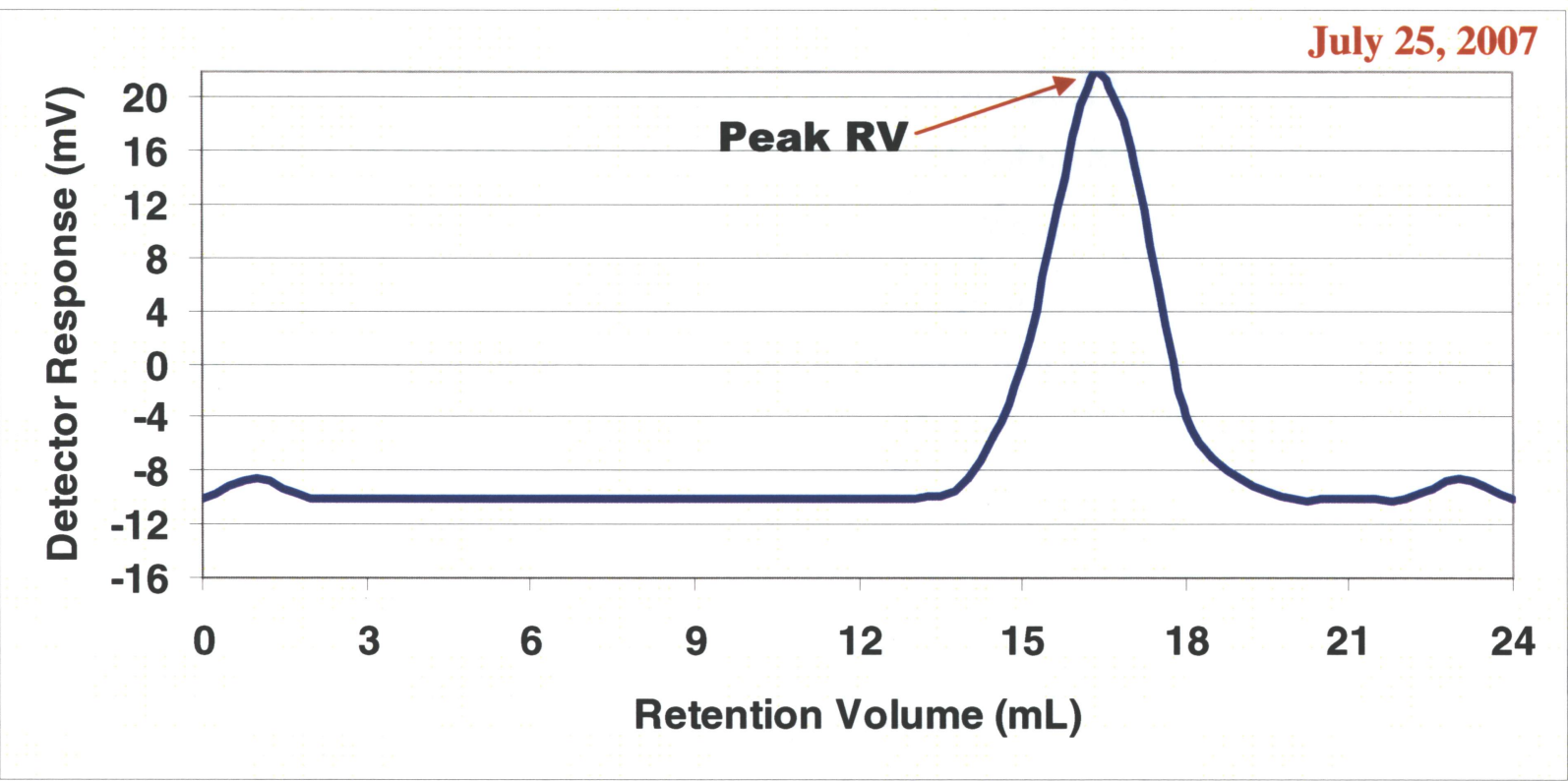

(b) CUP (bead diameter: 595 - 1680 microns)

Figure 56: GPC Graph of Grade A5 (0.550 g) 


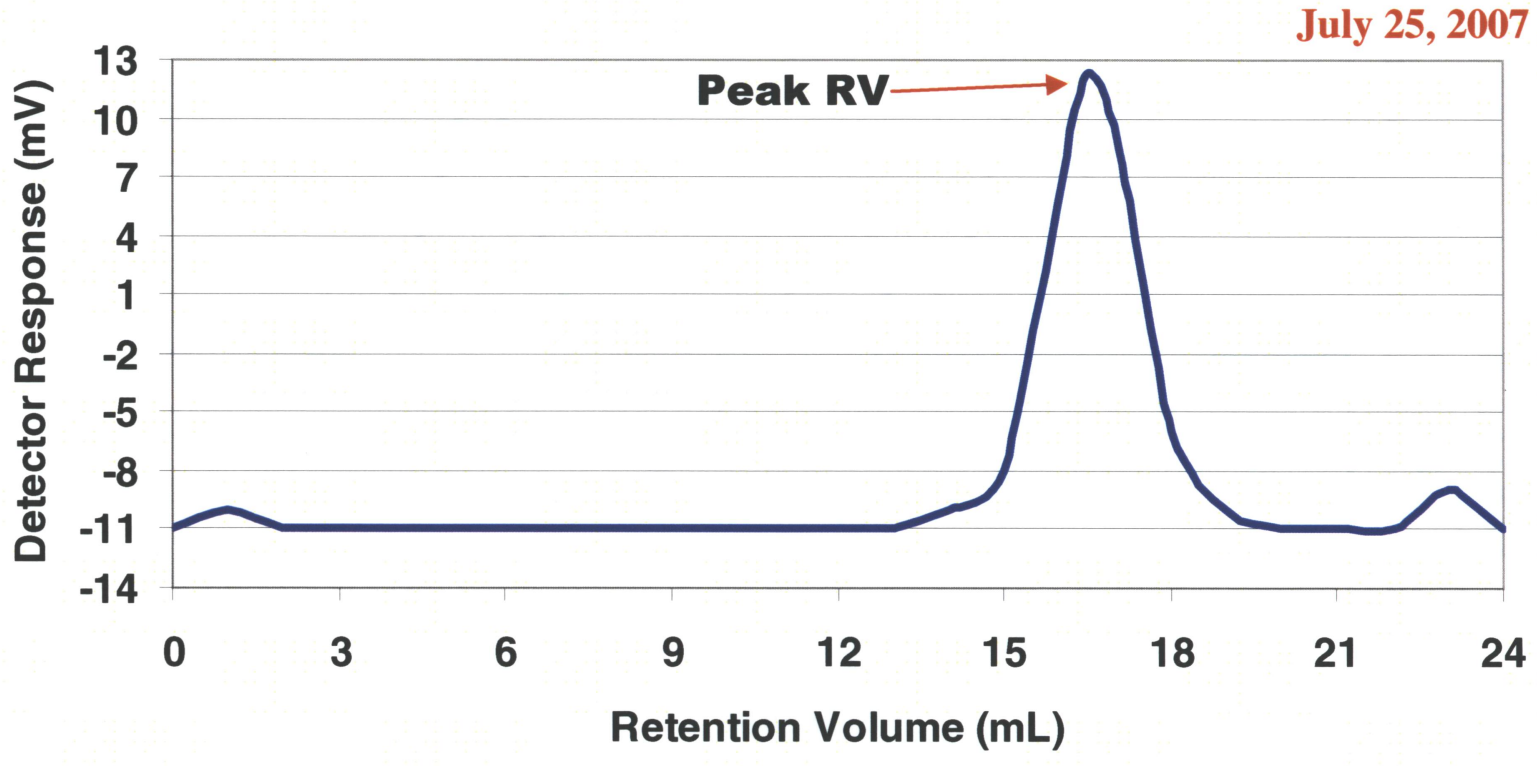

(a) LFC (bead diameter: 150 - 595 microns)

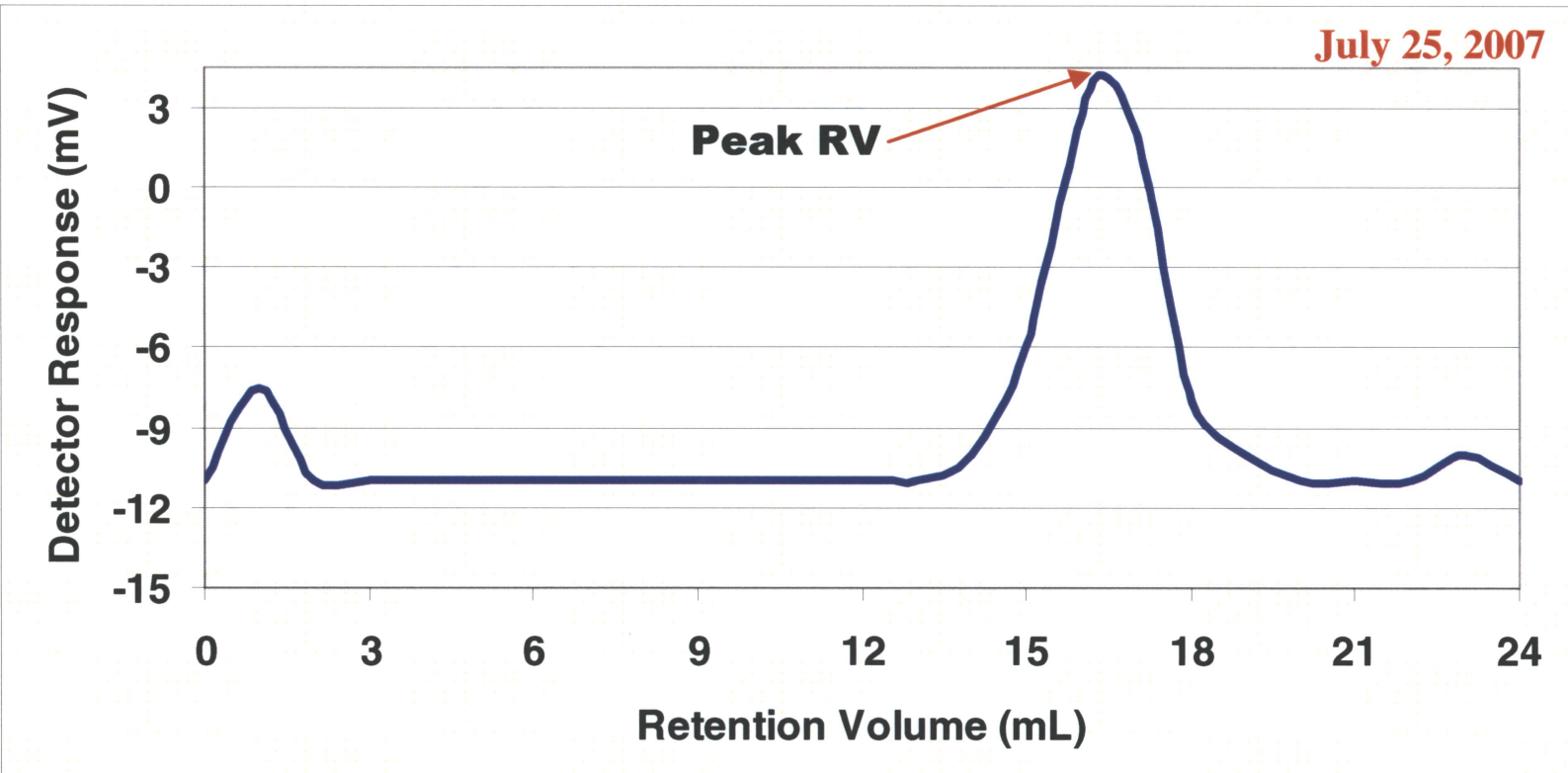

(b) CUP (bead diameter: 595 - 1680 microns)

Figure 57: GPC Graph of Grade A6 (0.500 g) 


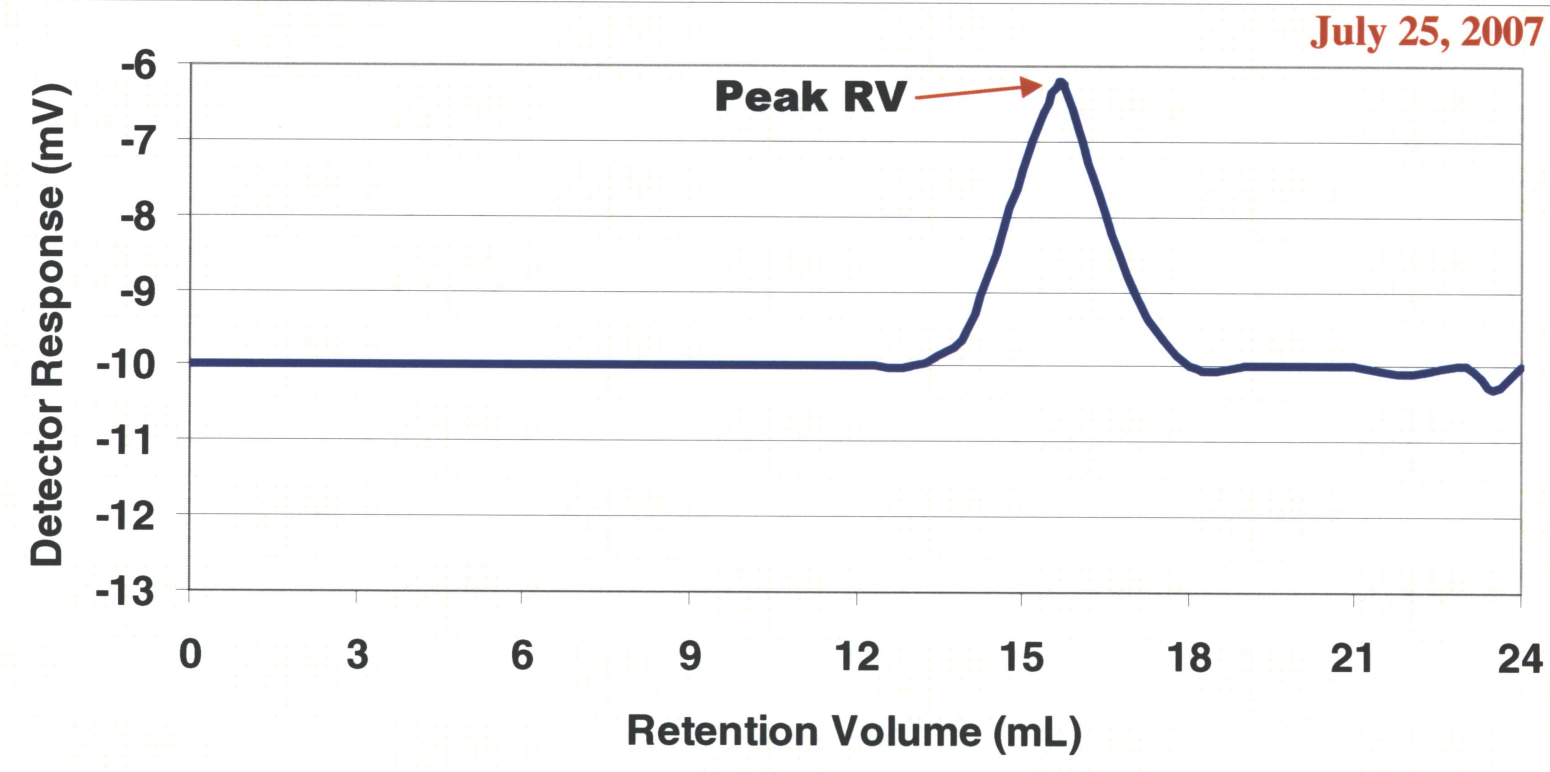

(a) LFC (bead diameter: 150 - 595 microns)

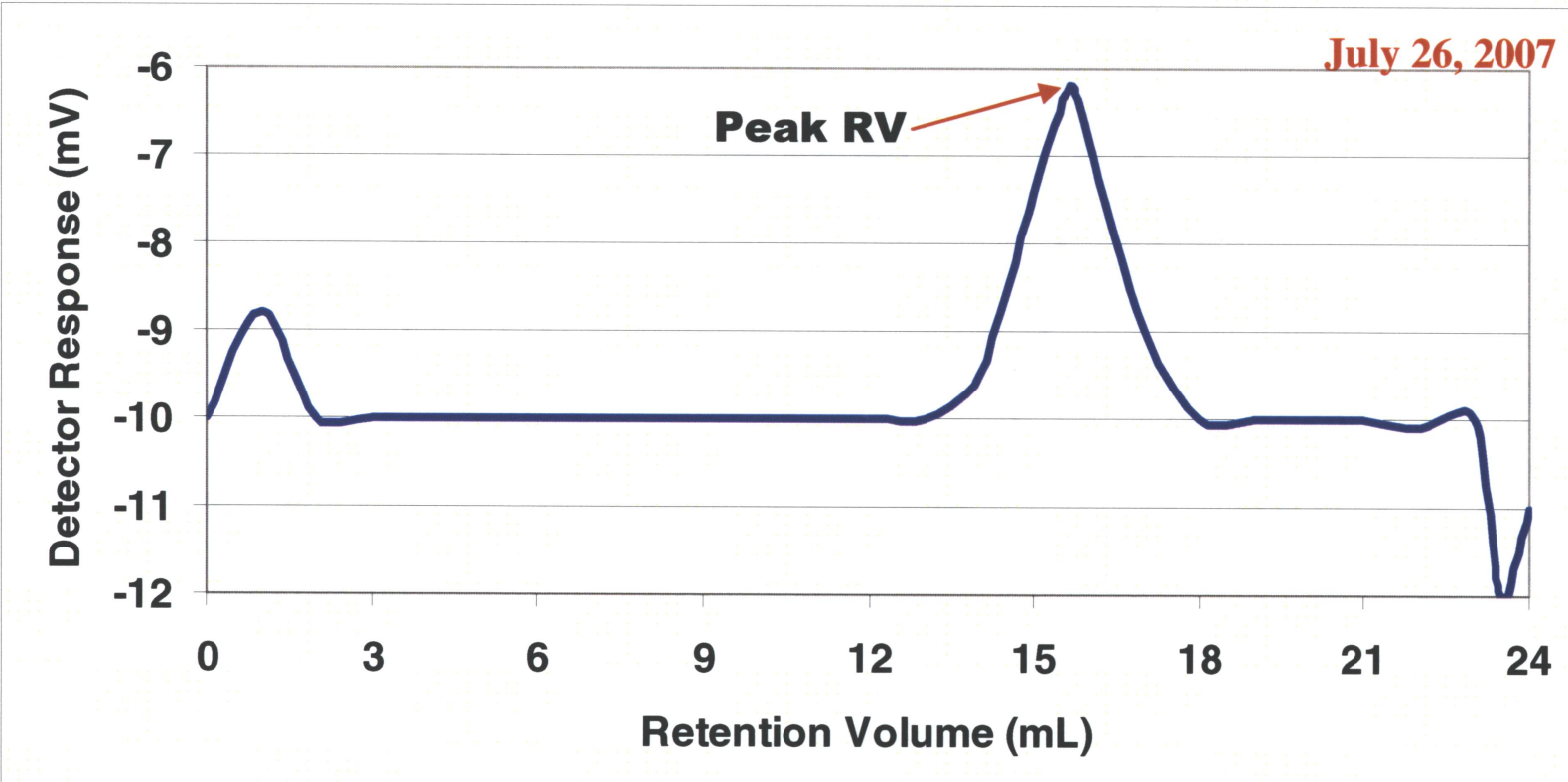

(b) CUP (bead diameter: 595 - 1680 microns)

Figure 58: GPC Graph of Grade A7 (0.450 g) 


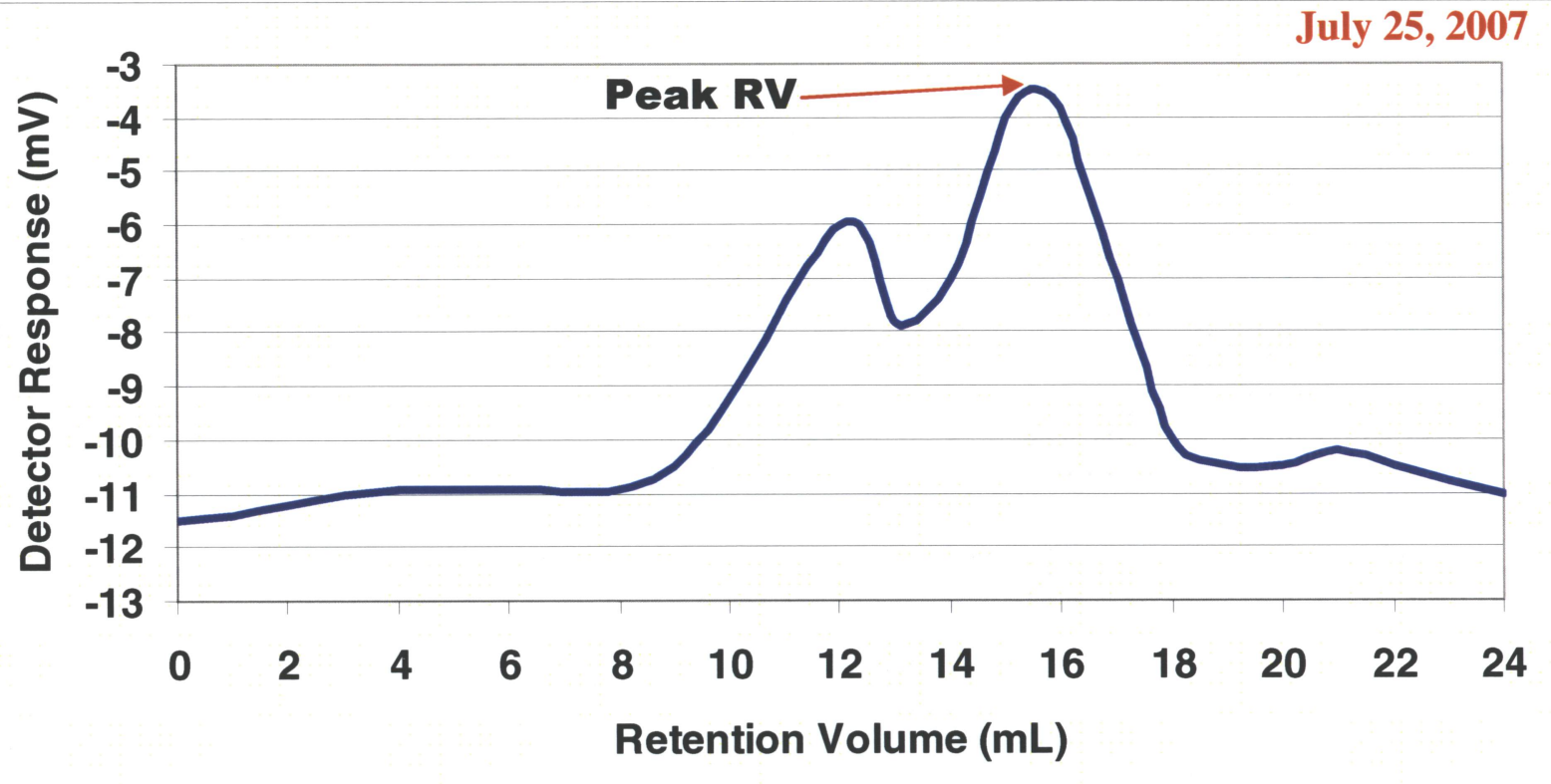

(a) LFC (bead diameter: 150 - 595 microns)

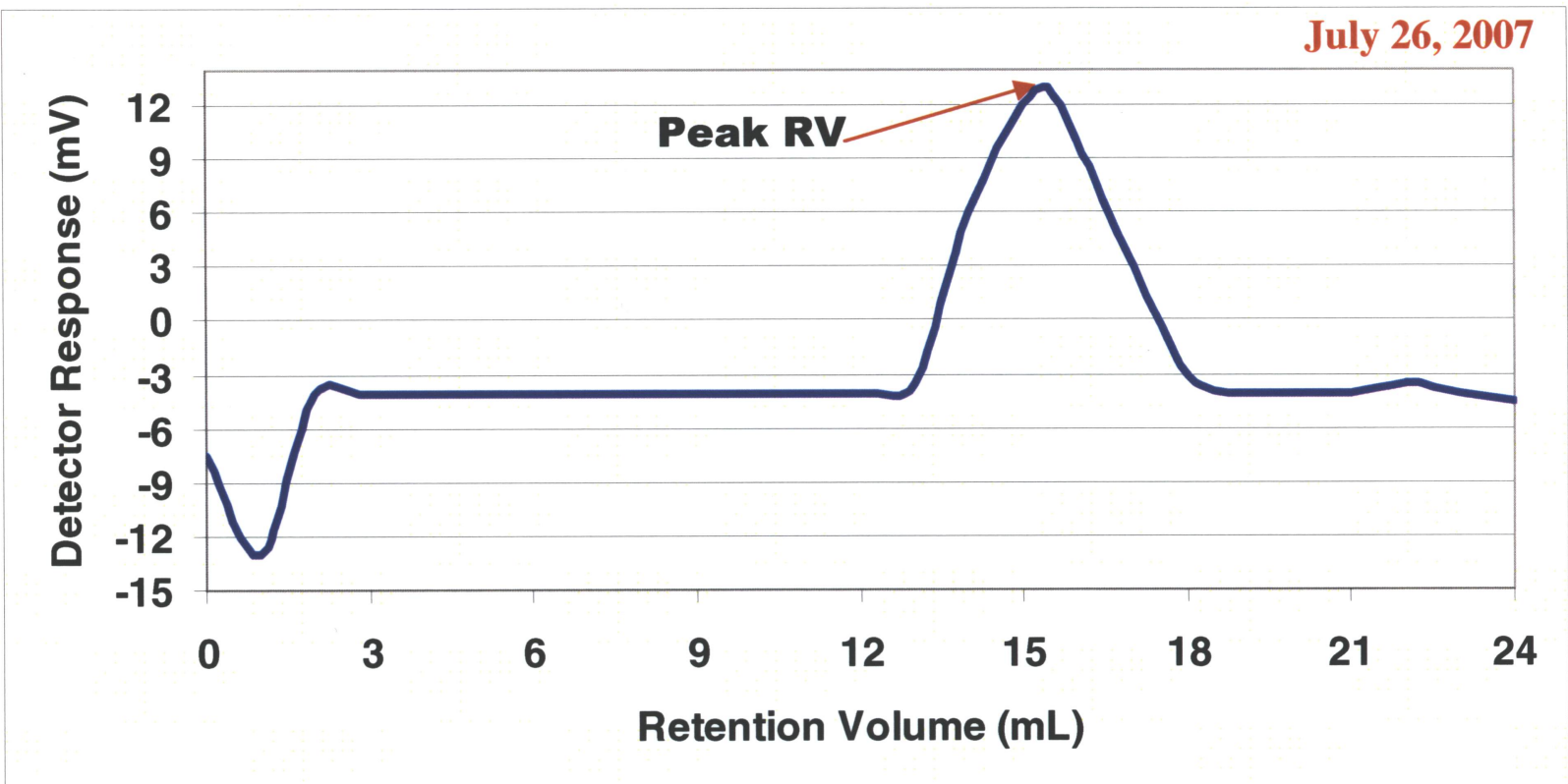

(b) CUP (bead diameter: 595 - 1680 microns)

Figure 59: GPC Graph of Grade A8 (0.400 g) 
Table 13: GPC Results for Grades A5, A6, A7 and A8

\begin{tabular}{|c|c|c|c|c|}
\hline Grade & $\overline{\mathbf{R V}}$ & $\overline{M_{n}(D a)}$ & $\overline{M_{w}(D a)}$ & $\overline{P \text { PDI }\left(M_{w} / M_{n}\right)}$ \\
\hline $\mathrm{A5}(0.550 \mathrm{~g})$ - LFC & 16.677 & 35,045 & 87,933 & 2.509 \\
\hline A5 (0.550 g) - CUP & 16.389 & 44,436 & 116,595 & 2.624 \\
\hline A6 (0.500 g) - LFC & 16.421 & 43,406 & 101,777 & 2.345 \\
\hline A6 (0.500 g) - CUP & 16.216 & 56,172 & 132,640 & 2.361 \\
\hline A7 (0.450 g) - LFC & 15.643 & 86,936 & 229,331 & 2.638 \\
\hline A7 (0.450 g) - CUP & 15.645 & 94,191 & 222,902 & 2.366 \\
\hline A8 (0.400 g) - LFC & 15.642 & 111,596 & 438,615 & 3.930 \\
\hline $\mathrm{A8}(0.400 \mathrm{~g})$ - CUP & 15.482 & 112,669 & 251,150 & 2.229 \\
\hline
\end{tabular}

\subsection{Results in the Production of High Molecular Weight Polystyrene with Silica-Alumina}

High molecular weight polystyrene beads with silica-alumina were produced using the recipe listed in Table 5. The percent yield of LFC beads is given in Table 14. It was found that the yield of the LFC beads increased with an increase in silica-alumina. It may be suggested that the silica-alumina particles acted as nucleates during monomer droplets formation.

Table 14: Bead Size and Percent Yield of LFC Beads

\begin{tabular}{||l||c||c||}
\hline & Bead Size (mm) & wt \% Solid Yield \\
\hline \hline Grade B1 (no additive) & $0.15-0.595$ & 14.3 \\
\hline \hline Grade B2 (1 wt \% silica-alumina) & $0.15-0.595$ & 17.9 \\
\hline \hline Grade B3 (2 wt \% silica-alumina) & $0.15-0.595$ & 19.1 \\
\hline \hline Grade B4 (3 wt \% silica-alumina) & $0.15-0.595$ & 18.2 \\
\hline \hline Grade B5 (5 wt\% silica-alumina) & $0.15-0.595$ & 20.9 \\
\hline
\end{tabular}




\subsubsection{SEM/EDX Analysis of High Molecular Weight Polystyrene with Silica-Alumina}

The cross-section of Grade B1 (Figure 60) shows the presence of spherical pores inside the bead. EDX analysis (Figure 61) shows the presence of oxygen, which may suggests the entrapment of water vapour. It may be suggested that the starch molecules helped to absorb the water vapour inside the beads [61].

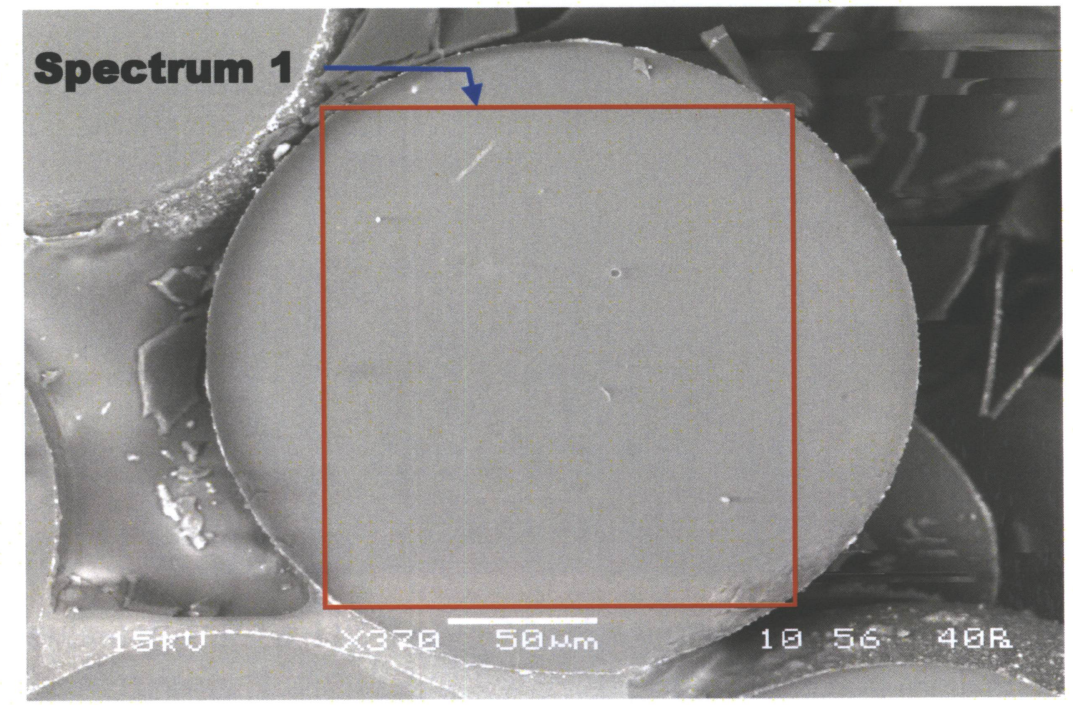

Figure 60: SEM Micrograph of Grade B1 (no additive)

(Magnification: 370X)

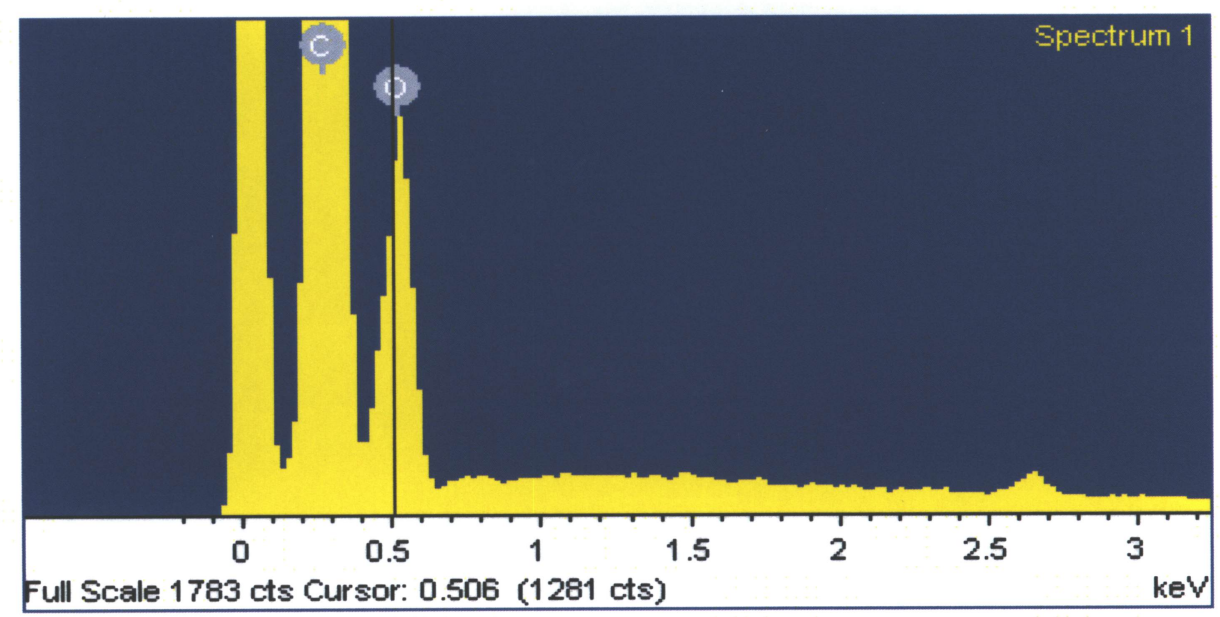

Figure 61: EDX Analysis of Grade B1 (no additive) 
The SEM micrographs of Grades B2, B3, B4 and B5 are shown in Figures $62-65$, respectively. These SEM micrographs show the presence of small beads ( 30 microns) embedded inside the main polystyrene composite beads. It was found that number of these small beads increased when higher amount silica-alumina was used during the polymerization process.

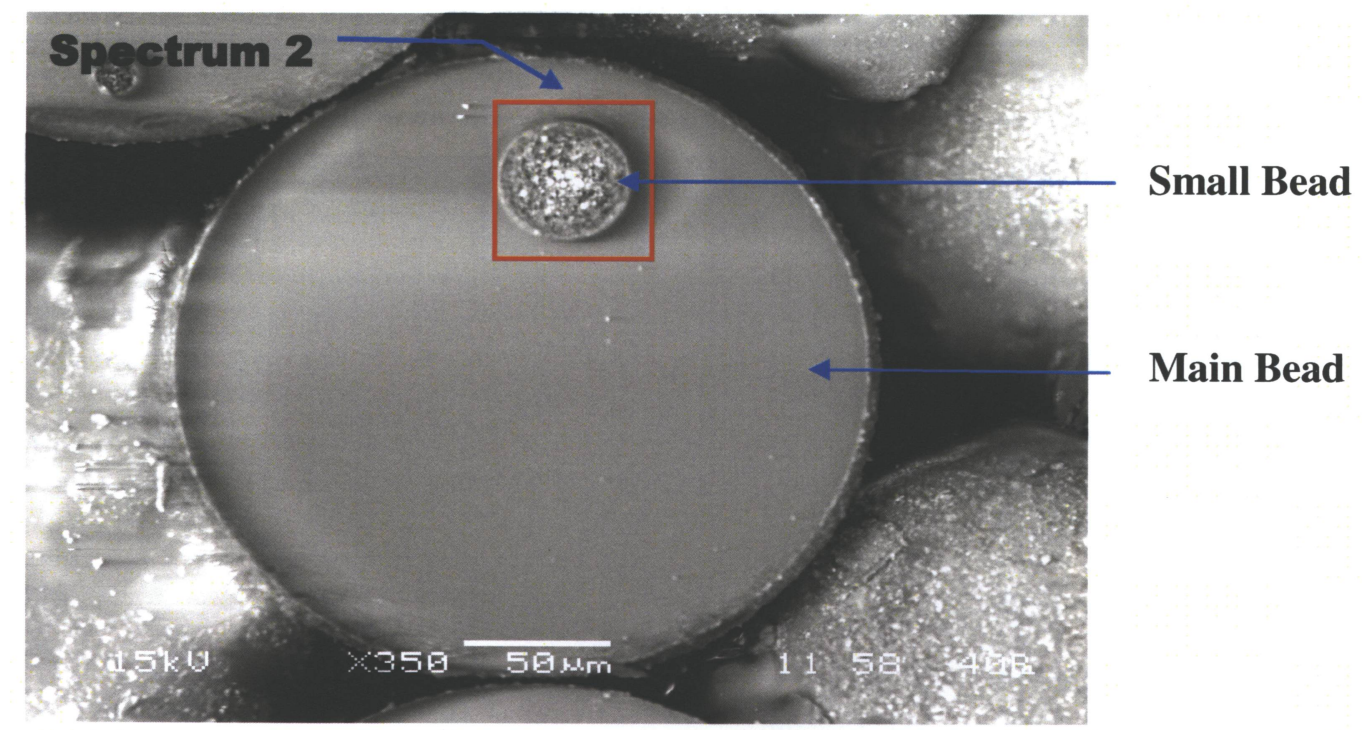

Figure 62: SEM Micrograph of Grade B2 (1 wt \% silica-alumina)

(Magnification: 350X)

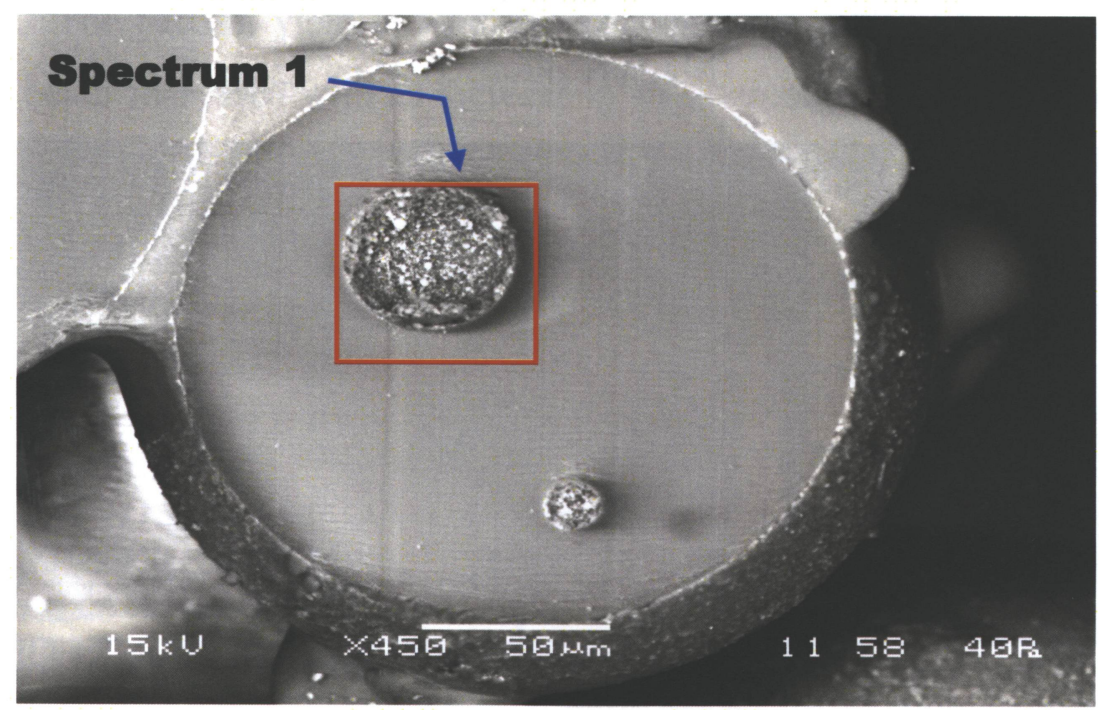

Figure 63: SEM Micrograph of Grade B3 (2 wt \% silica-alumina)

(Magnification: 450X) 


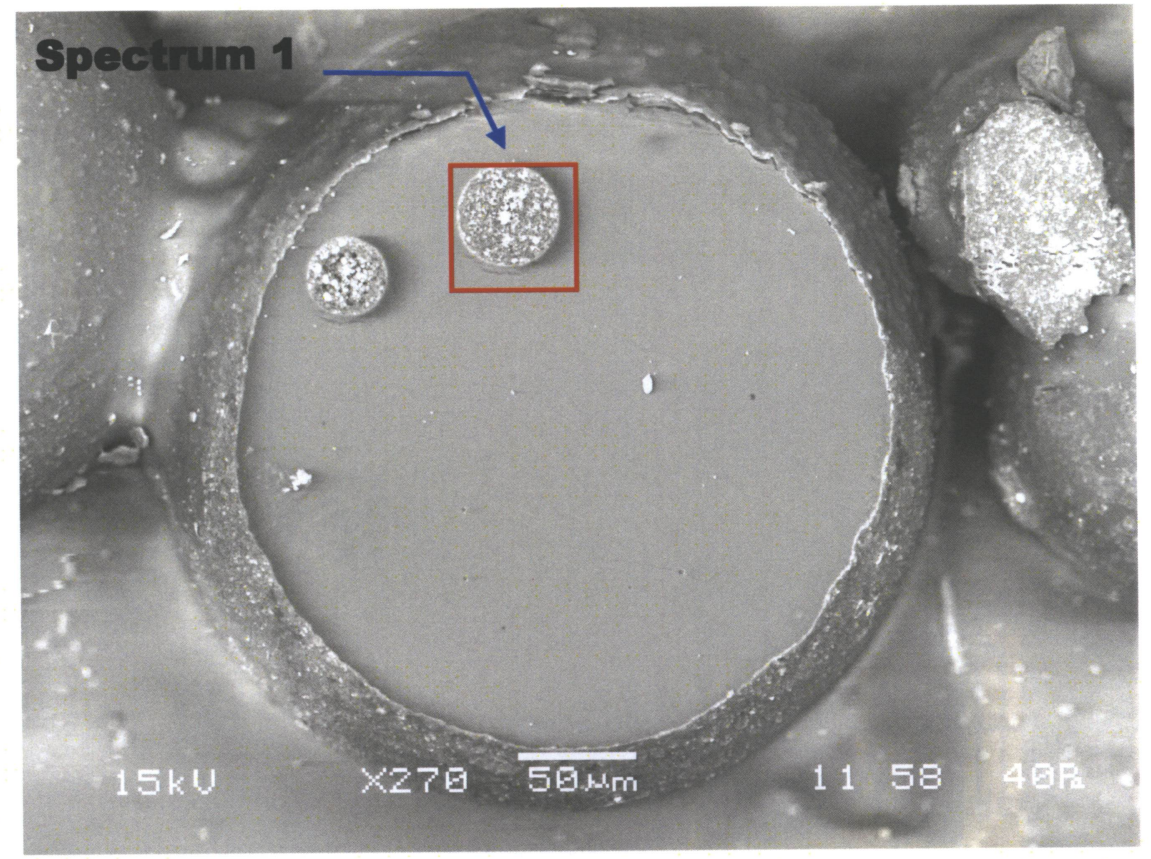

Figure 64: SEM Micrograph of Grade B4 (3 wt \% silica-alumina)

(Magnification: 270X)

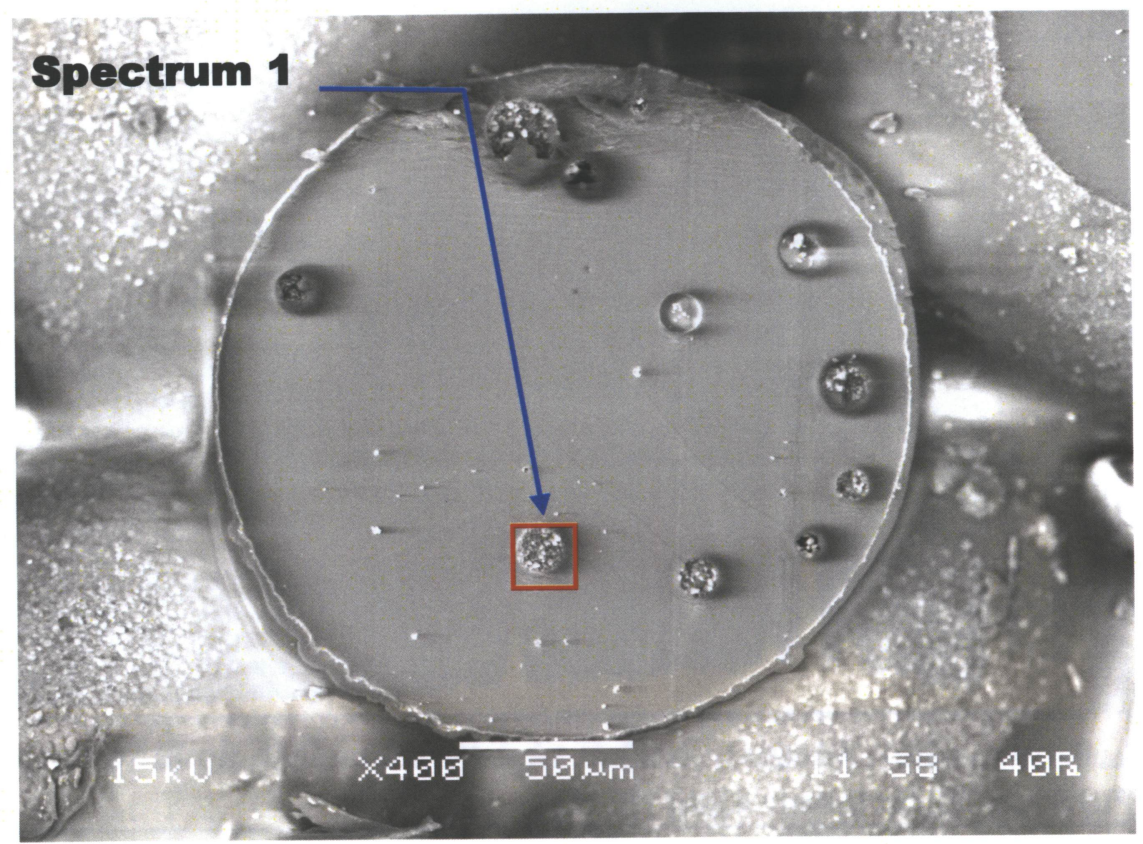

Figure 65: SEM Micrograph of Grade B5 (5 wt \% silica-alumina) (Magnification: 400X) 
EDX analysis confirmed the presence of silica-alumina inside the beads of Grades B2, B3, B4 and B5 as shown in Figures $66-69$, respectively. It was also found that TCP (suspending stabilizer) was also present inside these composite beads as impurities.

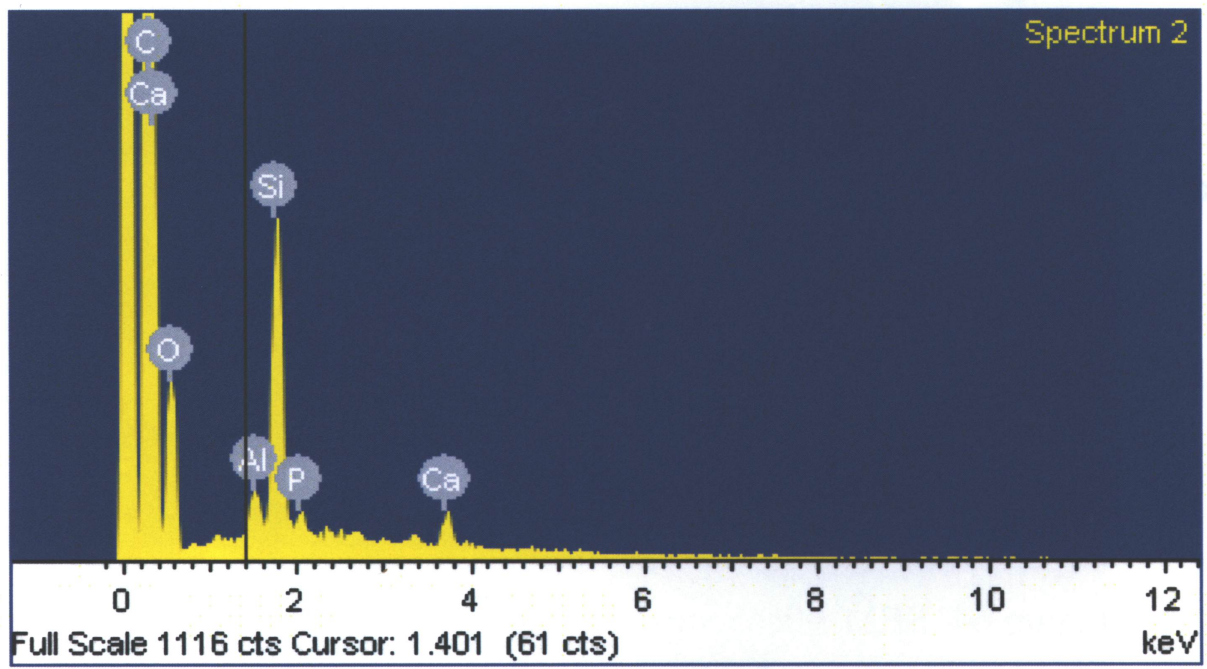

Figure 66: EDX Analysis of Grade B2 (1 wt \% silica-alumina)

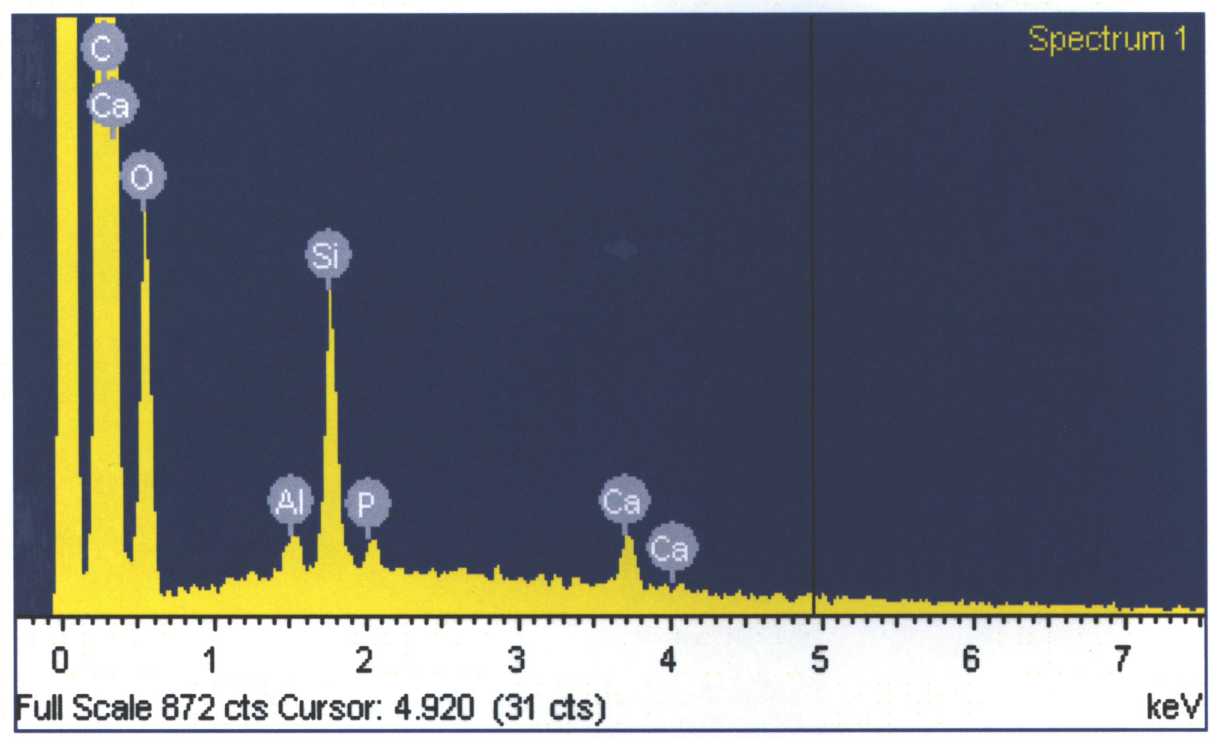

Figure 67: EDX Analysis of Grade B3 (2 wt \% silica-alumina) 


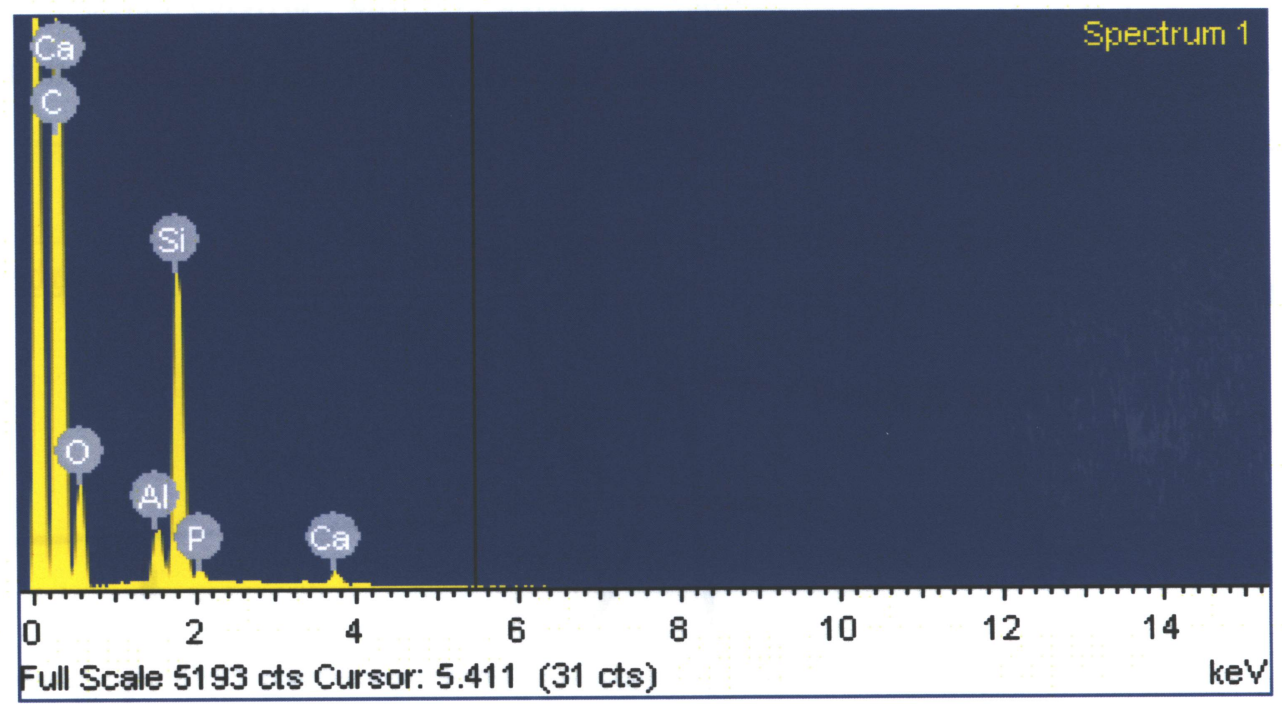

Figure 68: EDX Analysis of Grade B4 (3 wt \% silica-alumina)

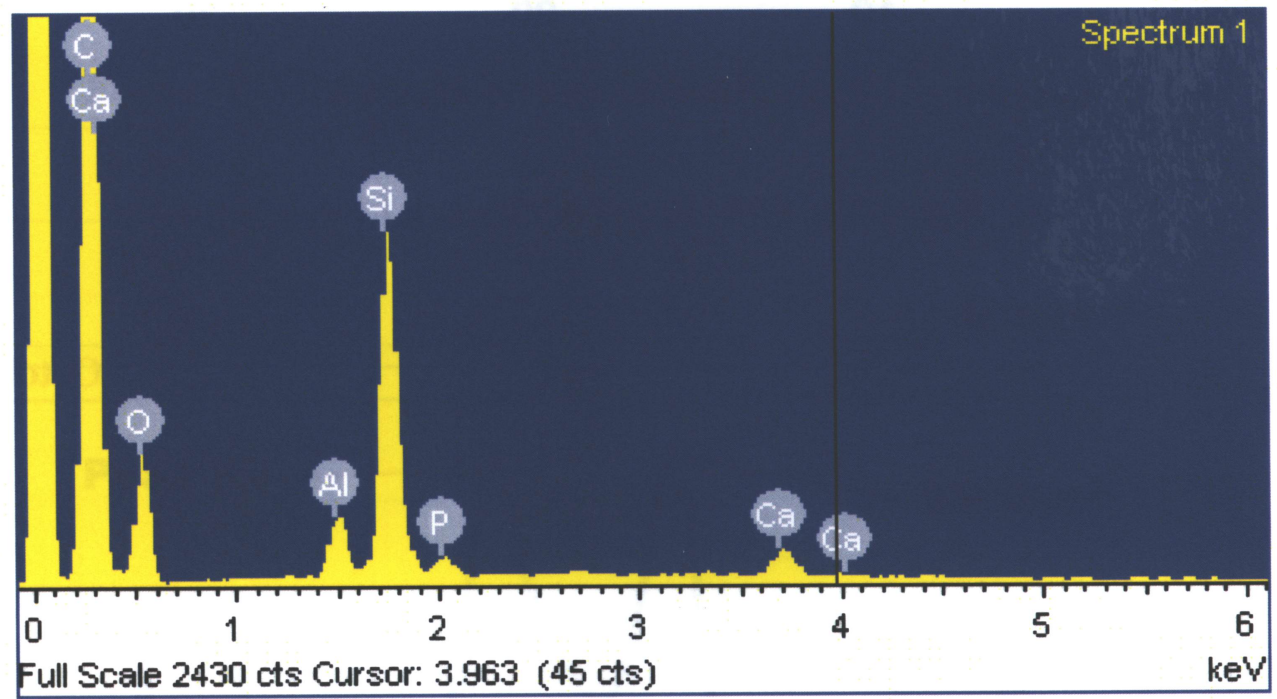

Figure 69: EDX Analysis of Grade B5 (5 wt \% silica-alumina)

\subsubsection{GPC Analysis of High Molecular Weight Polystyrene with Silica-Alumina}

The GPC graphs of Grades B1, B2, B3, B4 and B5 are shown in Figures 70 - 74, respectively. A summary of their GPC results is listed in Table 15. It was found that $\mathbf{M}_{\mathrm{w}}$ values for Grades B2, B3, B4 and B5 were low and their RV values were high relative to Grade B1 (please refer to 
section 3.6.2) . It may be suggested that the silica-alumina particles acted as plasticizers and decreased the $\mathrm{M}_{\mathrm{w}}$ of the polystyrene composite beads [37]. It was also found that the PDI for all the grades was in the range of $2.152-3.072$.

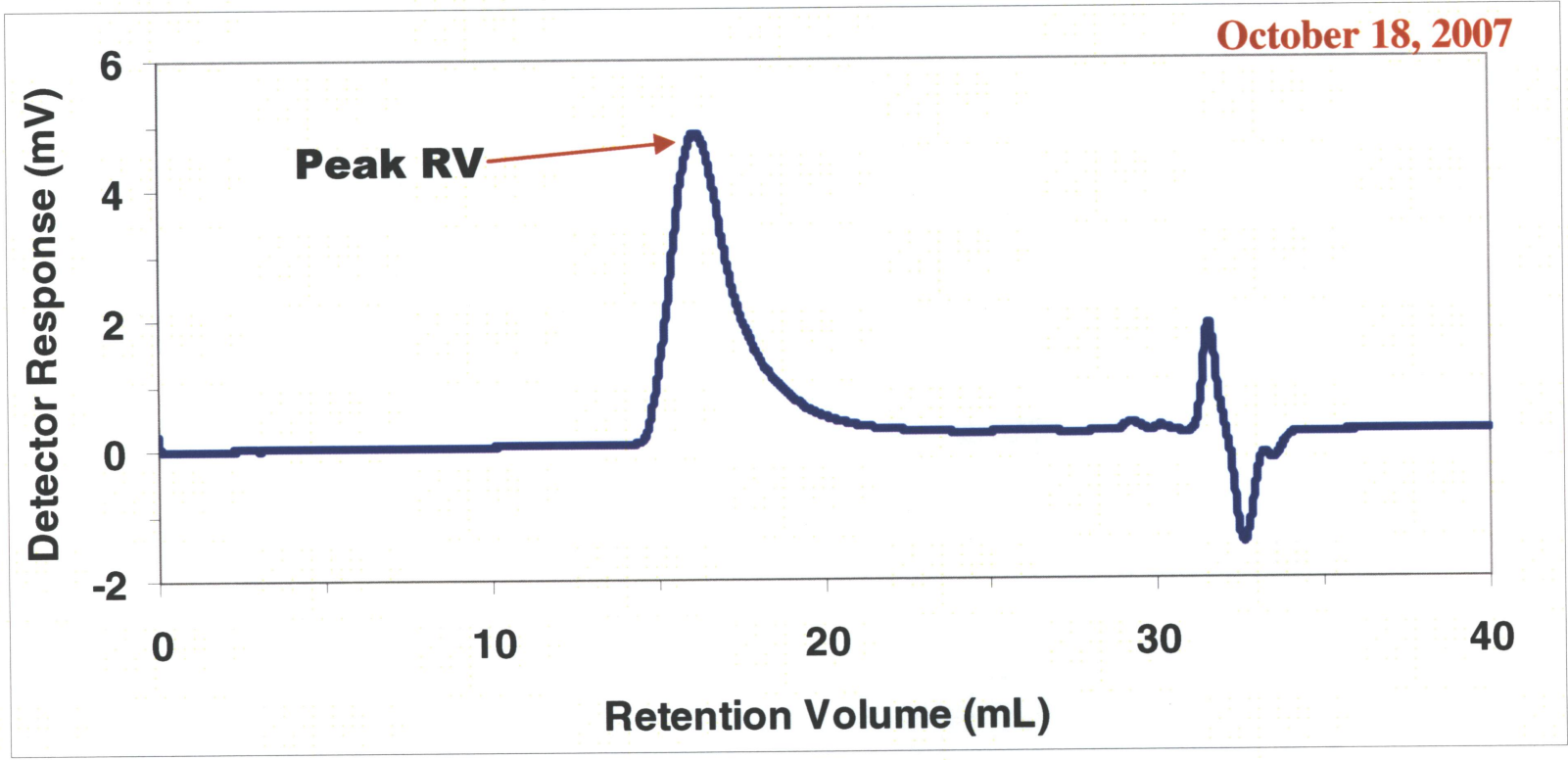

Figure 70: GPC Graph of Grade B1 (no additive)

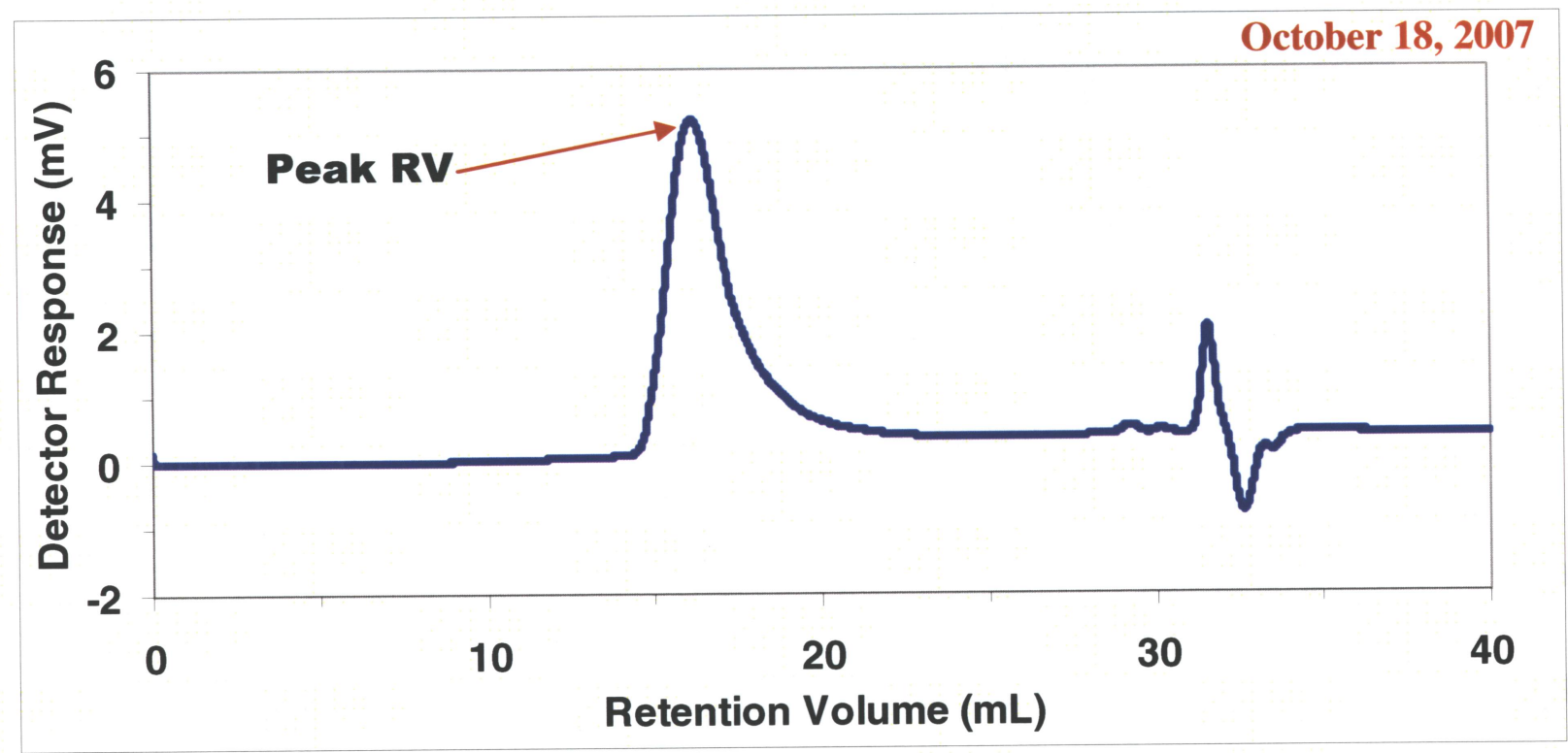

Figure 71: GPC Graph of Grade B2 (1 wt \% silica-alumina) 
October 18, 2007

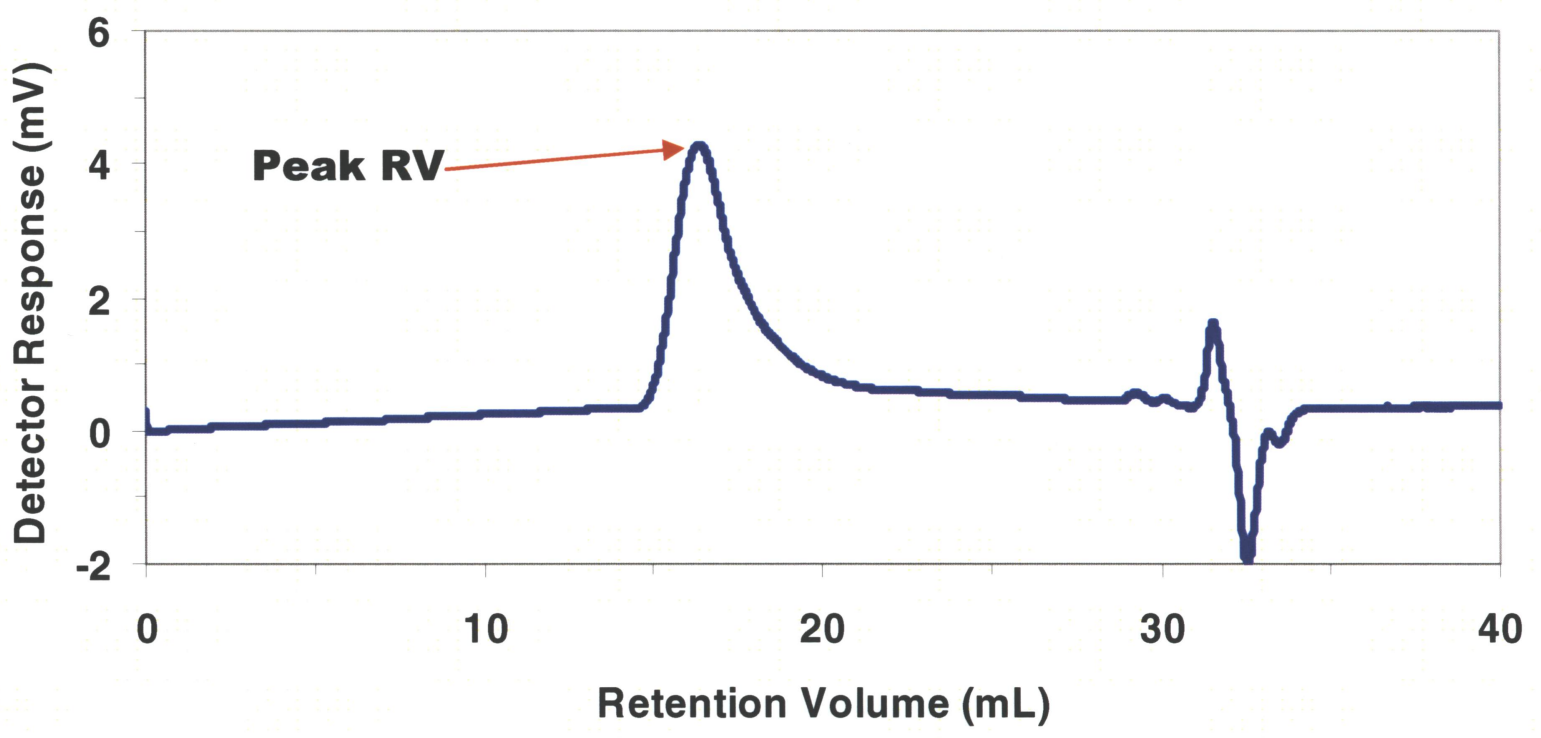

Figure 72: GPC Graph of Grade B3 (2 wt \% silica-alumina)

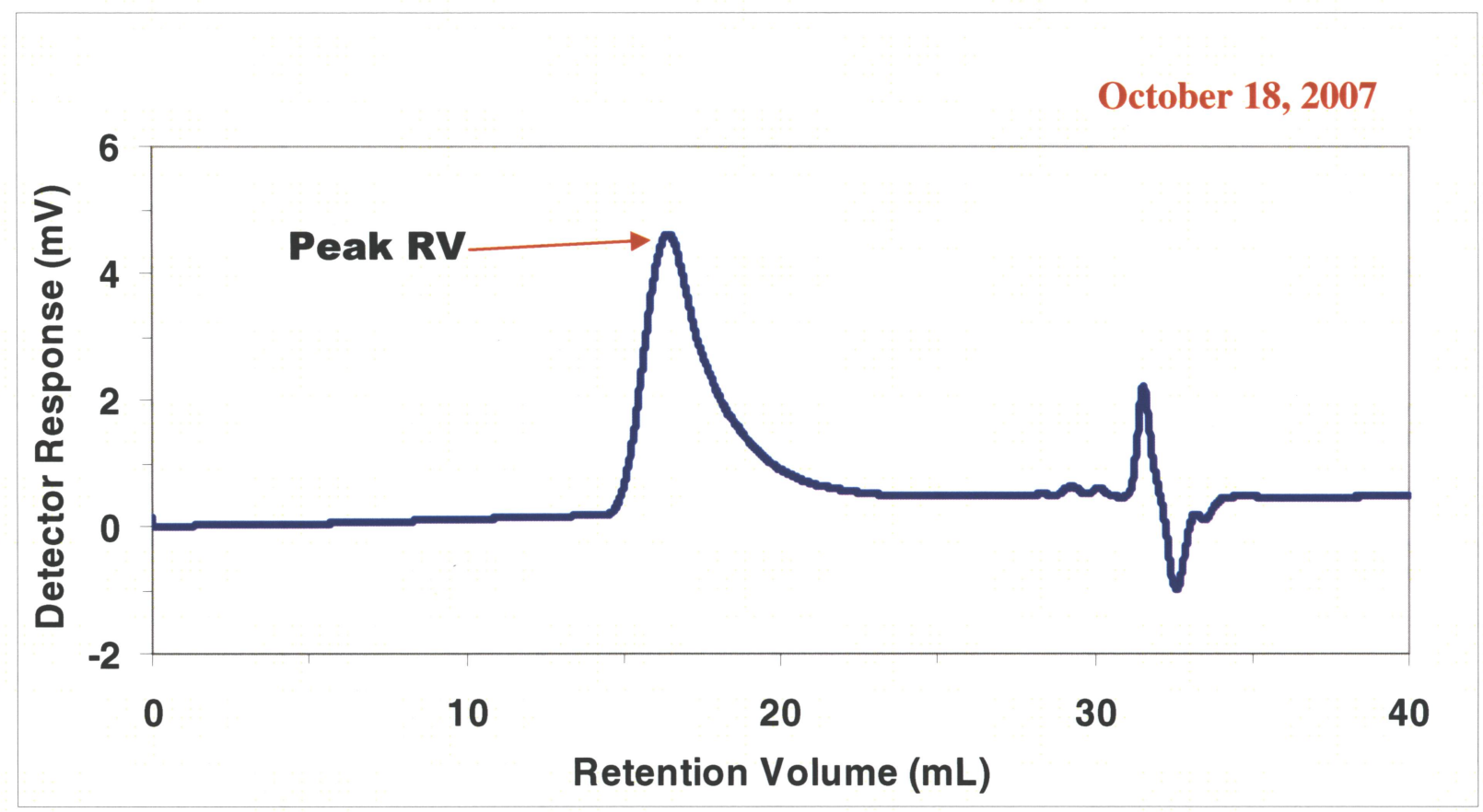

Figure 73: GPC Graph of Grade B4 (3 wt \% silica-alumina) 
October 18, 2007

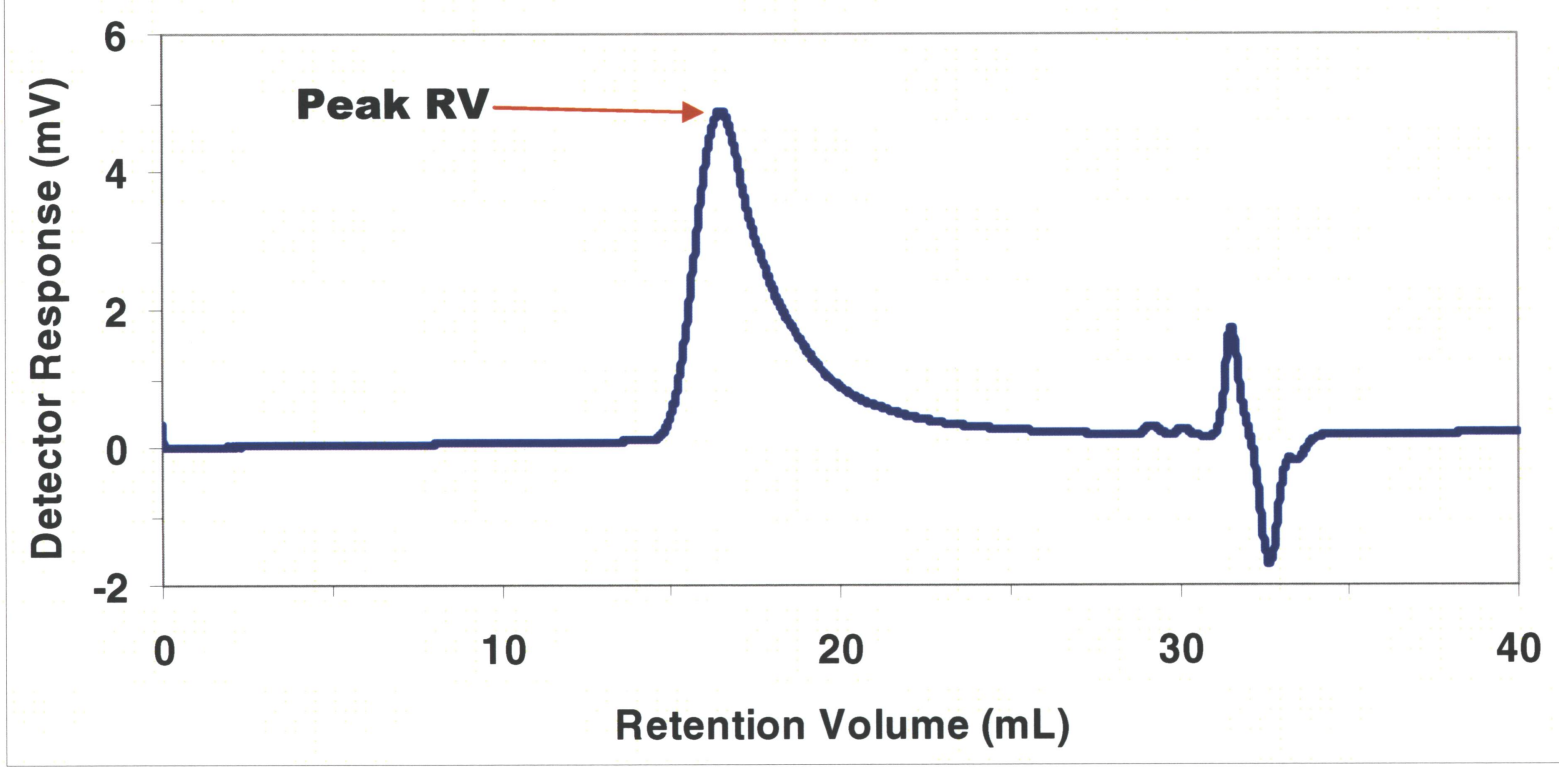

Figure 74: GPC Graph of Grade B5 (5 wt \% silica-alumina)

Table 15: Molecular Weight for Grades B1, B2, B3, B4 and B5

\begin{tabular}{|l|c|c|c|c|}
\hline & Peak RV $(\mathbf{m L})$ & $\mathbf{M}_{\mathbf{n}}(\mathbf{D a})$ & $\mathbf{M}_{\mathbf{w}}(\mathbf{D a})$ & PDI $\left(\mathbf{M}_{\mathbf{w}} / \mathbf{M}_{\mathbf{n}}\right)$ \\
\hline $\begin{array}{l}\text { Grade B1 } \\
\text { (no additive) }\end{array}$ & 16.150 & 129,195 & 278,010 & 2.152 \\
\hline $\begin{array}{l}\text { Grade B2 } \\
\text { (1 wt \% silica-alumina) }\end{array}$ & 16.169 & 98,186 & 277,125 & 2.822 \\
\hline $\begin{array}{l}\text { Grade B3 } \\
\text { (2 wt \% silica-alumina) }\end{array}$ & 16.389 & 83,060 & 255,178 & 3.072 \\
\hline $\begin{array}{l}\text { Grade B4 } \\
\text { (3 wt \% silica-alumina) }\end{array}$ & 16.451 & 71,938 & 197,322 & 2.743 \\
\hline $\begin{array}{l}\text { Grade B5 } \\
\text { (5 wt \% silica-alumina) }\end{array}$ & 16.510 & 61,459 & 180,262 & 2.933 \\
\hline
\end{tabular}




\subsubsection{DSC Analysis of High Molecular Weight Polystyrene with Silica-Alumina}

The DSC graphs for Grades B1, B2, B3, B4 and B5 are shown in Figures 75 - 79, respectively. A summary of the DSC results is given in Table 16. It was found that $T_{g}$ decreases with an increase in silica-alumina in the polystyrene composite beads.

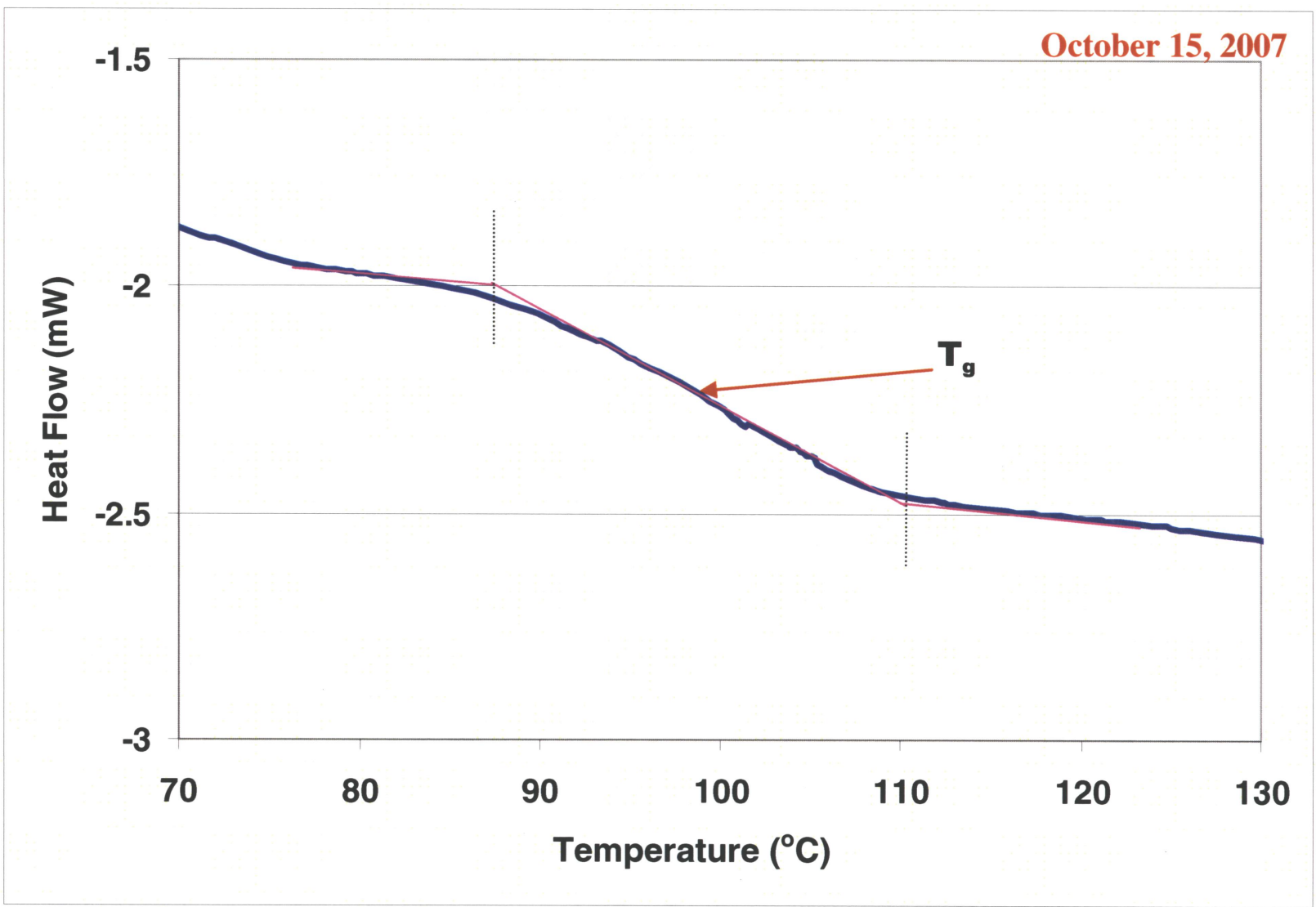

Figure 75: DSC Graph of Grade B1 (no additive) 


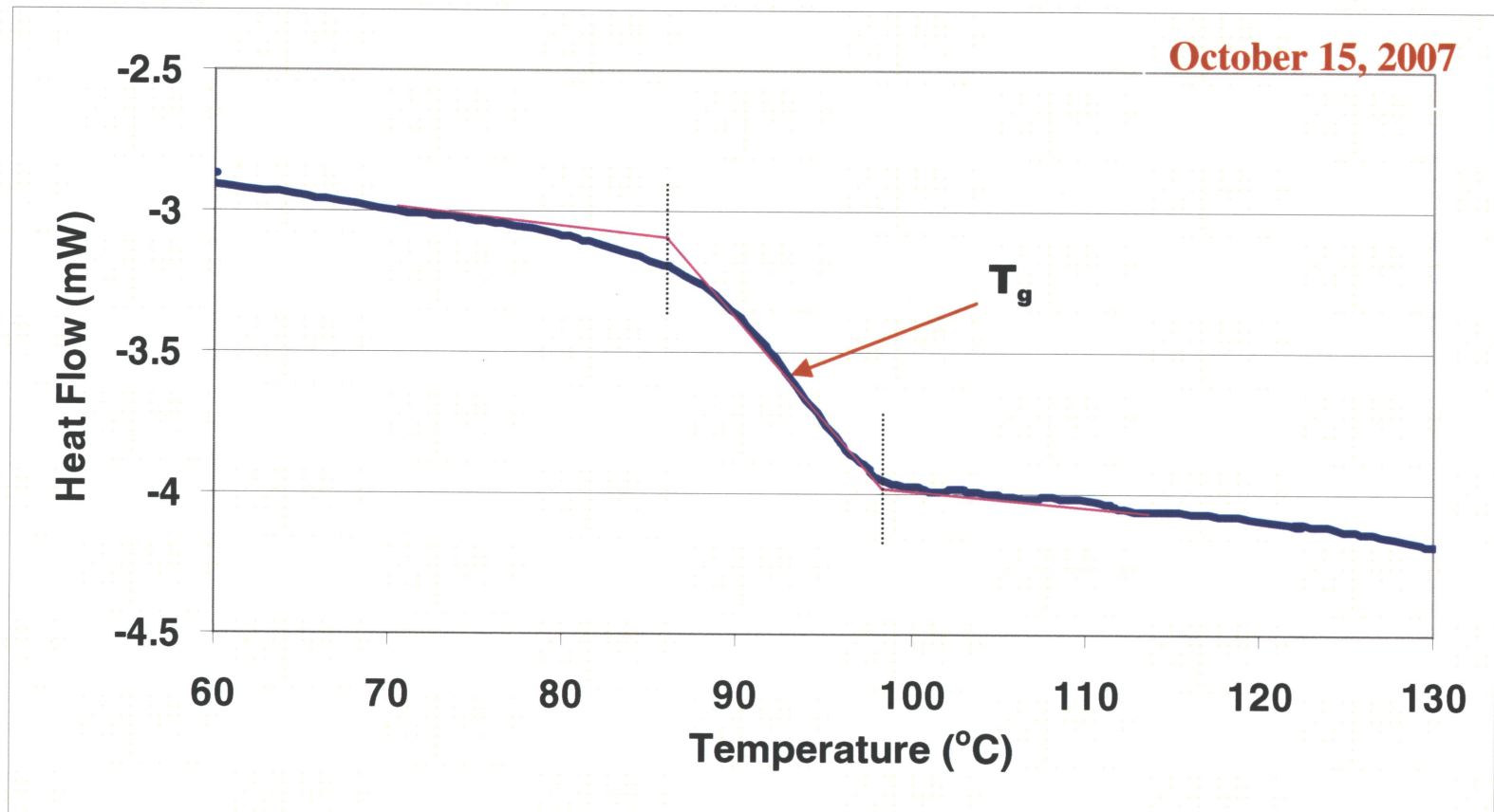

Figure 76: DSC Graph of Grade B2 (1 wt \% silica-alumina)

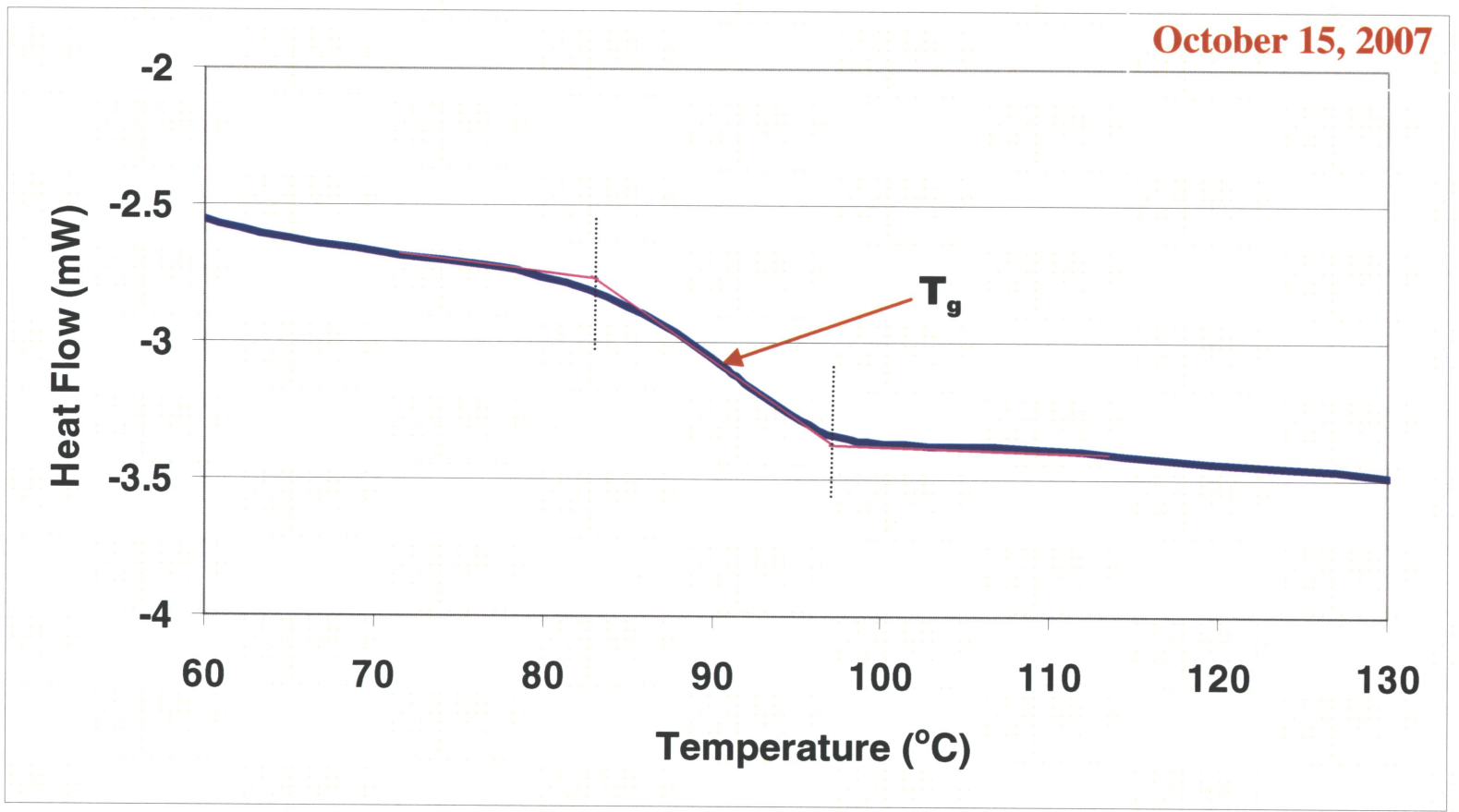

Figure 77: DSC Graph of Grade B3 (2 wt \% silica-alumina) 


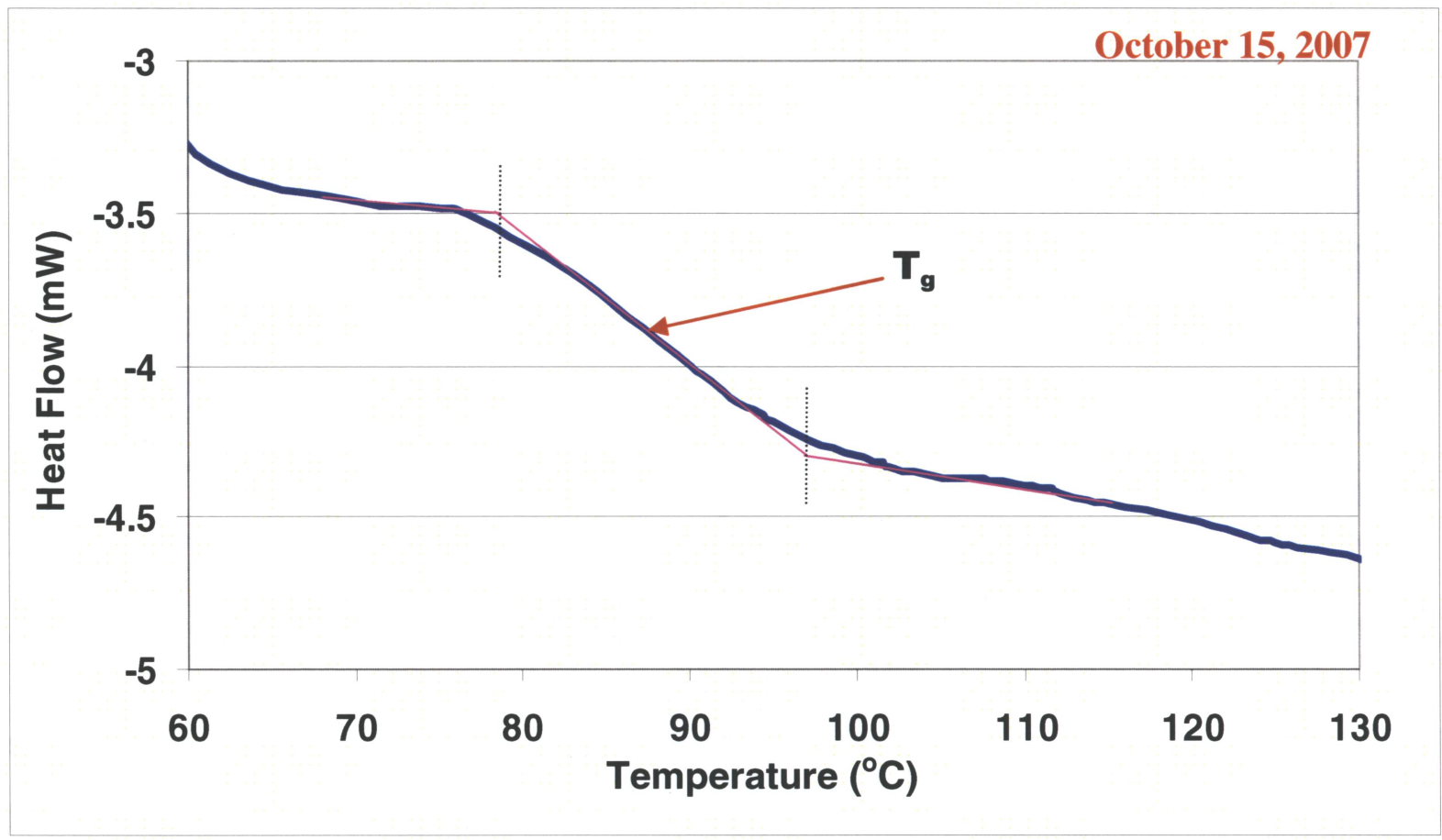

Figure 78: DSC Graph of Grade B4 (3 wt \% silica-alumina)

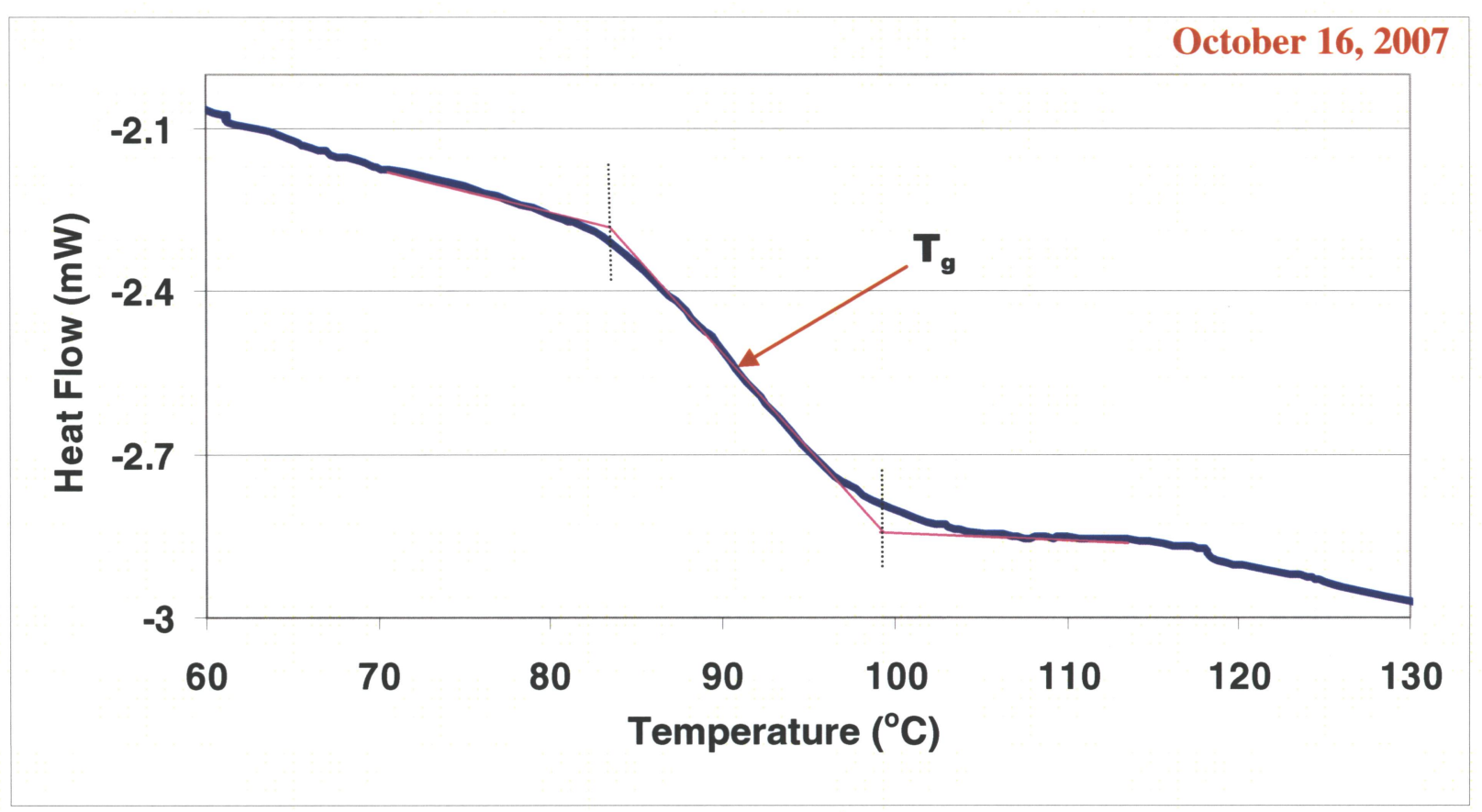

Figure 79: DSC Graph of Grade B5 (5 wt \% silica-alumina) 
Table 16: Glass Transition Temperature for Grades B1, B2, B3, B4 and B5

\begin{tabular}{||l||c||}
\hline \multicolumn{1}{|c||}{ Samples } & Glass Transition Temperature, $\mathbf{T}_{\mathbf{g}}{ }^{\mathbf{0}} \mathbf{C}$ ) \\
\hline \hline Grade B1 (no additive) & $98 \pm 0.5$ \\
\hline \hline Grade B2 (1 wt \% silica-alumina) & $94 \pm 0.5$ \\
\hline \hline Grade B3 (2 wt \% silica-alumina) & $91 \pm 0.5$ \\
\hline \hline Grade B4 (3 wt \% silica-alumina) & $91 \pm 0.5$ \\
\hline \hline Grade B5 (5 wt \% silica-alumina) & $89 \pm 0.5$ \\
\hline
\end{tabular}

\subsubsection{TGA Analysis of High Molecular Weight Polystyrene with Silica-Alumina}

The TGA graphs for Grades B1, B2, B3, B4 and B5 are shown in Figures 80 - 84, respectively. A summary of the TGA results is given in Table 17. These TGA graphs show an initial weight loss below $200{ }^{\circ} \mathrm{C}$ and it was found that the $\mathrm{T}_{\mathrm{o}}$ values for Grades B2, B3, B4 and B5 were low relative to Grade B1.

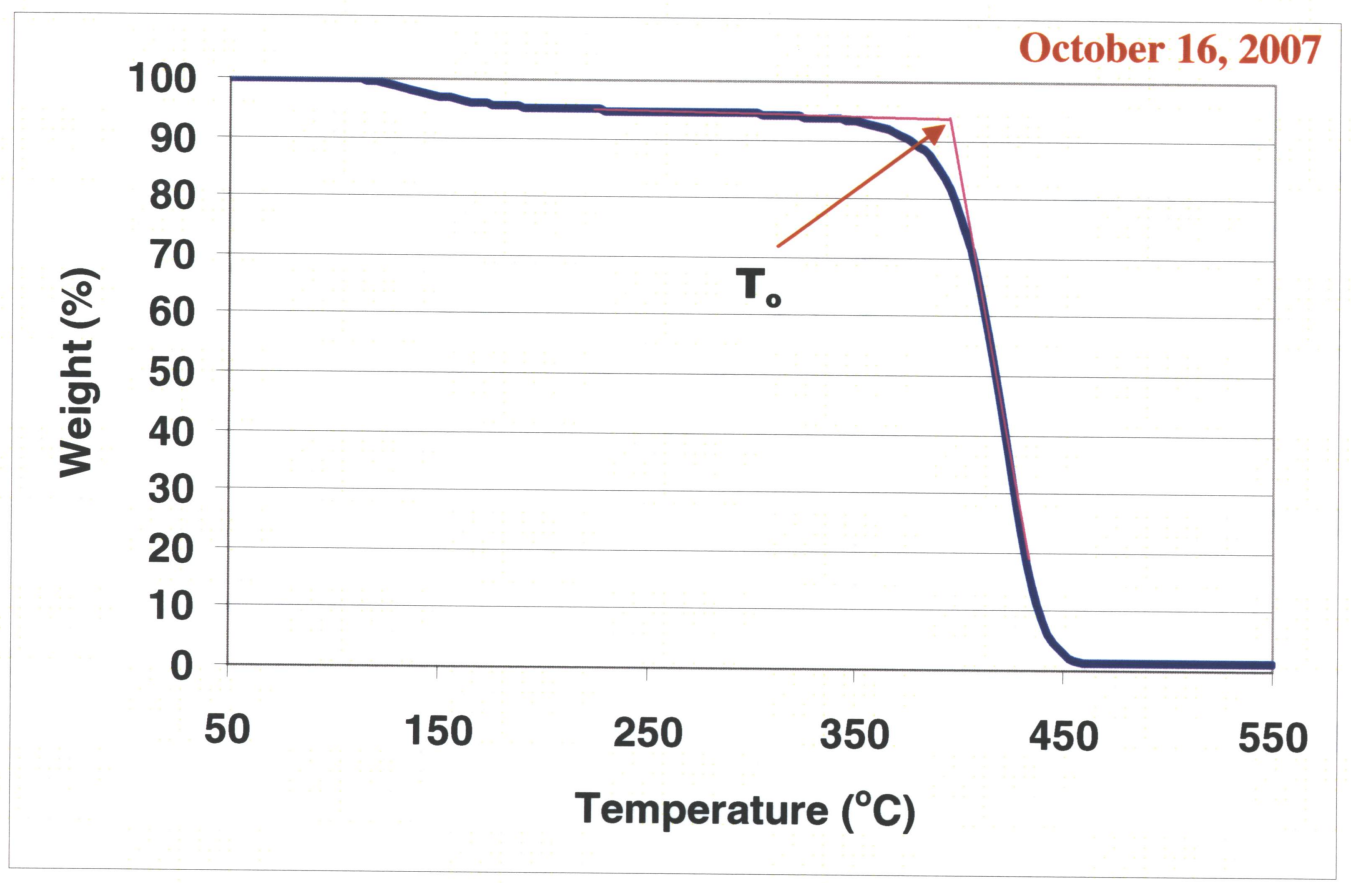

Figure 80: TGA Graph of Grade B1 (no additive) 


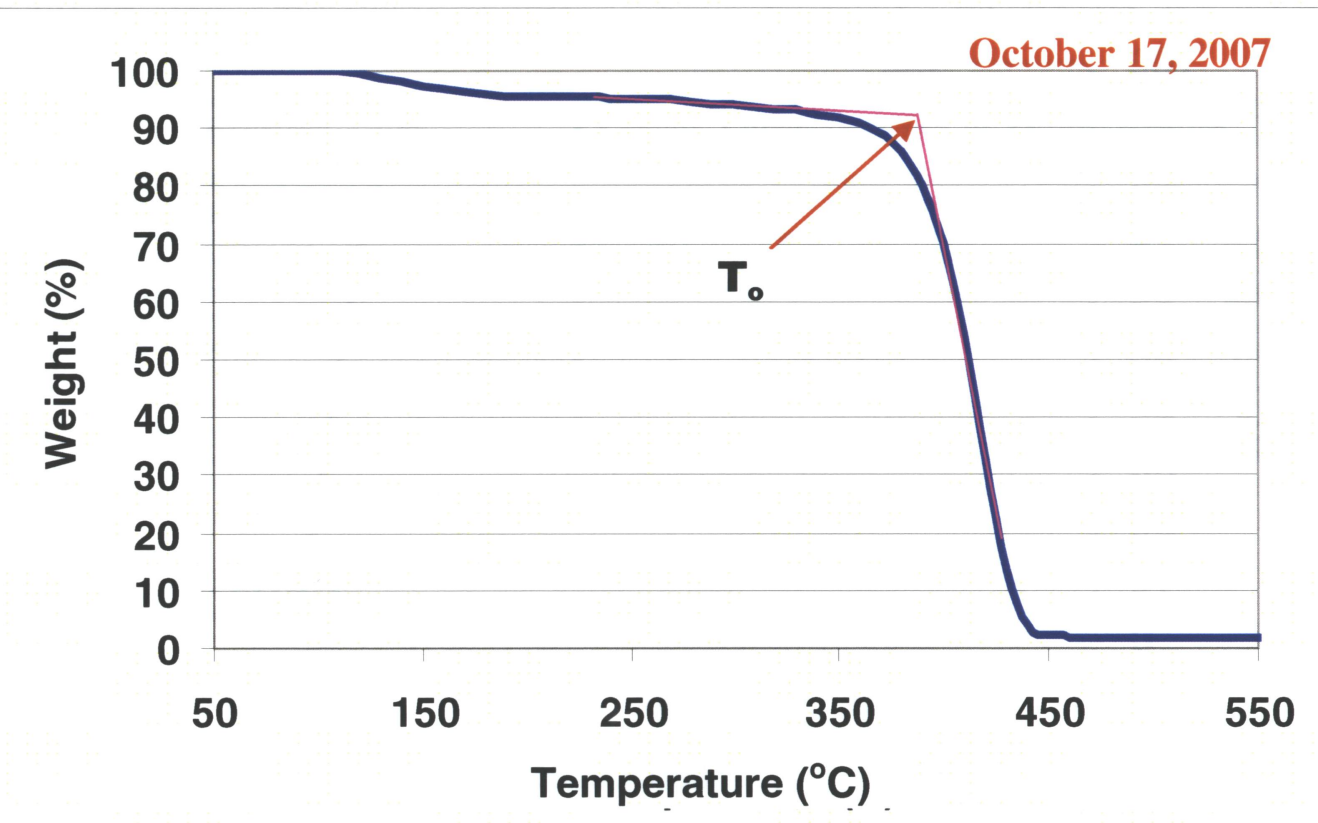

Figure 81: TGA Graph of Grade B2 (1 wt \% silica-alumina)

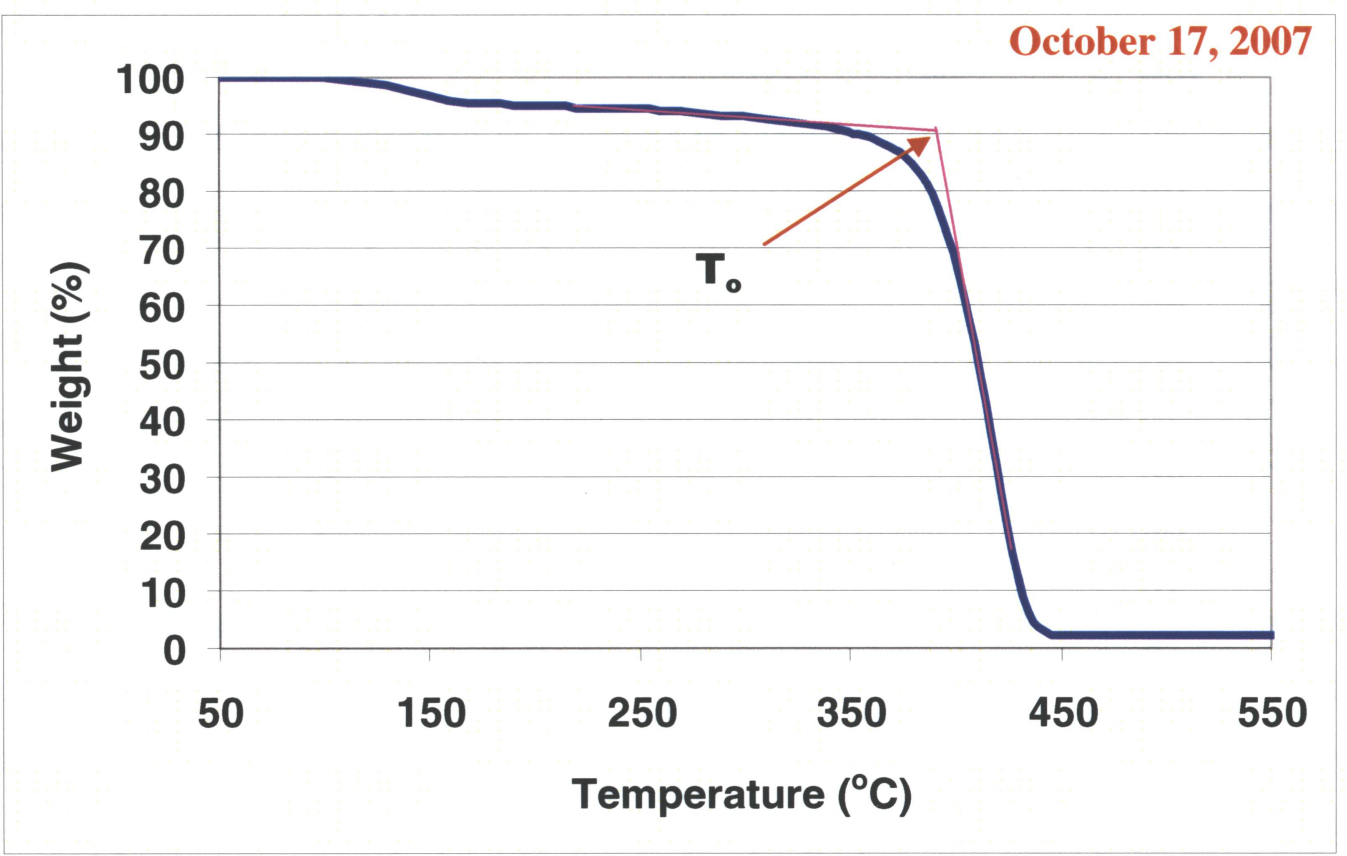

Figure 82: TGA Graph of Grade B3 (2 wt \% silica-alumina) 


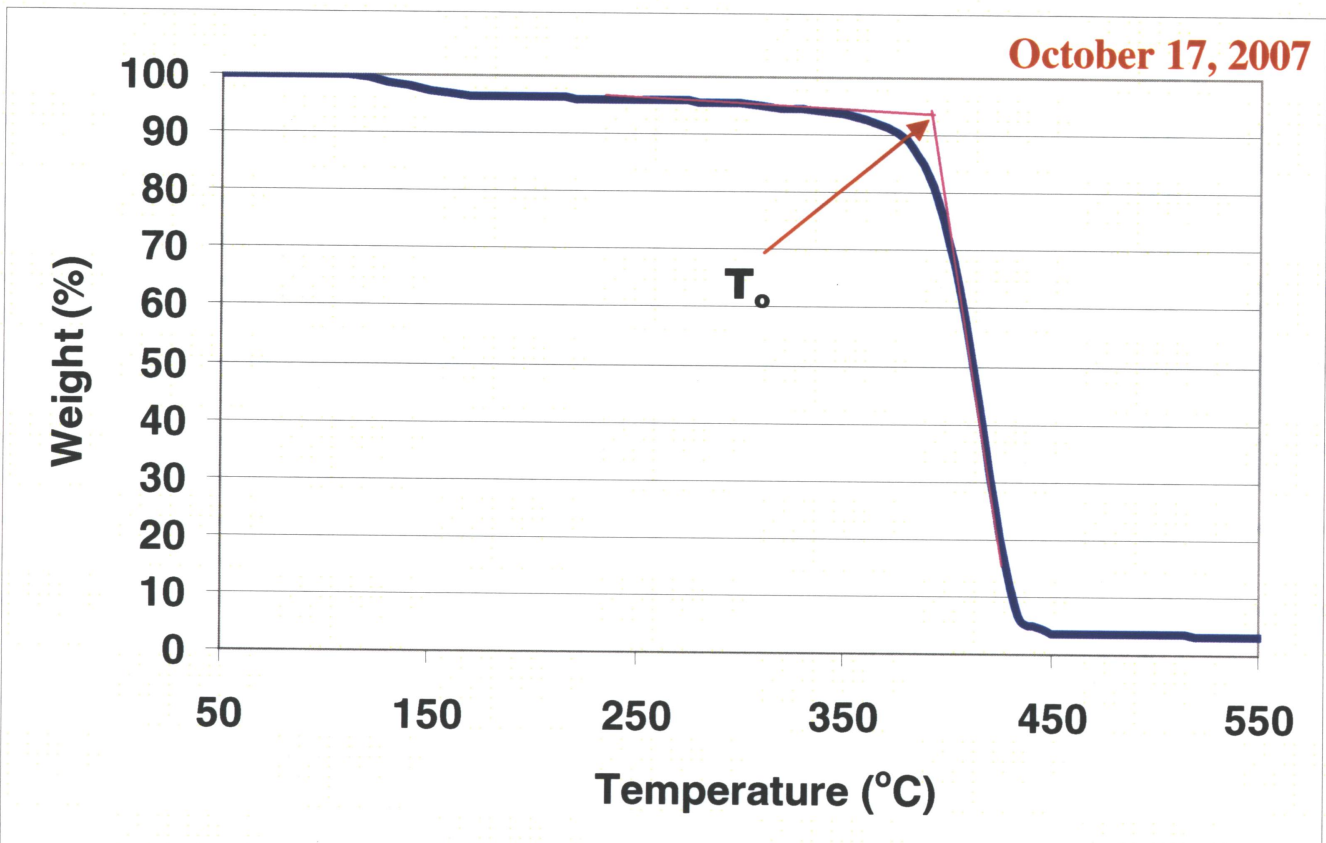

Figure 83: TGA Graph of Grade B4 (3 wt \% silica-alumina)

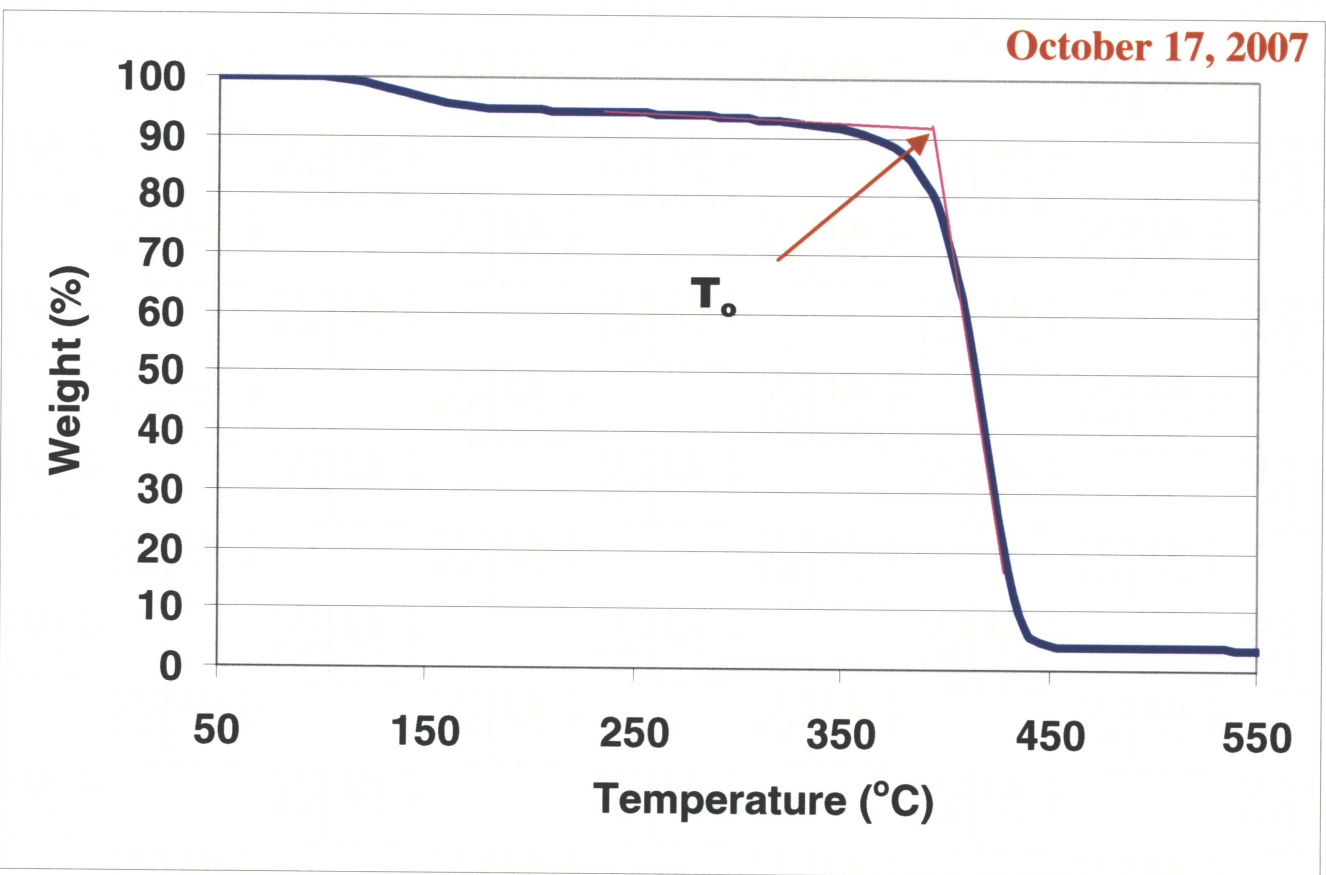

Figure 84: TGA Graph of Grade B5 (5 wt \% silica-alumina) 
Table 17: Onset Temperature of Degradation for Grades B1, B2, B3, B4 and B5

\begin{tabular}{|l||c||}
\hline \multicolumn{1}{|c||}{ Samples } & Onset Temperature of Degradation, $\mathbf{T}_{\mathbf{o}}\left({ }^{\mathbf{0}} \mathbf{C}\right)$ \\
\hline \hline Grade B1 (no additive) & $397 \pm 1$ \\
\hline \hline Grade B2 (1 wt \% silica-alumina) & $392 \pm 0.5$ \\
\hline \hline Grade B3 (2 wt \% silica-alumina) & $388 \pm 1$ \\
\hline \hline Grade B4 (3 wt \% silica-alumina) & $390 \pm 2$ \\
\hline \hline Grade B5 (5 wt \% silica-alumina) & $395 \pm 0.5$ \\
\hline \hline
\end{tabular}

\subsection{Summary of Results}

SEM/EDX analysis confirmed the presence of the additives (silica-alumina and iron based catalyst) inside the low molecular weight polystyrene composite beads. The $T_{g}$ and $T_{o}$ values of these polystyrene composite beads were low relative to the control (Grade A). However, the $\mathrm{M}_{\mathrm{w}}$ values for all the grades were less than the required value for $\operatorname{LFC}\left(M_{\mathrm{w}}: 180,000-280,000 \mathrm{Da}\right)$. The summary of the all the analyses in the production of low molecular weight polystyrene composite beads (Grade A to D) is listed in Table 18.

The molecular weight increased with an increase in reaction time and with a decrease in mass of initiators as revealed by the data for Grades A1 to A8. This increase was likely the result of an increase in monomer conversion and a decrease in the initiation rate. LFC and CUP polystyrene beads of Grades $A 7$ and $A 8$ possessed the required $M_{w}$ for the LFC process. The summary of the GPC analysis in the production of high molecular weight polystyrene beads (Grades A1 to A8) is given in Table 19.

SEM/EDX analysis confirmed the presence of the additive (silica-alumina) inside the beads. The $T_{g}$ and $T_{o}$ values of these polystyrene composite beads were low relative to the control (Grade B1). The $\mathrm{M}_{\mathrm{w}}$ values were above 180,000 $\mathrm{Da}$ for all the grades. The summary of the all the analysis in the production of high molecular weight polystyrene composite beads (Grades B1 to B5) with various level of silica-alumina is listed in Table 20. 
Table 18: Summary of Analysis of Low Molecular Polystyrene with Additives

\begin{tabular}{|c|c|c|c|c|}
\hline GRADE & $\begin{array}{c}\text { TGA } \\
\text { T }_{0}\left({ }^{\circ} \mathrm{C}\right)\end{array}$ & $\begin{array}{c}\text { DSC } \\
T_{g}\left({ }^{\circ} \mathrm{C}\right)\end{array}$ & $\begin{array}{c}\text { GPC } \\
M_{\mathbf{w}}(\text { Da })\end{array}$ & $\overline{\text { SEM/EDX }}$ \\
\hline A (no additive) & $352 \pm 2$ & $69 \pm 1$ & 30,213 & \\
\hline B (2 wt\% silica-alumina) & $332 \pm 2$ & $54 \pm 1$ & 20,155 & Oxygen, silicon and aluminum \\
\hline $\mathrm{C}(2 \mathrm{wt} \%$ iron based catalyst) & $338 \pm 2$ & $55 \pm 1$ & 21,948 & $\begin{array}{l}\text { Oxygen, iron, aluminum and } \\
\text { potassium }\end{array}$ \\
\hline $\begin{array}{l}\text { D (1 wt \% silica-alumina and } \& \\
1 \text { wt } \% \text { iron based catalyst })\end{array}$ & $341 \pm 2$ & $44 \pm 1$ & 25,873 & $\begin{array}{l}\text { Oxygen, silicon, aluminum, } \\
\text { potassium and iron }\end{array}$ \\
\hline
\end{tabular}


Table 19: Summary of GPC Results of High Molecular Weight Polystyrene

\begin{tabular}{|c|c|c|c|}
\hline GRADE & $\mathbf{M}_{\mathbf{n}}(\mathbf{D a})$ & $\mathbf{M}_{\mathbf{w}}(\mathrm{Da})$ & PDI $\left(M_{w} / M_{n}\right)$ \\
\hline A1 (3 hrs) - LFC & 28,470 & 68,253 & 2.397 \\
\hline A1 (3 hrs) - CUP & 29,460 & 75,592 & 2.566 \\
\hline A2 (4 hrs) - LFC & 40,313 & 104,996 & 2.605 \\
\hline A2 (4 hrs) - CUP & $4 \overline{44,262}$ & 123,963 & 2.801 \\
\hline A3 (6 hrs) - LFC & 43,830 & 101,363 & 2.313 \\
\hline A3 (6 hrs) - CUP & 50,199 & 110,905 & 2.209 \\
\hline A4 (8 hrs) - LFC & 60,539 & 155,183 & 2.563 \\
\hline A4 (8 hrs) - CUP & 61,212 & 157,220 & 2.568 \\
\hline A5 (0.550 g) - LFC & 35,045 & 87,933 & 2.509 \\
\hline A5 (0.550 g) - CUP & 44,436 & 116,595 & 2.624 \\
\hline $\mathrm{A6}(0.500 \mathrm{~g})$ - LFC & 43,406 & 101,777 & 2.345 \\
\hline A6 (0.500 g) - CUP & 56,172 & 132,640 & 2.361 \\
\hline A7 (0.450 g) - LFC & 86,936 & 229,331 & 2.638 \\
\hline A7 (0.450 g) - CUP & 94,191 & 222,902 & 2.366 \\
\hline 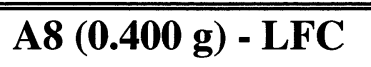 & $\overline{1111,596}$ & 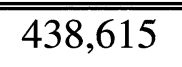 & 3.930 \\
\hline $\mathrm{A8}(0.400 \mathrm{~g})$ - CUP & 112,669 & 251,150 & 2.229 \\
\hline
\end{tabular}


Table 20: Summary of Analysis of High Molecular Polystyrene with Silica-Alumina

\begin{tabular}{|l|c|c|c||l||}
\hline \multicolumn{1}{|c|}{ GRADE } & $\begin{array}{c}\text { TGA } \\
\mathbf{T}_{\mathbf{0}}\left({ }^{\mathbf{0}} \mathbf{C}\right)\end{array}$ & $\begin{array}{c}\text { DSC } \\
\mathbf{T}_{\mathbf{g}}\left({ }^{\mathbf{0}} \mathbf{C}\right)\end{array}$ & $\begin{array}{c}\text { GPC } \\
\mathbf{M}_{\mathbf{w}}(\mathbf{D a})\end{array}$ & \multicolumn{1}{|c|}{ SEM/EDX } \\
\hline \hline B1 (no additive) & $397 \pm 1$ & $98 \pm 0.5$ & 278,010 & \\
\hline \hline B2 (1 wt\% silica-alumina) & $392 \pm 0.5$ & $94 \pm 0.5$ & 277,125 & Oxygen, silicon and aluminum \\
\hline B3 (2 wt\% silica-alumina) & $388 \pm 1$ & $91 \pm 0.5$ & 255,178 & Oxygen, silicon and aluminum \\
\hline \hline B4 (3 wt\% silica-alumina) & $390 \pm 2$ & $91 \pm 0.5$ & 197,322 & Oxygen, silicon and aluminum \\
\hline \hline B5 (5 wt\% silica-alumina) & $395 \pm 0.5$ & $89 \pm 0.5$ & 180,262 & Oxygen, silicon and aluminum \\
\hline
\end{tabular}




\section{Chapter 5 - Discussion}

In this chapter, all the results (Chapter 4) are discussed. The data related to the production of low molecular weight polystyrene composite beads are discussed in section 5.1. In the next section, the production of high molecular weight polystyrene beads is discussed. Finally, in section 5.3, data related to the production of high molecular weight polystyrene composite beads are examined.

\subsection{Discussion on the Production of Low Molecular Weight Polystyrene with Additives}

\subsubsection{Effect of Additives on Molecular Weight}

Grade A did not have any catalyst added during the polymerization process and its $M_{w}$ was found to be 30,213 $\mathrm{Da}$. However, the $\mathrm{M}_{\mathrm{w}}$ values for all the polystyrene composite beads (Grades B, C and D) were found to be less than $26,000 \mathrm{Da}$. Hence, it can be suggested that the catalysts added during the polymerization process resulted in a decrease of the average molecular weights. It is possible that the catalyst particles might have prevented the formation of long chain polymers by positioning themselves between the monomers [37].

In a recent published paper, Lenzi et al. [76] observed that the molecular weight of polystyrene was considerably reduced by adding emulsified particles during the suspension polymerization process. They suggested that these emulsified particles were caught in the sticky monomer droplets during the polymerization course, and this led to a consistent reduction in the average molecular weights. It is also known that an increase in concentration of the catalysts reduces the percent monomer conversion into polymer and thus reduces the average molecular weights [77]. 


\subsubsection{Effect of Additives on Onset Temperature of Degradation, $T_{o}$}

The study of degradation of polymers is an important aspect of polymer science and engineering in industrial applications such as plastic recycling and in the LFC process. In this study, it was found that two degradation mechanisms, namely, depolymerization and random chain scission, were involved [78 - 80]. Depolymerization was found to occur in the temperature range 100 $200{ }^{\circ} \mathrm{C}$ (Figure 85). In this temperature range, the breakage of the unstabilized chain-ends of the polymer is known to occur [40]. Also, a $10 \%$ decrease in the weight of all the samples was also observed in this temperature range. However, in the temperature range of $200-400{ }^{\circ} \mathrm{C}$, the random chain scission mechanism was probably involved [79]. Random chain scission was found to be the main mechanism in the degradation of these beads ( $90 \%$ weight loss).

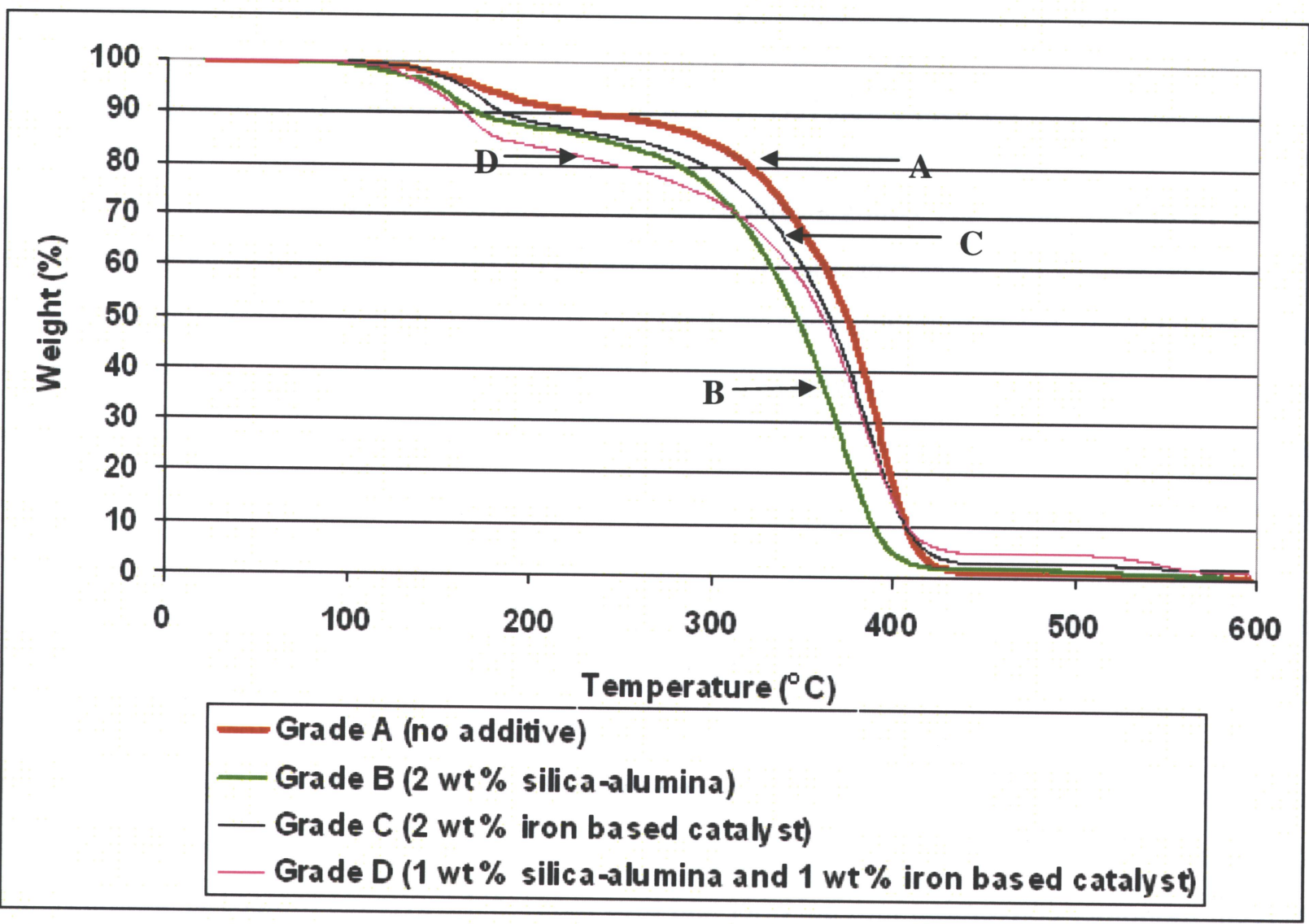

Figure 85: Degradation of Grades A, B, C and D (based on Figures 41 - 44) 
Archodoulaki et al. [40] found that the rate of degradation increases linearly with increasing molecular weight. They also found that this dependence on molecular weight is valid for a random chain scission mechanism. They stated that depolymerization occurs in the chain-ends and it depends on the number of reactive end-groups. High molecular weight polystyrene has fewer chain-ends and thus they degrade slower. The depolymerization mechanisms occurring in the range of $100-200{ }^{\circ} \mathrm{C}$ (Figure 85) confirmed that higher molecular weight degraded slower. The average $\mathrm{T}_{\mathrm{o}}$ for Grade A was found to be $352{ }^{\circ} \mathrm{C}$ and the average $\mathrm{T}_{\mathrm{o}}$ values for the novel polystyrene composite beads (Grades B, C and D) were found to be less than $341^{\circ} \mathrm{C}$. Hence, the degradation of these novel polystyrene composite beads was less endothermic.

The main goal of producing the novel polystyrene composite beads was to make the LFC process less endothermic. A less endothermic LFC process will take less thermal energy from the molten metal and thus fill the mold completely. This may reduce the entrapment of polystyrene pyrolysis products and formation of liquid styrene defects. A reduction in the degradation temperature of the foam will help to minimize entrapment of foam pyrolysis products in the solidifying melt and hence reduce fold defects [2-5]. At the $80 \%$ weight loss mark (i.e., $20 \%$ on the graph of Figure 86), it was found that the time taken to degrade Grade A was 2290 seconds, and it took less time to degrade the novel polystyrene composite beads. Further, it was found that Grade B took the least amount of time to degrade (2168 seconds). 


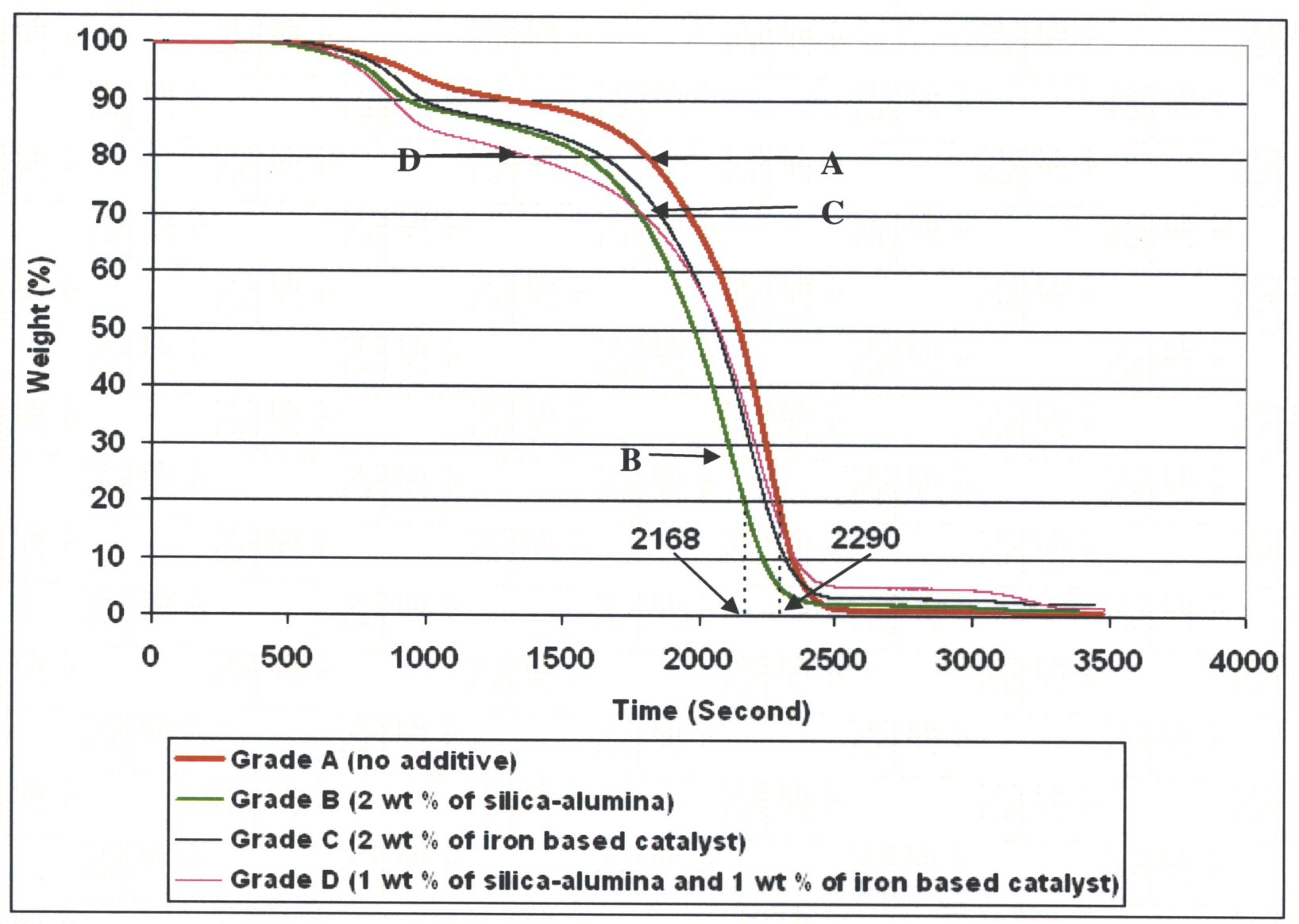

Figure 86: Degradation of Grades A, B, C and D with Respect to Time

Figure 87 also showed that the novel polystyrene composite beads degraded faster than Grade A. In the temperature range from 100 to $330{ }^{\circ} \mathrm{C}$, it was found that Grade D had the largest drop (20 wt \%) in weight mainly due to depolymerization. Following the observations of Archodoulaki et al. [40], it can be suggested that the chain-ends in Grades B, C and D were unstable due to their low molecular weight. At a temperature of $330{ }^{\circ} \mathrm{C}$, Grade B was found to degrade faster at a rate of $1.21 \%$ /minute than Grade A (0.79\%/minute), although it had a low molecular weight. Hence, it suggested that this high degradation rate of these novel polystyrene composite beads might be due to the catalysts. It was also found that in the temperature range of $200-300{ }^{\circ} \mathrm{C}$, the percent weight loss with respect to time was constant for all the grades, suggesting minimal degradation. Random scission was the likely degradation process at temperatures above $330{ }^{\circ} \mathrm{C}$ [78 - 80]. 


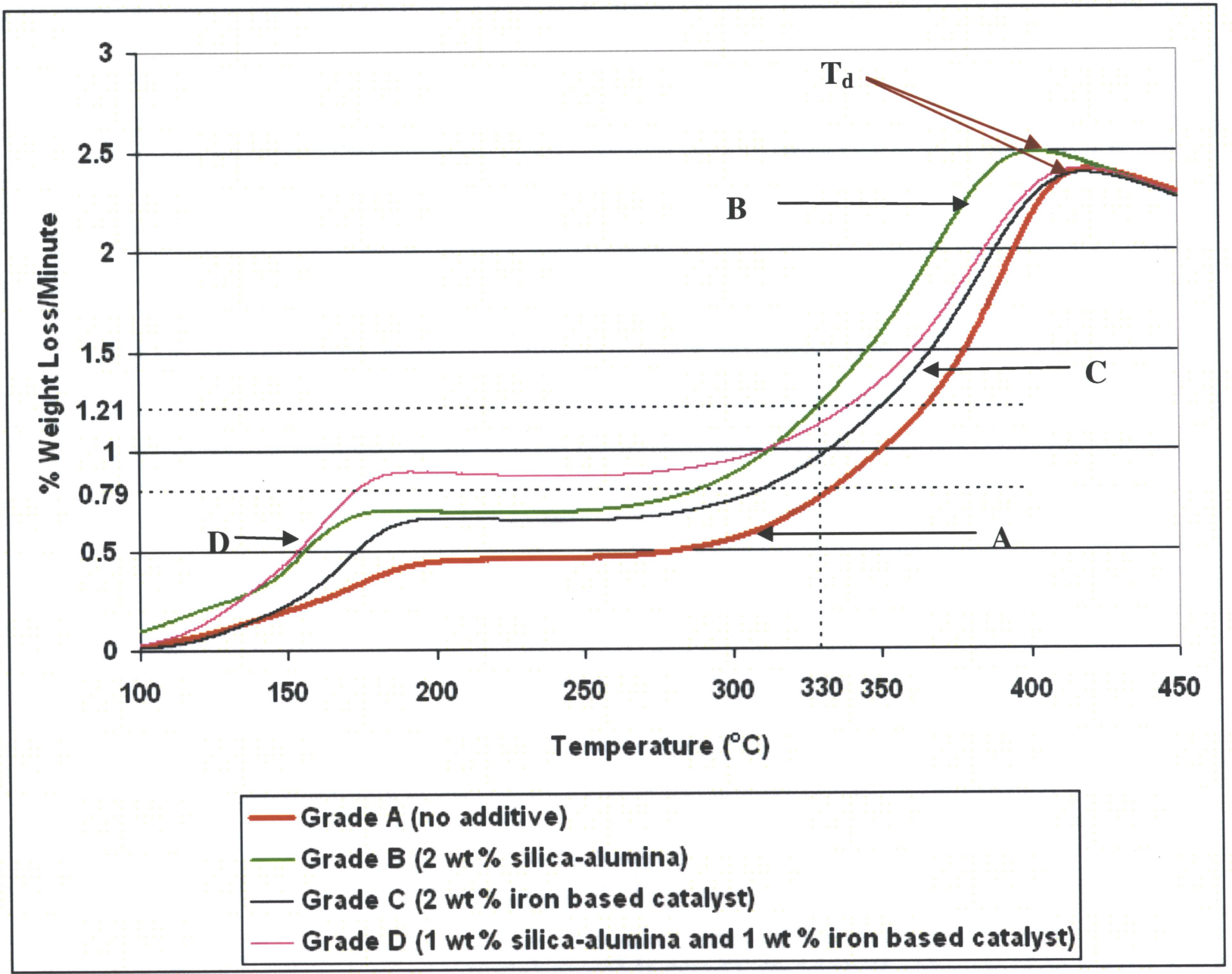

Figure 87: Rate of Degradation of Grades A, B, C and D with Respect to Temperature

\subsubsection{Effect of Additives on Glass Transition Temperature, $T_{g}$}

$\mathrm{T}_{\mathrm{g}}$ gives a good indication of the viscosity of the polymer [36] and it was found that the average $\mathrm{T}_{\mathrm{g}}$ values were reduced by addition of catalysts. As stated earlier, the catalyst particles acted like plasticizers into the polymer matrix and affected the molecular weight. The catalyst particles embedded themselves between the polymer chains, increasing the inter-chain spacing and allowing them to move past one another at lower temperatures [77]. Hence, it can be suggested that the catalysts caused a reduction in the molecular weight which in turn reduced the glass transition temperature (Figure 88). 


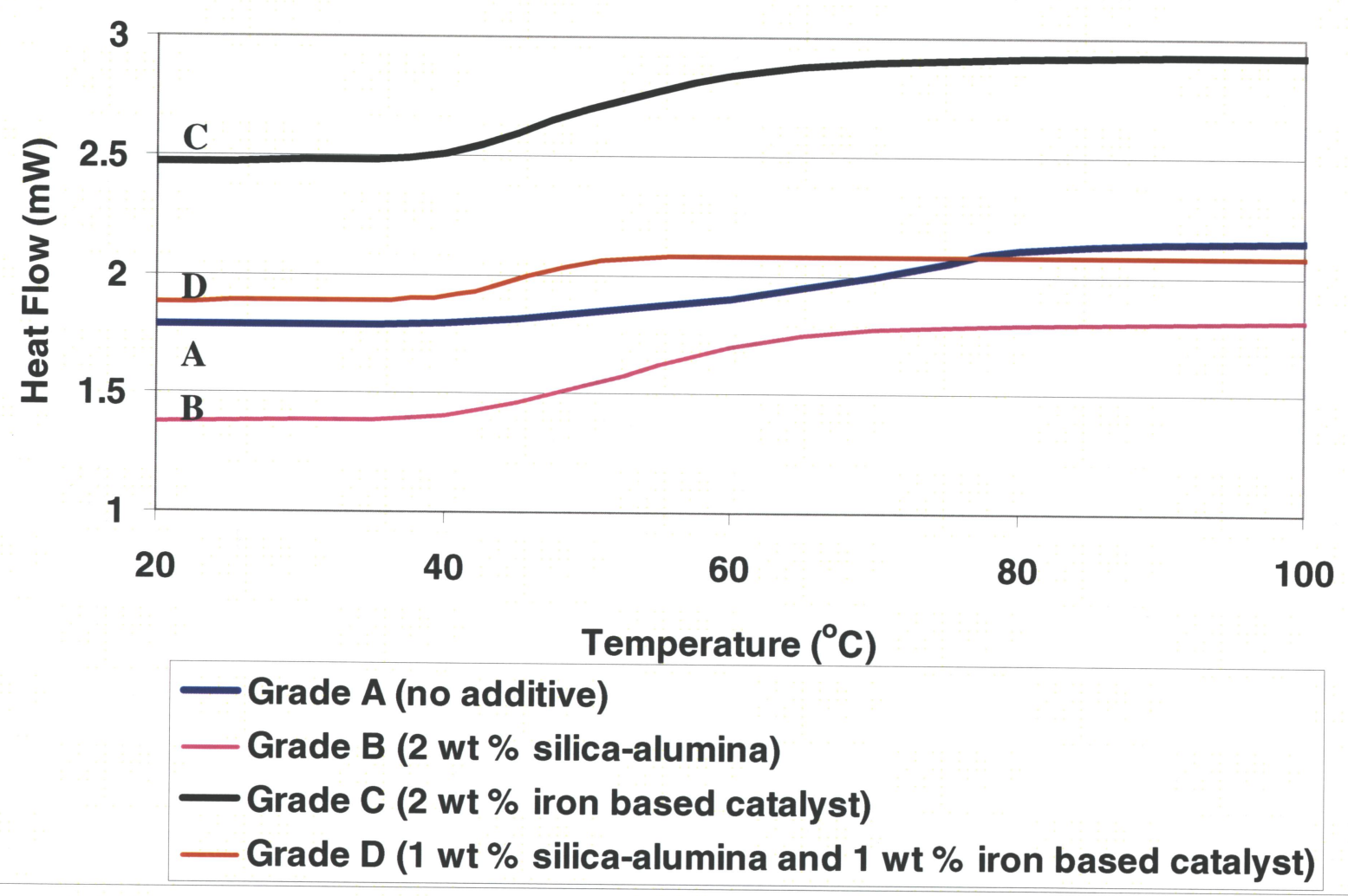

Figure 88: Effect of Additives on $\mathrm{T}_{\mathrm{g}}$ for Grades A, B, C and D (based on Figures 37 - 40)

\subsubsection{Effect of Molecular Weight on Thermal Degradation}

The $\mathrm{M}_{\mathrm{w}}$ for Grade A was found to be 30,213 Da and the $\mathrm{M}_{\mathrm{w}}$ for the polystyrene composite beads (Grades B, C and D) was found to be less than 26,000 Da. Hence, the difference between the rates of degradation of the control polymer beads and the composite beads might be a result of their molecular weights rather than the effect of the catalysts. Thus, it is important to understand the relationship between molecular weight and rate of degradation of a polymer to verify the effectiveness of the catalysts.

Grassie et al. [81] carried out the pioneering investigation of the influence of molecular weight on the degradation of a polymer. They found that the probability of complete disintegration of a polymer increased with higher molecular weight. Kokta et al. [82] studied the degradation of 
polystyrene and concluded that polystyrene degrades by two mechanisms. The first reaction occurred at lower temperatures (below $200{ }^{\circ} \mathrm{C}$ ) and the second reaction at higher temperatures (above $300{ }^{\circ} \mathrm{C}$ ). They also found that an increase in molecular weight of the polystyrene increased the rate of degradation.

Funt et al. [41] also found that the temperature at the maximum rate of degradation had a clear dependence on the molecular weight (Figure 89). They suggested that molecular weight affected the rate of decomposition of polystyrene through a change in the preexponential factor (A) (please refer to Equation 13). High molecular weight polystyrene has a higher preexponential factor than low molecular weight polystyrene.

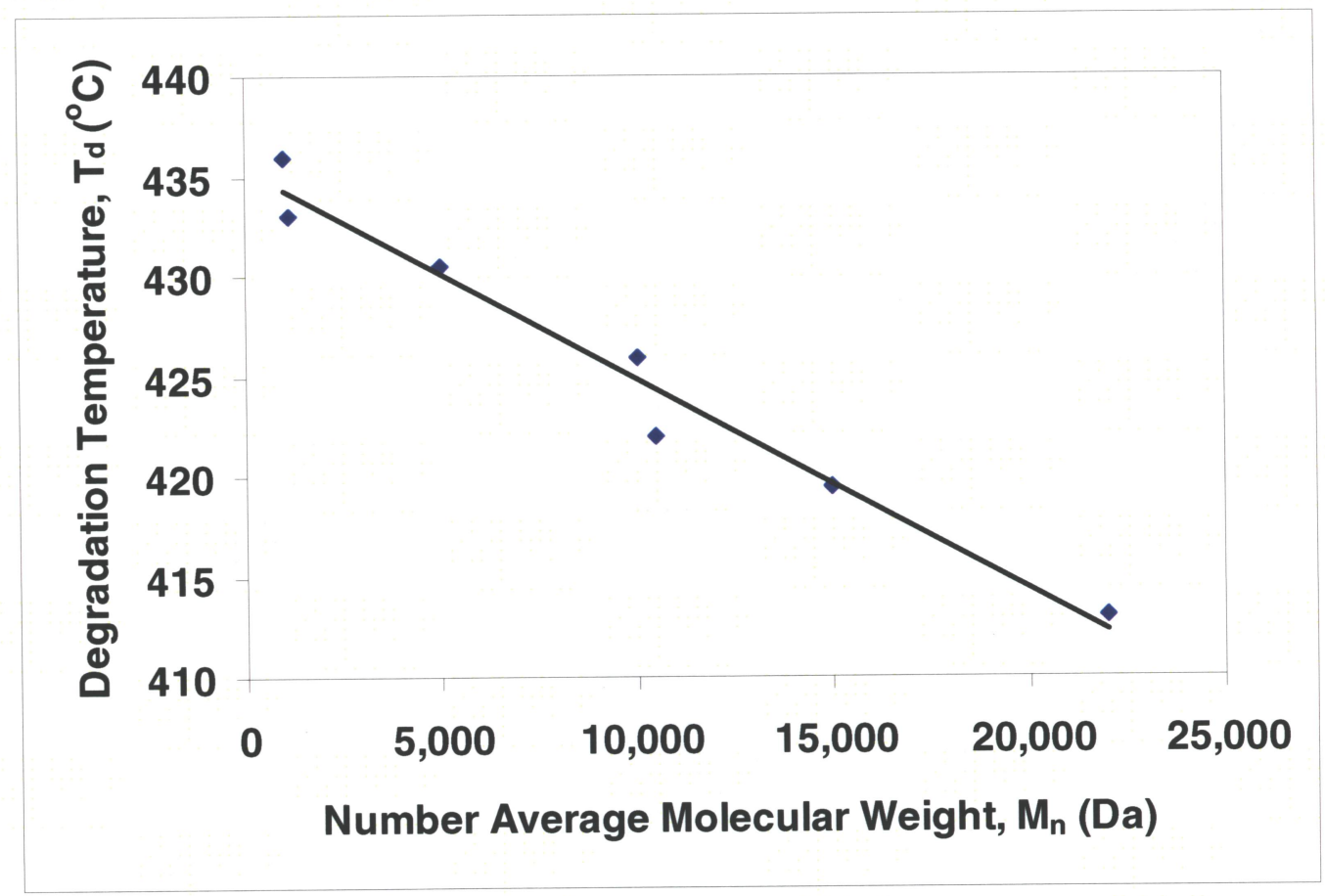

Figure 89: Dependence of Molecular Weight on the Decomposition Temperature [41]

Grade A had both higher $M_{n}$ and $T_{d}$ (please refer to Figure 87), which contradicted the observations of Funt et al. [41] (Figure 90). Nonetheless, it may be suggested that the catalysts were certainly responsible in the decrease of the $T_{d}$ for the Grades B, C and D beads. Porter $e t$ 
al. [83], Wade et al. [84] and Kitayama et al. [85] also found that the high molecular weight polymers were more susceptible to degradation. Furthermore, Gandhi et al. [86] found that high molecular weight polystyrene beads were readily thermo-mechanically degraded and they suggested that high molecular weight polystyrene were more susceptible to random chain scission. They also found that thermo-mechanical stability depended inversely on molecular weight and it was reduced for very high molecular weight polymers.

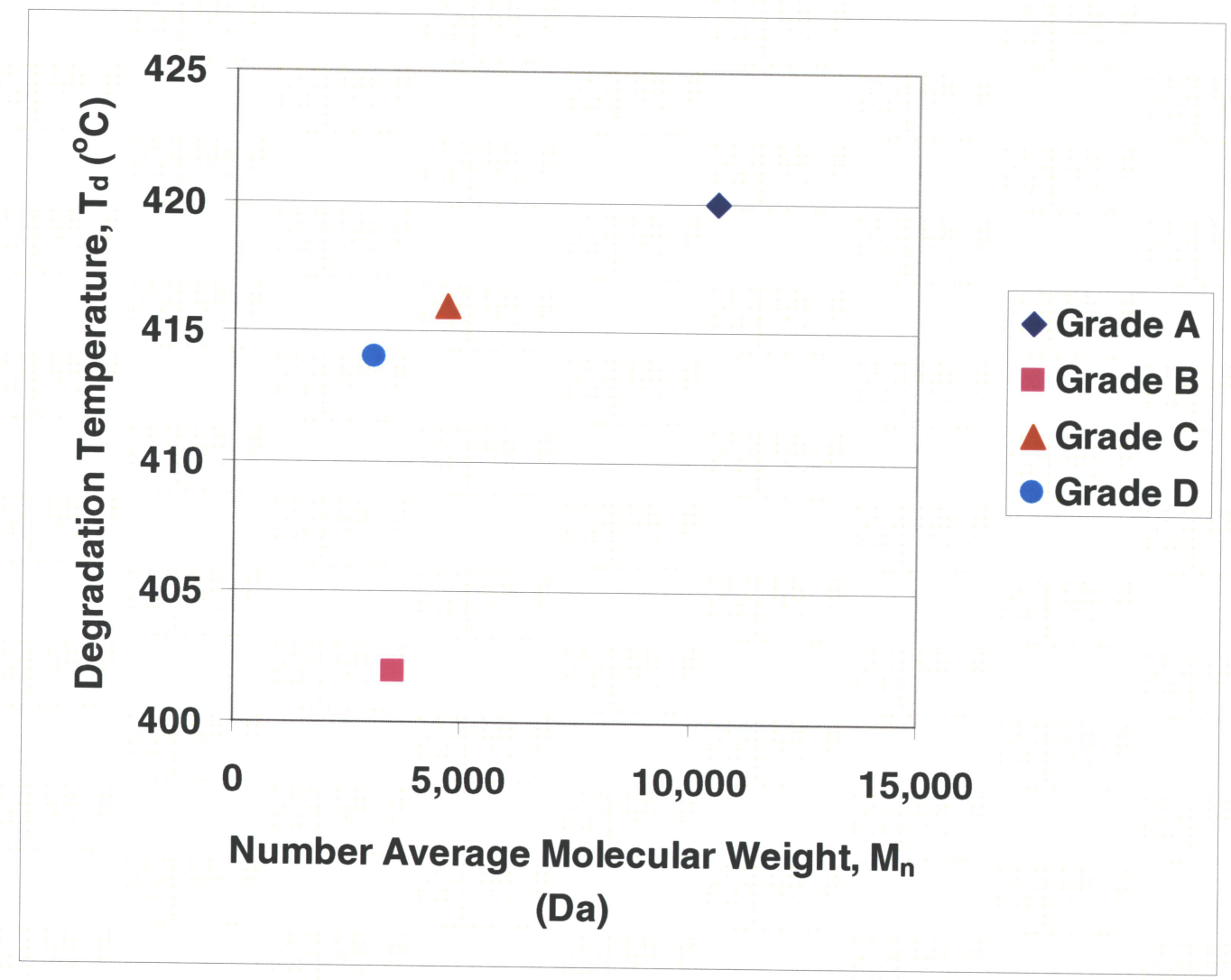

Figure 90: Effect of Molecular Weight on $\mathrm{T}_{\mathrm{d}}$ for Grades A, B, C and D

Nishizaki et al. [87] found that $T_{0}$ was dependent on $M_{n}$. According to them, an increase in molecular weight decreased the $T_{0}$ (Figure 91). However, the TGA graphs as already shown in Figure 85 contrasted the findings of Nishizaki et al. [87]. The effect of $M_{n}$ on $T_{o}$ was analyzed 
(Figure 92) and it was found that an increase in $M_{n}$ resulted in an increase in $T_{0}$. Hence, it can be confirmed that the depression of $\mathrm{T}_{\mathrm{O}}$ was attributable to the presence of the catalysts.

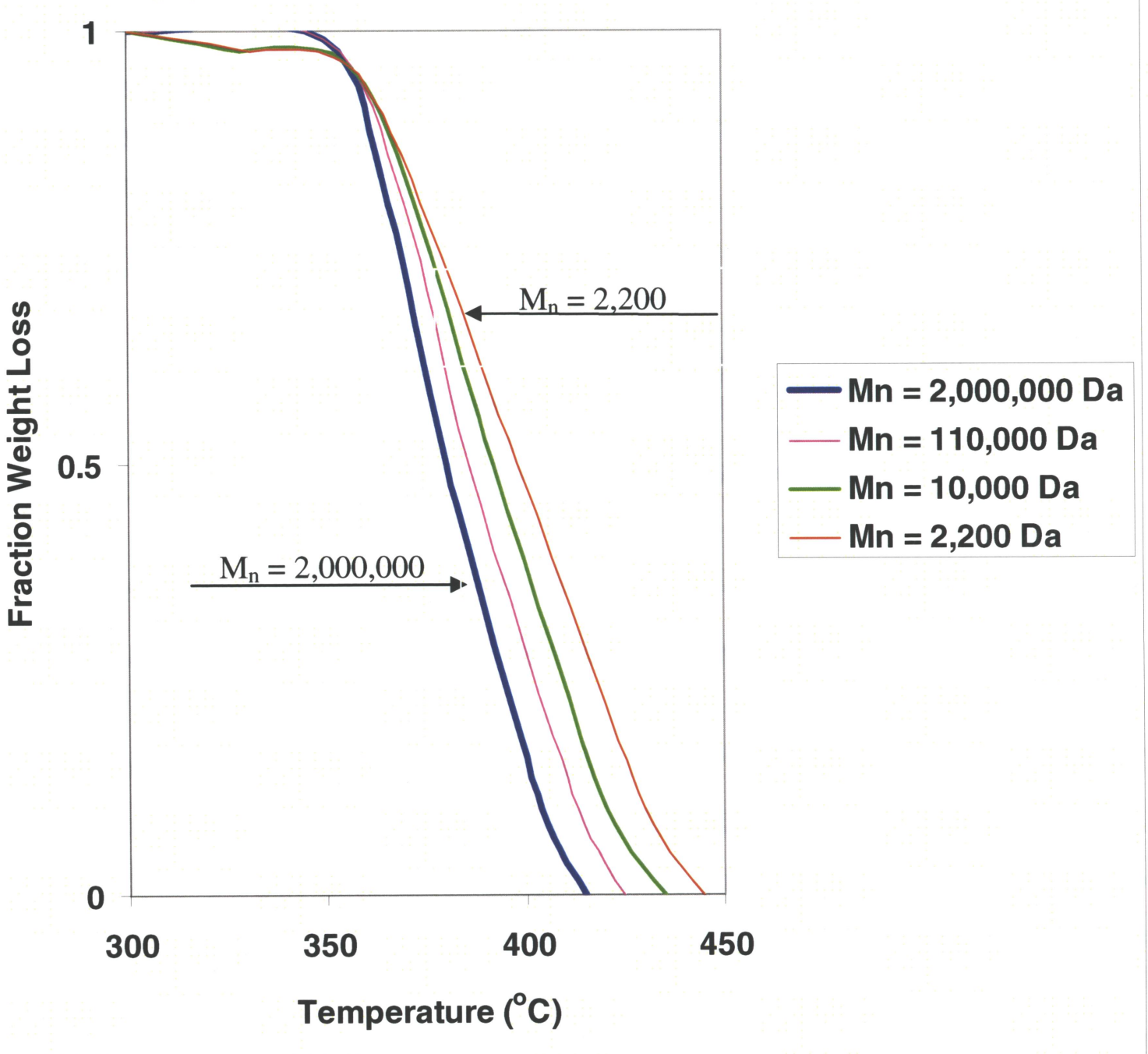

Figure 91: Molecular Weight of Polystyrene versus Temperature [87] 


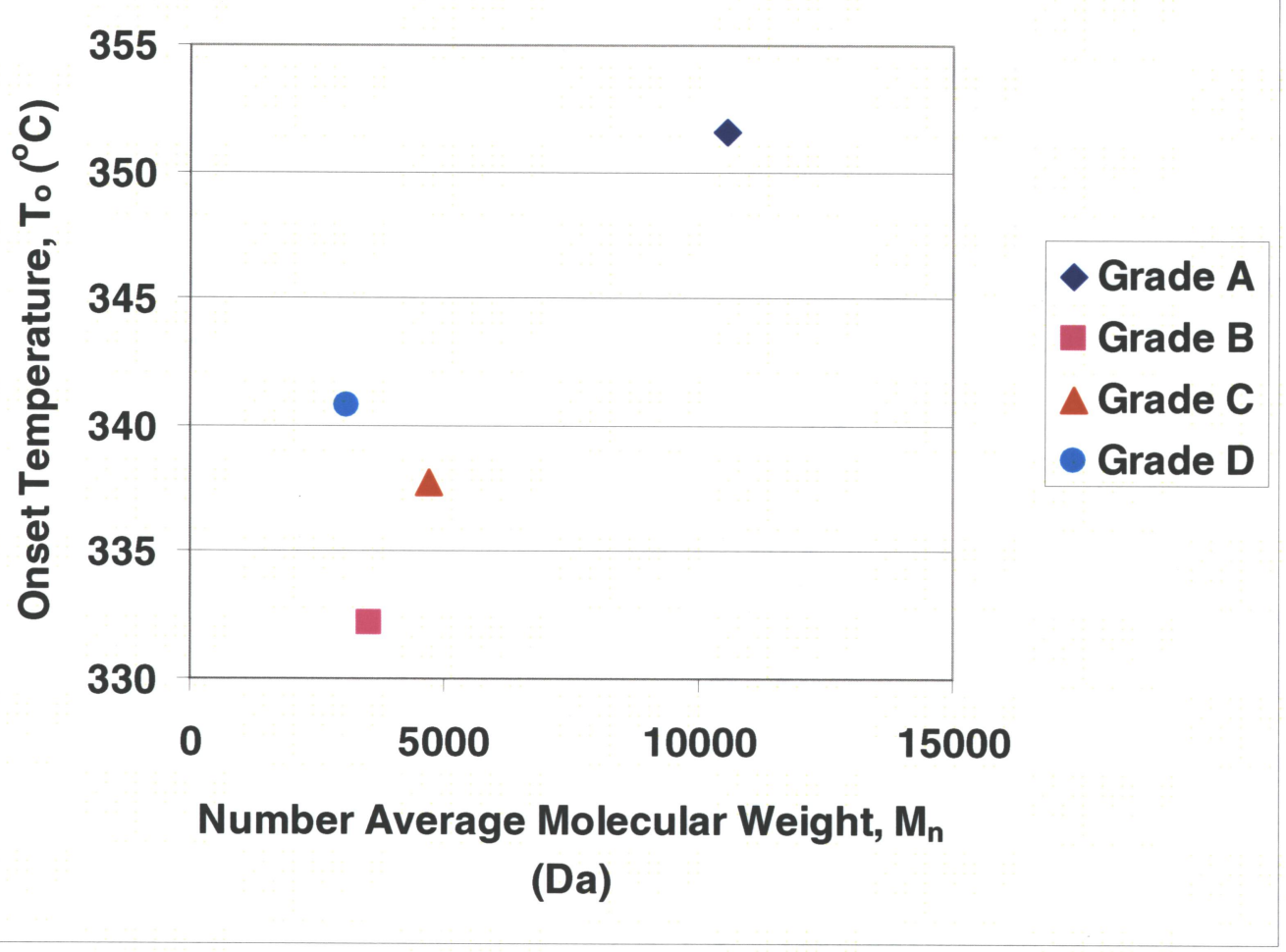

Figure 92: Effect of Molecular Weight on $\mathrm{T}_{\mathrm{o}}$ for Grades A, B, C and D

Madras et al. [88] found that the rate of random-chain scission increases with an increase in molecular weight. They found that the random-scission rate coefficient, k (Equation 13) was dependent on the molecular weight. At relatively low molecular weights, $\mathrm{k}$ varied linearly. At relatively high molecular weights, $\mathrm{k}$ followed a square dependence on $\mathbf{M}_{\mathrm{w}}$ (Figure 93). Furthermore, Reich et al. [89] explained this increase in rate of random-chain scission at higher molecular weight by enhanced intermolecular transfer (Equation 8), where the polymer radicals abstracted hydrogen atoms from polystyrene followed by random chain scission. Moreover, Vollhardt et al. [90] suggested that long chains had a greater tendency to form tight curves (kinks) than short chains. Thus, the resulting bond-angle weakened the $\mathrm{C}-\mathrm{C}$ bond strength, causing a higher $\mathrm{C}-\mathrm{C}$ scission rate. 


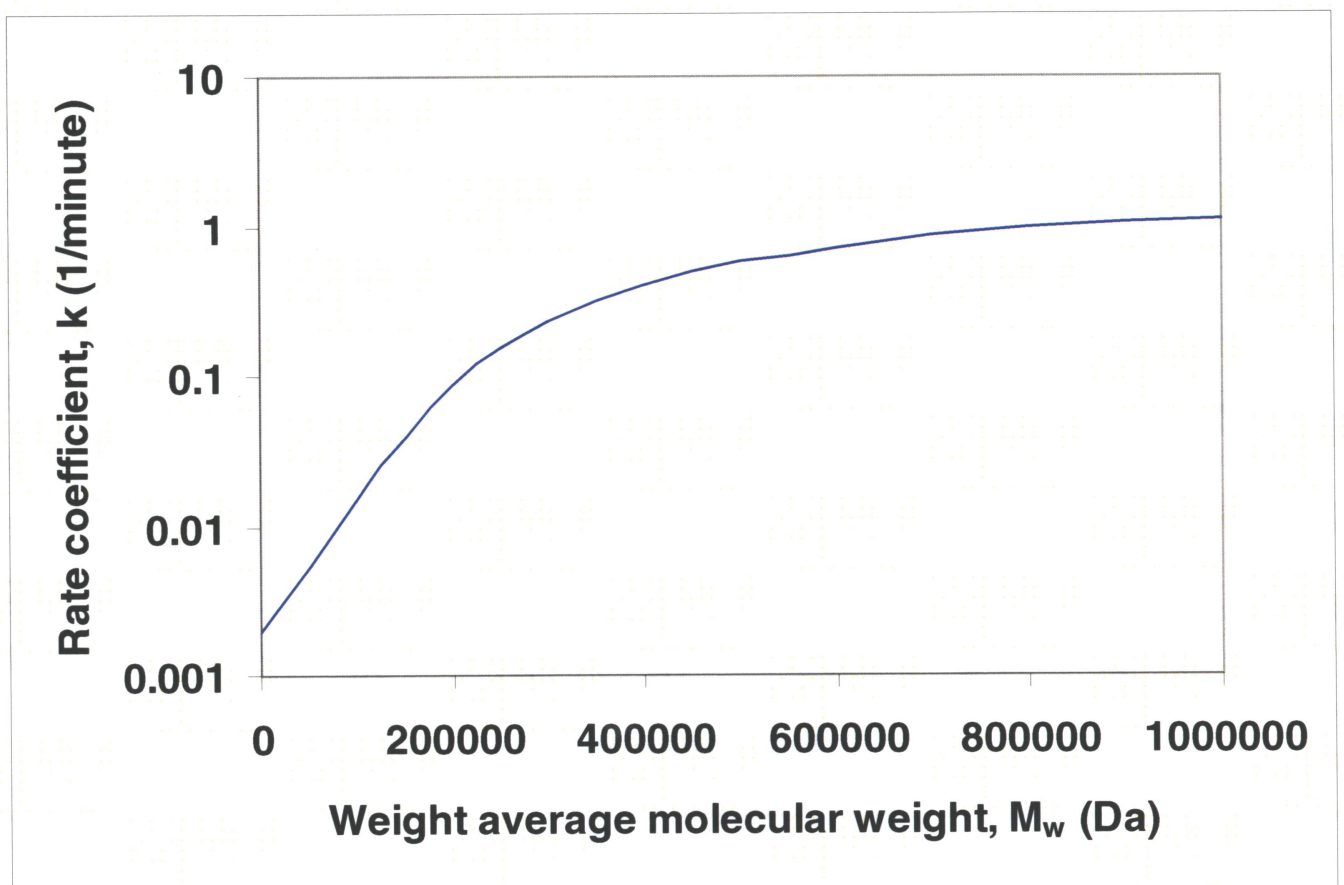

Figure 93: Dependence of Rate of Random Chain Scission, k on Weight Average Molecular Weight, $\mathrm{M}_{\mathrm{w}}[88]$

Vijayalakshmi et al. [91] also found that the rate of degradation increases with increase in molecular weight. They also suggested that the long chains had greater tendency to form tight curves than short chains. Hence, the resulting bond angle weakened the strength of the $\mathrm{C}-\mathrm{C}$ bond resulting in a higher scission rate. Furthermore, they suggested that longer chains had lower mobility and thus thermal energy applied to the system could not be released by chain motion.

It was well known that CTA reduces the molecular weight of a polymer. Hence, a new polymerization run was carried out to confirm the effect of molecular weight on the degradation profile of the polystyrene composite beads. The formulation for this new sample, which is referred to as Grade BM, was similar to the recipe of Grade B (Table 2), except that AMS was not added. Figure 94 shows the GPC graph of Grade BM and Table 21 represents a summary of the GPC results. 


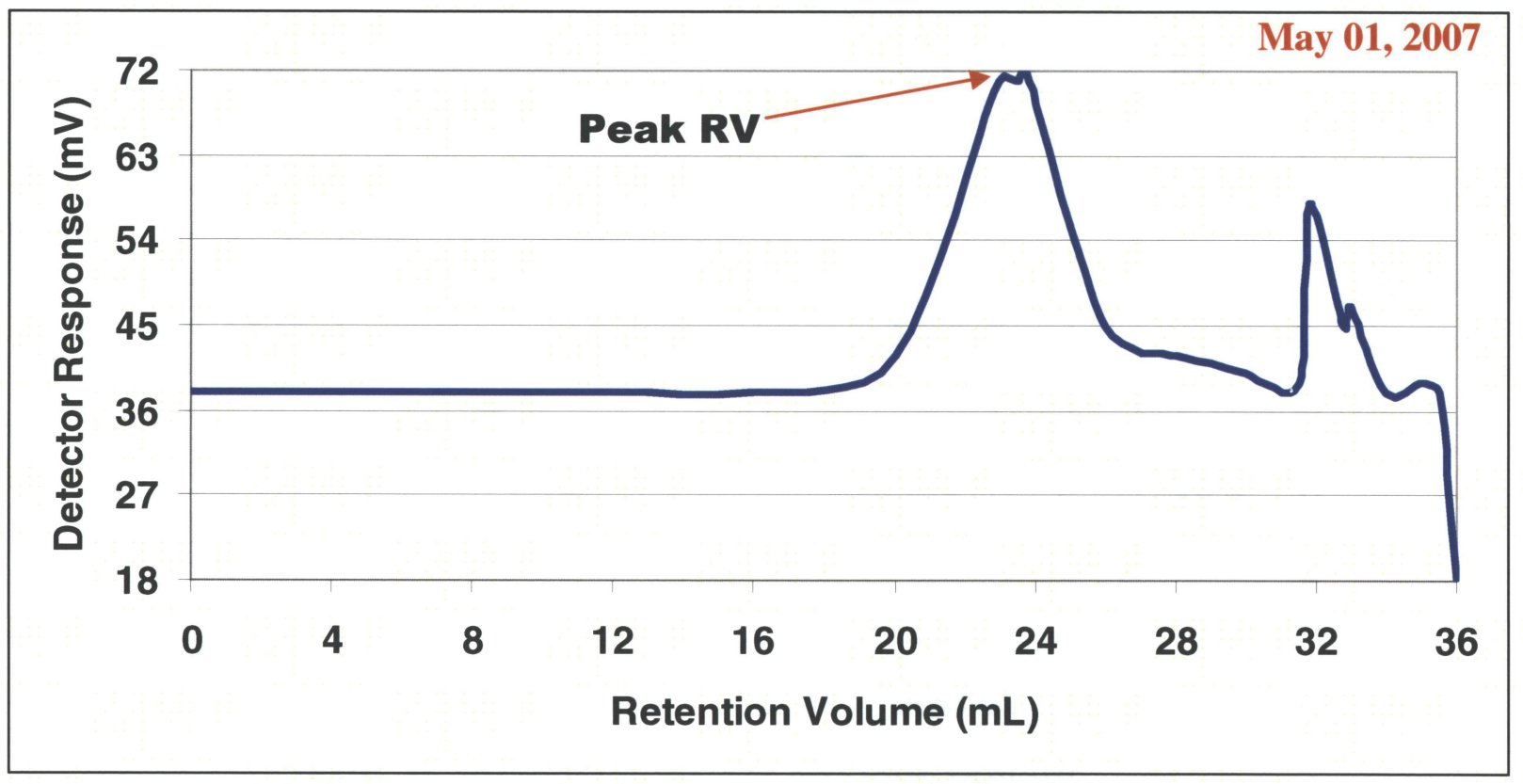

Figure 94: GPC Graph of Grade BM

Table 21: Molecular Weight for Grade BM

\begin{tabular}{|c|c|}
\hline Peak RV $(\mathbf{m L})$ & 23.728 \\
\hline $\mathbf{M}_{\mathbf{n}}$ (Daltons) & 13,193 \\
\hline $\mathbf{M}_{\mathbf{w}}($ Daltons) & 30,635 \\
\hline PDI $\left(\mathbf{M}_{\mathbf{w}} / \mathbf{M}_{\mathbf{n}}\right)$ & 2.322 \\
\hline
\end{tabular}

$\mathrm{T}_{\mathrm{o}}$ of Grade BM was found to be $336{ }^{\circ} \mathrm{C}$ (Figure 95). TGA graphs for Grades A, B and BM was plotted (Figure 96). This figure shows that depolymerization occurred at lower temperatures in the range of $100-200{ }^{\circ} \mathrm{C}$. The depolymerization mechanisms confirmed that higher molecular weight polymers degrade slower [40]. 


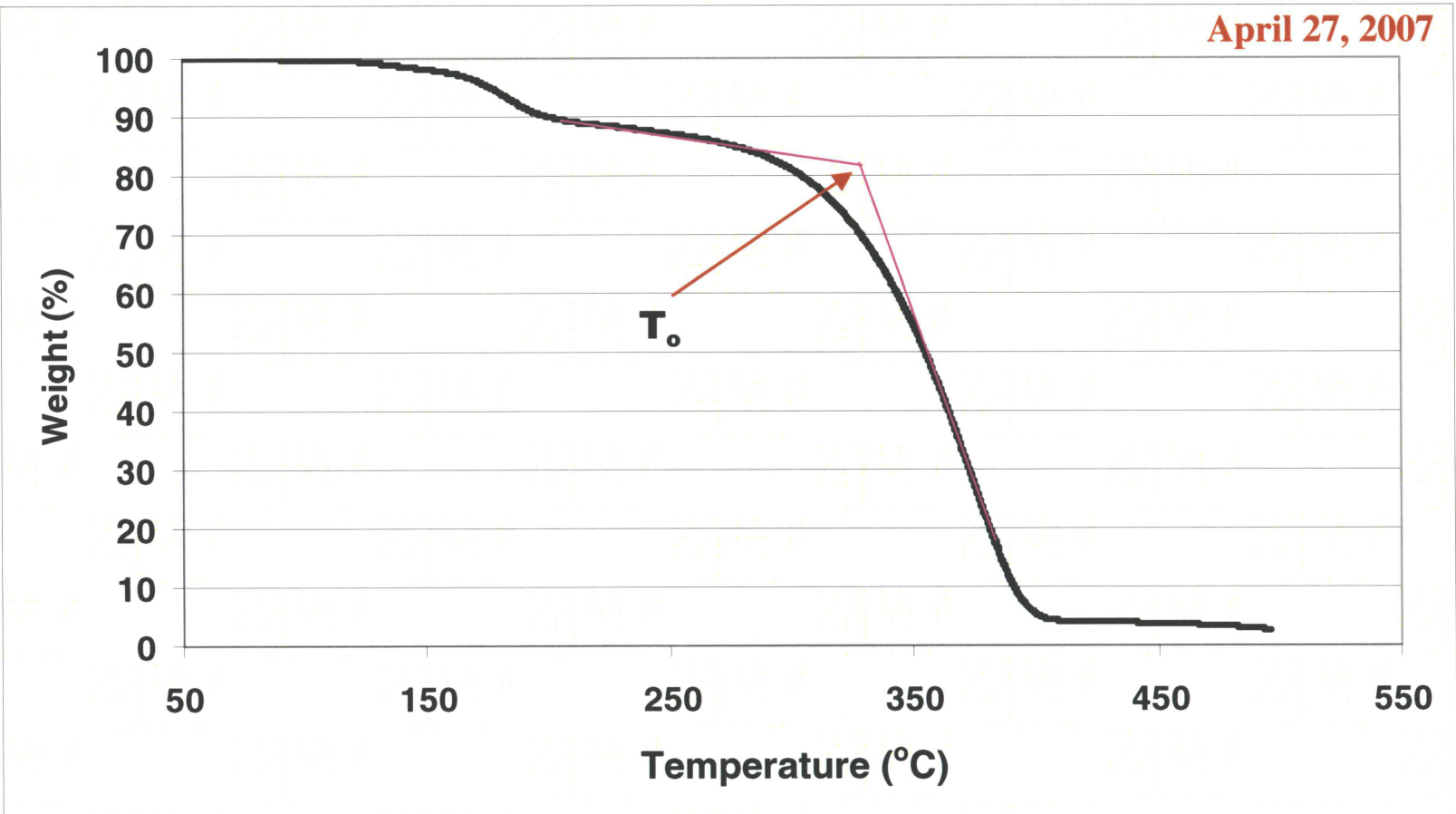

Figure 95: TGA Graph of Grade BM

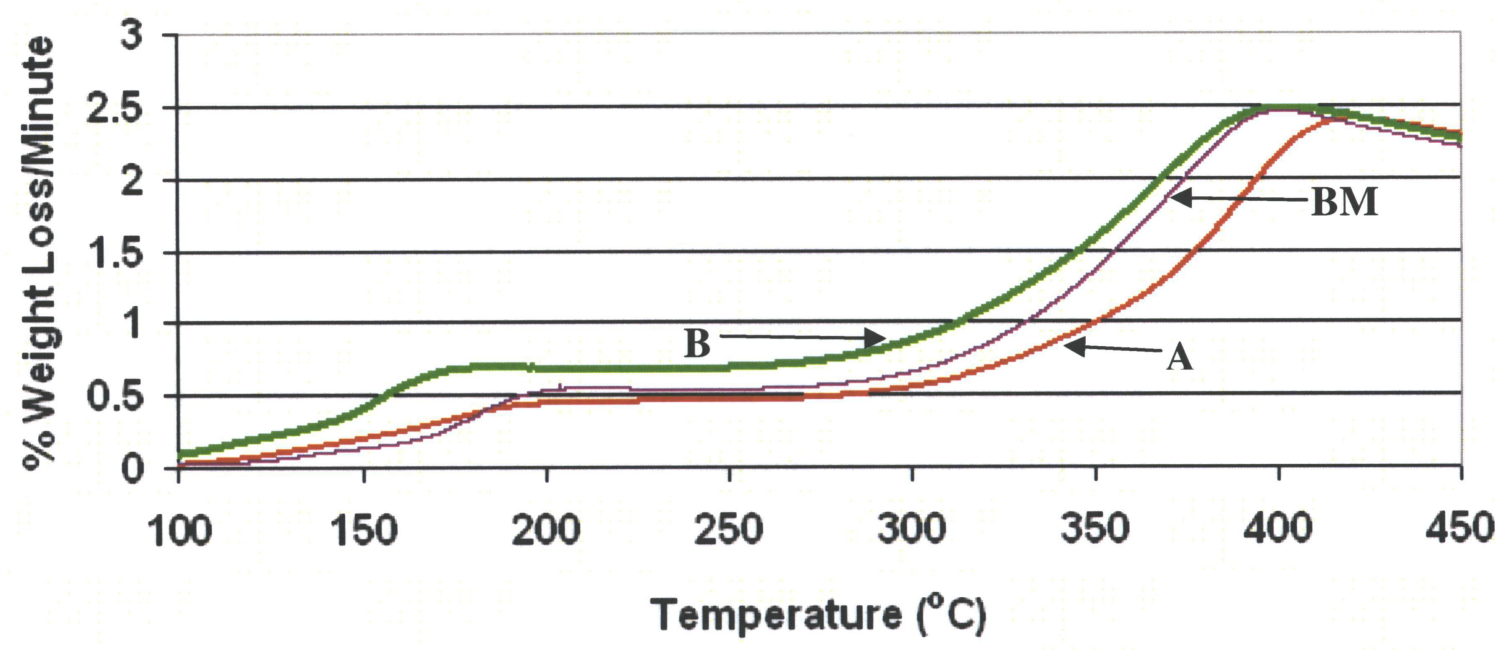

- Grade $A$ (no additive)

- Grade B (2 wt \% silica-alumina)

Grade BM (2 wt \% silica-alumina without alpha methyl styrene)

Figure 96: Rate of Degradation of Grades A, B and BM with Respect to Temperature 
Normally, high molecular weight polymers are expected to degrade faster due to random chain scission and to have a smaller onset temperature of degradation than low molecular weight polymers. However, the difference between Grades B and BM was not due to the molecular weight only, but also due to the presence of alpha methyl styrene in Grade B. Xue et al. [48] found that organic peroxide in the presence of AMS increases the rate of degradation of polystyrene by enhancing chain-transfer during the degradation process.

Finally, it can be concluded that the decrease in $T_{0}$ values and the increase in the rate of degradation for the novel polystyrene composite beads were due to the presence of the catalysts and not due to their low molecular weight. On the contrary, high molecular weight polymer degrades faster than low molecular weight polymer.

\subsection{Discussion on the Production of High Molecular Weight Polystyrene}

\subsubsection{Effect of Reaction Time on Monomer Conversion}

The monomer conversion was calculated from Equation 17 given below [29]:

$\%$ Conversion $=\{$ polymer weight $\times 100\} /\{$ monomer weight + polymer weight $\}$

The polymer weight consisted of LFC, CUP and agglomerate beads. The percent monomer conversion was found to increase with an increase in the reaction time (Figure 97). A longer reaction time provided the monomer more time to polymerize into polymer. It was well known that an increase in monomer conversion increased the molecular weight of the polymer $[7,16$, $18,20,23,27,28]$. Thus, a high monomer conversion was expected to produce polystyrene beads with high molecular weight. 


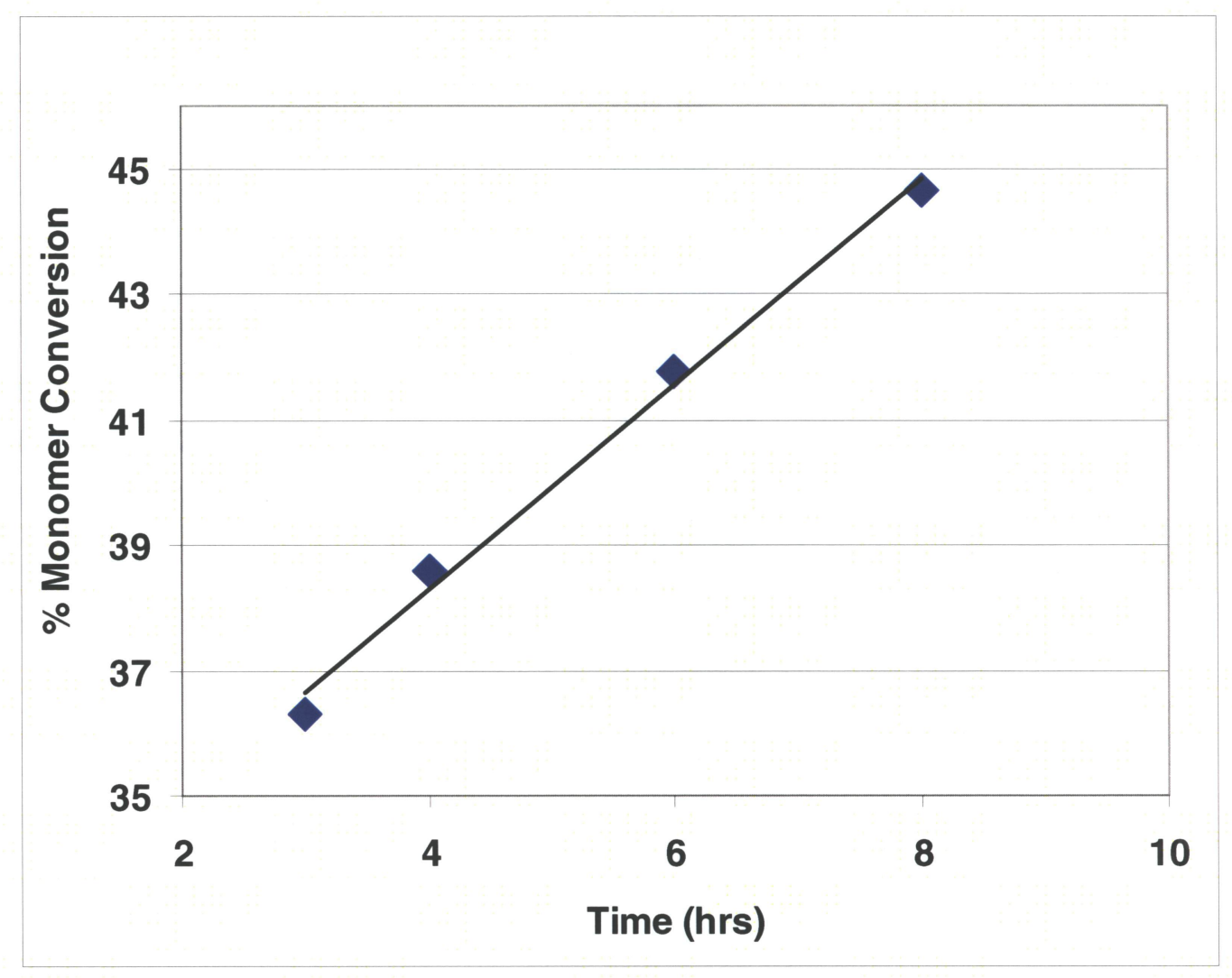

Figure 97: Effect of Reaction Time on Monomer Conversion

\subsubsection{Effect of Reaction Time on Bead Size Distribution}

The histogram (Figure 98) represents the mass distribution of the LFC, CUP and agglomerate beads (please refer to section 3.4) for Grade A1, A2, A3 and A4. It was found that the amount of agglomerate (please refer to section 4.2.1) decreased with increasing reaction time. This might be due to a depletion of the monomers (sticky). Further, Lazrak et al. [22] observed a decrease in drop coalesce due to a reduction in the interfacial tension and viscosity of the dispersed phase as the reaction time is increased. The amount of CUP beads was found to increase with reaction time, while the amount of LFC beads was decreased. Kichatov et al. [9] suggested that the small drops were more prone to coalesce into larger drops as the reaction time increases. 


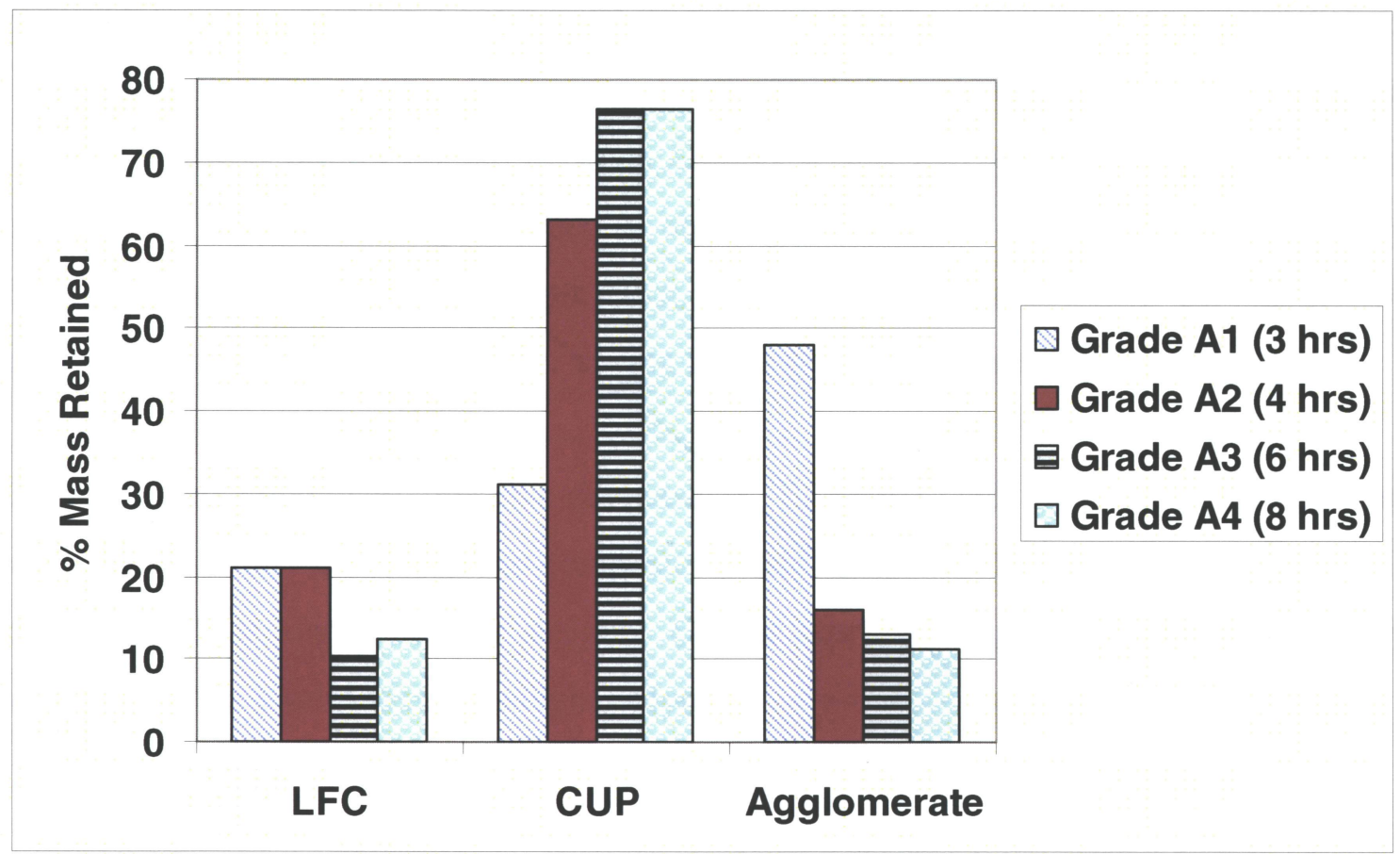

Figure 98: Effect of Reaction Time on Bead Size Distribution

\subsubsection{Effect of Reaction Time on Molecular Weight}

The $\mathrm{M}_{\mathrm{w}}$ values for both the LFC and CUP polystyrene beads were found to increase with an increase in the reaction time. Moreover, it was found that CUP beads had higher $\mathrm{M}_{\mathrm{w}}$ than LFC beads (Figure 99). Hence, it can be suggested that the size (diameter) of the beads also affected the molecular weight. Horak et al. [17] found that smaller beads provided a greater surface area to volume ratio and thus increased the absorption of oligomer radicals from the dispersed phase, resulting in higher molecular weight.

Interestingly, Bhargava et al. [92] found that larger-sized beads had higher molecular weight than smaller-sized beads (Figure 100). They suggested that turbulent motion produced during the polymerization process caused the monomer drops to undergo constant peripheral distortions and renewal of surfaces. Hence, this turbulent motion affected the thermal conditions in the beads, which resulted in the formation of higher molecular weight in the larger beads. Thus, it 
may be suggested that turbulence (e.g., broken flasks) might have caused the CUP beads to have higher $\mathbf{M}_{\mathrm{w}}$.

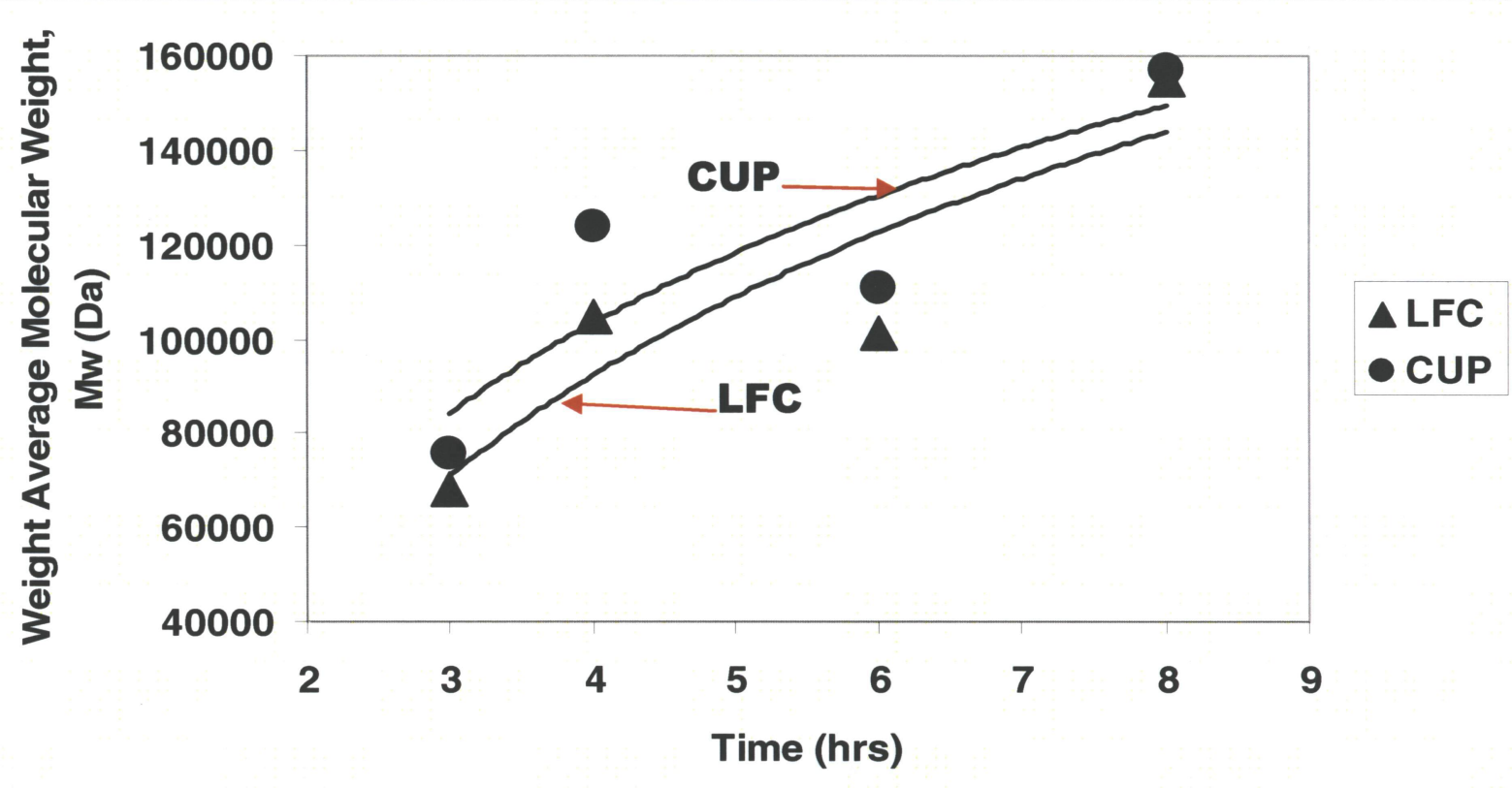

Figure 99: Effect of Reaction Time on Molecular Weight

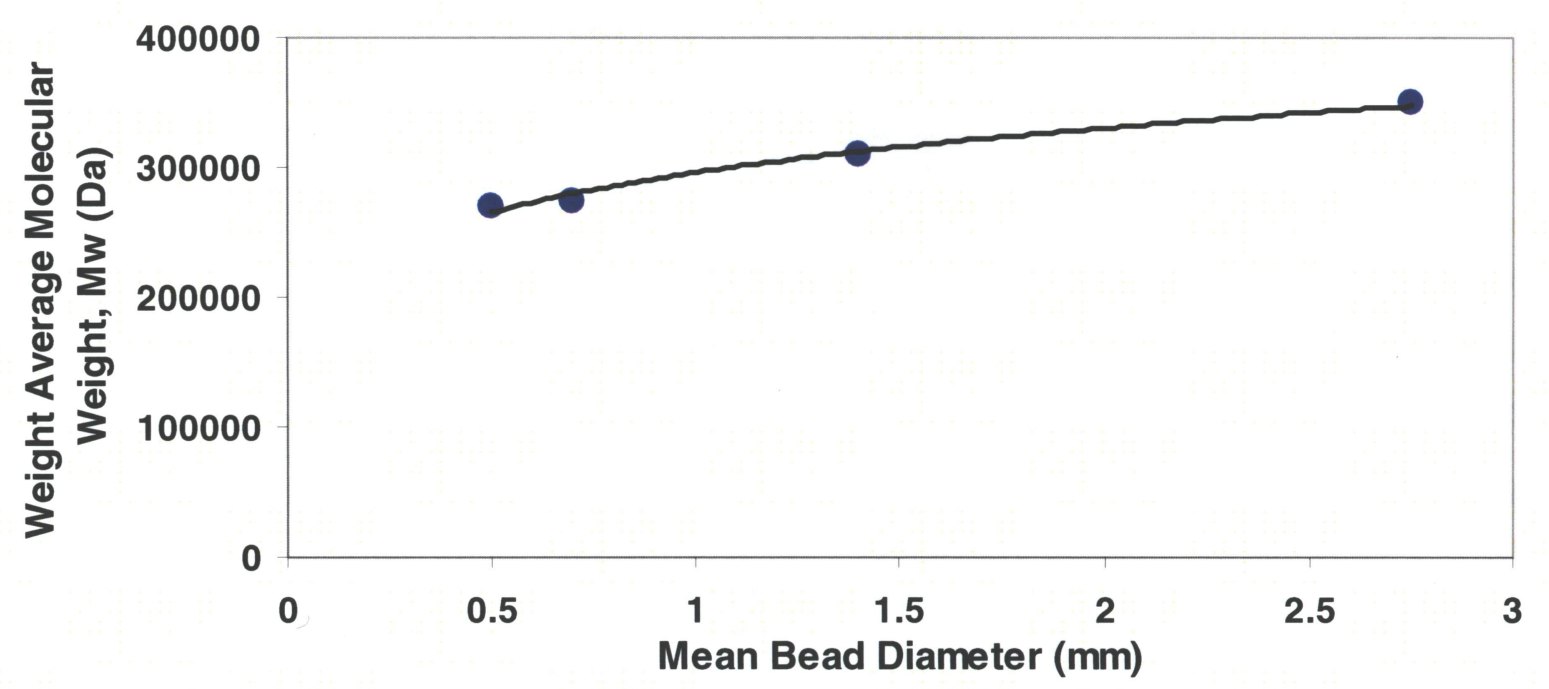

Figure 100: Effect of Bead Size on Molecular Weight [92] 


\subsubsection{Effect of Mass of Initiators on Size Distribution}

It was found that the amount of agglomerate increased with a decrease in the mass (or concentration) of the initiators (Figure 101). This decrease was related to the significant amount of unreacted monomer (sticky) in the suspension during polymerization. Horak et al. [17] found that a decrease in initiator concentration decreased both the initiation and termination rates during the polymerization process. Hence, they suggested that the polymerization cycles (or reaction time) were increased with a decrease in the initiator concentration. Thus, it may be suggested that the reaction time (4 hrs) was short, which in turn produced large amount of agglomerate.

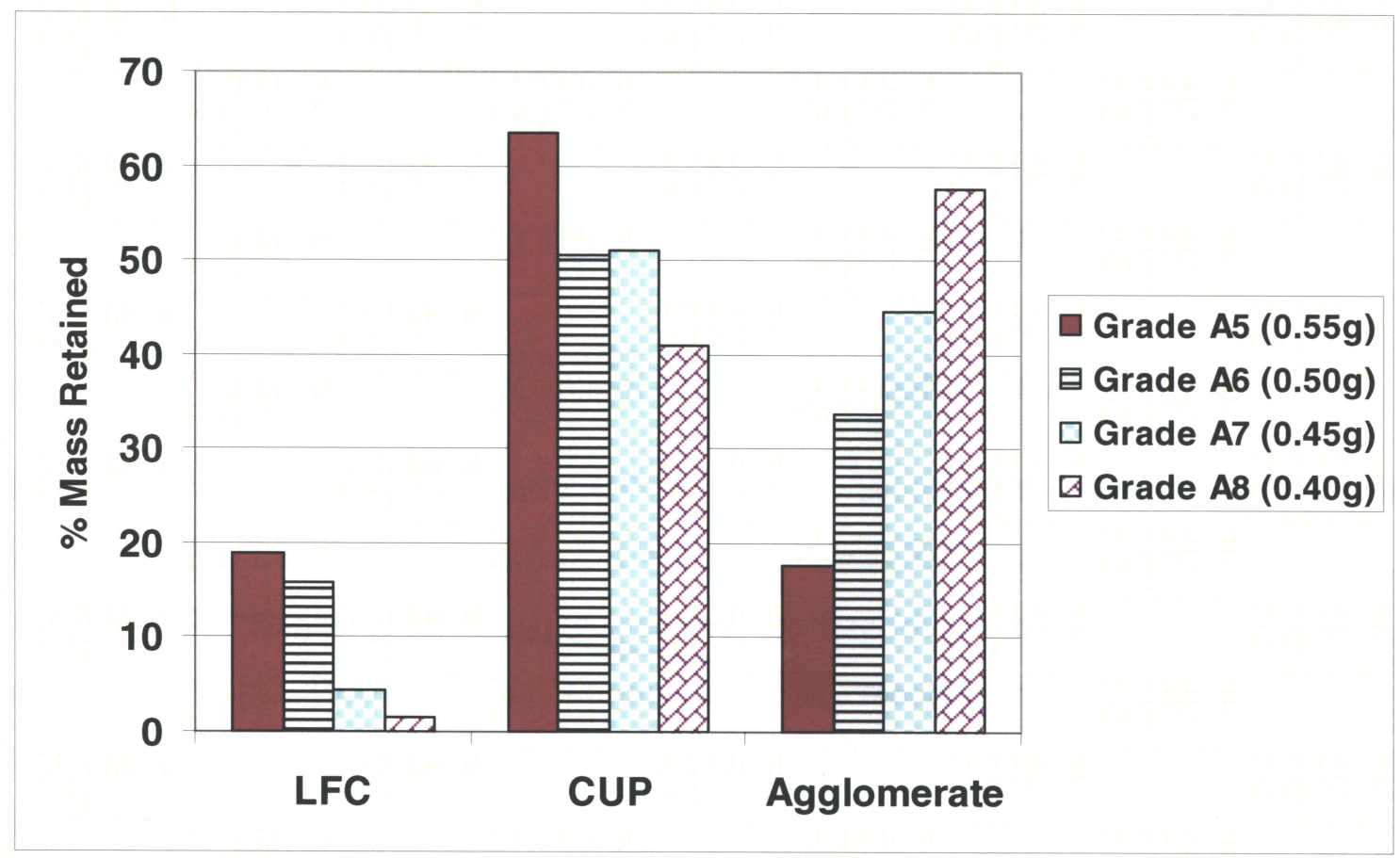

Figure 101: Effect of Mass of Initiators on Bead Size Distribution

\subsubsection{Effect of Mass of Initiators on Monomer Conversion}

The monomer conversion was found to decrease with an increase in the mass of initiators (Figure 102). It can be suggested that low initiator concentration lowered the termination rates, which in 
turn increased the monomer conversion [16]. Further, an increase in monomer conversion suggested an increase in $\mathbf{M}_{\mathrm{w}}[7,16,18,20,23,27,28]$.

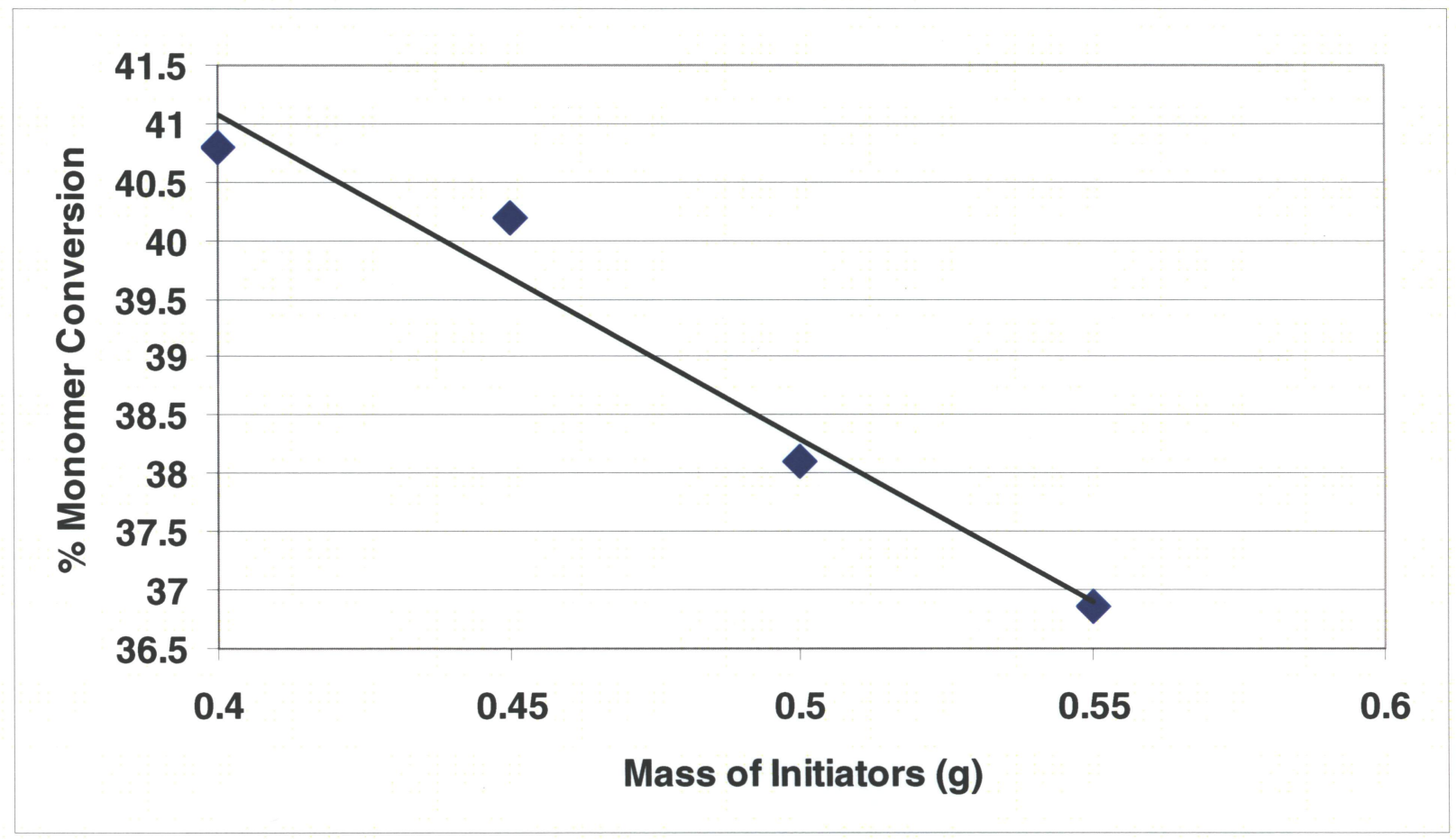

Figure 102: Effect of Mass of Initiators on Monomer Conversion

\subsubsection{Effect of Mass of Initiators on Molecular Weight}

The $\mathrm{M}_{\mathrm{w}}$ for both the LFC and CUP polystyrene beads increased with a decrease in the mass of initiators (Figure 103). It may be suggested that a low initiator concentration decreased the reaction rates, increased the polymerization cycles and decreased the terminal conversions $[7,16$, $18,20,23,27,28]$. Moreover, the polymerization process might have taken place inside the drops through the capture of oligomeric radicals [25]. These radicals might have grown into higher molecular weight. However, the formation of higher molecular weight in CUP beads relative to LFC beads again indicated that the turbulence affected the thermal conditions in the beads during the polymerization process [92]. 


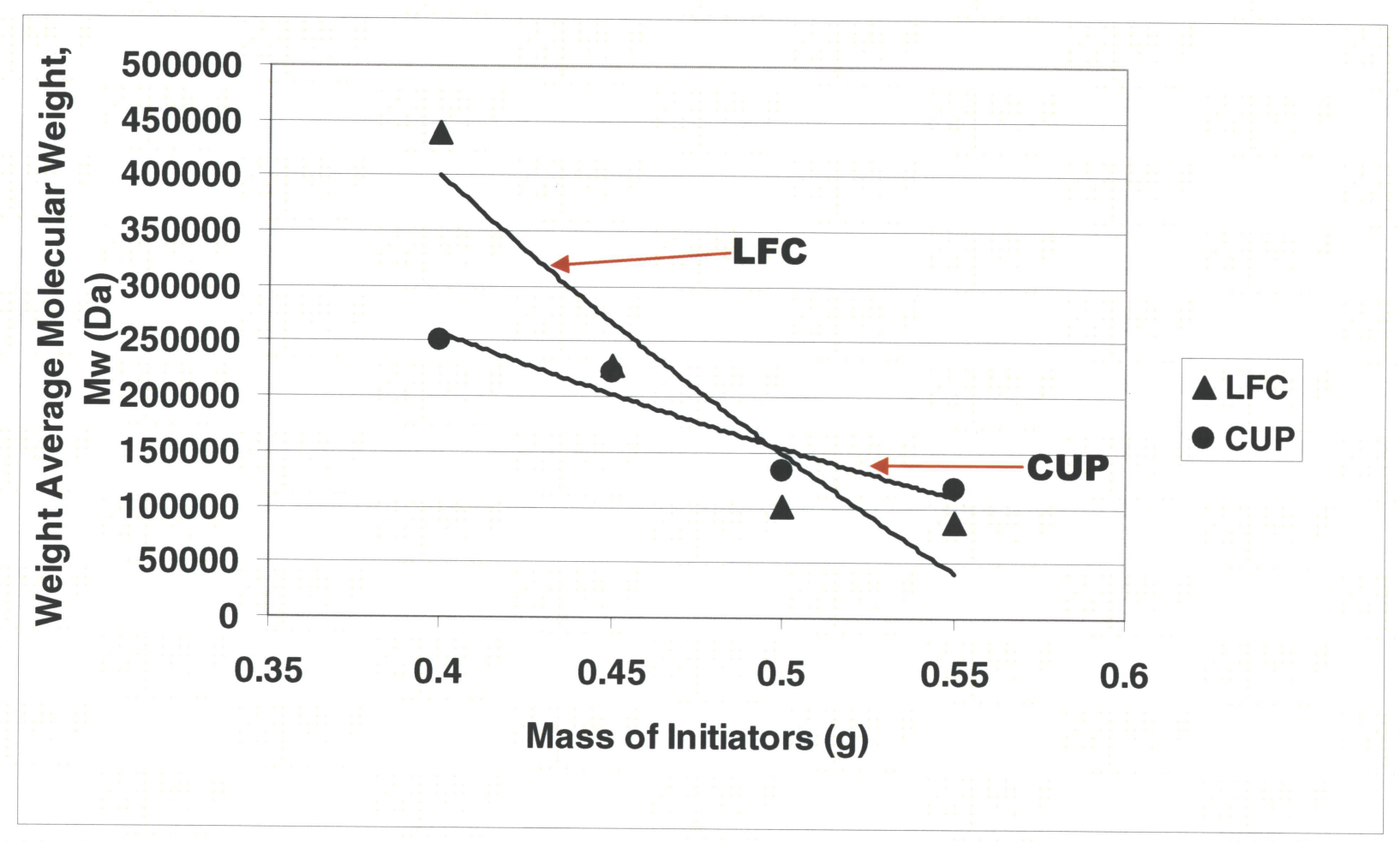

Figure 103: Effect of Mass of Initiators on Molecular Weight

\subsection{Discussion on the Production of High Molecular Weight Polymer with Silica-Alumina}

\subsubsection{Entrapment Mechanism of Silica-Alumina in the Production of Polystyrene Composite} Beads

It may be suggested that silica-alumina particles were trapped in the sticky monomer droplets during the early course of polymerization [76]. These particles prevented the formation of long chain polymer by positioning themselves between the monomers [77]. Hence, small-sized beads ( $\sim 30$ microns) were formed. Further, as the polymerization process progressed, these small-sized beads were engulfed by the larger monomer droplets (Figure 104 (a)). It was found that the number of these small-sized beads increased with an increase in the amount of silicaalumina. It was also found that some of these small-sized beads were pulled away during the microtome process leaving pores inside the main composite beads (Figure 104 (b)). 


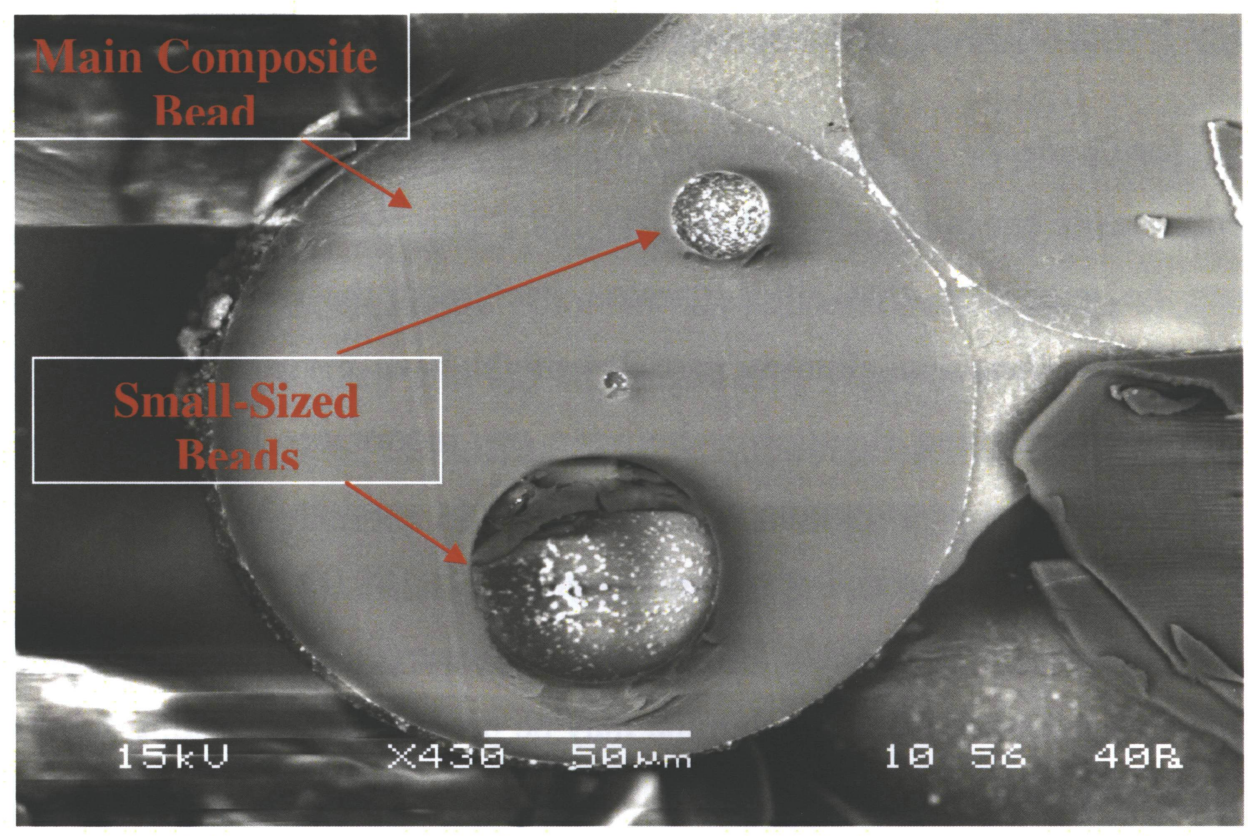

(a)

(Magnification: 430X)

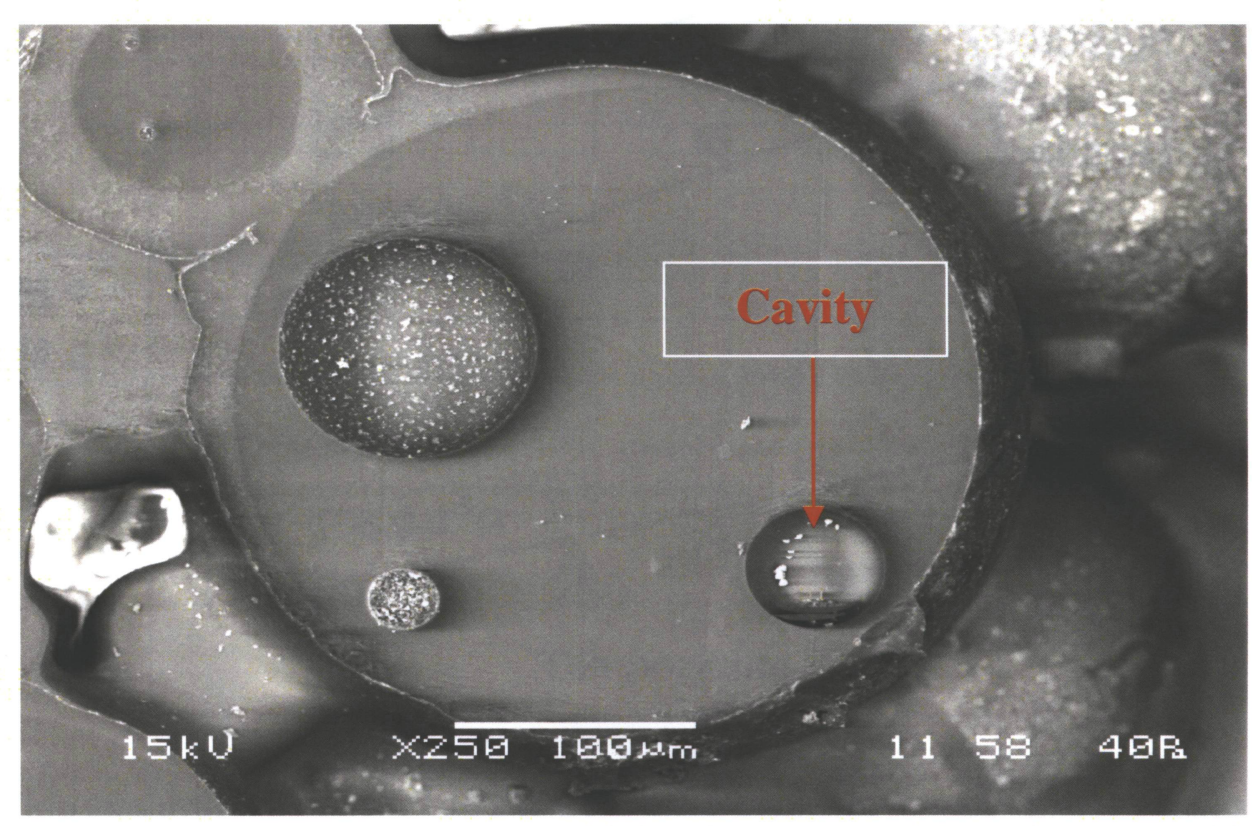

(b)

(Magnification: 250X)

Figure 104: SEM Micrograph of High Molecular Weight Polystyrene Composite Beads 


\subsubsection{Effect of Weight Percent of Silica-Alumina on Molecular Weight}

The $M_{w}$ value for Grade B1 (no additive) was found to be 278,010 Da and the $M_{w}$ values of the polystyrene composite beads (Grades B2, B3, B4 and B5) were less than Grade B1 (Figure 105). Hence, it can be suggested that silica-alumina decreased the molecular weight [76]. As explained previously, the silica-alumina particles might have prevented the formation of long polymer chain by positioning themselves between the monomers [77]. Further, it may be suggested that $5 \mathrm{wt} \%$ of silica-alumina was the maximum amount that could be incorporated in polystyrene to produce commercial standard beads $\left(M_{w}>180,000 \mathrm{Da}\right)$ using the formulations and reaction conditions given in Table 5. However, commercial standard polystyrene composite beads with more than $5 \mathrm{wt} \%$ of silica-alumina may be produced by adjusting some experimental conditions, such as the reaction time.

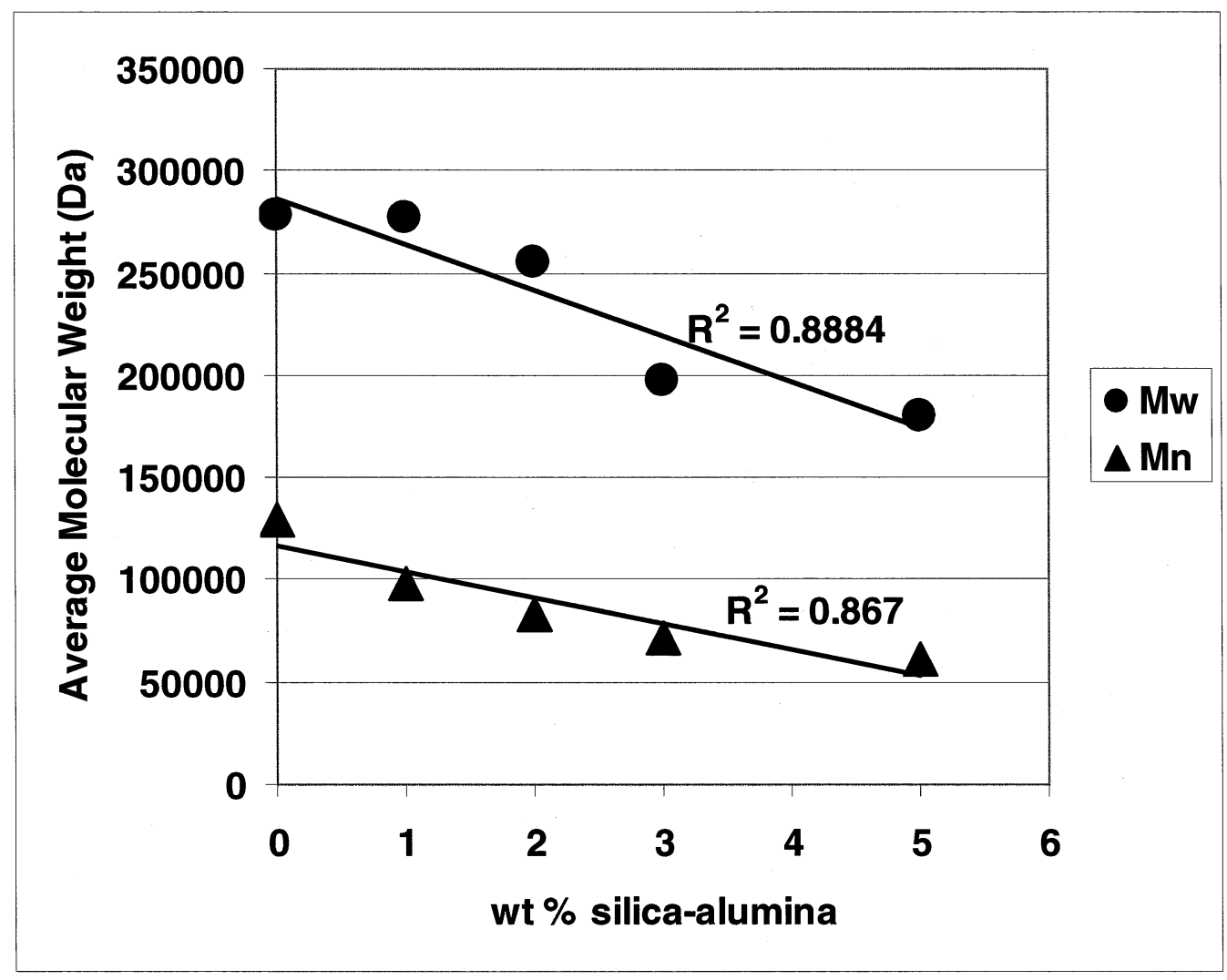

Figure 105: Effect of Amount of Silica-Alumina on Molecular Weight 


\subsubsection{Effect of Weight Percent of Silica-Alumina on Onset Temperature of Degradation, $T_{o}$}

It was found that depolymerization and random chain scission were involved in degrading Grades B1, B2, B3, B4 and B5 [78 - 80]. Depolymerization was found to occur in the temperature range $100-200{ }^{\circ} \mathrm{C}$ (Figure 106). In this temperature range, the unstabilized chainends of the polymer were broken and a $5 \%$ weight drop was noted for all the grades. In the temperature range of $200-450{ }^{\circ} \mathrm{C}$, random chain scission mechanism was found to be the main mechanism involved in degradation of the beads. The average $T_{0}$ for Grade B1 was found to be $397{ }^{\circ} \mathrm{C}$ and the average $\mathrm{T}_{\mathrm{o}}$ for Grades B2, B3, B4 and B5 were found to be less than $397{ }^{\circ} \mathrm{C}$. Hence, it appears that the degradation of Grades B2, B3, B4 and B5 beads required less thermal energy.

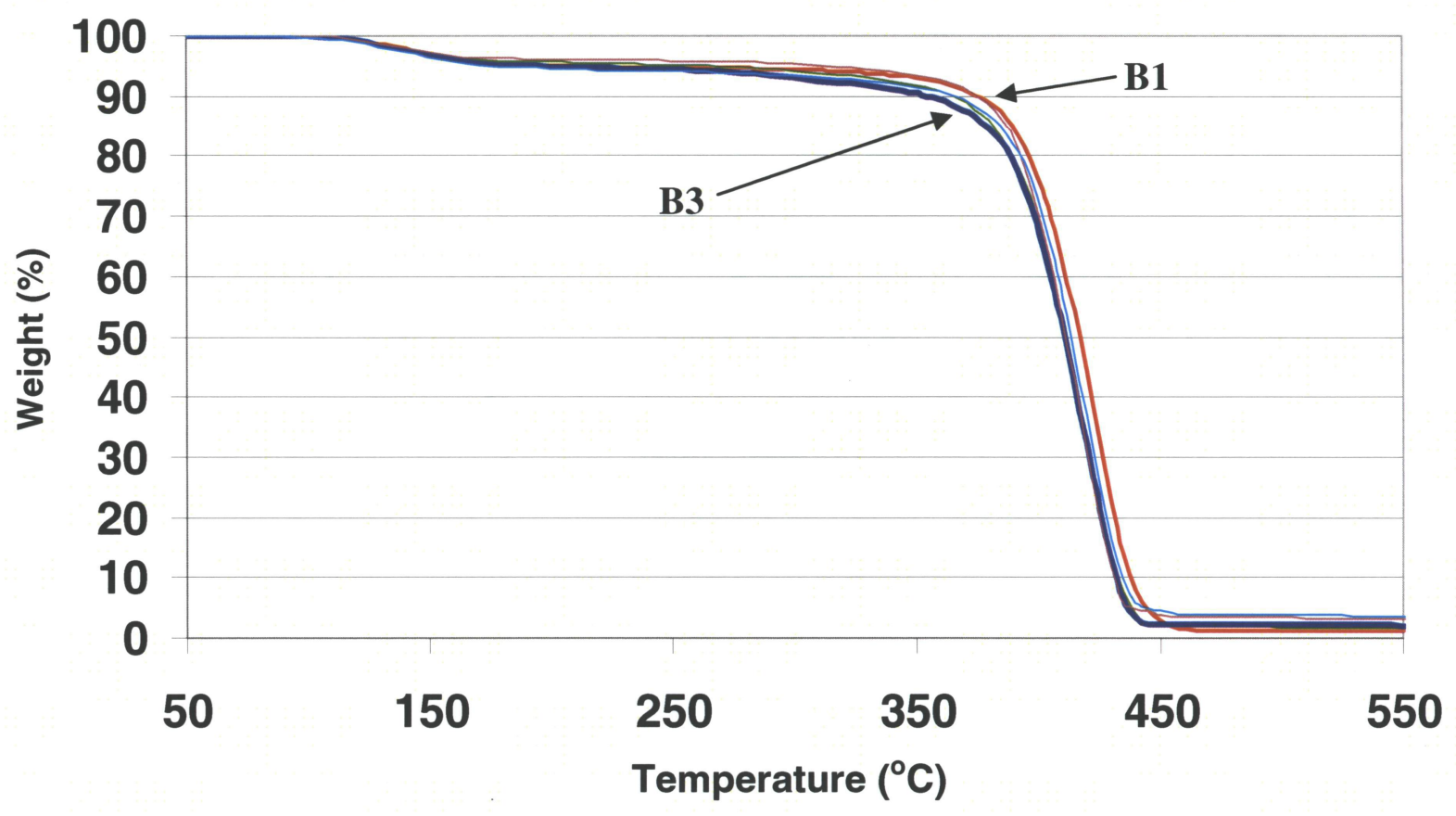

- B1 (no additive) — B2 (1 wt \% silica-alumina) —B3 (2 wt \% silica-alumina)

— B4 (3 wt \% silica-alumina) — B5 (5 wt \% silica-alumina)

Figure 106: Degradation of Grades B1, B2, B3, B4 and B5 (based on Figures 80 - 84) 
It was found that $\mathrm{T}_{0}$ decreased when silica-alumina was increased from 0 to $2 \mathrm{wt} \%$. However, a further increase in silica-alumina was found to increase $T_{0}$ (Figure 107). As previously explained, an increase in mass of silica-alumina decreased the molecular weight. High molecular weight polystyrene was found to degrade faster and at lower $\mathrm{T}_{\mathrm{o}}$ since they had: (a) higher pre-exponential factors, (b) higher random-scission rate coefficient, (c) higher intermolecular transfer, (d) weaker C-C bond strength and (e) lower mobility [81 - 91]. Hence, the effect of molecular weight on degradation was more pronounced relative to that of the catalyst, particularly when more than 2 wt \% silica-alumina was used. In this study, Grade B3 (2 wt $\%$ silica-alumina) was found to degrade at the lowest onset temperature $\left(388^{\circ} \mathrm{C}\right)$.

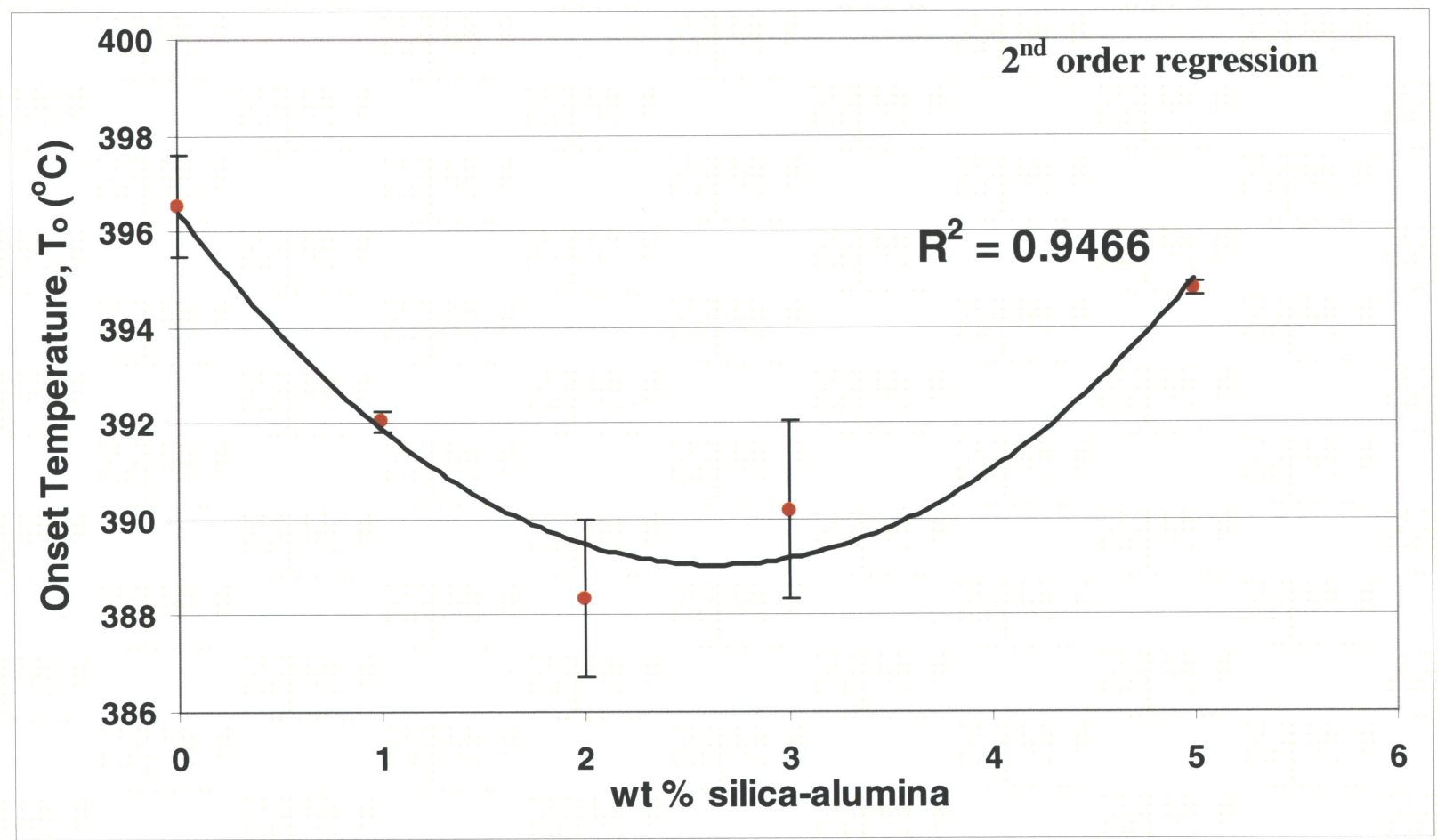

Figure 107: Effect of Amount of Silica-Alumina on $T_{o}$ 


\subsubsection{Effect of Weight Percent of Silica-Alumina on Rate of Degradation}

At the $80 \%$ weight loss mark (i.e., $20 \%$ on the graph of Figure 108), it was found that the time taken to degrade Grade B1 (no additive) was 2635 seconds, and it took less time to degrade the novel polystyrene composite beads. Further, it was found that Grade B3 (2 wt \% silica-alumina) took the least amount of time to degrade (2570 seconds).
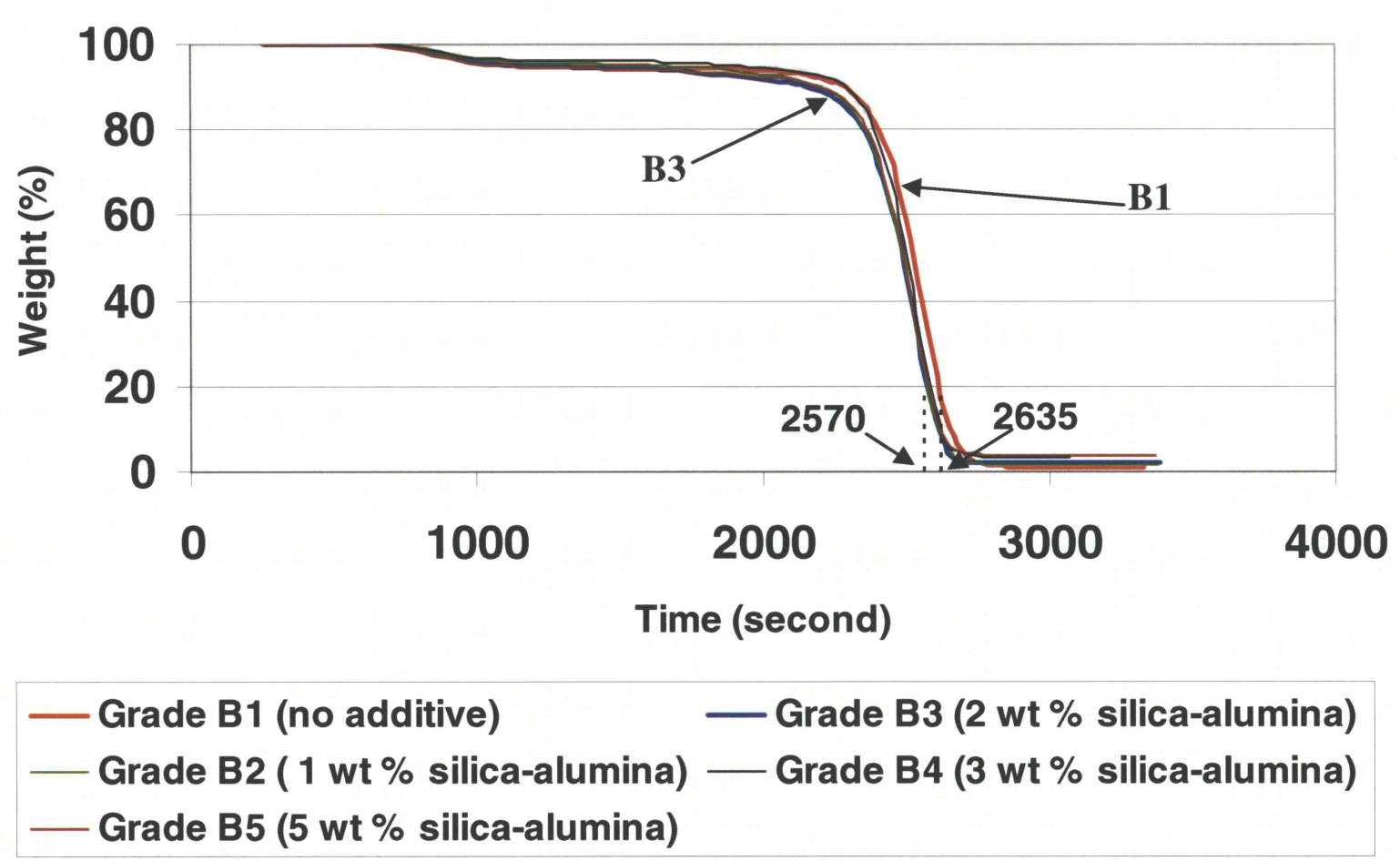

Figure 108: Degradation of Grades B1, B2, B3, B4 and B5 with Respect to Time

At a temperature of $350{ }^{\circ} \mathrm{C}$, Grade $\mathrm{B} 3$ was found to degrade faster at a rate of $0.27 \%$ /minute than Grade B1 (0.19\%/minute), although it had a low molecular weight. Hence, it suggested that this high degradation rate of these novel polystyrene composite beads might be due to the catalysts. 


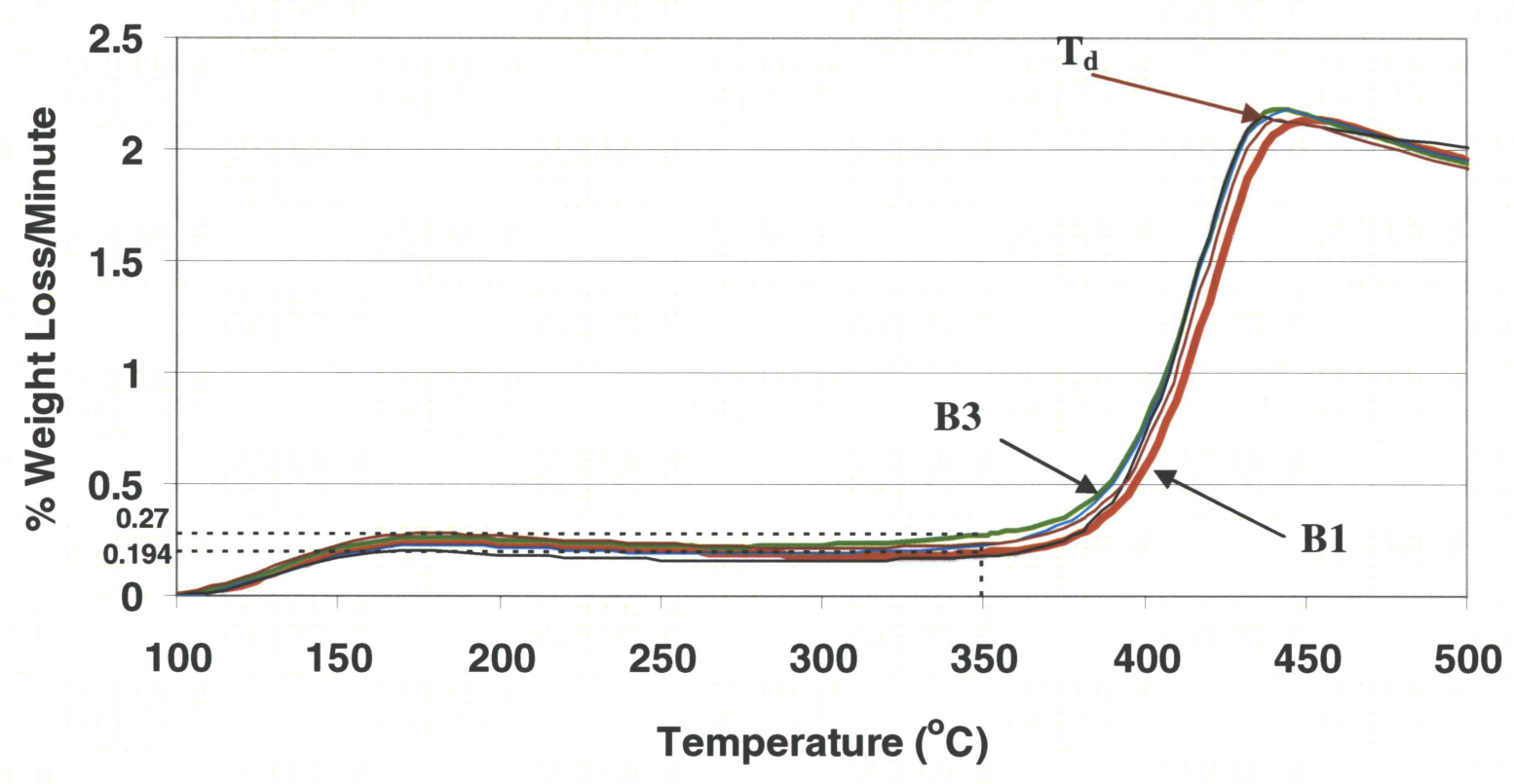

- Grade B1 (no additive)

— Grade B3 (2 wt \% silica-alumina)

— Grade B2 (1 wt \% silica-alumina) — Grade B4 (3 wt \% silica-alumina)

_ Grade B5 (5 wt \% silica-alumina)

Figure 109: Rate of Degradation of Grades B1, B2, B3, B4 and B5 with Respect to Temperature

\subsubsection{Effect of Weight Percent of Silica-Alumina on Glass Transition Temperature, $T_{g}$}

$\mathrm{T}_{\mathrm{g}}$ gives a good indication of the fluidity (or viscosity) of the polymer. Hence, it was highly desirable to decrease $T_{g}$ of polystyrene to prevent casting defects $[3,5]$. The average $T_{g}$ for Grade B1 was found to be $98{ }^{\circ} \mathrm{C}$ and it decreased with increasing the amount of silica-alumina in the polystyrene matrix (Figure 110). As explained earlier, the silica-alumina particles acted like plasticizers and they embedded themselves between the polymer chain, increasing the inter-chain spacing and allowing them to move past one another at lower temperatures [77]. Hence, it can be suggested that the plasticizing effect of silica-alumina was responsible in the reduction of the $T_{g}$ values for the polystyrene composite beads. 


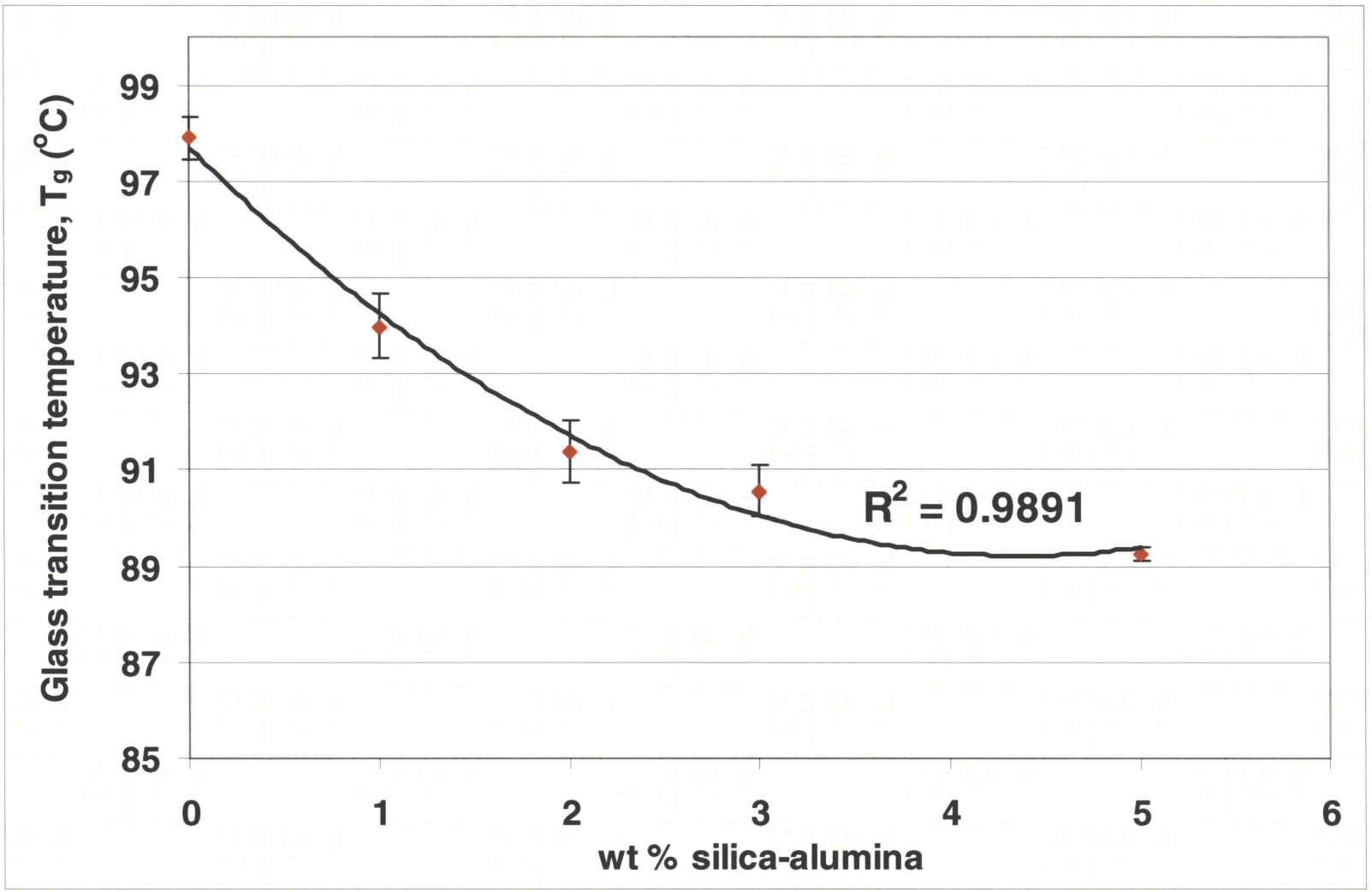

Figure 110: Effect of Amount of Silica-Alumina on $T_{g}$ 


\section{Chapter 6 - Conclusions and Suggestions for Further Work}

Suspension polymerization of polystyrene composite beads was seen to possess better thermal properties than the standard commercial polystyrene beads. In this study, low and high molecular weight polystyrene composite beads were produced in the laboratory and the main conclusions are listed below.

1. The catalyst particles were caught in the sticky monomer droplets during the early course of polymerization and formed small beads, which in turn were engulfed in the larger monomer droplets to form polystyrene composite beads.

2. The polystyrene composite beads had a higher rate of degradation, a lower onset temperature of degradation and a lower glass transition temperature relative to polystyrene beads (no additive).

3. The molecular weight of the polystyrene composite beads was low relative to that of polystyrene beads (no additive).

4. The molecular weight of the polystyrene composite beads was increased by increasing the reaction time, decreasing the initiator concentration, using a nitrogen atmosphere and using a condenser.

5. The size of the beads affected the molecular weight of the polystyrene beads. Larger diameter-sized beads had higher $\mathbf{M}_{\mathrm{w}}$ than smaller beads, and this is indeed unusual. This is attributed to turbulence in the reactor.

6. The effect of molecular weight on degradation of polystyrene composite beads was more pronounced relative to that of the catalyst, when silica-alumina was added in excess of 2 wt $\%$.

7. Polystyrene composite beads, Grade B3 ( $2 \mathrm{wt} \%$ silica-alumina) was found to be the best alternative to replace polystyrene beads that are currently used in the LFC industry. 
On basis of this current investigative work, the following suggestions have been made for further study:

1. The use of a Dynamic Mechanical Analysis (DMA) to measure the viscosity of the polystyrene composite beads.

2. The use of a Differential Scanning Calorimetry (DSC) to measure the heat capacity of the polystyrene composite beads.

3. The use of a magnetic stirrer instead of a stainless steel mechanical stirrer to reduce turbulence in the system.

4. The use of a stainless steel reaction flask for longer durability, safer and high pressure operations (e.g., blowing agent impregnation).

5. The quantitative analysis of the amount of additives incorporated in the polystyrene composite beads.

6. The impregnation of a blowing agent (pentane) in the polystyrene composite beads.

7. The expansion of the polystyrene composite beads into pre-puff.

8. The production of foam patterns using the polystyrene composite beads.

9. The casting of these foam patterns and analyzing for fold defects. 


\section{Appendix A - Molecular Weight Calculations}

An example to calculate the $\mathrm{M}_{\mathrm{n}}, \mathrm{M}_{\mathrm{w}}$ and PDI of a polymer is given below:

Table 22: Example of Mass Distribution in a Polymer

\begin{tabular}{|c|c|c|c|}
\hline $\begin{array}{l}\text { Number of } \\
\text { Molecules }\end{array}$ & $\begin{array}{l}\text { Mass of Each } \\
\text { Molecule (Da) }\end{array}$ & $\begin{array}{l}\text { Total Mass of Each } \\
\text { Type of Molecule }\end{array}$ & \\
\hline$\left(\mathrm{N}_{\mathrm{i}}\right)$ & $\left(\mathrm{M}_{\mathrm{i}}\right)$ & $\left(\mathrm{N}_{\mathrm{i}} \mathrm{M}_{\mathrm{i}}\right)$ & $\sum \mathrm{N}_{\mathrm{i}} \mathrm{M}_{\mathrm{i}}^{2}$ \\
\hline 1 & 800,000 & 800,000 & $6.4 \mathrm{E}+11$ \\
\hline 3 & 750,000 & $2,250,000$ & $1.69 \mathrm{E}+12$ \\
\hline 5 & 700,000 & $3,500,000$ & $2.45 \mathrm{E}+12$ \\
\hline 8 & 650,000 & $5,200,000$ & $3.38 \mathrm{E}+12$ \\
\hline 10 & 600,000 & $6,000,000$ & $3.6 \mathrm{E}+12$ \\
\hline 13 & 550,000 & $7,150,000$ & $3.93 \mathrm{E}+12$ \\
\hline 20 & 500,000 & $10,000,000$ & $5 \mathrm{E}+12$ \\
\hline 13 & 450,000 & $5,850,000$ & $2.63 \mathrm{E}+12$ \\
\hline 10 & 400,000 & $4,000,000$ & $1.6 \mathrm{E}+12$ \\
\hline 8 & 350,000 & $2,800,000$ & $9.8 \mathrm{E}+11$ \\
\hline 5 & 300,000 & $1,500,000$ & $4.5 \mathrm{E}+11$ \\
\hline 3 & 250,000 & 750,000 & $1.88 \mathrm{E}+11$ \\
\hline 1 & 200,000 & 200,000 & $4 \mathrm{E}+10$ \\
\hline$\Sigma_{\mathrm{i}} \mathrm{N}_{\mathrm{i}}=100$ & & $\Sigma_{\mathrm{i}} \mathrm{N}_{\mathrm{i}} \mathrm{M}_{\mathrm{i}}=50,000,000$ & $\sum_{\mathrm{i}} \mathrm{N}_{\mathrm{i}} \mathrm{M}_{\mathrm{i}}{ }^{2}=2.658 \mathrm{E} 13$ \\
\hline
\end{tabular}

Hence,

$$
\begin{array}{ll}
\mathrm{M}_{\mathrm{n}}=\Sigma_{\mathrm{i}} \mathrm{N}_{\mathrm{i}} \mathrm{M}_{\mathrm{i}} / \Sigma_{\mathrm{i}} \mathrm{N}_{\mathrm{i}} & =500,000 \mathrm{Da} \\
\mathrm{M}_{\mathrm{w}}=\Sigma_{\mathrm{i}} \mathrm{N}_{\mathrm{i}} \mathrm{M}_{\mathrm{i}}^{2} / \Sigma_{\mathrm{i}} \mathrm{N}_{\mathrm{i}} \mathrm{M}_{\mathrm{i}} & =531,600 \mathrm{Da} \\
\mathrm{PDI}=\mathrm{M}_{\mathrm{w}} / \mathrm{M}_{\mathrm{n}} & =1.063
\end{array}
$$




\section{Appendix B - Pictures of Sieves and SEM of Polystyrene Beads}

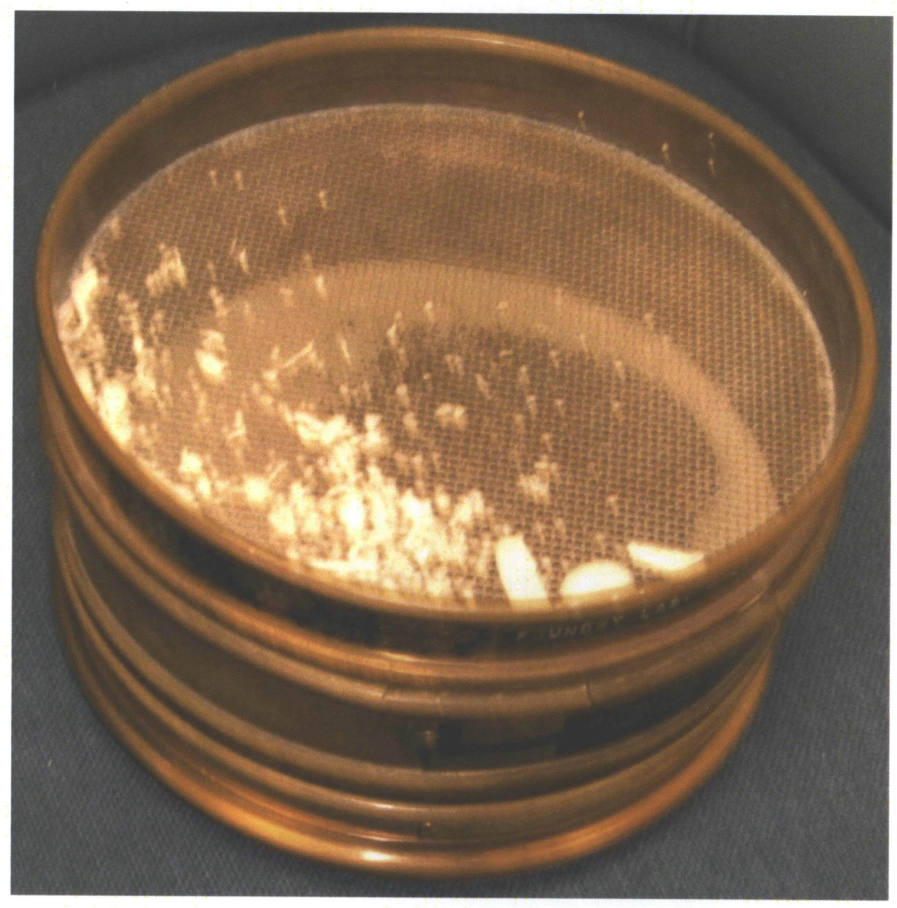

Figure 111: Top-Side View of the Sieves (showing the agglomerates)

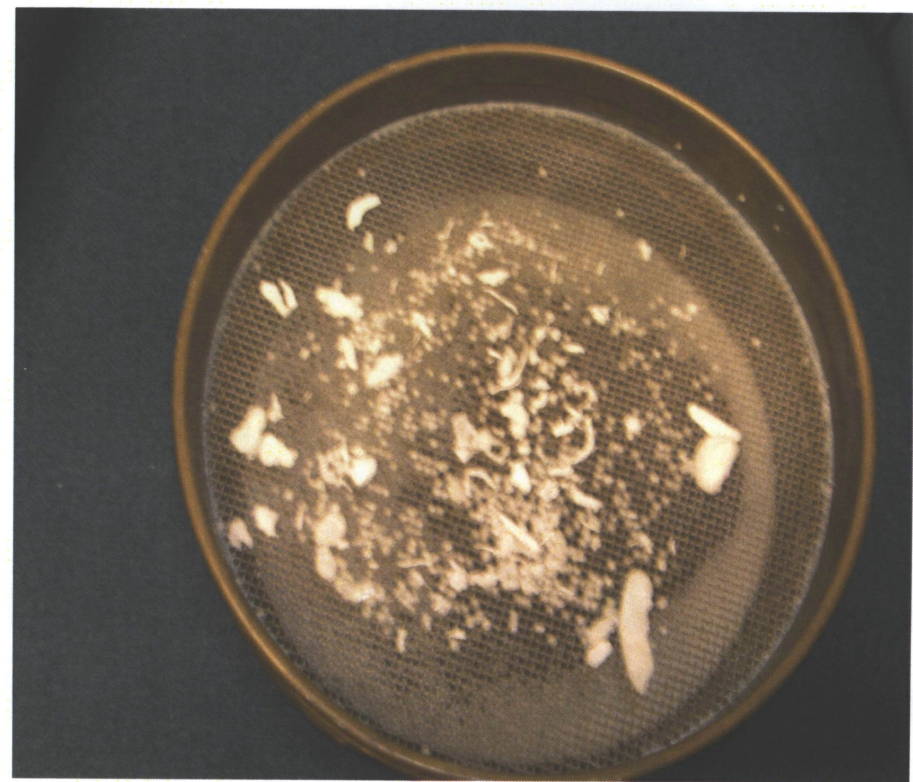

Figure 112: Top View of the Sieves (showing the agglomerates) 


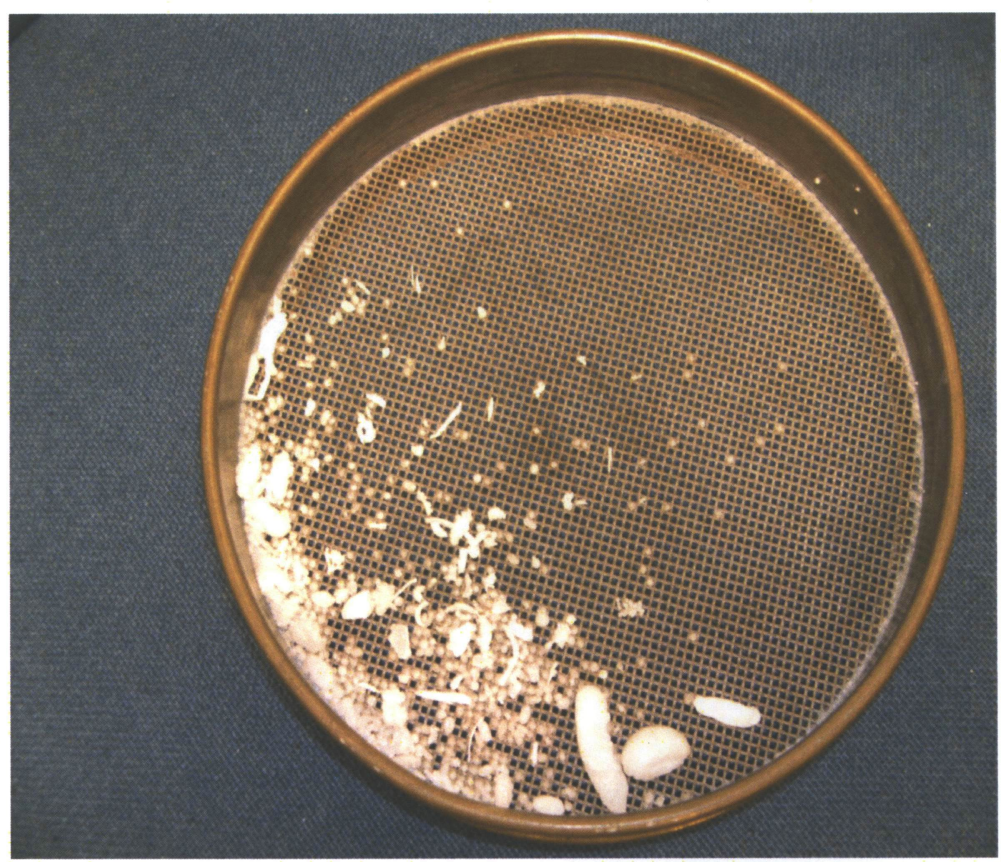

Figure 113: Top View of the Agglomerates and Large Beads (bead diameter: $>1680$ microns)

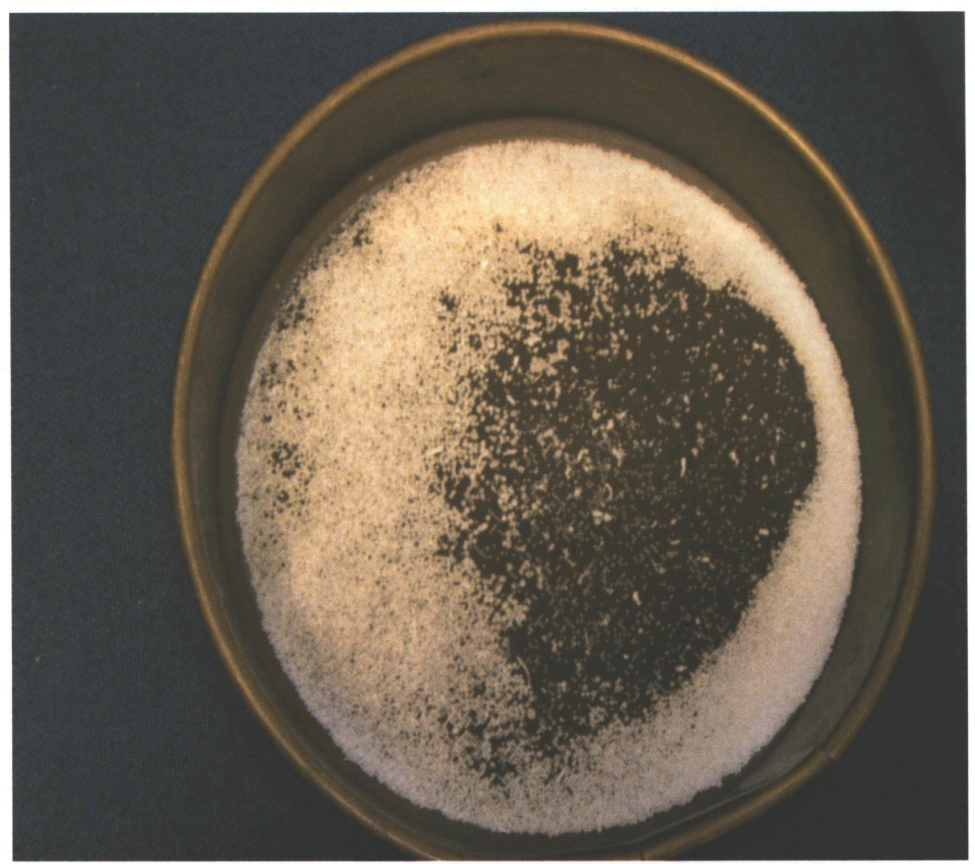

Figure 114: Top View of the CUP Beads (bead diameter: 595 - 1680 microns) 


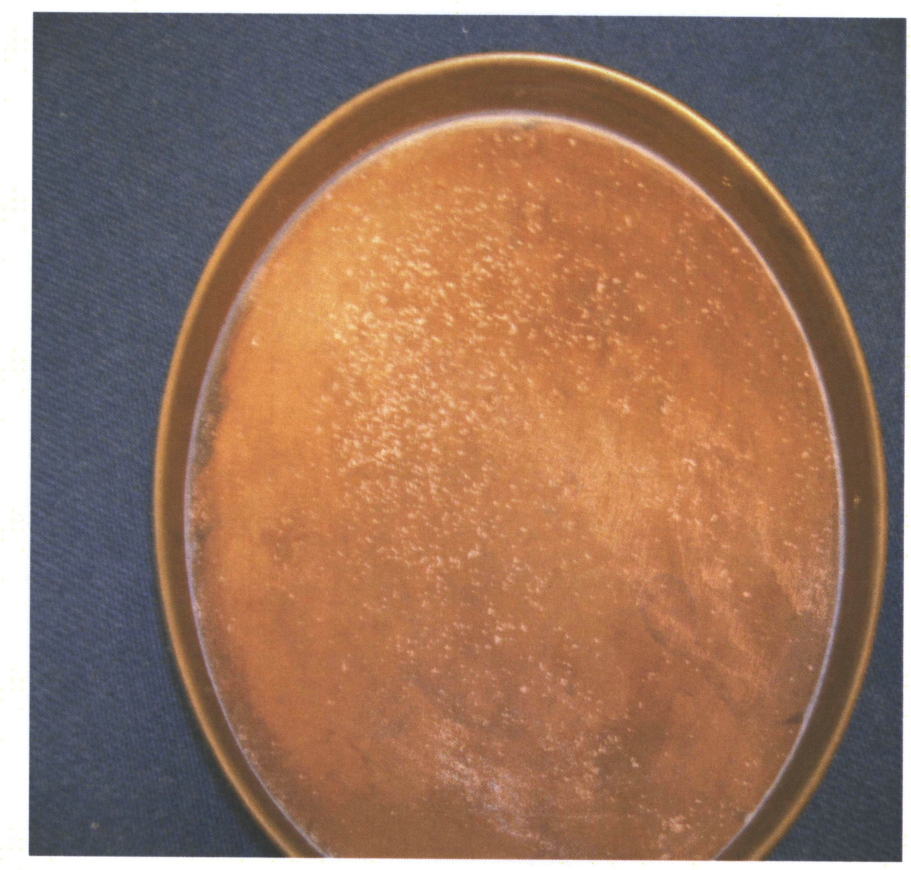

Figure 115: Top View of the LFC Beads (bead diameter: 150 - 595 microns)

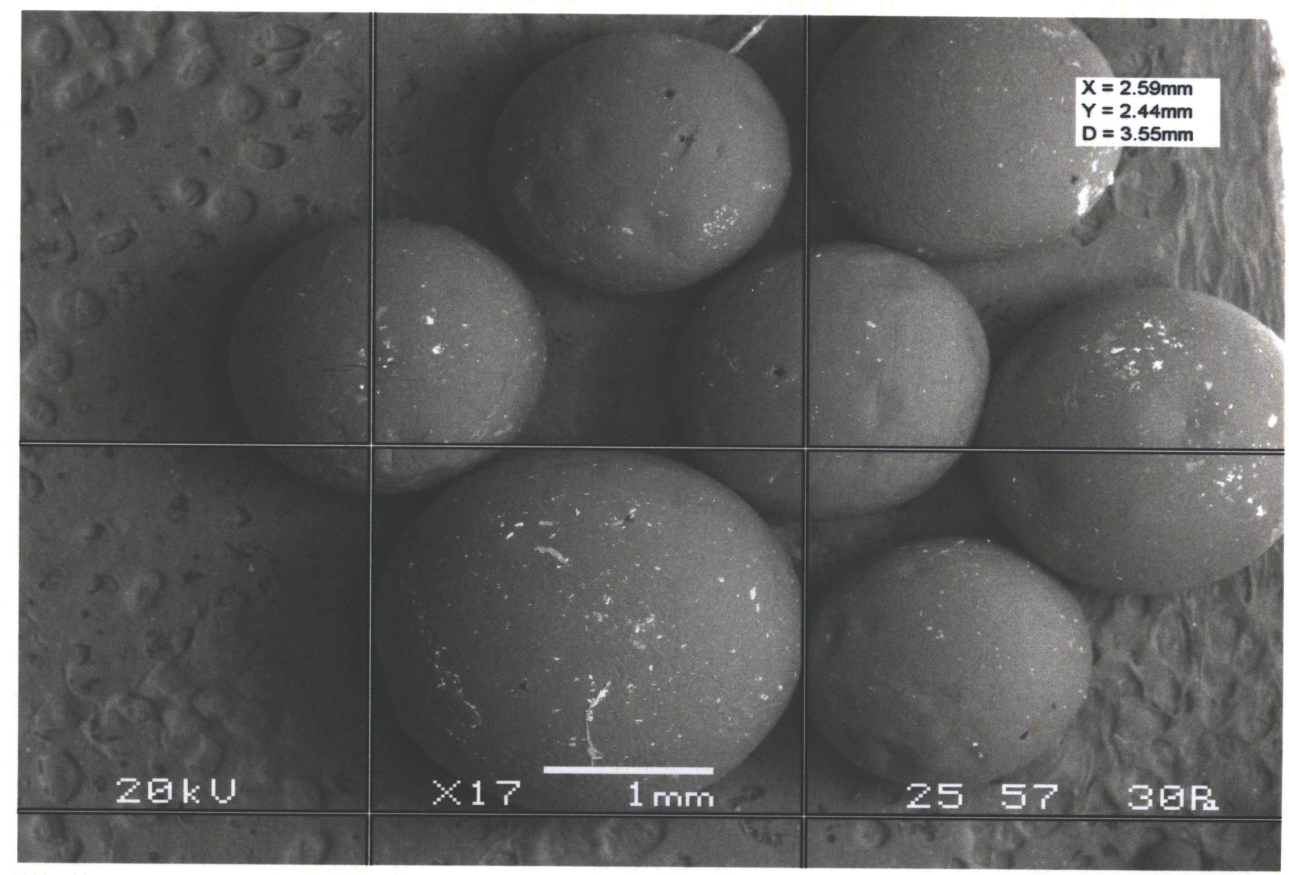

Figure 116: SEM of Large Beads (Referred to as agglomerates in this study) (bead diameter: > 1680 microns)

(Magnification: 17X) 


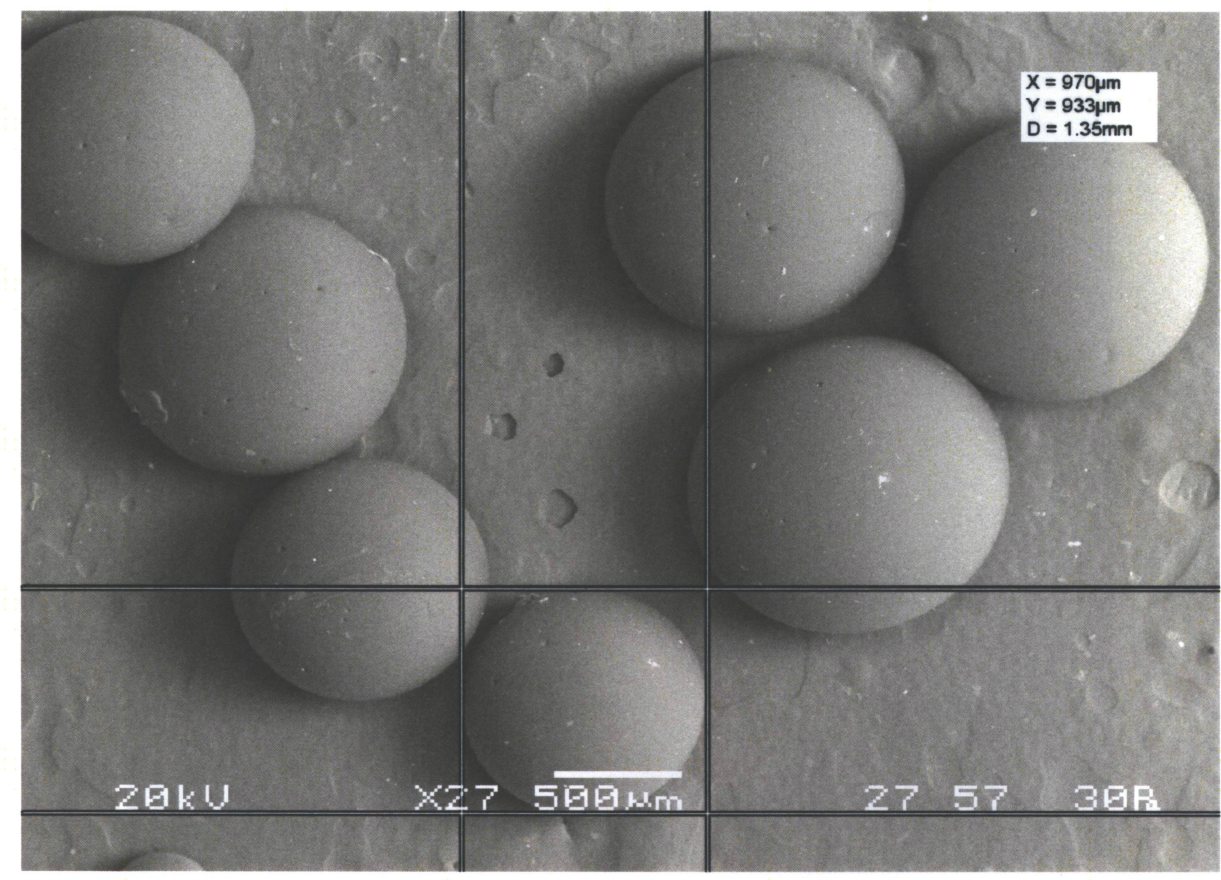

Figure 117: SEM of CUP Beads (bead diameter: 595 - 1680 microns) (Magnification: 27X)

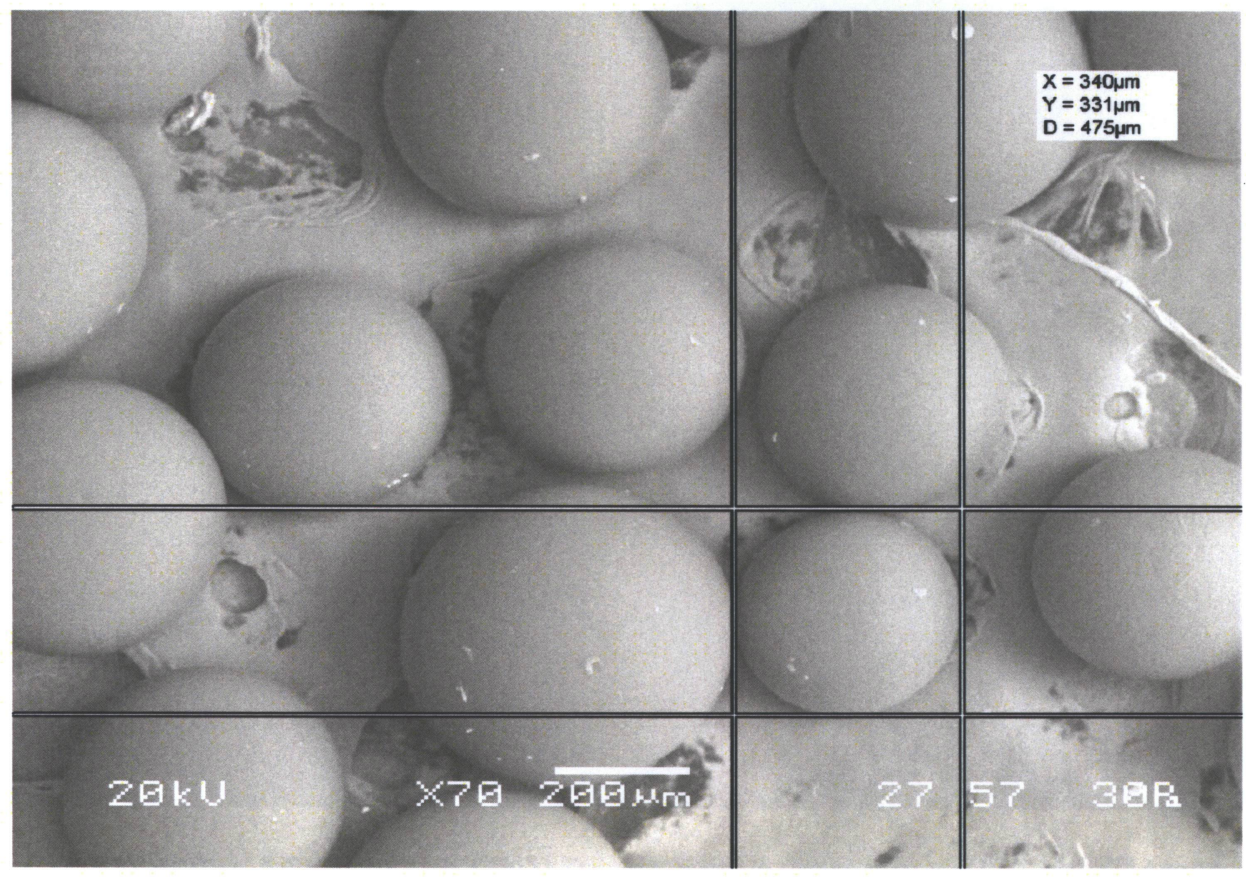

Figure 118: SEM of LFC Beads (bead diameter: 150 - 595 microns) (Magnification: 70X) 


\section{References}

1. K. Kirgin, "Domestic Supply Slows to a Drip in 2007", Modern Casting - A publication of the American Foundry Society, pp. 29 - 33 (March 2007)

2. Q. Zhao, T.W. Gustafson, M. Hoover and M.C. Flemings, "Folds Formation and Prevention in the Lost Foam Aluminum Process", AFS Transactions, Vol. 112, paper \# 04-080 (2004)

3. S. Jagoo, C. (Ravi) Ravindran and D. Nolan, "Minimizing Fold Defects in Aluminum Alloy A356 Lost Foam Casting”, AFS Transactions, paper \# 06-068 (2006)

4. R. J. Donahue, U. S. Patent 5,960,851 (1999)

5. F. Sonnenberg and M.E. Hoover, "Development of the Improved Casting Bead for Lost Foam", 2004 LFC Conference in Paderborn, Germany (2004)

6. F. Sonnenberg, "Recent Innovations with EPS Lost Foam Beads", AFS Transactions, Vol. 111, paper \# 03-006 (2003)

7. M. A. Villalobos, "Suspension Polymerization of Styrene Through Bifunctional Initiators", M. Eng Thesis, McMaster University (1989)

8. Ace-Glass, "http://www.aceglass.com/featured/pressure_reactors/PressReactors.pdf", Ace-Glass Inc., Accessed on June 10, 2006

9. B. V. Kichatov, A. M. Korshunov and P. V. Assorova, "Particle Size Distribution of the Product of Suspension Polymerization", Theoretical Foundations of Chemical Engineering, Vol. 37, No. 3, pp. $306-309$ (2003)

10. F. Sonnenberg and D. Halnik, U.S. Patent No. 4,994,499 (1991)

11. N. Nakano and S. Hasegawa, "Effect of Molecular Weight on the Mechanical Properties of Polystyrene", Japanese Society of Material Science, Vol. 33, p. 1206 -1210 (1984)

12. G. Xue, Y. Lu, G. Shi and Q. Dai, "Glass Transition of Expanded Polystyrene Coils", Polymer, Vol. 35, Issue 4, pp. 892 - 894 (1994)

13. P. J. Flory, "Tensile Strength in Relation to Molecular Weight of High Polymers", Journal of the American Chemical Society, Vol. 67, pp. 2048 - 2050 (1945)

14. T. Ogawa, "Effects of Molecular Weight on Mechanical Properties of Polypropylene", Journal of Applied Polymer Science, Vol. 44, pp. 1869 -1971 (1992) 
15. F.W. Billemeyer, Jr., Textbook of Polymer Science, $3^{\text {rd }}$ Edition, John Wiley \& Sons, New York, p. 61 and p. 337 (1984)

16. F. Jahanzad, S. Sajjadi and B. W. Brooks, "Characteristics Intervals in Suspension Polymerization Reactors: An Experimental and Modeling Study", Chemical Engineering Science, Vol. 60, pp. $5574-5589$ (2005)

17. D. Horak, M. Krystufek and J. Spevacek, "Effect of Reaction Parameters on the Dispersion Polymerization of 1-Vinyl-2-Pyrrolidone", Journal of Polymer Science: Part A: Polymer Chemistry, Vol. 38, pp 653 - 663 (2000)

18. H. Ahmad and K. Tauer, "Effects of Chain Transfer Agent on the Radical Polymerization of Styrene in Non-Aqueous Dispersion", Colloid Polymer Science, Vol. 281, pp. 686 $689(2003)$

19. N. Tefera, G. Weickert and K. R. Westerterp, "Modeling of Free Radical Polymerization up to High Conversion. II. Development of a Mathematical Model", Journal of Applied Polymer Science, Vol. 63, pp. 1663 - 1680 (1997)

20. W.S, Lyoo, S. G. Lee, J. P. Kim, S. S. Han and C. J. Lee, "Low Temperature Suspension Polymerization of Vinyl Acetate Using 2,2-azobis(2,4-dimethylvaleronitrile) for the Preparation of High Molecular Weight Poly(vinyl Alcohol) with High Yield", $\underline{\text { Colloid }}$ Polymer Science, Vol. 276, pp. 951 - 959 (1998)

21. D. S. S. Nunes and F. M. B. Coutinho, “Acrylonitrile-Divinylbenzende Copolymer Beads: Influence of Pre-Polymerization Step, Stirring Conditions and Polymerization Initiator Type on the Polymer Particle Characteristics", European Polymer Journal, Vol. 38 , pp. $1159-1165$ (2002)

22. N. Lazrak, N. Le Bolay, and A. Ricard, "Droplet Stabilization in High Holdup Fraction Suspension Polymerization Reactors", European Polymer Journal, No. 11, pp. 1637 1647 (1998)

23. G. Kalfas, H. Yuan and W. H. Ray, "Modeling and Experimental Studies of Aqueous Suspension Polymerization Processes. 2. Experiments in Batch Reactors", Industrial and Engineering Chemistry Research, Vol. 32, pp. 1831 - 1838 (1993)

24. A. Singh and D. Lal, "Effect of Reaction Parameters on the Particle Sizes of Crosslinked Spherical Phenolic Beads by Suspension Polymerization of Phenol and Formaldehyde", Journal of Applied Polymer Science, Vol. 100, pp. 2323 - 2330 (2006)

25. Q. Ye, X. Ge and Z. Zhang, "Formation of Monodisperse PMMA Particles by RadiationInduced Dispersion Polymerization - I. Synthesis and Polymerization Kinetics", Radiation Physics and Chemistry, Vol. 66, pp. 11 - 16 (2003) 
26. Y. Wu, Y. Shi and Z. Fu, "Synthesis of Heteroarm Star-Shaped (Polystyrene)n[Poly(ethyl Acrylate)]m via Atom Transfer Radical Polymerization”, Polymer, Vol. 46, pp.12722 - 12728 (2005)

27. C. N. Lopes, R. F. P. M. Moreira, R. A. F. Machado and P. H. H. Araujo, "Effect of Initiator on the Incorporation of Graphite into Polymer Matrix During Suspension Polymerization", Macromolecules Symposium, Vol. 229, pp. 72 - 80 (2005)

28. A. L. Nogueira, R. A. F. Machado and M. B. Quadri, "Styrene Suspension Polymerization Using a Stirred Vertical Tubular Reactor”, Macromolecules Symposium, Vol. 245 -246, pp. 398 - 402 (2006)

29. Y. Hatate, Y. Kurokawa, H. Hamada, A. Ikari and F. Nakashio, "Kinetics of Styrene Slurry Polymerization in Suspended Isooctane Droplets", Journal of Chemical Engineering of Japan, Vol. 18, No. 4, pp. 293 - 302 (1985)

30. X. Ding, Y. Jiang, K. Yu, Hari-Bala, N. Tao, J. Zhao and Z. Wang, "Silicon Dioxide as Coating on Polystyrene Nanoparticles in Situ Emulsion Polymerization”, Materials Letters, Vol. 58, pp. 1722-1725 (2004)

31. Q. Gu, Q. Lin, C. Hu and B. Yang, "Study on Emulsion and Suspension in Situ Polymerization”, Journal of Applied Polymer Science, Vol. 95, pp. 404-412 (2005)

32. S. P. Thomas, "Expendable Pattern Casting", American Foundry Society, Vol. 1: Process Manual, pp. 10 - 32 (1994)

33. M. G. Meyer, B. V. Smith, "Examining Lost Foam's 'White Side', Tooling and Molding Parameters", 2001 LFC Conference in Miami, USA (2001)

34. P. Stroom, “Today's Value Added Process for Tomorrow's Casting Application”, 2001 LFC Conference in Miami, USA (2001)

35. E. Vargas, "http://www.bloomerplastics.com/capabilities-glossary.html”, Bloomer Plastics Inc., Accessed on February 05, 2007

36. R. C. Penwell and R. S. Porter, "Viscosity of Polystyrene near the Glass Transition Temperature”, Journal of Applied Polymer Science, Vol. 13, pp. 2427 - 2437 (1969)

37. F. C. Chiu and C. G. Peng, "The Atactic Polystyrene Molecular Weight Effect on the Thermal Properties and Crystal Structure of Syndiotactic Polystyrene/Atactic Polystyrene Blends", Polymer, Vol. 43, pp. 4879-4886 (2002)

38. J.F. Fried, Polymer Science \& Technology, $2^{\text {nd }}$ Edition, Prentice-Hall of India, New Delhi, p. 180 and p. 265 (2005) 
39. MSEL,"http://www.msel.nist.gov/Nanotube2/Practice\%20Guide_Section\%202_TGA.pdf ", Materials Science and Engineering Laboratory, Accessed on February 05, 2007

40. V. M. Archodoulaki, S. Luftl and S. Seidler, "Thermal Degradation Behavior of Poly(oxymethylene): 1. Degradation and Stabilizer Consumption", Polymer Degradation and Stability, Vol. 86, pp. $75-83$ (2004)

41. J. M. Funt and J. H. Magill, "Thermal Decomposition of Polystyrene: Effect of Molecular Weight”, Journal of Polymer Science: Polymer Physics Edition, Vol. 12, pp. 217 - 220 (1974)

42. S. Shivkumar, X. Yao and M. Makhlouf, "Polymer - Melt Interactions During Casting Formation in the Lost Foam Process", Scripta Metallurgica et Materialia, Vol. 33, No. 1, pp. 39-46 (1995)

43. 3D-Cam, "http://www.3d-cam.com/materials/polystyrene.asp", 3D-Cam Inc, Accessed on February 04, 2006

44. Eagle Plastic, "http://www.eagleplastics.co.uk/techinfo/sdspoly.htm", Eagle Plastic Ltd., Accessed on February 04, 2006

45. L. Degirmenci and T. Durusoy, "Thermal Degradation Kinetics of Goynuk Oil Shake with Polystyrene", Journal of Thermal Analysis and Calorimetry, Vol. 79, pp. 663 - 668 (2005)

46. T. Faravelli, M. Pinciroli, F. Pisano, G. Bozzano, M. Dente and E. Ranzi, "Thermal Degradation of Polystyrene", Journal of Analytical and Applied Pyrolysis, Vol. 60, pp. $130-121(2001)$

47. T.C Pederson, "New Brominated Additives for Expanded Polystyrene Patterns to Reduce Fold Defects in Lost Foam Aluminum Castings", AFS Transactions, Vol. 114, paper \# 06-022 (2006)

48. F. Xue, D. Takeda, T. Kimura and M. Minabe, "Effect of Organic Peroxides on the Thermal Decomposition of Expanded Polystyrene with the Addition of Alpha-Methyl Styrene", Polymer Degradation and Stability, Vol. 83, pp. 461 - 466 (2004)

49. H. Ukei, T. Hirose, S. Horikawa, Y. Takai, M. Taka, N. Azuma and A. Ueno, "Catalytic Degradation of Polystyrene into Styrene and a Design of Recyclable Polystyrene with Dispersed Catalysts", Catalysis Today, Vol. 62, pp. 67 - 75 (2000)

50. J. Kim, W. Lee, S. Lee, S. Kim and M. Choi, "Degradation of Polystyrene Waste over Base Promoted Fe Catalysts”, Catalysis Today, Vol. 87, pp. 59 - 68 (2003) 
51. V. Chumbhale, J. Kim, S. Lee and M. Choi, "Catalytic Degradation of Expandable Polystyrene Waste (EPSW) over Mordenite and Modified Mordenites”, Journal of Molecular Catalysis A: Chemical, Vol. 222, pp. 133-141 (2004)

52. S. Jagoo, C. (Ravi) Ravindran and D. Nolan, "Fold Defects in Aluminum Alloy A356 Lost Foam Casting”, Advanced Materials Research, Vol. 15-17, pp. 1-6 (2007)

53. D.R. Hess, D.R. Askeland and C.W. Ramsay, "Influence of Bead Chemistry on Metal Velocity and Defect Formation in Aluminum Lost Foam Castings", AFS Transactions, Vol. 111, paper \# 03-105 (2003)

54. L.Wang, S. Shivkumar and D. Apelian, "Effects of Polymer Degradation on the Quality of Lost Foam Castings", AFS Transactions, Vol. 98, pp. 923 - 933 (1990)

55. M. Sands and S. Shivkumar, "EPS Bead Fusion Effects on Fold Defect Formation in Lost Foam Casting of Aluminum Alloys", Journal of Material Science, Vol. 41, pp. 2373 2379 (2006)

56. M. Cai, J. Siak, B.R. Powell, G. Nouaime and S.J. Swarin, "Physical and Chemical Analysis of the Thermal Degradation Products of Expanded Polystyrene Patterns with Short Thermal Exposures", AFS Transactions, Vol. 110, paper \# 02-094 (2002)

57. S. Jagoo, "Design of a New Expandable Polystyrene for Defect-Free Lost Foam Casting of Aluminum Alloy A356", B. Eng. Thesis, Ryerson University (2005)

58. S. Bennett, T. Moody, A. Vrieze, M. Jackson, D.R. Askeland and C.W. Ramsay, "Pyrolysis Defects in Aluminum Lost Foam Castings", AFS Transactions, Vol. 107, pp. $795-803$ (1999)

59. M.A. Tschopp, Jr., C.W. Ramsay and D.R. Askeland, "Mechanisms of Formation of Pyrolysis Defects in Aluminum Lost Foam Castings", AFS Transactions, Vol. 108, pp. $609-614(2000)$

60. E. A. Grulke, Encyclopedia of Polymer Science and Engineering, John Wiley and Sons, New York (1990)

61. J. Pallay, P. Kelemen, H. Berghmans and D. V. Dommelen, "Expansion of Polystyrene using Water as the Blowing Agent", Macromolecular Materials and Engineering, Vol. 275 , pp. 18-22 (2000)

62. Encyclopedia, "http://encarta.msn.com/encyclopedia_761553604_9/Plastics.html”, MSN Encarta Encyclopedia, Accessed on May 14, 2006. 
63. G. Mills, "http://www.glenmills.com/product_showcase/dry-fine-jar.shtml”, Glen Mills Inc., Accessed on June 10, 2006

64. D. Lausberg and K. Hahn, U.S. Patent No. 6,545,062 (April 8, 2003)

65. G. Gluck and K. H. Batscheider, U.S Patent No. 6,046,245 (April 4, 2000)

66. D. C. Lee and W. Jang, "Preparation and Characterization of PMMA-Clay Hybrid Composite by Emulsion Polymerization", Journal of Applied Polymer Science, Vol. 61, pp. $1117-1122(1996)$

67. Q. Zhao and E. T. Samulski, "A Comparative Study of Poly(Methyl Methacrylate) and Polystyrene/Clay Nanocomposites Prepared in Supercritical Carbon Dioxide," Polymer, Vol. 47, pp. $663-671$ (2006)

68. C. Zeng and L. J. Lee, "Poly(Methyl Methacrylate) and Polystyrene/Clay Nanocomposites Prepared by in-Situ Polymerization," Macromolecules, Vol. 34, pp. $4098-4103$ (2001)

69. G. Oye, V. Roucoules, A. M. Cameron and L. J. Oates, "Plasmachemical Amine Fictionalization of Porous Polystyrene Beads: The Importance of Pore Architecture" American Chemical Society, Langmuir, Vol. 18, pp. 8996-8999 (2002)

70. L. Mathias, "http://www.pslc.ws/mactest/sec.htm", The Macrogalleria, Accessed on February 05, 2007

71. Encyclopedia, "http://en.wikipedia.org/wiki/Number_average_molecular_weight", Online Wikipedia, Accessed on March 10, 2007

72. L. Mathias, "http://www.pslc.ws/mactest/dsc.htm", The Macrogalleria, Accessed on February 05, 2007

73. J.J. Crevecoeur, L. Nelissen and P.J. Lemstra, "Water Expandable Polystyrene (WEPS) Part 1: Strategy and Procedures”, Polymer, Vol. 40, pp. 3685-3689 (1999)

74. Encyclopedia, "http://en.wikipedia.org/wiki/Glass_transition_temperature", Online Wikipedia, Accessed on March 10, 2007

75. Encyclopedia, "http://en.wikipedia.org/wiki/TGA",Online Wikipedia, Accessed on March 10, 2007

76. M. K. Lenzi, F. Machado, E. L. Lima and J. C. Pinto, "Semibatch Styrene Suspension Polymerization Processes", Journal of Applied Polymer Science, Vol. 89, pp. 3021 3038 (2003) 
77. J. K. Sears and J. R. Darby, Technology of Plasticizers, John Wiley and Sons, New York (1982)

78. H. Bockhorn, A. Hornung and U. Hornung, "The Twenty-Seventh International Symposium on Combustion Conference", University of Colorado, Boulder (1998)

79. C. Bouster, P. Vermande and J. Veron, "Study on the Pyrolysis of Polystyrenes I: Kinetics of Thermal Decomposition", Journal of Analytical and Applied Pyrolysis, Vol. 1, pp. $297-313$ (1980)

80. S. L. Modarsky, Thermal Degradation of Organic Polymers, Interscience, New York (1964)

81. N. Grassie and H. W. Melville, "The Thermal Degradation of Polyvinyl Compounds. II. The Degradation of Benzoyl Peroxide Catalyzed Polymethyl Methacrylates", Proceedings of the Royal society of London. Series A, Mathematical and Physical Sciences, Vol. 199, No. 1056, pp. 14-23 (1949)

82. B. K. Kokta, J. L. Valade and W. N. Martin, "Dynamic Thermogravimetric Analysis of Polystyrene: Effect of Molecular Weight on Thermal Decomposition”, Journal of Applied Polymer Science, Vol. 17, pp. 1 - 19 (1973)

83. R. S. Porter, M. J. R. Cantow and J. F. Johnson, "Polymer degradation VI-Distribution Changes on Polyisobutene Degradation in Laminar Flow", Polymer, Vol. 8, pp. 87 - 96 (1967)

84. J. H. T. Wade and P. Kumar, "Electron Microscope Studies of Polymer Degradation", Journal of Hydronautics, Vol. 6, No. 1, pp. $40-45$ (1972)

85. T. Kitayama, H. Horli, K. Hatada and T. Kashiwagi, "Tacticity Dependence of Thermal Degradation of PMMAs with the Same Chemical Structure”, Polymer Bulletin, Vol. 21, pp. $433-437$ (1989)

86. K. Gandhi, M. Park, L. Sun, D. Zou, C. X. Li, Y. D. Lee, J. J. Aklonis and R. Salovey, "Model-Filled Polystyrene Beads in a Polystyrene Matrix", Journal of Polymer Science: Part B: Polymer Physics, Vol. 28, pp. 2707 - 2717 (1990)

87. H. Nishizaki and K. Yoshida, "Effect of Molecular Weight on Various TGA Methods in Polystyrene Degradation," Journal of Applied Polymer Science, Volume 26, Issue 10, pp. $3503-3504$ (1981)

88. G. Madras, G. Y. Chung, J. M. Smith and B. J. McCoy, "Molecular Weight Effect on the Dynamic of Polystyrene Degradation", Industrial and Engineering Chemistry Research, Vol. 36, pp. 2019 - 2024 (1997) 
89. L. Reich and S. S. Stivala, Elements of Polymer Degradation, McGraw-Hill, New York, p. $186(1971)$

90. K. P. C. Vollhardt and N. E. Schore, Organic Chemistry, $2^{\text {nd }}$ Edition, Freeman, New York, p. 111 (1994)

91. S. P. Vijayalakshmi and G. Madras, "Effect of Initial Molecular Weight and Solvents on the Ultrasonic Degradation of Poly(ethylene Oxide)", Polymer Degradation and Stability, Vol. 90, pp. 116 - 122 (2005)

92. G. S. Bhargava, H. U. Khan and K. K. Bhattacharyya, "SAN Copolymer by Suspension Polymerization. II. Bead Size Distribution and Molecular Weight", Journal of Applied Polymer Science, Vol. 23, pp. 1181 - 1187 (1979) 


\section{CURRICULUM VITAE}

Name:

Mr. Satiendra Jagoo

Place of Birth: $\quad$ Mauritius

Year of Birth: 1980

Post Secondary Ryerson University

Education and Toronto, Ontario, Canada

Degree:

B.Eng. Aerospace Engineering (2001 - 2005)

MASc. Mechanical Engineering (2005 - 2007)

Honors and

Awards:

Ryerson Graduate Scholarship

(Fall 2006 - Winter 2007)

Ryerson Graduate Research Stipend Scholarship

(Fall 2005 - Summer 2006)

Thermec'2006 National Science Foundation (NSF) Award (July 2006)

American Foundry Society (AFS) - Ontario Chapter Scholarship (February 2005)

Related Work Research and Graduate Assistant

Experience:

Ryerson University (Summer 2004 - Summer 2007)

\section{Publications:}

1. S. Jagoo, C. Ravindran and D. Nolan, "Minimizing Fold Defects in Aluminum Alloys A356 Lost Foam Casting”, AFS Transactions, Vol. 111, paper \# 07 - 068 (2007)

2. S. Jagoo, C. Ravindran and D. Nolan, "Fold Defects in A356 Aluminum Alloys Lost Foam Casting", Advanced Materials Research, Vol. 15-17, pp. 1 - 6 (2007) 
